\title{
SRAT CHEMISTRY AND ACID CONSUMPTION DURING SIMULATED DWPF MELTER FEED PREPARATION
}

D. C. Koopman

D. R. Best

B. R. Pickenheim

December 2008

E\&CPT Research Programs

Savannah River National Laboratory

Aiken, SC 29808

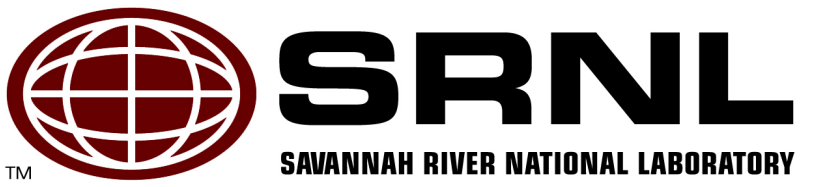


WSRC-STI-2008-00131

Revision 0

\title{
DISCLAIMER
}

This document was prepared in conjunction with work accomplished under Contract No. DE-AC0908SR22470 with the U.S. Department of Energy.

This work was prepared under an agreement with and funded by the U.S. Government. Neither the U.S. Government or its employees, nor any of its contractors, subcontractors or their employees, makes any express or implied: 1. warranty or assumes any legal liability for the accuracy, completeness, or for the use or results of such use of any information, product, or process disclosed; or 2. representation that such use or results of such use would not infringe privately owned rights; or 3. endorsement or recommendation of any specifically identified commercial product, process, or service. Any views and opinions of authors expressed in this work do not necessarily state or reflect those of the United States Government, or its contractors, or subcontractors.

\author{
Printed in the United States of America \\ Prepared For \\ U.S. Department of Energy
}


Key Words: $D W P F$, Hydrogen, Noble Metals, Catalysis, SRAT, SME, Formic Acid, Nitric Acid

Retention: Permanent

\section{SRAT CHEMISTRY AND ACID CONSUMPTION DURING SIMULATED DWPF MELTER FEED PREPARATION}

D. C. Koopman

D. R. Best

B. R. Pickenheim

December 2008

E\&CPT Research Programs

Savannah River National Laboratory Aiken, SC 29808

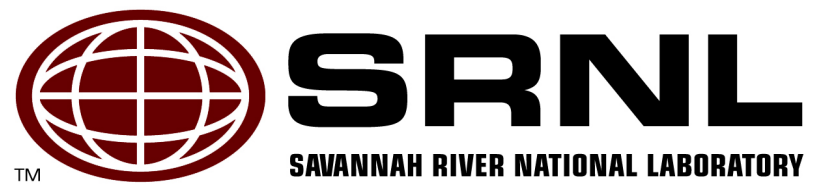



AUTHORS:
D. C. Koopman, Process Engineering Technology
Date
D. R. Best, Process Engineering Technology
Date
B. R. Pickenheim, Process Engineering Technology
Date

\section{TECHNICAL REVIEWERS:}

M. E. Stone, Process Engineering Technology

Date

R. E. Eibling, Engineering Process Development

Date

\section{APPROVERS:}

J. C. Griffin, E\&CPT Research Programs Manager

Date

C. C. Herman, Manager, Process Engineering Technology

Date

J. E. Occhipinti, Manager

Date

Waste Solidification Engineering 


\section{EXECUTIVE SUMMARY}

Simulations of the Defense Waste Processing Facility (DWPF) Chemical Processing Cell vessels were performed with the primary purposes of producing melter feeds for the beaded frit program and obtaining samples containing high concentrations of noble metals for off-site analytical studies. Sample and processing data were also analyzed to refine the understanding of chemistry and acid consumption during the Sludge Receipt and Adjustment Tank (SRAT) cycle. Results from this aspect of the simulations are reported here.

Eight pairs of mercury-free 22-L simulations were performed of the SRAT and Slurry Mix Evaporator (SME) cycles. Six pairs had a single noble metal (Ag, Pd, Rh, or Ru). One pair had all four noble metals, and one pair had no noble metals. Mercury was not added to the 22-L runs, because they were used to prepare melter feed. One supporting 4-L scale run with $\mathrm{Hg}$ was completed for comparison. The correlations between noble metal solubility and hydrogen generation in these tests were reported separately in WSRC-STI-2008-00002.

A preliminary timeline of reactions between acid and various soluble and insoluble species was developed from the sample, off-gas, and process data. A distinct sequence of major series-parallel reactions was observed in the sample data that was fairly universal. Variations in minor reactions were noted as well.

- Soluble species such as hydroxide, carbonate, and aluminate were the first to consume acid. These reactions occurred as slurry $\mathrm{pH}$ fell to seven.

- Sequential dissolution of $\mathrm{Mg}(\mathrm{OH})_{2}$ and $\mathrm{CaCO}_{3}$ followed. $\mathrm{CaCO}_{3}$ dissolution was accompanied by the destruction of any remaining carbonate and bicarbonate species. Dissolution of $\mathrm{Pd}$, followed by $\mathrm{Rh}$ and $\mathrm{Ru}$, were significant minor reactions during this period of acid addition.

- Near the end of $\mathrm{CaCO} 3$ dissolution, the reductive dissolution of $\mathrm{MnO}_{2}$ started. Slow nitrite destruction was detectable at low rates until near the end of $\mathrm{CaCO}_{3}$ dissolution. The rate of nitrite destruction increased significantly during $\mathrm{MnO}_{2}$ reduction. These two reactions were competing for available acid near the end of acid addition.

- Some less soluble species, such as $\mathrm{Ni}(\mathrm{OH})_{2}, \mathrm{ZnO}$, and $\mathrm{CuO}$ were partially dissolved while $\mathrm{MnO}_{2}$ reduction and nitrite destruction went to completion. The product distribution from nitrite ion varied with noble metal loading.

- Formic acid addition was accompanied by a nearly linear increase in formate ion concentration that suggested minimal formate ion destruction until the $\mathrm{pH}$ had fallen below 5 . The formate loss rate increased noticeably below this $\mathrm{pH}$, which coincided with $\mathrm{MnO}_{2}$ reduction and the destruction of the last $\sim 80 \%$ of the initial nitrite ion. The soluble noble metals were precipitating near the end of acid addition.

The SRAT cycles divided into roughly two groups following acid addition, those with significant catalytic activity (with $\mathrm{Rh}$ and/or $\mathrm{Ru}$ ) and those with minimal catalytic activity (without $\mathrm{Rh}$ and $\mathrm{Ru}$ ).

- The SRAT cycles with low activity remained at fairly low $\mathrm{pH}$ values $(<6)$. Dissolution of less soluble species such as $\mathrm{Ni}, \mathrm{Zn}$, and $\mathrm{Cu}$ continued during reflux, while highly dissolved species such as $\mathrm{Mg}, \mathrm{Ca}$, and $\mathrm{Mn}$ remained primarily in the supernate.

- Consumption of free formic acid continued in the SRAT cycles with high catalytic activity driving the $\mathrm{pH}$ up. Less soluble species never reached high extents of dissolution, and then precipitated before the end of the SRAT. Measurable concentrations of total inorganic 
carbon (TIC) reappeared, presumably from the aqueous absorption of $\mathrm{CO}_{2}$ produced during formate destruction. Dissolved $\mathrm{Mg}, \mathrm{Mn}$, and $\mathrm{Ca}$ began to precipitate during reflux. In some cases, the reprecipitated species appear to be carbonates (or bicarbonates). Limited redox probe data indicate that these systems may have reverted to an oxidizing state. Nitrate destruction was also directly observed, or else inferred from extremely low overall nitrite-tonitrate conversion percentages. Ammonium ion was observed in the SRAT product and FAVC condensate, and it was probably formed by a catalyzed formic acid-nitric acid (or formate-nitrate) reaction.

Significant additional new SRAT chemistry findings included:

- $\mathrm{Pd}, \mathrm{Rh}$, and $\mathrm{Ru}$ were all catalytically active in multiple ways. The overall rate of nitrite destruction was accelerated by all three.

- Ag showed minimal catalytic activity in the absence of other noble metals.

- The distribution of oxides of nitrogen in the off-gas was a strong function of the noble metal type and concentration and presence or absence of $\mathrm{Hg}$.

- Some fraction of nitrite was destroyed via the homogeneous (non-catalyzed) conversion to nitrate and NO in all systems.

- Significant conversion of nitrite to $\mathrm{N}_{2} \mathrm{O}$ did not require a catalyst, but this reaction was accelerated when catalysts were present. Pd was the most active catalyst for promoting $\mathrm{N}_{2} \mathrm{O}$ formation, with $0.2 \mathrm{wt} \% \mathrm{Pd}$ doubling the mass of $\mathrm{N}_{2} \mathrm{O}$ produced without noble metals.

- Nitrite reduction by formic acid to $\mathrm{NO}$ and $\mathrm{CO}_{2}$ was not significant in the absence of a catalyst. $\mathrm{Ru}$ was the most effective catalyst for increasing $\mathrm{NO}$ formation. $\mathrm{Ru}$ plus $\mathrm{Hg}$ was even more effective at producing these gases and minimizing $\mathrm{N}_{2} \mathrm{O}$ formation.

- Accelerating nitrite destruction came at the expense of decelerating Mn reduction.

- The stoichiometric acid required to destroy a mole of nitrite ion was a function of the noble metal and $\mathrm{Hg}$ composition. The coefficient for nitrite in the current DWPF stoichiometric acid addition equation is not a true constant.

- Refluxed nitrate ion from the MWWT to the SRAT contributed a relatively small fraction of the nitrite-to-nitrate conversion total when nitrite destruction was completed before dewatering (high acid stoichiometry scenario).

- The majority of carbonate conversion to $\mathrm{CO}_{2}$ occurred before significant destruction of formate ion to $\mathrm{CO}_{2}$ began except in the test with $\mathrm{Hg}$.

- $\mathrm{CO}_{2}$ formed during nitrite destruction was partially absorbed in the SRAT condenser condensate stream. Bubbles of what was presumably $\mathrm{CO}_{2}$ were seen disengaging from the condensate in the MWWT, and TIC was detected in a simultaneous sample of the MWWT condensate.

- Destruction of formate and formic acid by $\mathrm{Rh}$ and $\mathrm{Ru}$ catalysts caused the SRAT pH to rise during reflux to the point that some of the $\mathrm{CO}_{2}$ being evolved was absorbed by the supernate. This coincided with precipitation of cations such as $\mathrm{Mg}, \mathrm{Mn}$, and to some extent $\mathrm{Ca}$.

- Ammonium ion formation occurred to a significant extent in some of the catalytically active systems. Ammonium ion was detected in SRAT FAVC condensate samples, as well as in several SRAT product slurry samples.

The principal identified acid consumers were combined to derive a new stoichiometric acid equation. It was assumed that $50 \%$ of the Mn would reduce during nitrite destruction to less than $1000 \mathrm{mg} / \mathrm{kg}$, since the two reactions were in parallel. A potential new minimum acid requirement equation is given by the following (with all terms in moles per liter slurry). 


$$
\frac{\text { moles acid }}{L \text { slurry }}=\text { base equivalents }+H g+\text { soluble } T I C+1.5 *(C a+M g)+1.0 * \text { nitrite }+1.5 * M n
$$

Base equivalents is the current slurry titration result to a $\mathrm{pH}$ seven endpoint. An alternative approach is proposed for the computation of the acid requirement. An equation was derived that attempts to calculate a nominal acid addition instead of a minimum acid addition.

$$
\frac{\text { moles acid }}{L \text { slurry }}=\text { base equivalents }+H g+\text { soluble } T I C+1.8 *(C a+M g)+1.1 * \text { nitrite }+3 * M n
$$

This equation recognizes that post-acid addition sampling frequently shows that $\mathrm{Mn}$ reduction proceeds to $90-100 \%$ completion, not $50 \%$, and that nitrite has also been destroyed to well below $1000 \mathrm{mg} / \mathrm{kg}$, but there is insufficient excess acid remaining to produce hydrogen above the DWPF SRAT or SME limits. SRNL currently recommends continued use of the current DWPF stoichiometric acid equation pending completion of some additional validation tests. These two proposed acid equations need further validation because:

- Only limited soluble TIC data exists for historical simulants.

- Complete data for $\mathrm{Ca}$ and $\mathrm{Mg}$ have not been incorporated into some of the smaller databases used to evaluate alternative acid equations.

- Speciation of $\mathrm{Ca}$ and $\mathrm{Mg}$ probably varies between the current simulant, coprecipitated simulants, and real waste. This could impact the coefficients of these two terms.

Revisions to some of the databases are in progress to add more $\mathrm{Ca}$ and $\mathrm{Mg}$ data. Some archived simulants could be analyzed for soluble TIC content. Additional testing with coprecipitated simulants is needed to determine if the presence of significant $\mathrm{Ca}(\mathrm{OH})_{2}$, instead of $\mathrm{CaCO}_{3}$, alters the timing of $\mathrm{Ca}$ dissolution and carbonate destruction.

The basis for this report was seventeen SRAT/SME simulations with nine different noble metal and mercury combinations that produced an enormous quantity of useful data. The amount of insight gained on the SRAT process chemistry was commensurate with the effort expended. Process simulations with single noble metals are uncommon, so much of the new data are unique in the context of current sludge batch chemistry. Documentation of this data has produced several major reports. The sample, off-gas, and processing results of these tests have been incorporated into the SRNL SRAT chemistry database. 


\section{TABLE OF CONTENTS}

EXECUTIVE SUMMARY ..................................................................................................................... III

LIST OF FIGURES................................................................................................................................. VIII

LIST OF TABLES...............................................................................................................................

LIST OF ACRONYMS ...................................................................................................................... XI

1.0 INTRODUCTION AND BACKGROUND ...............................................................................

2.0 APPROACH ..........................................................................................................................

2.1 StRUCtURE AND OBJeCtIVES OF TeSt PROGRAM...............................................................

2.2 Chemical Process Cell SimUlation DetaILS ................................................................. 4

2.3 PROCESS AND SAMPLE ANALYTICAL MethodS .....................................................................

2.4 PROCESS MODELING AND CALCULATIONS .....................................................................

2.4.1 Temperature corrections for $\mathrm{pH}$....................................................................... 9

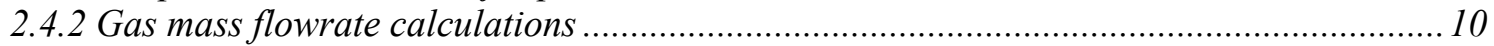

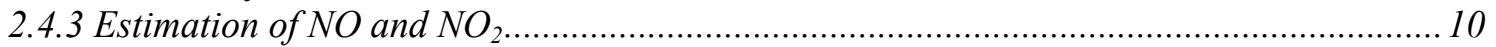

2.4.4 Nitrite destruction reactions …………………………............................................. 12

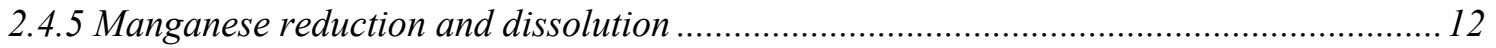

2.4.6 Calculation of extent of dissolution ……………………………………………….... 12

3.0 SRAT RESULTS CALCULATED FROM RAW DATA ............................................................15

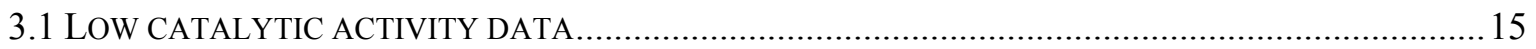

3.1.1 No noble metal baseline tests.................................................................................. 15

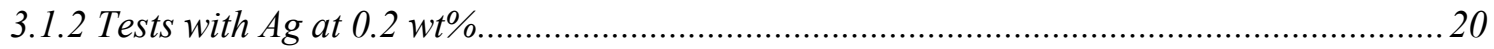

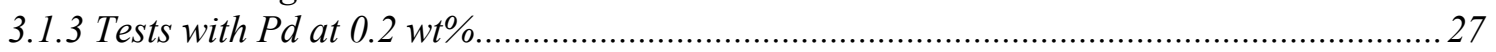

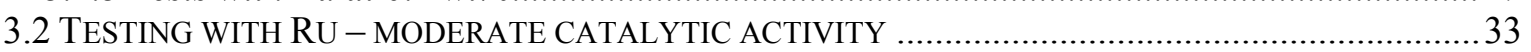

3.2.1 Tests with Ru at $0.2 \mathrm{wt} \%$ (no $\mathrm{Hg}$ ) .............................................................................. 33

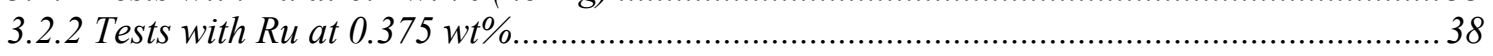

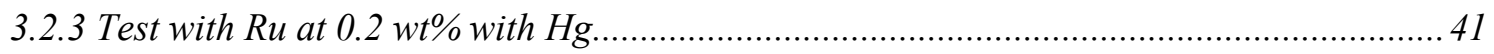

3.3 TESTING WITH RH - HIGH CATALYTIC ACTIVITY …………………………………….......4

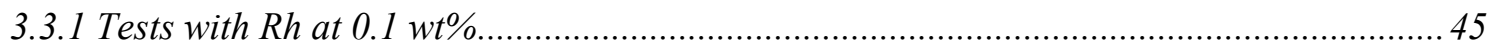

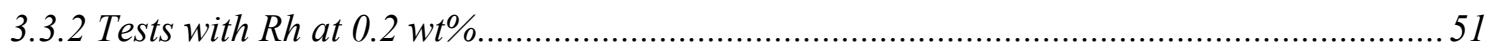

3.4 TESTING WITH ALL NOBLE METALS COMBINED .....................................................................56

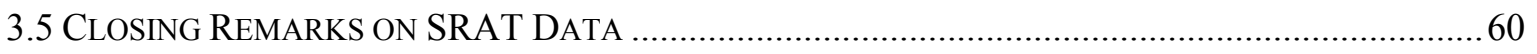

4.0 SUMMARY OF SRAT AND SME PRODUCT PROPERTIES .................................................63

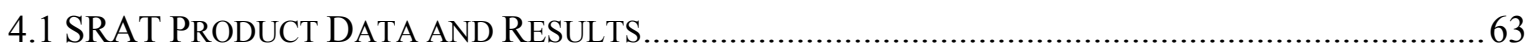

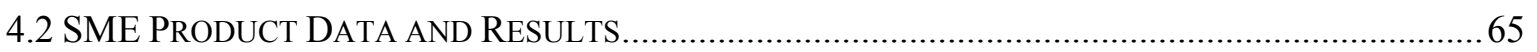

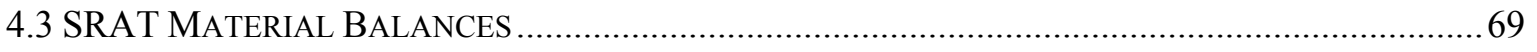

5.0 DEVELOPMENT OF SRAT CHEMISTRY TIMELINE ...........................................................77

5.1 Period 1: InITIAL Sludge Neutralized to PH 7.4 (0-16.6\% TOtal ACID) ...........................77

5.2 PERIOD 2: PH 7.4 TO PH 5.1 (16.6-50\% TOTAL ACID) …………………………………...... 77

5.3 PERIOD 3: PH 5 TO THE END OF ACID AdDITION ………………………………………........ 81

5.3.1 Destruction of nitrite .............................................................................................. 81

5.3.2 Implications of nitrite destruction data for acid consumption...........................................8 86

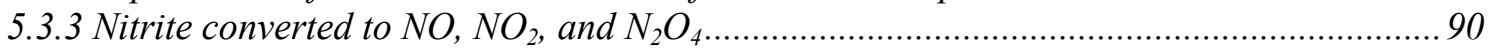

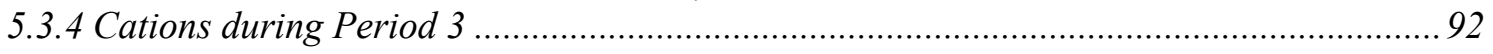


WSRC-STI-2008-00131

Revision 0

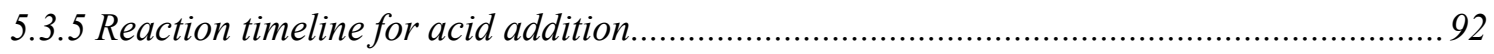

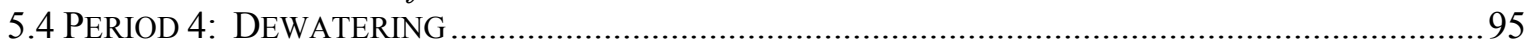

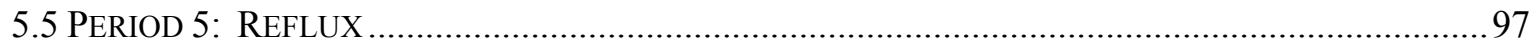

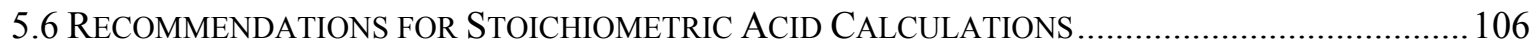

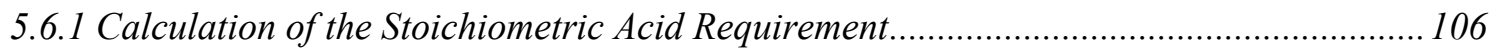

5.6.2 Estimation of Anion Changes During Processing ....................................................... 110

5.7 ClOSING THOUGHTS ON CHEMISTRY AND ACID CONSUMPTION .......................................... 111

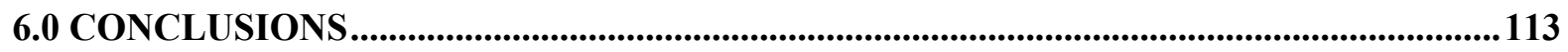

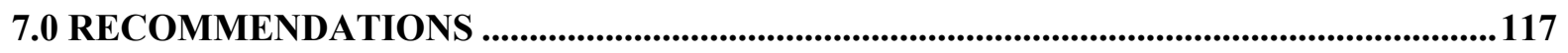

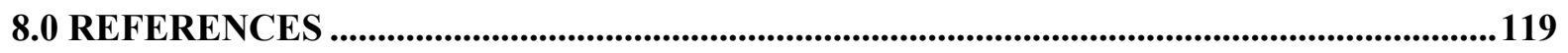

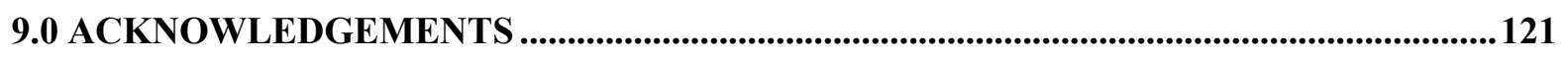

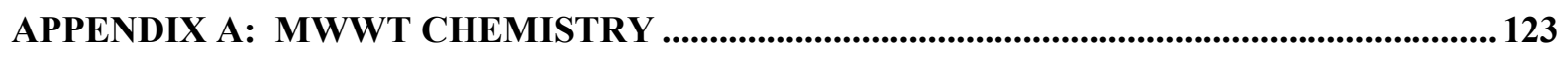

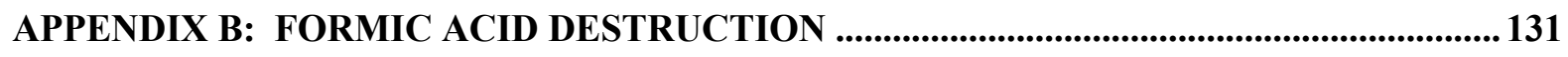




\section{LIST OF FIGURES}

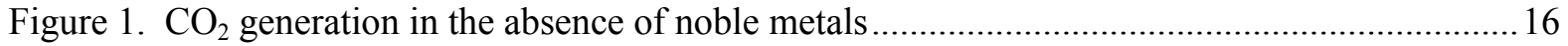

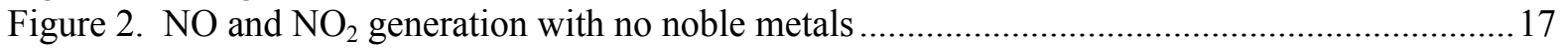

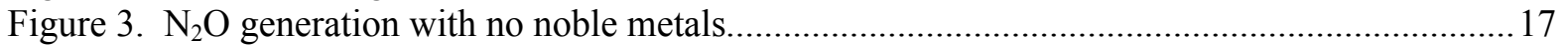

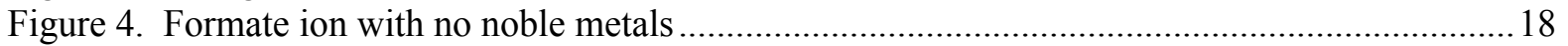

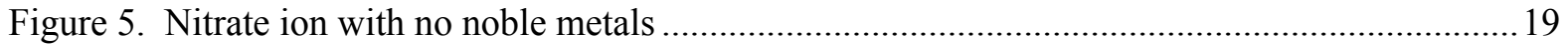

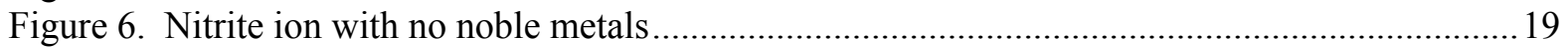

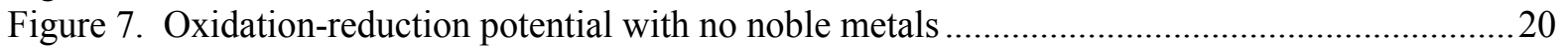

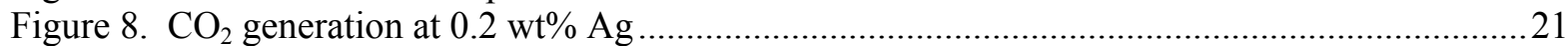

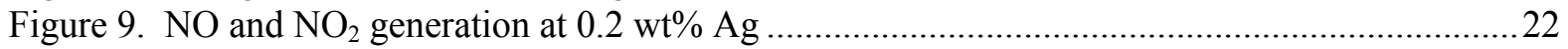

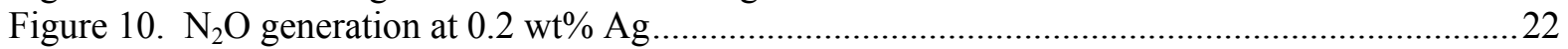

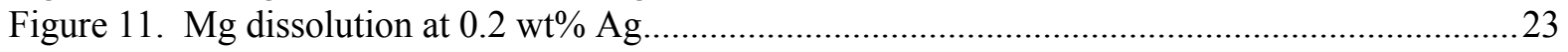

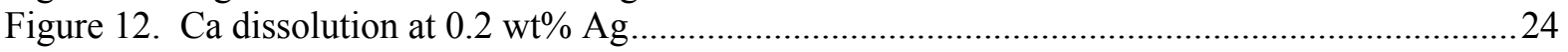

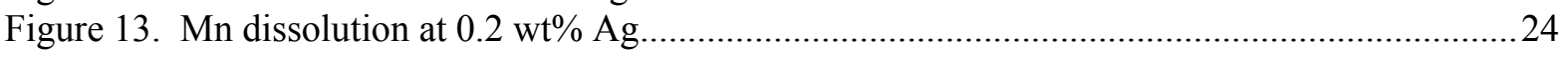

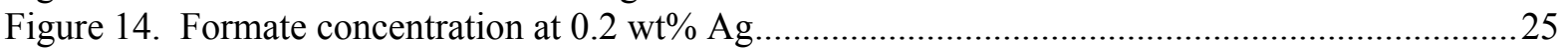

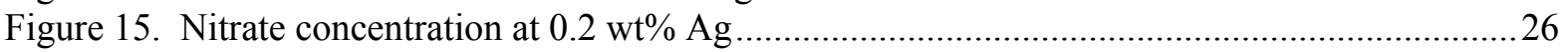

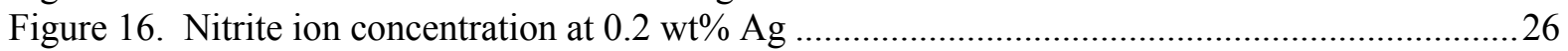

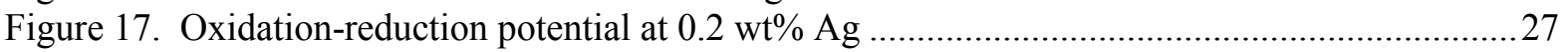

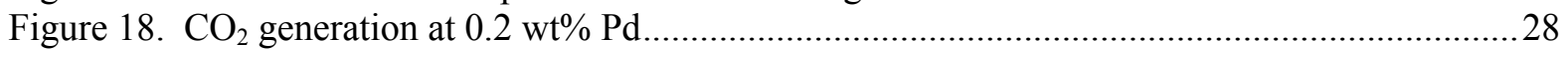

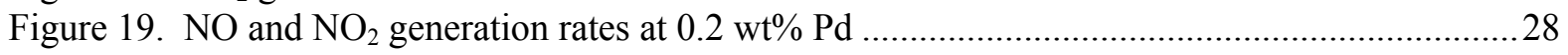

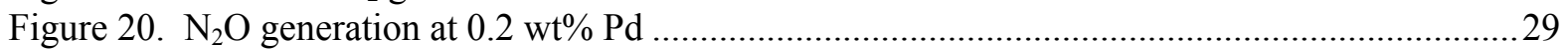

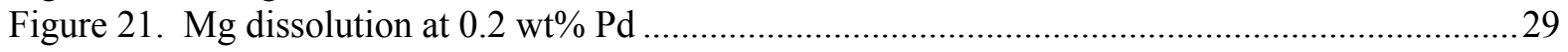

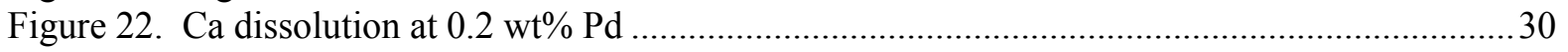

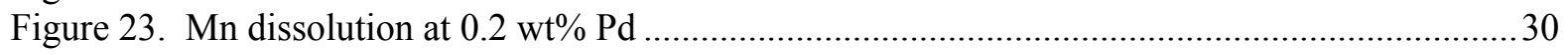

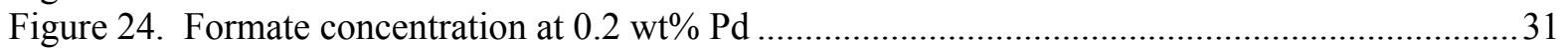

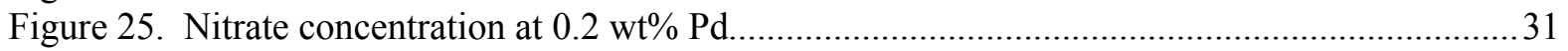

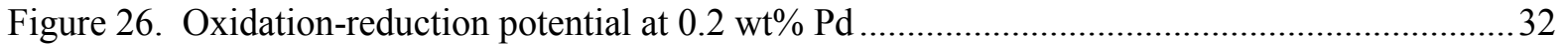

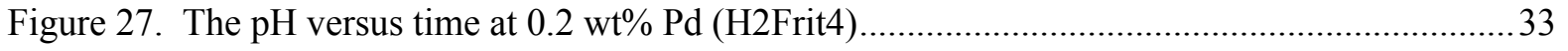

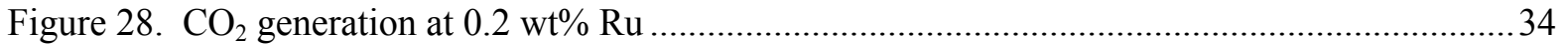

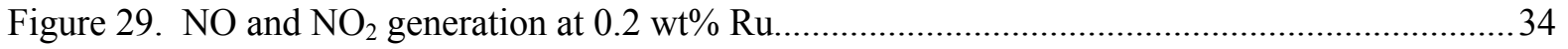

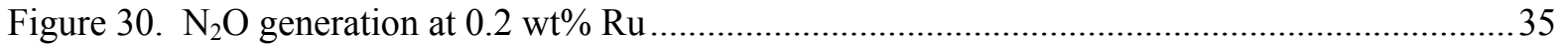

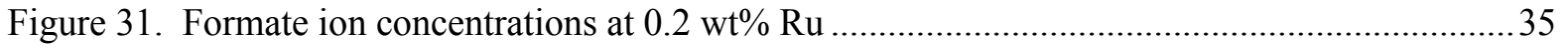

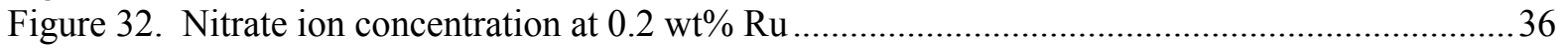

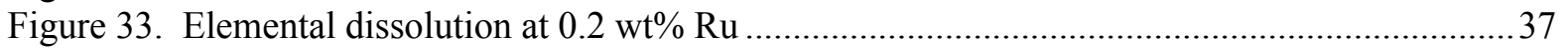

Figure 34. Oxidation-Reduction Potentials at $0.2 \mathrm{wt} \% \mathrm{Ru}$

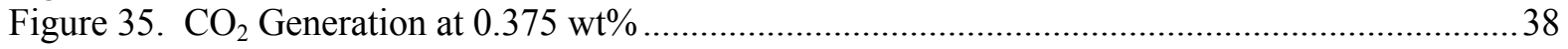

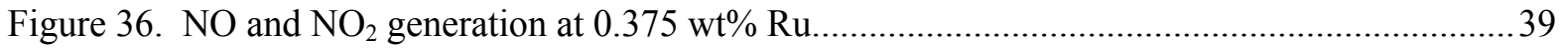

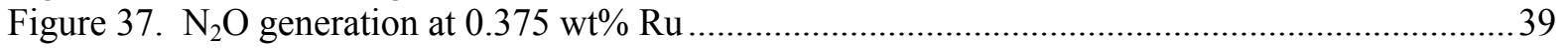

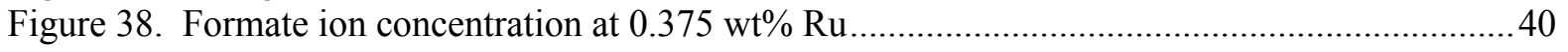

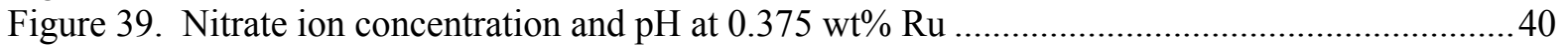

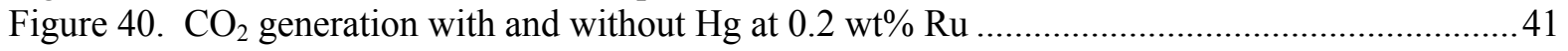

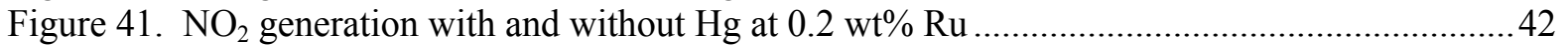

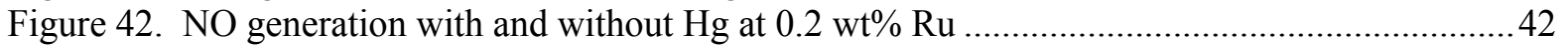

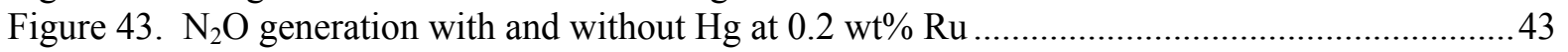

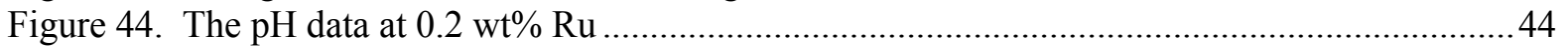

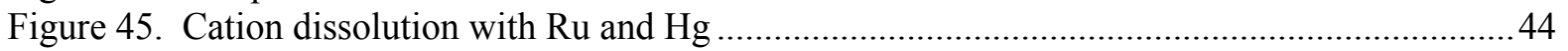

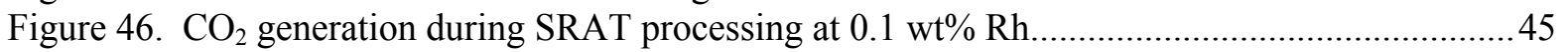

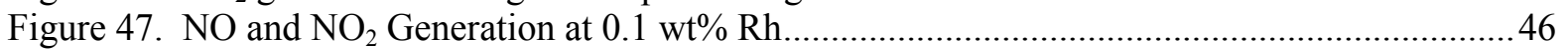




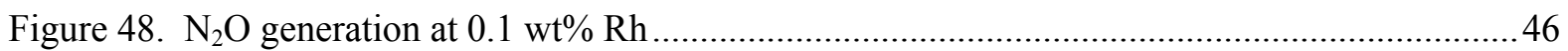

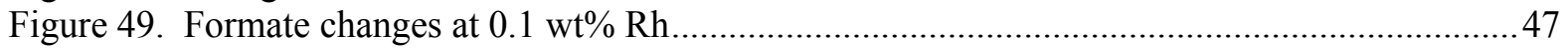

Figure 50. Detail of formate concentration during formic acid addition......................................... 48

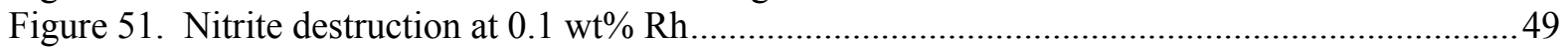

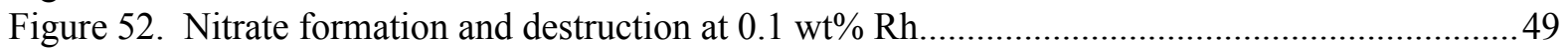

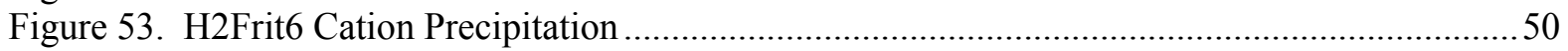

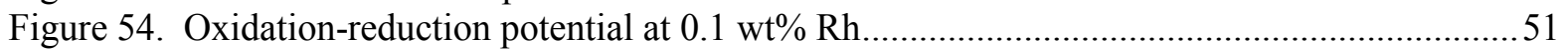

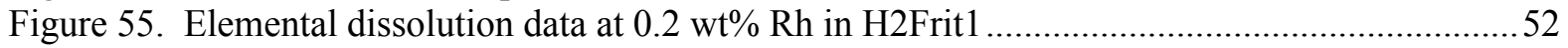

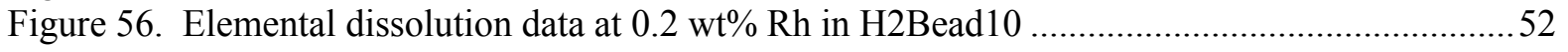

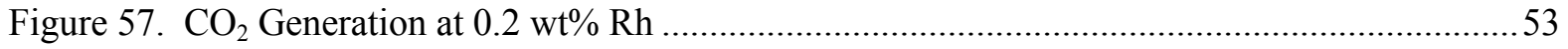

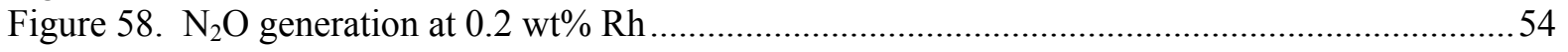

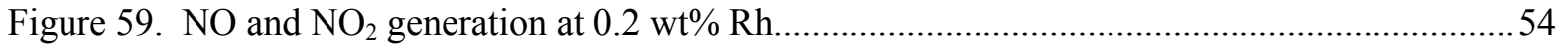

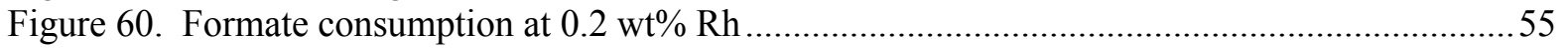

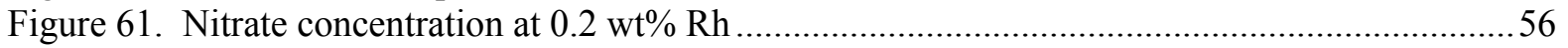

Figure 62. Rh dissolution during processing with all noble metals.............................................57

Figure 63. $\mathrm{NO}$ and $\mathrm{NO}_{2}$ generation at $0.1 \mathrm{wt} \% \mathrm{Rh}$ with other noble metals ..................................57

Figure 64. $\mathrm{N}_{2} \mathrm{O}$ generation at $0.1 \mathrm{wt} \% \mathrm{Rh}$ with other noble metals..............................................58

Figure 65 . Formate changes at $0.1 \mathrm{wt} \% \mathrm{Rh}$ with other noble metals ............................................5

Figure 66. Formate and hydrogen with all noble metals ..............................................................5

Figure 67. Nitrate concentration at $0.1 \mathrm{wt} \% \mathrm{Rh}$ with other noble metals.........................................59

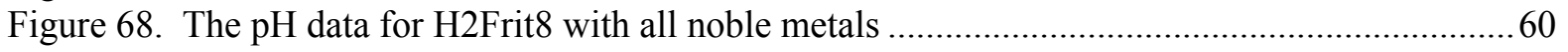

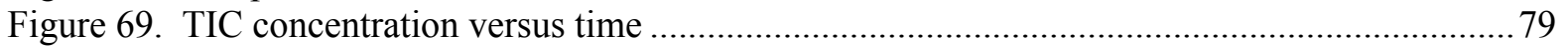

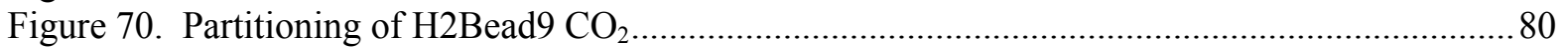

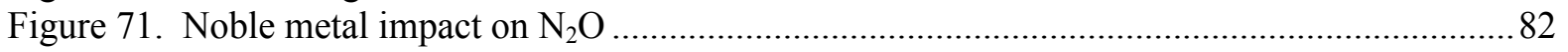

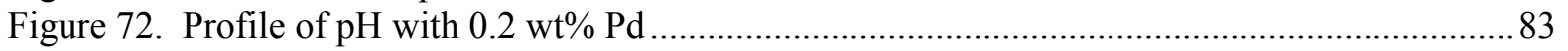

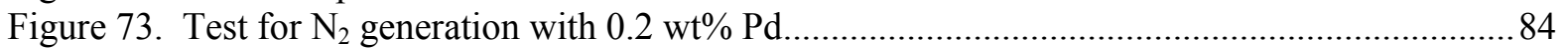

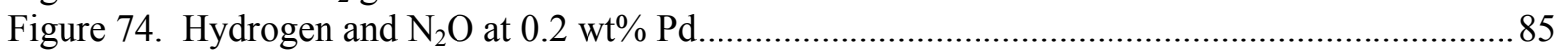

Figure 75. Comparison of minimum acid data versus model equation ............................................ 88

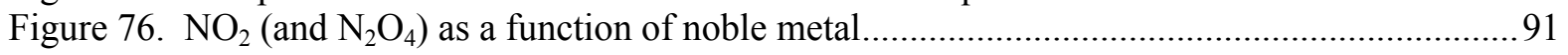

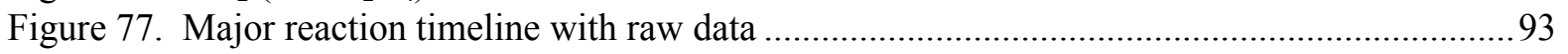

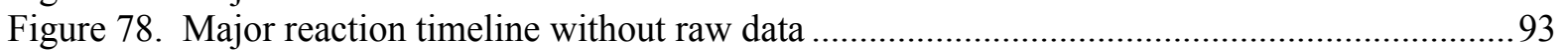

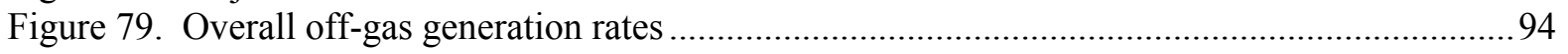

Figure 80. MWWT nitrate ion concentration by ISE ................................................................95

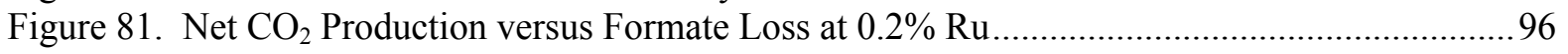

Figure 82. Composite $\mathrm{pH}$ profiles for frit runs .......................................................................... 97

Figure 83. Total off-gas generation rate during Period 5 .......................................................... 98

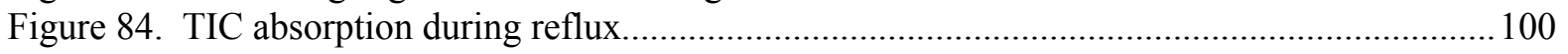

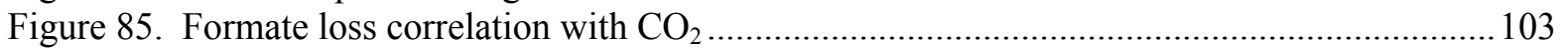

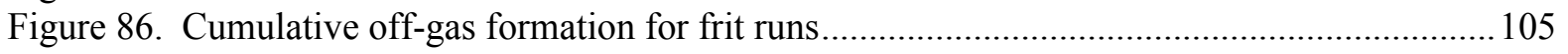

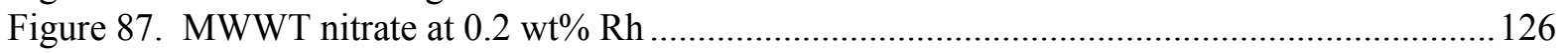

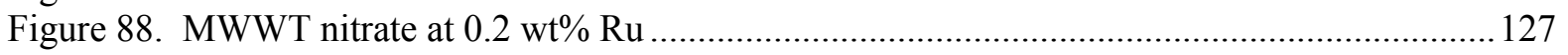

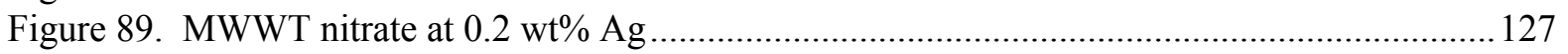

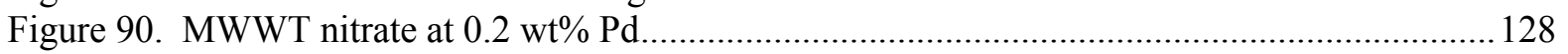

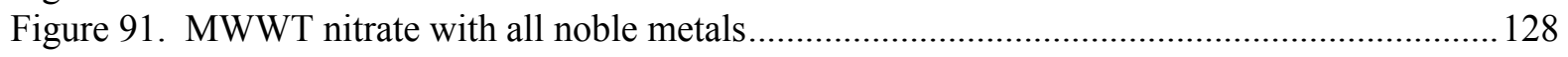

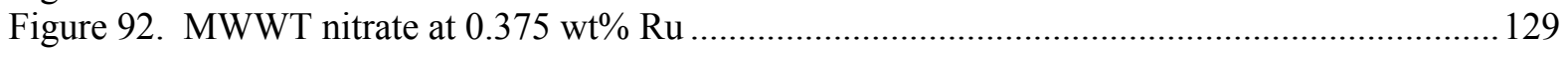




\section{LIST OF TABLES}

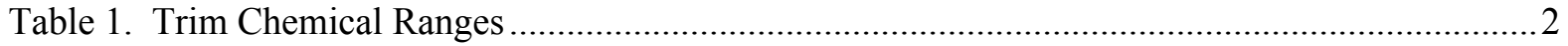

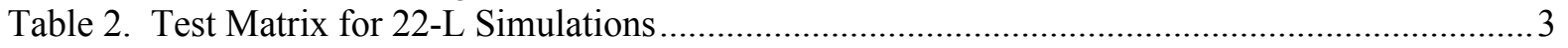

Table 3. Wt\% Calcined Elemental Composition of Sludge............................................................ 5

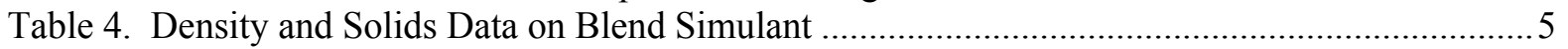

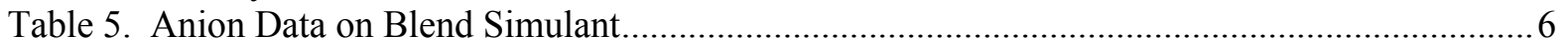

Table 6. Composite Blend Sludge Noble Metal Concentrations ..........................................................63

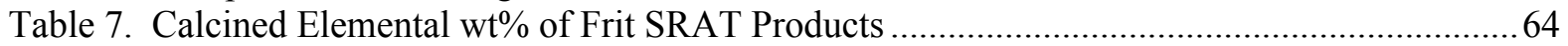

Table 8. Calcined Elemental wt\% of Bead SRAT Products................................................................64

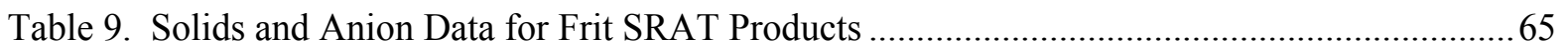

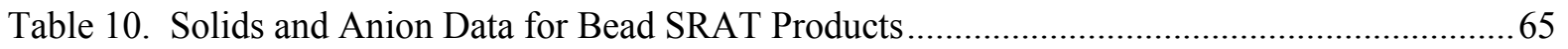

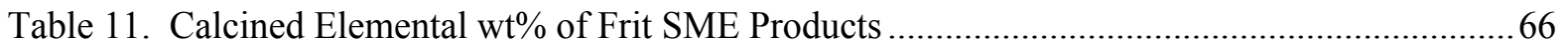

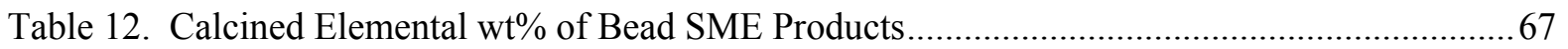

Table 13. Solids and Anion Data for Frit SME Products ................................................................67

Table 14. Solids and Anion Data for Bead SME Products ................................................................6 68

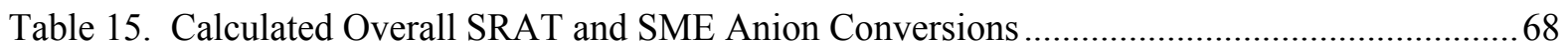

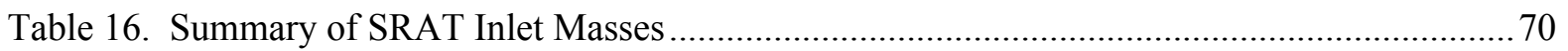

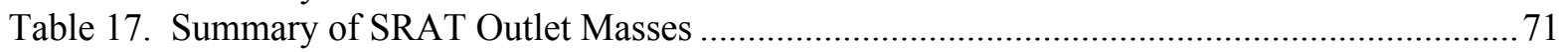

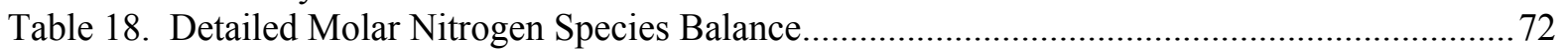

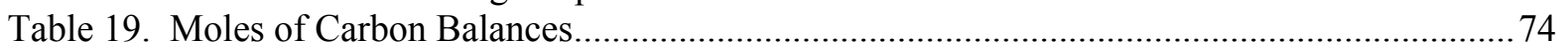

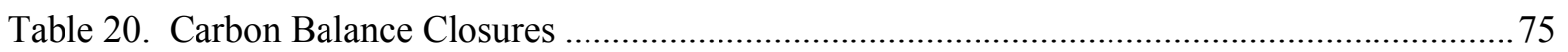

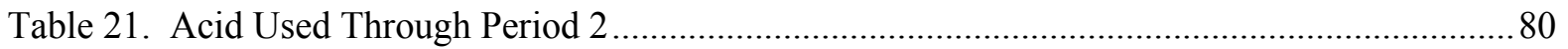

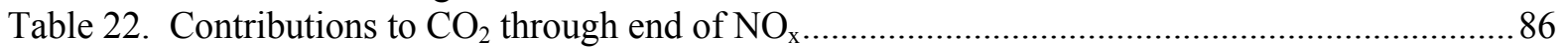

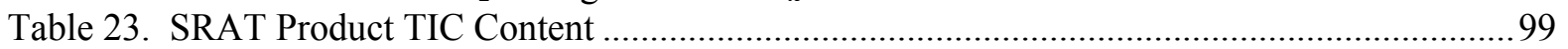

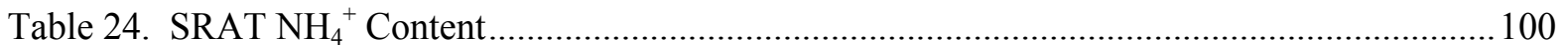

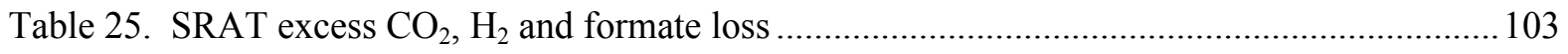

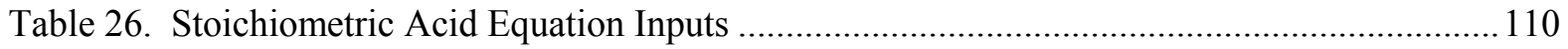

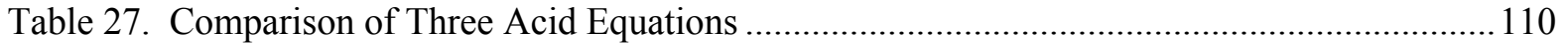




\section{LIST OF ACRONYMS}

$\begin{array}{ll}\text { ACTL } & \text { Aiken County Technology Laboratory } \\ \text { AD } & \text { Analytical Development } \\ \text { ASP } & \text { Analytical Study Plan } \\ \text { BFMT } & \text { Bead Frit Matching Test } \\ \text { CPC } & \text { Chemical Process Cell } \\ \text { CWAO } & \text { Catalytic Wet Air Oxidation } \\ \text { DWPF } & \text { Defense Waste Processing Facility } \\ \text { E\&CPT } & \text { Environmental and Chemical Process Technology } \\ \text { FAVC } & \text { Formic Acid Vent Condenser } \\ \text { GC } & \text { Gas Chromatograph } \\ \text { HM } & \text { H-canyon Modified Purex process } \\ \text { H2Bead } & \text { Run prefix for a 22-L simulation with beaded frit 418 } \\ \text { H2Frit } & \text { Run prefix for a 22-L simulation with frit 418 } \\ \text { IC } & \text { Ion Chromatography } \\ \text { ICP-AES } & \text { Inductively Coupled Plasma-Atomic Emission Spectroscopy } \\ \text { ICP-MS } & \text { Inductively Coupled Plasma-Mass Spectroscopy } \\ \text { ISE } & \text { Ion Selective Electrode } \\ \text { LFL } & \text { Lower flammability limit } \\ \text { LWO } & \text { Liquid Waste Operations } \\ \text { MWWT } & \text { Mercury Water Wash Tank } \\ \text { ORP } & \text { Oxidation-Reduction Probe } \\ \text { PSAL } & \text { Process Science Analytical Laboratory } \\ \text { ppm } & \text { parts per million } \\ \text { QA } & \text { Quality Assurance } \\ \text { SB } & \text { Sludge Batch } \\ \text { SME } & \text { Slurry Mix Evaporator vessel } \\ \text { SRAT } & \text { Sludge Receipt and Adjustment Tank } \\ \text { SRNL } & \text { Savannah River National Laboratory } \\ \text { TIC } & \text { Total Inorganic Carbon } \\ \text { TR } & \text { Technical Report } \\ \text { TT\&QAP } & \text { Task Technical and Quality Assurance Plan } \\ \text { TTR } & \text { Task Technical Request } \\ \text { WSRC } & \text { Washington Savannah River Company } \\ \text { XAFS } & \text { X-ray Absorption Fine Structure spectroscopy } \\ \text { XAS } & \text { X-ray Absorption Spectroscopy } \\ & \end{array}$


WSRC-STI-2008-00131

Revision 0

This page intentionally left blank. 


\subsection{INTRODUCTION AND BACKGROUND}

Due to higher than expected hydrogen generation during the Tank 51-Sludge Batch 4 (SB4) qualification run, DWPF engineering requested the Savannah River National Laboratory (SRNL) to expand the ongoing catalytic hydrogen generation program. The work presented in this Technical Report was identified as part of SRNL/Liquid Waste Organization (LWO) meetings to define potential causes of catalytic hydrogen generation as well as from an external technical review panel commissioned to evaluate SRNL hydrogen related data and programs. ${ }^{1}$ New scope included improving the understanding of SRAT/SME process chemistry, particularly as it related to acid consumption and hydrogen generation. The expanded hydrogen program scope was covered under the technical task request (TTR): HLW-DWPF-TTR-20070016. ${ }^{2}$ A task technical and quality assurance plan (TT\&QAP) was issued to cover focus areas raised in meetings with LWO plus a portion of the recommendations made by the review panel. ${ }^{3}$ A supporting analytical study plan was issued. ${ }^{4}$

It was also noted in the review of catalytic hydrogen generation that control of the DWPF acid stoichiometry was an important element in controlling hydrogen generation. A separate TTR was issued to investigate ways of improving the determination of the acid requirement during processing: HLWDWPF-TTR-0015. ${ }^{5}$ A separate TT\&QAP was prepared for this task request. ${ }^{6}$ This report discusses some progress on this task related to developing alternative acid equations and to performing experimental work to supplement the existing database.

Simulant preparation and preliminary flowsheet studies were already documented. ${ }^{7}$ The prior work produced a sufficient quantity of simulant for the hydrogen program and melter feed rheology testing. It also defined a suitable acid addition stoichiometry. The results presented in this report come from samples and process data obtained during sixteen 22-L SRAT/SME simulations that were performed in the second half of 2007 to produce eight SME products with frit 418 and a matching set of eight SME products with spherically beaded frit 418 . The requirement to produce two 25 gallon batches of melter feed for the melter feed rheology modifier program fell under a separate task plan. ${ }^{8}$ One supporting 4-L SRAT simulation was performed with mercury, since the 22-L melter feed preparation runs had no mercury due to melter off-gas constraints.

As a result of this work, a timeline of reactions has been developed showing the sequence of major reactions occurring during and shortly after acid addition. The traditional-style simulant used in this testing had fairly well defined speciation which enabled the reactions being observed to be related to acid consumption. The new coprecipitated simulants have somewhat different speciation, and it will be necessary to validate some of the conclusions from this testing using sample data from SRAT simulations with coprecipitated simulant. Noble metal dissolution data on timing and concentration were presented in a separate report discussing hydrogen generation. ${ }^{9}$ A few of those results will be brought into this report as part of the description of the SRAT chemistry timeline. The noble metal and mercury concentrations used in the preliminary flowsheet studies are summarized in Table 1 along with the ranges covered in this study. 
Table 1. Trim Chemical Ranges

\begin{tabular}{|c|c|c|}
\hline $\begin{array}{c}\text { Trim } \\
\text { Element }\end{array}$ & $\begin{array}{c}\text { Baseline Runs } \\
\mathrm{wt} \%\end{array}$ & $\begin{array}{c}\text { This Study } \\
\mathrm{wt} \%\end{array}$ \\
\hline $\mathrm{Ag}$ & 0.0030 & $0-0.20$ \\
\hline $\mathrm{Pd}$ & 0.0010 & $0-0.20$ \\
\hline $\mathrm{Rh}$ & 0.0078 & $0-0.20$ \\
\hline $\mathrm{Ru}$ & 0.0300 & $0-0.375$ \\
\hline $\mathrm{Hg}$ & 1.5000 & $0-1.50$ \\
\hline
\end{tabular}

Noble metal concentrations were an order of magnitude higher than in the preliminary baseline testing in order to support X-ray absorption spectroscopy (XAS) studies. High noble metal concentrations had the potential to produce more extreme catalytic chemistry than in conventional flowsheet simulations. The impact of noble metals on chemical reactions other than hydrogen generation, such as nitrite destruction, was expected to be more readily apparent in these tests. Suspected catalytic reactions from past testing had the potential to be confirmed by data at these higher noble metal concentrations rather than being indistinguishable from the measurement uncertainty. Observations of specific catalytic effects by individual noble metals were further facilitated by creating a test matrix with single noble metal simulations.

The DWPF process simulations served several purposes. Consequently, the results are spread over several technical reports. Three interrelated reports are focused on hydrogen generation, noble metal chemistry, SRAT chemistry, and acid consumption. The focus of this report is on SRAT chemistry and acid consumption. A second report presented the preliminary data on noble metal behavior during processing as evaluated by XAS. ${ }^{10}$ The third report covered hydrogen generation as it related to noble metal dissolution data. ${ }^{9}$ Each of these reports addressed one or more of the recommendations of the catalysis review panel and the proposed tasks in the catalytic hydrogen generation program TT\&QAP. The results of subsequent melter feed comparison testing (settling, sampling characteristics, etc. of regular frit versus spherically beaded frit) are to be discussed in a separate future report. 


\subsection{APPROACH}

\subsection{Structure and Objectives of Test Program}

Sixteen SRAT/SME simulations were performed using the 22-L SRAT-scale equipment at ACTL. One simulation in the 22-L equipment typically produces 3-3.5 gallons of melter feed. The primary purpose of these sixteen simulations was to prepare 25 gallons of melter feed containing frit 418 plus a matching 25 gallons of melter feed where the frit 418 was replaced with spherical glass beads of approximately the same size and composition as frit 418 (bead 418). These 16 runs collectively have become the bead-frit runs. The two 25 gallon batches of melter feed needed to have the same processing history in order to eliminate that as a source of variation in rheological and settling properties.

The bead-frit melter feed preparations were seen as an opportunity to make pairs of SRAT/SME simulations containing single noble metals at high concentrations. The eight SRAT/SME simulations needed to produce a single 25 gallon batch of melter feed with either beads or frit did not need to be identical to each other. The only requirement was that each SRAT/SME simulation with frit 418 had a matching simulation with beads. A test structure consisting of eight different pairs was adopted where the two runs within a given pair were identical in all respects except that one was given frit while the other was given beads during the SME cycle. In particular, SRAT cycles within a pair were as nearly identical as possible. SME cycles were nearly identical as well except for the substitution of bead 418 for frit 418 .

The 22-L scale of the simulations also meant that the desired sample volumes to support studies of SRAT chemistry would not be a potential issue (large sample volume is a bigger issue in the 4-L and smaller scale tests). Consequently, the sixteen 22-L simulations were given the task of producing samples for XAS characterization studies on the noble metals as a second primary objective. Additional samples were taken to support the XAS task and to track selected chemical reactions during the SRAT cycle.

The sixteen 22-L simulations were given the noble metal loadings and run identifiers listed in Table 2.

Table 2. Test Matrix for 22-L Simulations

\begin{tabular}{|l|c|c|}
\hline Noble Metal Loading & Frit run with & Bead run with \\
\hline $0.2 \% \mathrm{Rh}$ & H2Frit1 & H2Bead10 \\
\hline $0.2 \% \mathrm{Ru}$ & H2Frit2 & H2Bead13 \\
\hline $0.2 \% \mathrm{Ag}$ & H2Frit3 & H2Bead9 \\
\hline $0.2 \% \mathrm{Pd}$ & H2Frit4 & H2Bead15 \\
\hline $0.375 \% \mathrm{Ru}$ & H2Frit5 & H2Bead 12 \\
\hline $0.1 \% \mathrm{Rh}$ & H2Frit6 & H2Bead11 \\
\hline No noble metals & H2Frit7 & H2Bead14 \\
\hline All noble metals & H2Frit8 & \\
\hline
\end{tabular}

The first four pairs each had an identical loading of a single noble metal to permit direct comparisons of the relative effects. The all noble metals tests had $0.1 \mathrm{wt} \%$ each of $\mathrm{Ag}, \mathrm{Pd}$, and $\mathrm{Rh}$ along with $0.375 \mathrm{wt} \%$ $\mathrm{Ru}$. This noble metal combination put the two key noble metals, $\mathrm{Rh}$ and $\mathrm{Ru}$, at their relative fission yields while having all noble metals at or above the minimum detection limits for the off-site lab methods. It also permitted direct comparisons of results with the pairs of runs at $0.1 \mathrm{wt} \% \mathrm{Rh}$ and at 0.375 $\mathrm{wt} \% \mathrm{Ru}$. The no noble metals tests were performed to provide a catalyst-free baseline for the chemistry in the absence of noble metals. The need for baseline testing was confirmed after completing the initial $\mathrm{Ag}$ and Pd tests. 
The sixteen simulations were successfully performed in pairs in numerical sequence per Table 2, e.g. $1+2$, $3+4$, etc. through $15+16$. Several months elapsed between the eighth and ninth runs due to a delay in delivery of the bead 418. One 4-L bead-frit matching test (BFMT) was performed in this period with $\mathrm{Hg}$. It was trimmed to $0.2 \mathrm{wt} \% \mathrm{Ru}$ and $1.494 \% \mathrm{Hg}$. This pair was chosen because XAS beam time was available that could perform analyses of $\mathrm{Ru}$ and $\mathrm{Hg}$, but not $\mathrm{Rh}$. The first bead-frit matching test became BFMT1.

The sequence of the bead runs was reordered relative to the frit runs for two reasons. The primary reason was to have one high hydrogen producer and one low hydrogen producer in each of the last four pairs of runs. Equipment was modified in one hood (larger diameter off-gas line, increased air purge capacity, taller manometer) to better handle the high hydrogen generation rates during the second pass through the list. Reordering the tests also tended to randomize some of the potential sources of bias that might be present.

The tests with no noble metals, $0.2 \mathrm{wt} \% \mathrm{Ag}$, and $0.2 \mathrm{wt} \% \mathrm{Pd}$ were expected to behave like simulations with low concentrations of all noble metals. These tests were seen as the best opportunity to study acid consumption reactions under nearly prototypical conditions. The other five run pairs had high $\mathrm{Rh}$, high $\mathrm{Ru}$, or high $\mathrm{Rh}$ plus $\mathrm{Ru}$. These tests were expected to produce significant hydrogen and have significant formate losses (potentially much higher than normally encountered). Consequently, these pairs were not sampled as extensively in support of SRAT chemistry studies except for the two all noble metals tests that were seen as potentially bounding future SRAT runs with all noble metals. Considerable data were obtained on the impact of noble metals on nitrite destruction, the dissolution-neutralization of insoluble hydroxides and carbonates during acid addition, and the reduction of manganese and destruction of nitrite ion. These results are presented in raw form in Section 3.0.

\subsection{Chemical Process Cell Simulation Details}

Simulated DWPF washed sludge was prepared for both the bead-frit melter feed testing and for the catalytic hydrogen generation program. ${ }^{7}$ The sludge was prepared by combining three generic simulants available in drum quantities plus trim chemicals to produce a bulk composition intermediate between Purex and HM wastes and with a supernate similar to recent sludge batches. The composition was analyzed using inductively coupled plasma-atomic emission spectroscopy (ICP-AES) and ion chromatography (IC). The nominal composition data of the untrimmed simulant (without noble metals and mercury obtained from samples of the blended simulant) are summarized in the next three tables. Eight SRAT receipt samples (with all trim chemicals) were also analyzed extensively, and average results plus standard deviations are given for these as well. Table 3 gives the calcined elemental composition of the untrimmed $\mathrm{ABC}$ simulant along with the average composition of the eight SRAT receipt samples from the frit series of runs. 
Table 3. Wt\% Calcined Elemental Composition of Sludge

\begin{tabular}{|l|c|c|}
\hline & $\begin{array}{c}\text { ABC Blend Simulant } \\
\text { wt\% }\end{array}$ & $\begin{array}{c}\text { SRAT Receipt } \\
\text { wt\% (std. dev.) }\end{array}$ \\
\hline $\mathrm{Al}$ & 16.1 & $16.0(0.30)$ \\
\hline $\mathrm{Ba}$ & 0.221 & $0.207(0.006)$ \\
\hline $\mathrm{Ca}$ & 2.55 & $2.50(0.13)$ \\
\hline $\mathrm{Cr}$ & 0.163 & $0.148(0.006)$ \\
\hline $\mathrm{Cu}$ & 0.143 & $0.087(0.008)$ \\
\hline $\mathrm{Fe}$ & 21.8 & $21.4(0.76)$ \\
\hline $\mathrm{K}$ & 0.276 & $0.169(0.051)$ \\
\hline $\mathrm{Mg}$ & 1.76 & $1.45(0.077)$ \\
\hline $\mathrm{Mn}$ & 4.05 & $3.85(0.147)$ \\
\hline $\mathrm{Na}$ & 12.2 & $12.9(0.53)$ \\
\hline $\mathrm{Ni}$ & 0.998 & $0.847(0.023)$ \\
\hline $\mathrm{Pb}$ & 0.055 & $0.045(0.004)$ \\
\hline $\mathrm{Si}$ & 1.72 & $1.60(0.078)$ \\
\hline $\mathrm{Ti}$ & 0.018 & $0.019(0.001)$ \\
\hline $\mathrm{Zn}$ & 0.213 & $0.202(0.008)$ \\
\hline $\mathrm{Zr}$ & 0.628 & $0.426(0.019)$ \\
\hline
\end{tabular}

Untrimmed sludge elemental results were generally within two standard deviations of the corresponding SRAT receipt elemental average. The three noteworthy differences between the untrimmed sludge and the SRAT receipt sample averages were investigated by reviewing SRAT product results (the SRAT product should have the sample elemental break down as the trimmed sludge). SRAT product Ni averaged $0.93 \%$ with a standard deviation of 0.08 , which was intermediate between the sludge and SRAT receipt sample results. SRAT product $\mathrm{Mg}$ averaged $1.69 \%$ with a standard deviation of 0.13 . SRAT product $\mathrm{Zr}$ averaged $0.46 \%$ with a standard deviation of 0.07 . The sludge $\mathrm{Zr}$ value is the only result that appears to be inconsistent with both SRAT receipt and SRAT product sample results. Weight percent and solids data for untrimmed simulant are given in Table 4.

Table 4. Density and Solids Data on Blend Simulant

\begin{tabular}{|l|c|}
\hline & ABC Blend Simulant \\
\hline Wt. \% total solids & 22.8 \\
\hline Wt. \% insoluble solids & 16.8 \\
\hline Wt. \% soluble solids & 6.0 \\
\hline Wt. \% calcined solids & 16.0 \\
\hline Slurry Density, g/mL & 1.175 \\
\hline Supernate Density, g/mL & 1.053 \\
\hline
\end{tabular}

Anion data have been obtained by various methods and are given in Table 5. Species below currently available detection limits were estimated by calculation from the simulant preparation recipe. In addition, a complete charge and mass balance was prepared on the simulant which indicated that total hydroxide was about $80,000 \mathrm{mg} / \mathrm{kg}$ and total oxide was about $13,000 \mathrm{mg} / \mathrm{kg}$ in the slurry. These two anions constitute the majority of the negative charge, while the anions in Table 5 make up about $20 \%$ of the negative charge. 
Table 5. Anion Data on Blend Simulant

\begin{tabular}{|l|r|}
\hline $\mathrm{ABC}$ Blend Simulant & $\mathrm{mg} / \mathrm{kg}$ \\
\hline $\mathrm{Cl}^{-}$ & 390 \\
\hline $\mathrm{F}^{-}$(recipe calculation) & 47 \\
\hline $\mathrm{HCO}_{2}^{-}$ & 0 \\
\hline $\mathrm{NO}_{2}{ }^{-}$ & 17,950 \\
\hline $\mathrm{NO}_{3}{ }^{-}$ & 10,850 \\
\hline $\mathrm{C}_{2} \mathrm{O}_{4}{ }^{2-}$ (recipe calculation) & 1,400 \\
\hline $\mathrm{PO}_{4}{ }^{3-}$ (by ICP P) & 160 \\
\hline $\mathrm{SO}_{4}{ }^{2-}$ (by IC) & 1,625 \\
\hline $\mathrm{SO}_{4}{ }^{2-}$ (by ICP S) & 1,350 \\
\hline Total Inorganic Carbon & 849 \\
\hline
\end{tabular}

Fluoride was below the $100 \mathrm{mg} / \mathrm{kg}$ detection limit for IC, but was known to be present in the blend simulant from the recipe. Phosphate was below the detection by IC, so it was calculated from the slurry P value (a measure of total phosphate rather than soluble phosphate). Total sulfate calculated from ICPAES sulfur was somewhat less than sulfate by IC but within reasonable expectations for analytical data. Oxalate was reported at the recipe value, since the weighted dilution preparation does not bring $100 \%$ of the oxalate ion into solution. Subsequent sample data and analysis support a nitrate ion concentration of about $13,800 \mathrm{mg} / \mathrm{kg}$. The simulant was titrated using the ACTL auto-titrator to $\mathrm{pH} 7$ and $\mathrm{pH} 5.5$. The average result at $\mathrm{pH} 7$ was $0.313 \mathrm{M}$ equivalent hydroxide. The result at $\mathrm{pH} 5.5$ was $0.381 \mathrm{M}$. A separate sample of the supernate was titrated to $\mathrm{pH} 7$. It had $0.268 \mathrm{M}$ equivalent hydroxide content.

Sample data from the preliminary flowsheet testing supported a total inorganic carbon value (TIC) of $\geq 1,350 \mathrm{mg} / \mathrm{kg}$ instead of $849 .^{7}$ The $849 \mathrm{mg} / \mathrm{kg}$ was an average of three analyses. TIC sample data obtained during acid addition in this phase of testing were consistent with starting sludge TIC as high as $2,800 \mathrm{mg} / \mathrm{kg}$. Consequently, the generic simulant recipes used to prepare the feed for these tests were examined in detail for sources of TIC. It was difficult to support a starting sludge TIC value greater than about $1,400 \mathrm{mg} / \mathrm{kg}$ based on recipe considerations. A TIC value was extracted using GC data by mathematically decoupling the two $\mathrm{CO}_{2}$ peaks into a separate TIC peak and a Mn-nitrite reduction peak. Integration of the decoupled $\mathrm{CO}_{2}$ flowrate to a $\mathrm{CO}_{2}$ mass and conversion to carbon produced a TIC value of $1,420 \mathrm{mg} / \mathrm{kg}$. A subsequent 4-L SRAT experiment using predominantly nitric acid produced $\mathrm{CO}_{2}$ equivalent to $1,330 \mathrm{mg} \mathrm{TIC} / \mathrm{kg}$ slurry with no formic acid production of $\mathrm{CO}_{2}$. Carbon material balances presented in Section 4.3 were based on $1,350 \mathrm{mg} / \mathrm{kg}$. The actual value of TIC in the ABC simulant probably lies somewhere between the supernate value of $660 \mathrm{mg} / \mathrm{kg}$ and the larger slurry values approaching 2,800 mg/kg, and presumably closer to $1,300-1,400 \mathrm{mg} / \mathrm{kg}$ than either extreme based on the evidence to date. The uncertainty in initial TIC content potentially impacted the closure of the carbon species material balance calculations, as well as some of the conclusions about acid consumption as a function of time during formic acid addition.

The nominal sludge composition was used to prepare an acid calculation for each of the eight pairs of 22$\mathrm{L}$ simulations. Variations in nitrate due to the noble metal nitrate trim chemicals led to very minor differences in the ratio of nitric acid to formic acid. Formic acid made up about $91 \%$ of the total acid. A stoichiometric factor of $198 \%$ was chosen based on the preliminary acid window study and the $849 \mathrm{mg} / \mathrm{kg}$ TIC value. ${ }^{7}$ About $14.4 \mathrm{~L}$ of untrimmed simulant was added to the SRAT vessel. The SRAT receipt volume was about $14.9 \mathrm{~L}$ with trim chemicals added. The stoichiometric factor led to an acid addition of about 1.96 moles acid per liter of untrimmed simulant or 1.89 moles acid per liter of SRAT receipt material. SRAT receipt sample results supported the $\mathrm{Mn}$ and nitrite values measured for the sludge simulant, and there was no mercury, so only the TIC input to the acid calculation carried high uncertainty. 
Nominal DWPF scaled SRAT/SME processing conditions were generally used; however, neither cycle had a heel from a prior batch. A $200 \mathrm{ppm}$ antifoam addition was made prior to nitric acid addition. A $100 \mathrm{ppm}$ antifoam addition was made prior to formic acid addition. A $500 \mathrm{ppm}$ antifoam addition was made prior to going to boiling following acid addition. Acid additions were at roughly two gallons per minute scaled from 6000 gallons to $14.9 \mathrm{~L}$. Slurry volume reached a maximum of about $16.5 \mathrm{~L}$ following acid addition and antifoam additions. Boiling targeted the scaled equivalent to the DWPF maximum potential rate of $5000 \mathrm{lbs} / \mathrm{hr}$, or about $29 \mathrm{~g} /$ minute. Dewatering was delayed by up to an hour in the three pairs of runs containing $\mathrm{Rh}$ due to the high hydrogen generation rates at the end of acid addition. Dewatering typically took about 50 minutes. Dewatering was followed by twelve hours of reflux. The end of reflux defined the end of the SRAT cycle. After SRAT product samples were pulled, the air purge was adjusted from the SRAT rate to the SME rate (nominally equivalent to $230 \mathrm{scfm}$ to $74 \mathrm{scfm}$ ). A 100 ppm antifoam addition was made followed by the first frit-water-formic acid slurry addition (or beadwater-formic acid). No canister decon dewatering periods were simulated in the SME cycle. After the first frit addition dewatering, the second frit-water-formic acid slurry addition was made, and the SME was concentrated to the target $\mathrm{wt} \%$ total solids.

A complete pair of SRAT/SME simulations took about 30-33 hours measured from the start of heating prior to acid addition in the SRAT until the time that the SME product had cooled to less than $50^{\circ} \mathrm{C}$. Simulations were run around the clock using shift coverage. The last 8-10 hours of the second day was used to disassemble the equipment, clean key pieces, reassemble the equipment, and charge the SRAT with the next batch of sludge and trim chemicals. The GC's were given a quick bake-out during this period as well. A second pair of SRAT/SME simulations started on the third day and ended on the fourth. Two pairs of simulations consumed one week, so the sixteen simulations took four weeks. The eight frit runs were performed the weeks of $7 / 9$ and $7 / 16 / 2007$, while the eight bead runs were performed the weeks of $11 / 12$ and $11 / 26 / 2007$.

\subsection{Process and Sample Analytical Methods}

The automated data acquisition system developed for the 4-L SRAT rigs was modified and used to collect electronic data from the sixteen 22-L SRAT/SME simulations. Data included SRAT temperature, bath temperatures for the cooling water to the SRAT condenser and Formic Acid Vent Condenser (FAVC), $\mathrm{pH}$, mixer speed and torque, air and helium purge flows (He is used as an internal standard and is set to $0.5 \%$ of the nominal SRAT or SME air purge flow), and raw gas chromatograph (GC) data. Acid addition rate data were also collected by the data acquisition system on the 4-L tests based on the known performance of the automatic burette titrator pumps used at that scale. The MasterFlex pumps used to feed acids during the 22-L runs were not compatible with the data acquisition system. Actual flowrates delivered by the MasterFlex pumps varied by $\pm 15 \%$ from the targeted value.

Agilent 3000A micro GC's were used on twelve of the sixteen runs. Four of the frit runs used an older Agilent $200 \mathrm{H}$ micro GC. Both models have two columns. Column-A collects data related to $\mathrm{He}_{2} \mathrm{H}_{2}, \mathrm{O}_{2}$, $\mathrm{N}_{2}$, NO, and $\mathrm{CO}$, while column-B collects data related to $\mathrm{CO}_{2}$ and $\mathrm{N}_{2} \mathrm{O}$. GC's were calibrated with a calibration gas containing 0.499 vol $\% \mathrm{He}, 1.010$ vol $\% \mathrm{H}_{2}, 20.00$ vol $\% \mathrm{O}_{2}, 51.0 \mathrm{vol} \% \mathrm{~N}_{2}, 25.0 \mathrm{vol} \% \mathrm{CO}_{2}$ and $2.50 \mathrm{vol} \% \mathrm{~N}_{2} \mathrm{O}$. Air was also used to give a two point calibration for $\mathrm{N}_{2}$. NO vol\% data was obtained semi-quantitatively using the historical ratios of $\mathrm{He} / \mathrm{NO}$ area factors for the three GC's, since no calibration gas with $\mathrm{NO}$ was available. No evidence for $\mathrm{CO}$ generation was obtained. The DWPF-scale gas generation rates were calculated from the ratio of gas vol\%/He vol \%, the known He flow, and the scale factor for the test. He flow was controlled by an MKS mass flow controller. In several tests, step change testing of the He flow rate suggested that the MKS was improperly zeroed. Actual He flowrate was probably lower than indicated/targeted in all of these instances. This potential bias leads to calculated hydrogen generation rates that are higher than the actual rates. This issue has no impact on the 
timing of events, which was one of the primary observations being made. Issues with the He flowrate did have the potential to impact the $\mathrm{CO}_{2}, \mathrm{~N}_{2} \mathrm{O}, \mathrm{NO}_{2}$, and $\mathrm{NO}$ production terms in material balance calculations by up to $10 \%$. Generation rates of these gases are integrated over the SRAT cycle to produce total masses for the species material balances.

The GC's were checked with calibration gas before and after the SRAT cycle and following the SME cycle. GC operation was particularly problematic during four of the eight frit runs. GC data indicated that significant step changes in the sum of gases were occurring randomly during operation (as monitored during periods with little off-gas generation by adding $\mathrm{O}_{2}, \mathrm{~N}_{2}$ and $\mathrm{He}$ volume \%s). The sum of gases could increase to the neighborhood of $125 \%$ or decline to the neighborhood of $80 \%$. The similarity of these two numbers (one is the inverse of the other) did not go unnoticed. It was suspected that something was temporarily impacting the column injection volumes, but sometimes it was removed during bake-out between runs. When these shifts were noticed during the runs, a period was allotted to collect additional data from the calibration gas cylinder at the expense of obtaining process data. There was no spare GC available to replace the $\mathrm{M} 200 \mathrm{H}$ that gave the most problems. The post-processing of $\mathrm{GC}$ data was complicated by the fact that the two columns within the micro GC did not appear to be impacted equivalently by the shifts.

Small sintered metal filters were obtained prior to the eight bead runs, and these were placed inline on the small diameter sample line to the GCs during the eight bead runs. Dynamic tests indicated that the filters did not delay sampling during the SRAT by more than one sample cycle (about 4-4.5 minutes). Process lags due to vessel volumes are of the order of 2-3 sample cycles in the SRAT and 4-6 sample cycles in the SME, so the impact of the filters was considered acceptable. GC performance was much smoother during the eight bead runs. The GC's held calibration fairly well through the entire SRAT/SME simulation in all but one case where some gases were slightly more than $10 \%$ out of calibration by the end of the test (H2Bead14). A one-hour period was observed in the data where the concentrations of all gases dropped about $10 \%$ and then remained off-set from their expected values for the remainder of the run.

The $\mathrm{pH}$ probes used during these runs were problematic. Problems included frequent breakage, loss of calibration, and long delivery times. The $\mathrm{pH}$ probe protocol called for the probe to be calibrated in $\mathrm{pH} 4$ and 10 buffers and checked against $\mathrm{pH} 7$ buffer prior to the SRAT and then checked in all three buffers following the SME cycle.

A nitrate ion selective electrode (ISE) was mounted in the MWWT during one run in each of the eight pairs of runs. This probe is similar to a $\mathrm{pH}$ probe in that there is a correlation between a millivolt reading and the logarithm of nitrate ion concentration. The MWWT data were taken to assess the contribution of the MWWT reflux during acid addition to nitrate formation as well as to track nitrate condensation in the SRAT condenser during boiling. The data quality suffers somewhat during acid addition due to the lack of mixing in the MWWT. The MWWT clearly stratifies, although the probe tip is near the top of the liquid level in the MWWT where the fresh condensate comes in. Pulsing the accumulated condensate back to the SRAT during acid addition was used in an attempt to get a little more mixing inside the MWWT. The liquid turnover in the MWWT during boiling is much greater and tends to mix the contents more effectively.

An oxidation-reduction probe (ORP) was mounted in the SRAT slurry during six of the sixteen simulations. A specially modified 22-L SRAT was fabricated with this fitting. The ORP successfully monitored the transition of the slurry from an oxidizing environment to a reducing environment during nitric acid (oxidizer) and formic acid (reductant) addition. The ORP was only present during heat-up, acid addition, and some of the time before the start of boiling, since the probe was not sealed (the fill solution might have boiled when the SRAT started boiling). Some of the ORP data was taken by the PC 
data acquisition system, but some had to be logged manually with a corresponding loss in the temporal resolution of the reading.

Process samples were analyzed by various methods. Slurry and supernate elementals were determined by ICP-AES at PSAL. However, slurry samples were calcined at $1100^{\circ} \mathrm{C}$, which adversely impacted recovery of $\mathrm{Pb}$ and $\mathrm{Cr}$. Slurry anions were determined by IC on weighted dilutions of the slurries, which were filtered before injection into the IC. Supernate anions were determined by IC using volumetric dilutions. SRAT and SME product slurry and supernate densities were measured at ACTL using the Anton-Parr DMA-4500 density instrument $\left(25^{\circ} \mathrm{C}\right)$. Wt. $\%$ total, dissolved, and calcined solids were determined by oven drying to $115^{\circ} \mathrm{C}$ or $1100^{\circ} \mathrm{C}$. Soluble and insoluble solids were calculated from the total solids and dissolved solids (total solids in the supernate phase). Condensate samples from the MWWT and FAVC were submitted to PSAL for IC analysis to support overall material balances and the ISE probe calibration. Samples of slurry and condensate were submitted to AD for TIC analysis and for IC cation analysis for ammonium ion. Nitrogen balance data from several runs indicated that select samples should to be checked for ammonium ion by IC. TIC samples were primarily intended to characterize carbonate destruction during acid addition, but the high SRAT product $\mathrm{pHs}$ in several pairs of runs permitted absorption of significant carbon dioxide into the slurry as either newly made bicarbonate or carbonate ion during reflux.

A modified sampling plan was developed for the bead runs relative to the matching frit runs in order to answer questions about supernate elementals that were raised by the slurry sample supernate results in support of the XAS analyses. A number of slurry samples were also taken for anion analyses. Anion samples were generally taken in $15-\mathrm{mL}$ vials. A typical slurry sample was about $13 \mathrm{~g}$. Each of these samples was combined with about $1 \mathrm{~g}$ of $\sim 1 \mathrm{M} \mathrm{NaOH}$ solution in order to stop acid driven reactions. Subsequent data confirmed that anion concentrations were still changing slowly with time in unquenched samples. There was also evidence of continuing dissolution of some of the partially soluble cations in some of the samples that had been held as slurries for several months before separating off supernate for analysis.

Sixteen SRAT product samples and sixteen SME product samples were submitted to PSAL for ICP-AES, IC, wt. \% solids, and $\mathrm{pH}$. A matching set of 32 samples was submitted to ACTL for density measurements. The eight frit run SRAT and SME products were analyzed for both slurry and supernate density. Supernate density was fairly insensitive to processing changes during the eight frit runs, so the bead run products were only analyzed for slurry density. (Slurry density is more dependent on $\mathrm{wt} \%$ total solids which varied somewhat from product to product.)

\subsection{Process Modeling and Calculations}

The raw data obtained during the run and analysis of samples by AD and PSAL often required subsequent mathematical processing. This section outlines how these calculations were made.

\subsubsection{Temperature corrections for $\mathrm{pH}$}

The $\mathrm{pH}$ probe data were recorded by the $\mathrm{PC}$ data acquisition system along with the measurement temperature of the $\mathrm{pH}$ probe monitor. The measurement temperature must be entered manually to match the slurry temperature. The electronic data files show that the temperatures on the probe monitor and in the SRAT were not always matched. When they were significantly different, the $\mathrm{pH}$ readings were corrected as follows.

$$
p H_{c}=7+\left(p H_{r}-7\right) * \frac{59+0.2 *\left(T_{p H}-25\right)}{59+0.2 *\left(T_{S R A T}-25\right)}
$$


$\mathrm{pH}_{\mathrm{c}} \quad$ corrected $\mathrm{pH}$ reading

$\mathrm{pH}_{\mathrm{r}} \quad$ recorded $\mathrm{pH}$ reading

$\mathrm{T}_{\mathrm{pH}} \quad$ temperature entered on $\mathrm{pH}$ monitor, $\mathrm{C}$

$\mathrm{T}_{\mathrm{SRAT}}$ temperature of SRAT vessel slurry, $\mathrm{C}$

Although linear corrections (as a function of time) for drifts in $\mathrm{pH}$ probe calibration have been applied in previous run sets to the $\mathrm{pH}$ data, the $\mathrm{pH}$ data was sufficiently problematic in the bead-frit runs that this was not attempted.

\subsubsection{Gas mass flowrate calculations}

The gas generation rate at DWPF scale was calculated from the He flow rate, He vol\% and gas vol\% combined with the scale factor and unit conversions as follows:

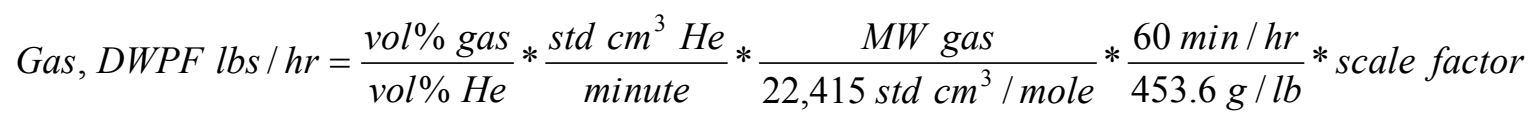

The He flowrate was generally close to 21.3 standard $\mathrm{cm}^{3}$ per minute $(\mathrm{sccm})$ and the scale factor was close to 1520 for the SRAT cycle. The He flowrate was generally close to $6.5 \mathrm{sccm}$ and the scale factor was close to 1600 for the SME cycle. Variations between runs were larger in the SME cycle parameters due to variations in the quantity of samples removed during the SRAT cycle. Fortunately, the ratio of gas to $\mathrm{He}$ volume percents is not as sensitive to the $\mathrm{GC}$ injection volume as the individual values are when results come from the same column. $\mathrm{CO}_{2}$ and $\mathrm{N}_{2} \mathrm{O}$, however, come from a different column than $\mathrm{He}$, so variations in injection volume on one column relative to the other introduce error into the mass flowrate calculations for $\mathrm{CO}_{2}$ and $\mathrm{N}_{2} \mathrm{O}$. The other primary source of error in this calculation is the He flowrate.

\subsubsection{Estimation of $\mathrm{NO}$ and $\mathrm{NO}_{2}$}

The absence of an analyzer for $\mathrm{NO}, \mathrm{NO}_{2}$, and $\mathrm{N}_{2} \mathrm{O}_{4}$ meant that the $\mathrm{GC}$ data were evaluated in more detail in order to draw inferences about these species and where they evolved on the SRAT chemistry timeline. NO is detected by the A-column of the micro GC. It is a fairly broad and unsymmetrical peak. Nevertheless, the time that NO first appears and last appears can be obtained from the raw chromatograms. Although there was no calibration gas containing NO available, the historical performance of the three GC's used was known, and the approximate ratios of the factor to convert He area to vol\% and the factor to convert NO area to vol\% were known. This factor was about seven for the two Agilent 3000A GC's. This approach was justified by examining the reproducibility of the He area factor over the last twelve runs. The range was 9,344 to 10,568 , so the factor stayed within about a $\pm 12 \%$ window. The concentration of NO in equilibrium with air is also typically 10-20 times smaller than the concentration of $\mathrm{NO}_{2}$ that it is in equilibrium with through:

$$
2 \mathrm{NO}+\mathrm{O}_{2} \leftrightarrow 2 \mathrm{NO}_{2}
$$

Consequently, it was not critical to determine the NO vol\% accurately in order to determine an NO mass flowrate for integration into an adequate total NO mass produced for use in the nitrogen material balance calculation. A $20-30 \%$ error in the NO mass would only be expected to introduce a $1-2 \%$ error into the nitrogen material balance closure, whereas neglecting the NO mass could introduce an error of $4-8 \%$ in the nitrogen material balance. 
Determination of $\mathrm{NO}_{2}$ and $\mathrm{N}_{2} \mathrm{O}_{4}$ required more assumptions. Nitrite destruction reactions have been identified that produce $\mathrm{NO}$ and $\mathrm{N}_{2} \mathrm{O}$ directly, but not $\mathrm{NO}_{2}$ or $\mathrm{N}_{2} \mathrm{O}_{4}$ directly. The $\mathrm{NO}_{2}$ and $\mathrm{N}_{2} \mathrm{O}_{4}$ are believed to come from the NO through a series of two reactions with temperature dependent equilibrium:

$$
2 \mathrm{NO}+\mathrm{O}_{2} \leftrightarrow 2 \mathrm{NO}_{2} \leftrightarrow \mathrm{N}_{2} \mathrm{O}_{4}
$$

Neither conversion reaction is essentially irreversible or instantaneous. The half-life of $0.1 \mathrm{vol} \% \mathrm{NO}$ in normal air for conversion to $\mathrm{NO}_{2}$ is about 3.5 minutes, and the half-life is inversely proportional to the initial $\mathrm{NO}$ concentration to the first power. The equilibrium between $\mathrm{NO}_{2}$ and $\mathrm{N}_{2} \mathrm{O}_{4}$ is very dynamic and temperature dependent. ${ }^{11} \mathrm{~N}_{2} \mathrm{O}_{4}$ is favored over $\mathrm{NO}_{2}$ at lower temperatures such as are found at the outlet of the FAVC. Consequently, a mixture of $\mathrm{NO}, \mathrm{NO}_{2}$, and $\mathrm{N}_{2} \mathrm{O}_{4}$ exists, but $\mathrm{NO}$ is expected to be a relatively minor component when the sum of the three gases is significant. The kinetic effects that maintain equilibrium have not been researched.

On a practical note, the actual speciation of $\mathrm{NO}_{2}$ and $\mathrm{N}_{2} \mathrm{O}_{4}$ is not required to perform a nitrogen material balance. Only the total nitrogen tied up in these two species needs to be known for the nitrogen material balance. Consequently, all $\mathrm{N}_{2} \mathrm{O}_{4}$ that should have been present will be treated as though it were two $\mathrm{NO}_{2}$ molecules in this report. The determination of the effective $\mathrm{NO}_{2}$ (including $\mathrm{N}_{2} \mathrm{O}_{4}$ ) concentration was made by assuming that oxygen consumption was limited to the conversion of $\mathrm{NO}$ to $\mathrm{NO}_{2}$ during nitrite destruction. A loss in moles of $\mathrm{O}_{2}$ was converted by a factor of two into a gain in moles of $\mathrm{NO}_{2}$ by eqn. [4]. The loss in $\mathrm{O}_{2}$ was determined by fixing the ratio of $\mathrm{O}_{2} / \mathrm{N}_{2}$ and calculating the expected $\mathrm{O}_{2}$ concentration for each measured $\mathrm{N}_{2}$ concentration. The measured $\mathrm{O}_{2}$ concentration was subtracted from the expected $\mathrm{O}_{2}$ concentration to determine the $\mathrm{O}_{2}$ loss. This loss was converted into the $\mathrm{NO}_{2}$ gain.

One set of GC data were analyzed using ratios of oxygen to both nitrogen and helium for calculating the oxygen loss. Nearly identical results were obtained, i.e. the ratio of $\mathrm{He} / \mathrm{N}_{2}$ was virtually constant. The ratio of $\mathrm{O}_{2} / \mathrm{N}_{2}$ was set such that roughly half of the oxygen losses were small negative values during times when $\mathrm{NO}$ was not being generated. This constraint was imposed in an attempt to prevent overstating $\mathrm{NO}_{2}$ production. Nevertheless, if there is any significant source of oxygen consumption other than conversion of $\mathrm{NO}$ to $\mathrm{NO}_{2}$, then this calculation cannot distinguish between them and treats all lost oxygen as representing $\mathrm{NO}$ converted $\mathrm{NO}_{2}$. Any unidentified oxygen consuming reactions would cause this calculation to overstate $\mathrm{NO}_{2}$ production. Specifically, catalytic wet air oxidation has been previously inferred during reflux to occur in parallel with hydrogen generation from formic acid. Catalytic wet air oxidation (CWAO) is not normally a large source of oxygen loss, and doesn't appear to overlap nitrite destruction, but that may not have been the case for one or more of the runs with high concentrations of active noble metals. CWAO has primarily been associated with the later stages of the SRAT cycle after acid addition and nitrite destruction. The entire determination of oxygen loss for $\mathrm{NO}_{2}$ gain was constrained to the period from the start of nitric acid addition until just after the start of reflux to avoid as much as possible assigning CWAO oxygen loss to $\mathrm{NO}_{2}$ production. No nitrite ion should be present during the rest of the SRAT or SME cycle that could form fresh NO to consume oxygen. The GC data with $\mathrm{O}_{2}$ loss converted into vol\% $\mathrm{NO}_{2}$ have the feature that the sum of measured and calculated gas compositions ( $\mathrm{He}, \mathrm{H}_{2}, \mathrm{O}_{2}, \mathrm{~N}_{2}, \mathrm{NO}, \mathrm{NO}_{2}, \mathrm{CO}_{2}$, and $\mathrm{N}_{2} \mathrm{O}$ ) exceed $100 \%$ during the period of peak nitrite destruction rates. Most of this can be explained by the partial dimerization of $\mathrm{NO}_{2}$ to $\mathrm{N}_{2} \mathrm{O}_{4}$.

A second potential issue is that the temperatures of the two $\mathrm{GC}$ columns are not identical. The A-column used for $\mathrm{He}, \mathrm{H}_{2}, \mathrm{O}_{2}$, and $\mathrm{N}_{2}$ is typically set to $80^{\circ} \mathrm{C}$, while the B-column used for $\mathrm{CO}_{2}$ and $\mathrm{N}_{2} \mathrm{O}$ is typically set to $70^{\circ} \mathrm{C}$. Therefore, the extent of dimerization of $\mathrm{NO}_{2}$ to $\mathrm{N}_{2} \mathrm{O}_{4}$ was probably different in one column compared to the other. This change would in turn alter the dilution of $\mathrm{CO}_{2}$ and $\mathrm{N}_{2} \mathrm{O}$ on column-B relative to the dilution of $\mathrm{He}, \mathrm{H}_{2}$, etc. on column-A. Consequently, $\mathrm{CO}_{2}$ and $\mathrm{N}_{2} \mathrm{O}$ total masses could be overstated or understated depending on column conditions due to a mismatch between the moles of gases 
diluting $\mathrm{He}$ relative to the moles of gases diluting $\mathrm{CO}_{2}$ and $\mathrm{N}_{2} \mathrm{O}$. Unfortunately, the peak in $\mathrm{N}_{2} \mathrm{O}$ formation and one of the two peaks in $\mathrm{CO}_{2}$ formation occur simultaneously with the peak in $\mathrm{NO}_{2}$ formation calculated from $\mathrm{O}_{2}$ loss. The dilution bias will therefore be near its maximum impact when significant quantities of the $\mathrm{CO}_{2}$ and $\mathrm{N}_{2} \mathrm{O}$ are being measured and quantified for the species material balances. Potential future solutions could include setting the two columns to an identical temperature or obtaining a different instrument to make the $\mathrm{NO}, \mathrm{NO}_{2}$, and $\mathrm{N}_{2} \mathrm{O}_{4}$ analyses. Fourier transform infrared and chemoluminescent instruments are possibilities.

\subsubsection{Nitrite destruction reactions}

The following three overall reactions are assumed for the destruction of nitrite in the SRAT during formic acid addition:

$$
\begin{aligned}
& 3 \mathrm{NaNO}_{2}+3 \mathrm{HCOOH} \rightarrow 3 \mathrm{HNO}_{2}+3 \mathrm{HCOONa} \rightarrow \mathrm{HNO}_{3}+2 \mathrm{NO}+\mathrm{H}_{2} \mathrm{O}+3 \mathrm{HCOONa} \\
& 2 \mathrm{NaNO}_{2}+3 \mathrm{HCOOH} \rightarrow 2 \mathrm{HCOONa}+2 \mathrm{NO}+\mathrm{CO}_{2}+2 \mathrm{H}_{2} \mathrm{O} \\
& 2 \mathrm{NaNO}_{2}+4 \mathrm{HCOOH} \rightarrow \mathrm{N}_{2} \mathrm{O}+2 \mathrm{HCOONa}+3 \mathrm{H}_{2} \mathrm{O}+2 \mathrm{CO}_{2}
\end{aligned}
$$

The reactions were written for sodium nitrite, since that is the initial nitrite species in the sludge. Actual nitrite destruction occurred primarily after the $\mathrm{pH}$ had fallen below 5.1 in these tests. The second and third reactions could be written for $\mathrm{HNO}_{2}$, instead, since that species probably dominates at the $\mathrm{pH}$ range seen for nitrite destruction.

$$
\begin{aligned}
& 2 \mathrm{HNO}_{2}+\mathrm{HCOOH} \rightarrow 2 \mathrm{NO}+\mathrm{CO}_{2}+2 \mathrm{H}_{2} \mathrm{O} \\
& 2 \mathrm{HNO}_{2}+2 \mathrm{HCOOH} \rightarrow \mathrm{N}_{2} \mathrm{O}+3 \mathrm{H}_{2} \mathrm{O}+2 \mathrm{CO}_{2}
\end{aligned}
$$

The production of $\mathrm{N}_{2} \mathrm{O}$ is the most acid intensive of the three overall reactions, requiring two moles of acid per mole of nitrite destroyed. If changes in processing led to increased $\mathrm{N}_{2} \mathrm{O}$ formation, then the mean acid requirement per mole of nitrite destroyed (the coefficient in the DWPF stoichiometric acid equation on nitrite, currently 0.75 moles acid per mole nitrite) would also increase. Both the second and third overall reactions also lead to formate destruction and $\mathrm{CO}_{2}$ formation. The complications in breaking down the nitrite destruction chemistry arise from internal refluxing of the aqueous condensation products of $\mathrm{NO}_{2}$ on the SRAT vessel walls. Condensation of $\mathrm{NO}_{2}$ produces fresh $\mathrm{HNO}_{2}$ and $\mathrm{HNO}_{3}$. The $\mathrm{HNO}_{2}$ is destroyed again when it reaches the bulk slurry.

\subsubsection{Manganese reduction and dissolution}

Manganese reduction from the +4 to +2 state, and the dissolution of the +2 salt, is an important source of acid consumption in the DWPF SRAT. The stoichiometry of this reaction is given below.

$$
\mathrm{MnO}_{2}+3 \mathrm{HCOOH} \rightarrow(\mathrm{HCOO})_{2} \mathrm{Mn}+\mathrm{CO}_{2}+2 \mathrm{H}_{2} \mathrm{O}
$$

This reaction requires three moles of acid per mole of $\mathrm{MnO}_{2}$ converted to manganese(II) formate. Manganese(II) formate is dissolved as $\mathrm{Mn}^{2+}$ plus two formate ions.

\subsubsection{Calculation of extent of dissolution}

The supernate concentrations of elemental species needed to be related to the total concentration of the species present in the system in order to evaluate the extent of dissolution. Generally, the expense of measuring the concentration of a given cationic elemental species in the slurry as a function of time is not justified, since everything non-volatile put in the SRAT vessel stays in the vessel. The calculation of the total concentration of a species in the SRAT as a function of time can be approached from several 
different directions. One of the simplest methods is to take the mass of the species added initially to the vessel and to divide it by the time-dependent slurry mass neglecting samples. In this approach, the timedependent slurry mass is calculated from the initial mass plus all additions less off-gas generation and less dewatered condensates. Samples that fall during nitric acid addition, formic acid addition, and dewatering have gained/lost only a fraction of the total acid or condensate. The start and end times, along with the sample time, are used to calculate the fraction of a gain/loss that has occurred up to the sample time. For example, a sample falling 45 minutes into a 3:22 hour formic acid addition would have a total mass calculated as follows

$$
\begin{aligned}
& \text { total slurry mass }=(\text { initial mass }+ \text { initial antifoam mass }+ \text { nitric acid mass } \\
& + \text { second antifoam mass }+(45 / 202) * \text { formic acid mass })- \text { current total offgas mass }
\end{aligned}
$$

The total mass concentration of a given species at a given time is then calculated simply as

$$
\frac{\text { grams of species } A}{k g \text { slurry }}=\left(\frac{\text { initial mass of species } A}{\text { total slurry mass }}\right)
$$

Neglecting the masses of small slurry samples ( $15 \mathrm{~g}$ out of 17,000 g), along with the mass of the species removed in the sample, is a trivially small potential source of error when compared to actual run data. Run data show about $1-2 \%$ missing mass in the SRAT product relative to what can be counted (probably due to a small but steady loss of water vapor through air leaks).

When supernate samples are submitted, the results obtained are not grams of species per kg of slurry. Instead, the results are reported either as grams of species per $\mathrm{kg}$ supernate or gram of species per liter of supernate. In these cases, it is necessary to relate the supernate mass or volume to the corresponding slurry mass. An accurate estimate of $\mathrm{wt}_{\mathrm{t}} \%$ insoluble solids is needed in both cases, and the supernate density is also needed when results are reported per unit volume.

The SRAT receipt slurry contained about $16 \mathrm{wt} \%$ insoluble solids, and the SRAT product slurries ranged from about 14.5-16.8 wt $\%$ insoluble solids. The time of minimum insoluble solids occurred at the end of acid addition and prior to dewatering, where the insoluble solids were probably about $91-92 \%$ of what they were in the SRAT product based on the dewatered mass relative to the SRAT product mass. Simply assuming that the $\mathrm{wt} \%$ insoluble solids was $15 \%$ throughout the SRAT cycle would not introduce a large error in the grams supernate/gram slurry calculation, although the actual process material balance data were used to provide better estimates as a function of time. Similarly, the supernate density of the untrimmed sludge was $1.053 \mathrm{~g} / \mathrm{mL}$, while the supernate density of the SRAT products ranged from 1.054$1.093 \mathrm{~g} / \mathrm{mL}$. The high values occurred in runs with low catalytic activity, while the low values occurred in runs with a lot of catalytic activity (destruction of soluble anions). Although a single average supernate density of $1.07 \mathrm{~kg} / \mathrm{L}$ would only lead to $2 \%$ errors in the conversion calculations, actual data and process knowledge were used to reduce that potential error even further. The conversion of a result in grams/L supernate to grams species dissolved/kg total slurry is illustrated below:

$$
\frac{g \text { species }}{\mathrm{kg} \text { slurry }}=\frac{g \text { species }}{L \text { supernate }} * \frac{L}{1.07 \mathrm{~kg} \text { su pernate }} * \frac{(100 \%-w t \% \text { insol. solids }) \mathrm{kg} \text { supernate }}{100 \mathrm{~kg} \text { slurry }}
$$

The determination of percent dissolution of a given species follows from the last two calculations by forming the ratio of dissolved species grams $/ \mathrm{kg}$ slurry with the total species grams $/ \mathrm{kg}$ slurry. 
WSRC-STI-2008-00131

Revision 0

This page intentionally left blank. 


\subsection{SRAT RESULTS CALCULATED FROM RAW DATA}

The processed SRAT cycle data are presented in this section. Results include GC vol\%'s that have been converted into DWPF-scale $\mathrm{lbs} / \mathrm{hr}$ generation rates and supernate cation concentrations in $\mathrm{mg} / \mathrm{L}$ that have been converted into percent of total element dissolved. The IC data have all been converted to a common $m g$ anion $/ \mathrm{kg}$ slurry basis. A limited quantity of supernate anion data was converted to a slurry basis, and caustic quenched slurry sample anion data were converted back to an unquenched state. The $\mathrm{pH}$ data have been corrected to remove unintentional temperature differences between the actual SRAT temperature and the temperature setting of the $\mathrm{pH}$ monitor.

The data presented in subsequent sections include extents of dissolution of species in various runs as a function of time, $\mathrm{pH}$, and off-gas generation rates for $\mathrm{CO}_{2}, \mathrm{NO}, \mathrm{N}_{2} \mathrm{O}$, and $\mathrm{NO}_{2}$. Dissolution data for $\mathrm{Na}$ and $\mathrm{K}$ are not shown, since these two species were always observed at $100 \%$ solubility within analytical uncertainty. Dissolution data for some cationic species show minimal dissolution throughout the SRAT, and data for these species are not included in the graphs, e.g. Fe, Al, Zr. Dissolution data for the catalytic species $\mathrm{Ag}, \mathrm{Pd}, \mathrm{Rh}$, and $\mathrm{Ru}$ were presented separately in the report on noble metal dissolution and hydrogen generation. ${ }^{9}$ Hydrogen generation rate data were also presented in that report, so that data will not be emphasized here. Anion data were obtained on the MWWT and FAVC contents at the end of the SRAT and on the condensate dewatered during the SRAT in order to prepare material balances on carbon and nitrogen. These data are not particularly interesting individually, and the results are left for the material balance discussion in Section 4.3.

The data are presented by matched pairs of runs. Discussion starts with the low catalytic activity runs and proceeds through the more catalytically active runs. The presentation of run data concludes with the pair of all noble metals runs. At one extreme, each pair of runs can be taken as a separate study of a different sludge. At the other extreme, all runs are potentially comparable and the changing noble metal loadings represent nothing more than a perturbation to the bulk sludge composition. The majority of the data tended to support the first extreme viewpoint that each run pair was relatively unique although there were comparable features in all of the runs. One of the goals in comparing data within a pair was to establish the equivalency of the chemistry occurring in the two runs in order to combine noble metal concentration data, fill gaps in $\mathrm{GC}$ and/or $\mathrm{pH}$ data with data from the other run, etc.

A higher level analysis of the results presented in Section 3.0 that considers the results in groups is reserved for Section 5.0 on development of the SRAT chemistry timeline and the implications of these data for acid consumption during SRAT processing and potential improvements to the current DWPF stoichiometric acid equation.

\subsection{Low catalytic activity data}

\subsubsection{No noble metal baseline tests}

Two 22-L runs, H2Frit7 and H2Bead11, were performed with no added noble metals in order to baseline the processing data. SRAT $\mathrm{CO}_{2}$ generation data are shown in Figure 1. 
WSRC-STI-2008-00131

Revision 0

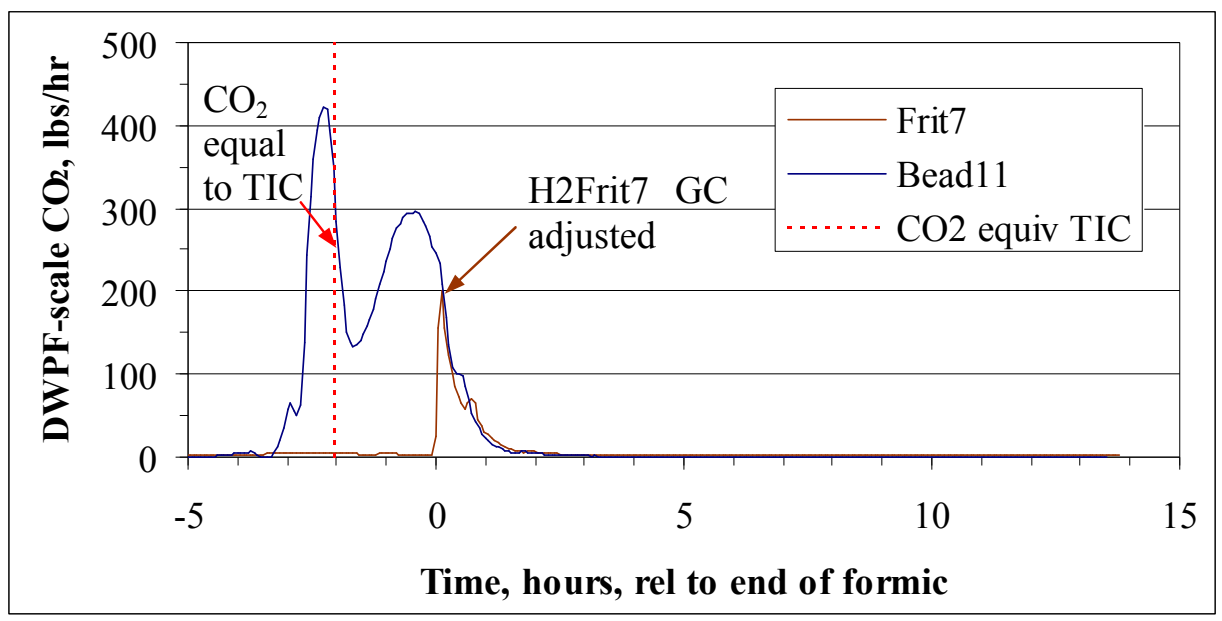

Figure 1. $\mathrm{CO}_{2}$ generation in the absence of noble metals

The data agree reasonably well from the point where the B-column in H2Frit7 began providing useful data (near the end of acid addition). The point where the mass of $\mathrm{CO}_{2}$ produced was equivalent to $100 \%$ conversion of the basis slurry TIC $(1,350 \mathrm{mg} / \mathrm{kg})$ into $\mathrm{CO}_{2}$ is shown as a dashed red line at about -2 hours relative to the end of formic acid addition. About $85 \mathrm{~g}$ of $\mathrm{CO}_{2}$ are produced from destruction of TIC in the feed. The TIC-equivalent $\mathrm{CO}_{2}$ break point fell slightly before the intermediate minimum in $\mathrm{CO}_{2}$ generation rate between carbonate destruction and formate destruction in all $\mathrm{ABC}$ simulant tests. Total $\mathrm{CO}_{2}$ production in $\mathrm{H} 2 \mathrm{Bead} 11$ was comparable to the pair with $0.2 \mathrm{wt} \% \mathrm{Ag}$ (200-260 grams). The other twelve 22-L runs produced 360-660 grams of $\mathrm{CO}_{2}$. The implication was that the silver runs were catalytically inactive for formate destruction, and that the two no noble metal runs and two Ag runs provide lower bounds for the formate loss.

Data for the oxides of nitrogen are given in the next two figures. Details on the determination of NO and $\mathrm{NO}_{2}$ from the available $\mathrm{GC}$ data are given in Section 2.4.3. $\mathrm{N}_{2} \mathrm{O}$ data were mostly lost for $\mathrm{H} 2 \mathrm{Frit}$, since most of the evolution occurred prior to the end of acid addition when the B-column of the GC was malfunctioning. $\mathrm{NO}_{2}$ and $\mathrm{NO}$ were obtained from the A-column data which was giving integrable peaks for $\mathrm{He}, \mathrm{O}_{2}, \mathrm{~N}_{2}$, and $\mathrm{NO}$ throughout the SRAT cycle. 
WSRC-STI-2008-00131

Revision 0

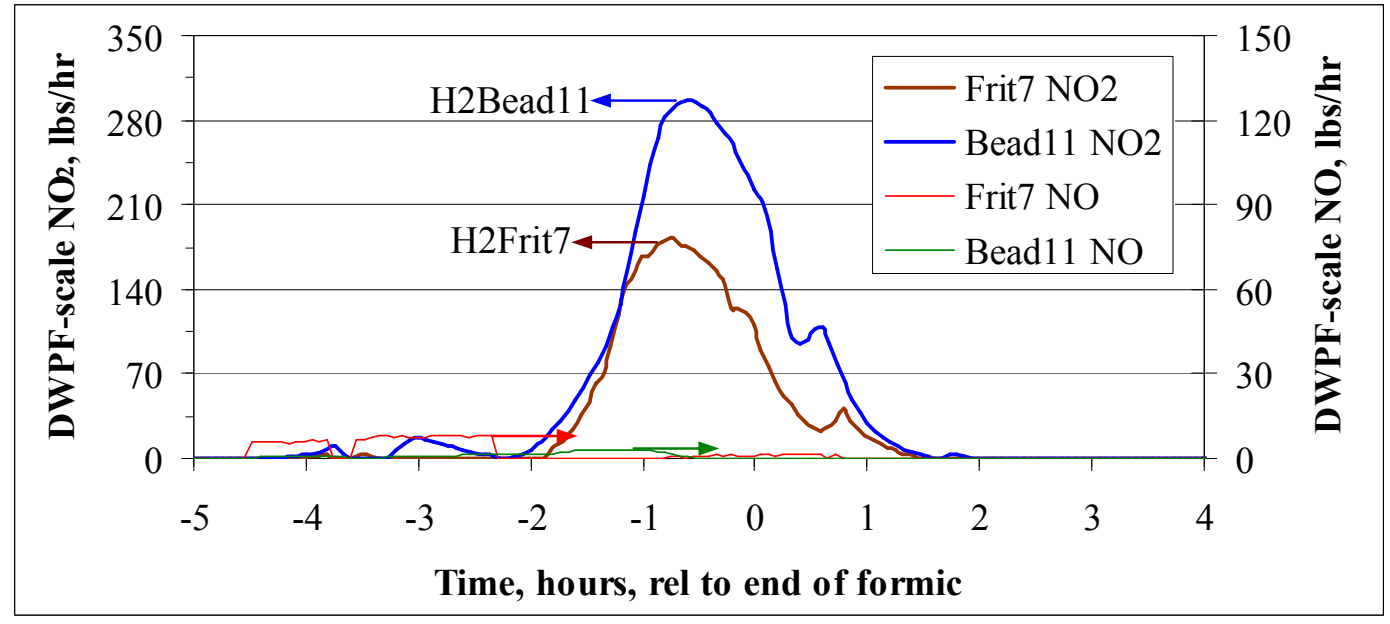

Figure 2. $\mathrm{NO}$ and $\mathrm{NO}_{2}$ generation with no noble metals

This pair was one where one set of GC data came from an $\mathrm{M} 200 \mathrm{H}$ and the other set came from a 3000A. The four sets of $\mathrm{M} 200 \mathrm{H} \mathrm{GC}$ data were the most problematic. M200H data were reprocessed extensively perhaps to the detriment of the numerical accuracy of the $\mathrm{NO}$ and $\mathrm{NO}_{2}$ data for H2Frit7 compared with the $\mathrm{H} 2 \mathrm{Bead} 11$ data. The two sets of $\mathrm{NO}_{2}$ data were very similar qualitatively though they differed in absolute magnitude. $\mathrm{NO}_{2}$ was the major gas produced during nitrite destruction. The $\mathrm{NO}$ data were unusual not only in that the two curves were qualitatively different, but in that the rate of $\mathrm{NO}$ generation calculated from the vol\% data was almost zero. This relative absence of NO was not expected based on the known equilibrium distribution of $\mathrm{NO}$ to $\mathrm{NO}_{2}$ in the presence of $\mathrm{O}_{2}$. The no noble metal pair ratio of $\mathrm{NO}_{2} / \mathrm{NO}$ was the largest of any run pair in this study due to the small $\mathrm{NO}$ generation values. There were some similarities in the data, including an onset of NO generation at the start of acid addition (about -4.5 hours), a brief lull between nitric acid and formic acid additions (in the -3.5 to -3.8 period), and very little generation in the last 1.5 hours before the end of formic acid addition when the primary destruction of nitrite occurred.

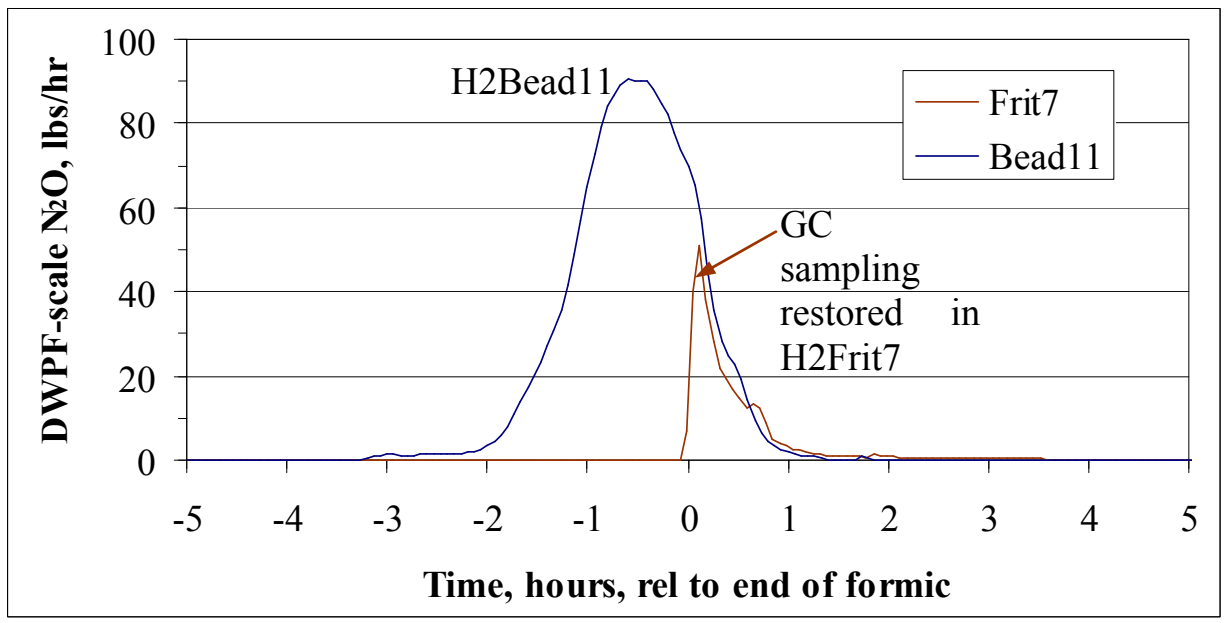

Figure 3. $\mathrm{N}_{2} \mathrm{O}$ generation with no noble metals 
The two sets of $\mathrm{N}_{2} \mathrm{O}$ generation data match well from 0 to +1.5 hours when the H2Frit7 GC B-column began injecting adequate sample. Prior to that, the $\mathrm{H} 2 \mathrm{Frit} 7 \mathrm{GC}$ obtained no integrable B-column data for either $\mathrm{CO}_{2}$ or $\mathrm{N}_{2} \mathrm{O}$. Presumably the actual $\mathrm{N}_{2} \mathrm{O}$ peak for $\mathrm{H} 2 \mathrm{Frit} 7$ would have resembled the $\mathrm{H} 2 \mathrm{Bead} 11$ peak if the sample injector had been working properly. Such an assumption was made to fill gaps in the data for subsequent nitrogen material balance calculations.

Samples from both runs targeted anion concentrations, but they were timed to provide minimal overlap. H2Bead11 focused on formic acid addition, while H2Frit7 primarily targeted the period after acid addition. The data for formate ion concentration as a function of processing time are shown in Figure 4.

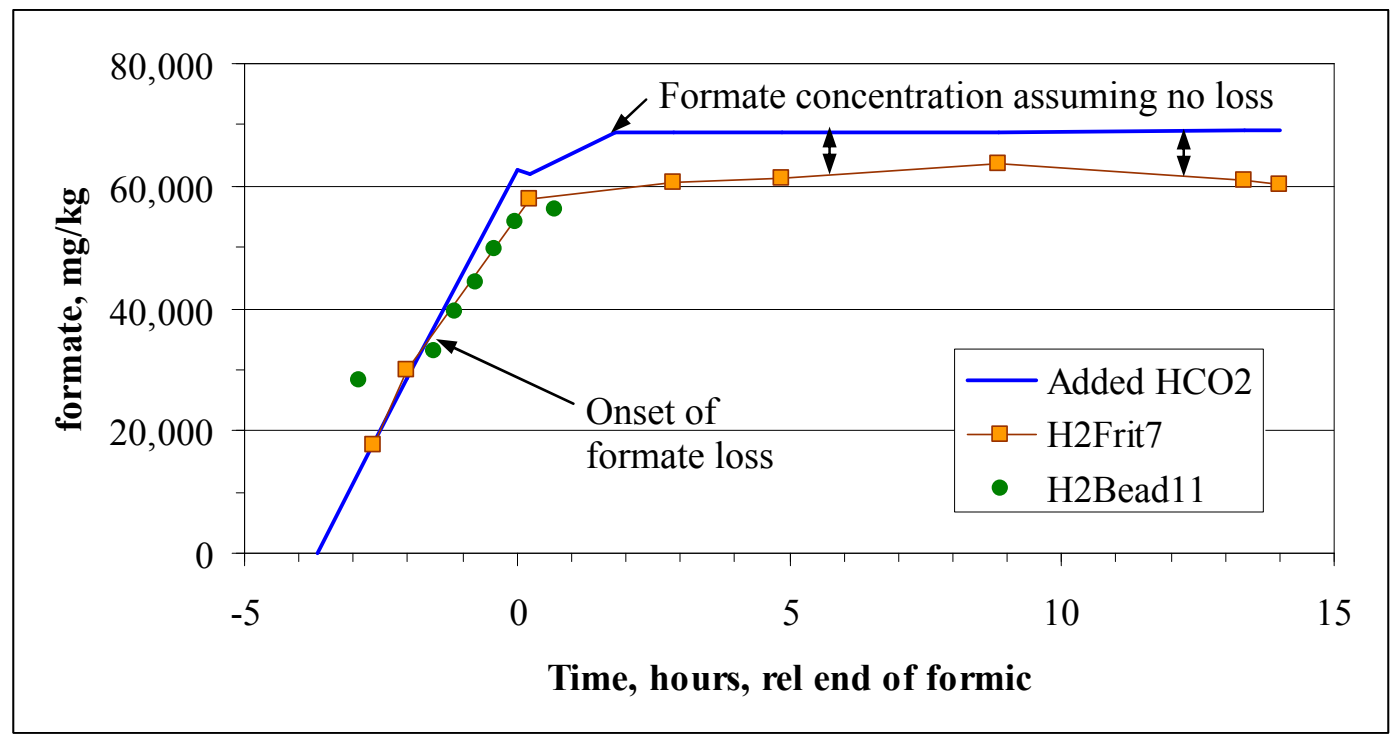

Figure 4. Formate ion with no noble metals

The data show a small loss in formate during the end of acid addition (period of nitrite destruction and Mn reduction) which did not change appreciably during the remainder of the SRAT cycle. Corresponding data for the nitrate ion concentration are given in Figure 5. 
WSRC-STI-2008-00131

Revision 0

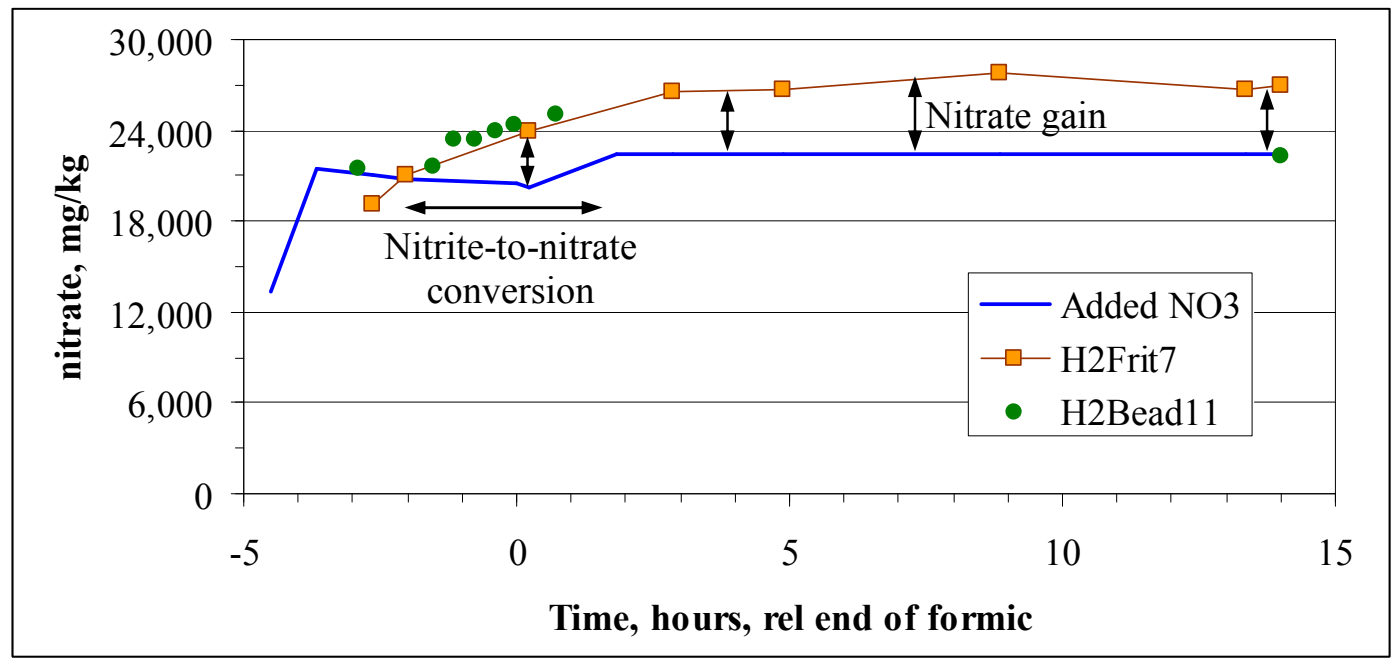

Figure 5. Nitrate ion with no noble metals

All of the nitrate ion data show nitrate formation and a sustained gain in total nitrate except for the H2Bead11 SRAT product result, or solid green circle at +14 hours, which consequently was considered suspect since it shows no nitrate formation. A profile of nitrite ion destruction versus time was developed from the sample data, Figure 6.

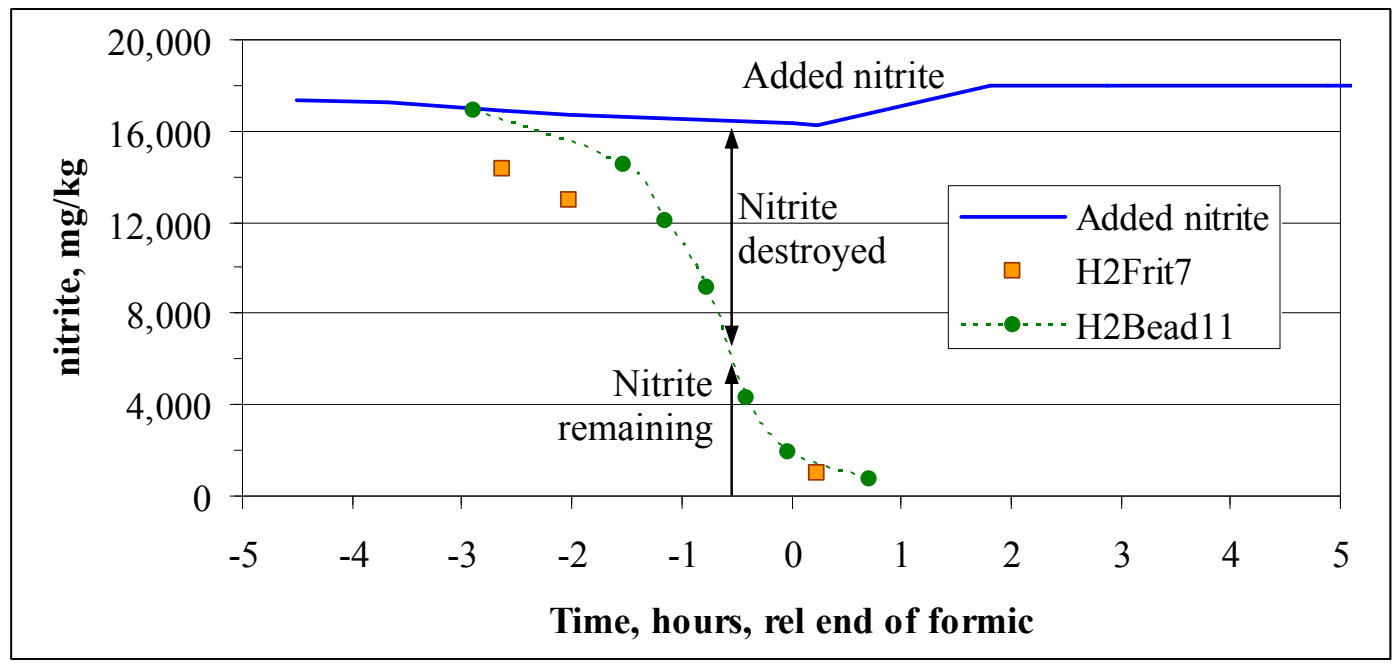

Figure 6. Nitrite ion with no noble metals

Nitrite ion behavior was generally similar to that in other run pair data with a slow initial destruction rate that increased during the last 1.5 hours of formic acid addition with nitrite destruction effectively complete by 1-2 hours after the end of acid addition. The H2Frit7 data in the -2 to -3 hour range were off the curve for H2Bead11. The 16 minute difference in total formic acid addition time between runs was inadequate to realign the data. It appears that the H2Bead11 data may be slightly biased high, given that the first point falls on the added nitrite curve and the balance of data for the sixteen runs suggests that at least some nitrite has been destroyed by that point. The H2Frit7 data may be slightly low. The two sets of data are within the anticipated $\pm 10 \%$ uncertainty associated with IC measurements. 
The prototype oxidation-reduction probe was used during H2Bead11 to collect redox potential measurements. The readings were recorded manually at about 20 minute intervals, Figure 7.

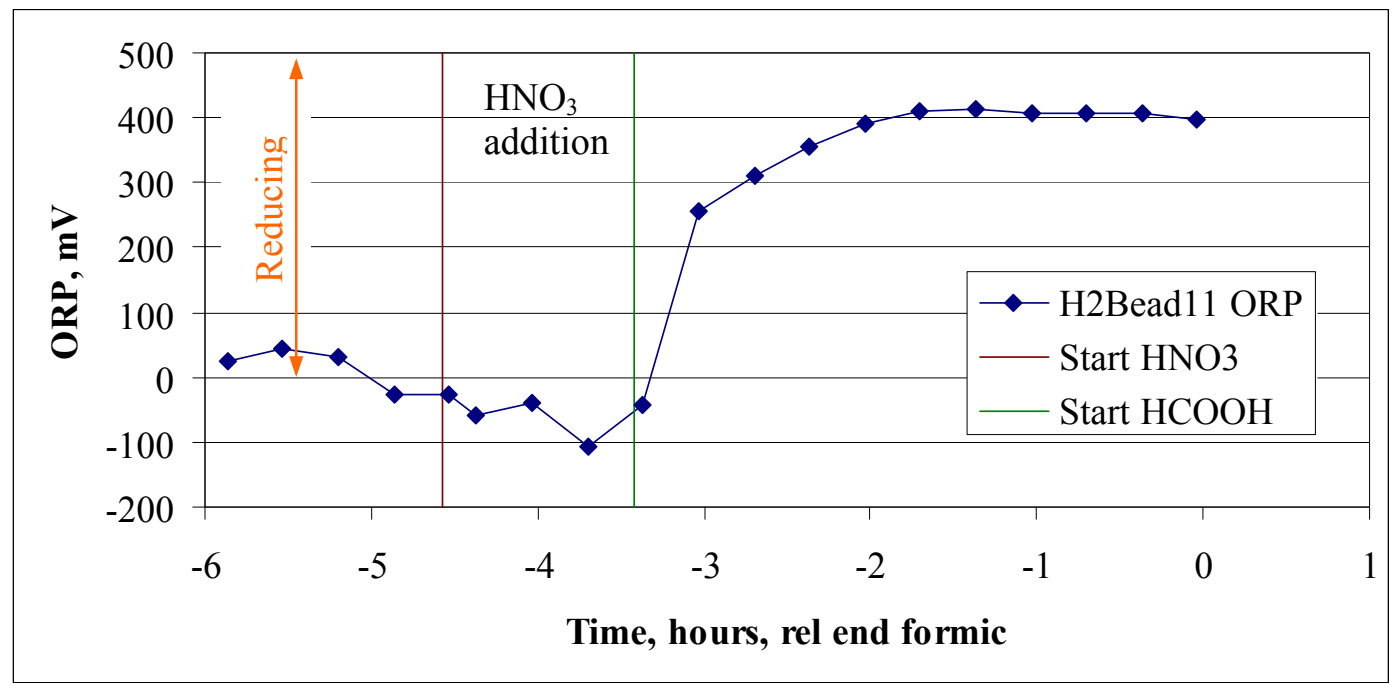

Figure 7. Oxidation-reduction potential with no noble metals

The system was neither strongly oxidizing nor reducing initially (during heat-up to $93^{\circ} \mathrm{C}$ ). Negative millivolts indicate oxidizing and positive millivolts indicate reducing. The system became more oxidizing during nitric acid addition, and then became progressively more reducing during formic acid addition. Electronically recorded data for some of the other runs (data every minute) shows no more finescale structure than this plot.

\subsubsection{Tests with Ag at $0.2 \mathrm{wt} \%$}

Silver was tested at $0.2 \mathrm{wt} \%$. The two tests with silver were $\mathrm{H} 2 \mathrm{Frit} 3$ and $\mathrm{H} 2 \mathrm{Bead} 9$. The $\mathrm{CO}_{2}$ generation rate profiles are given in Figure 8. 
WSRC-STI-2008-00131

Revision 0

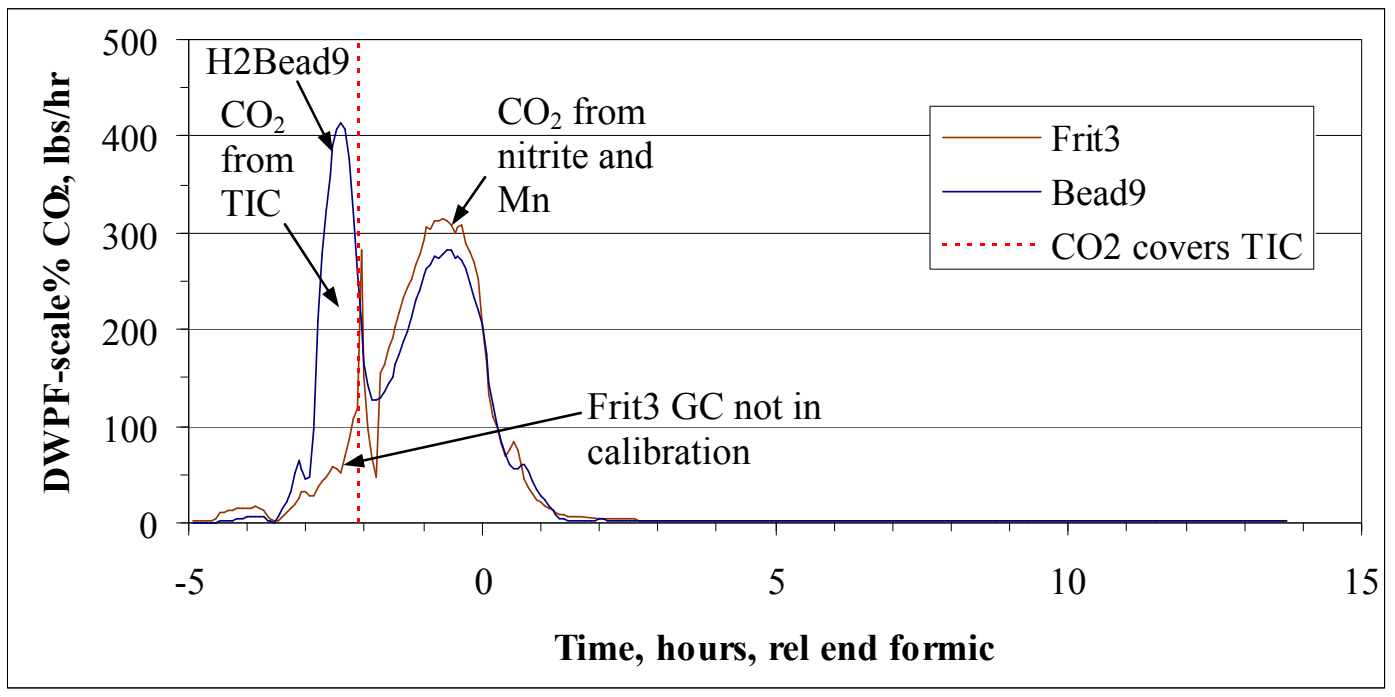

Figure 8. $\mathrm{CO}_{2}$ generation at $0.2 \mathrm{wt} \% \mathrm{Ag}$

There were issues with the $\mathrm{H} 2 \mathrm{Frit} 3 \mathrm{M} 200 \mathrm{H}$ GC. Most of the $\mathrm{CO}_{2}$ from TIC destruction was missed. There were no suitable cal gas checks during acid addition which prevented reconstruction of the $\mathrm{CO}_{2}$ profile between -2 and -3 hours. The GC picked up the tail end of the large TIC peak at -2.5 hours, but missed the majority of the peak that was seen in H2Bead9 and essentially all of the other fourteen runs during this period (H2Frit7 also missed this period of time completely). Other than during the one period of poor GC performance, however, there was excellent agreement between the two traces. A dashed line is shown where the cumulative $\mathrm{CO}_{2}$ produced in $\mathrm{H} 2 \mathrm{Bead} 9$ was equivalent to $100 \%$ destruction of the feed carbonate $(1,350 \mathrm{mg} / \mathrm{kg})$. The $\mathrm{pH}$ in both runs was about five at that point $(-2.1$ hours $)$, and the $\mathrm{CaCO}_{3}$ had also been essentially dissolved into the supernate. Silver results were comparable to the no noble metals results.

Data for the oxides of nitrogen are shown on the next two graphs. H2Frit3 data from column A (where $\mathrm{NO}$ vol\% and $\mathrm{O}_{2}$ loss were measured) had to be reprocessed, so the H2Frit3 data is potentially more susceptible to unidentified errors than the H2Bead9 data. There were not any spot checks with cal gas during acid addition, and only one afterwards before the end of the SRAT, partly because the expected behavior of these gases without $\mathrm{Pd}, \mathrm{Rh}$, and $\mathrm{Ru}$ was relatively uncertain. 
WSRC-STI-2008-00131

Revision 0

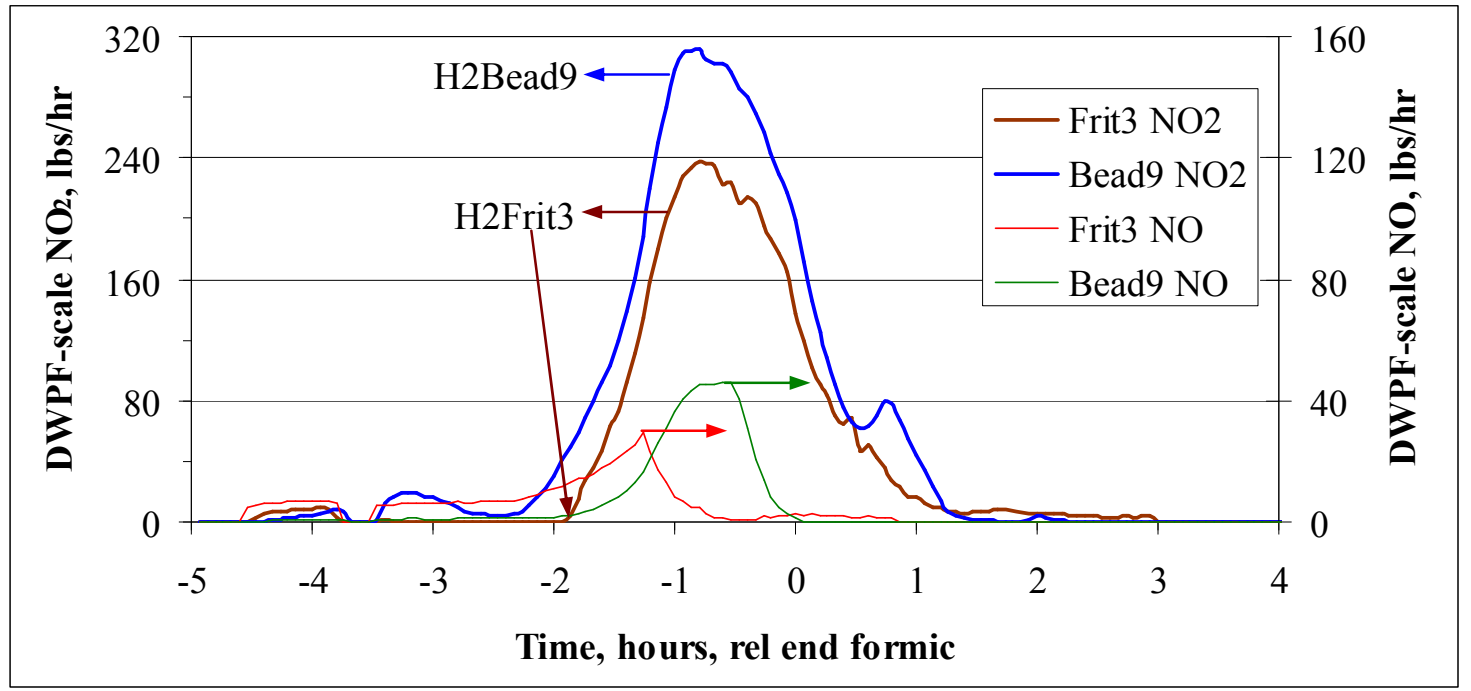

Figure 9. $\mathrm{NO}$ and $\mathrm{NO}_{2}$ generation at $0.2 \mathrm{wt} \% \mathrm{Ag}$

One problem with reprocessed GC data was that it tended to contain more error than data from a run that did not require reprocessing. The calculation of oxygen loss for use in the $\mathrm{NO}_{2}$ calculation was particularly susceptible to the magnitude of uncertainty in the final data. The abrupt start of $\mathrm{NO}_{2}$ generation at -1.9 hours for $\mathrm{H} 2 \mathrm{Frit} 3$ compared to the gradual decline in $\mathrm{NO}_{2}$ generation at +1 to +3 hours is visual evidence that the nominal oxygen to nitrogen ratio used to determine $\mathrm{NO}_{2}$ was probably different in these two periods after reprocessing. A drift in $\mathrm{O}_{2} / \mathrm{N}_{2}$ ratio could also explain the difference in peak $\mathrm{NO}_{2}$ heights. Other data suggest that the difference in peak height was not due to differences in the zero point or range settings of the He mass flow controllers between the two runs. The NO data were less well aligned than the $\mathrm{NO}_{2}$ data and were not complimentary to $\mathrm{NO}_{2}$ as in some of the other pairs. The absolute quantity of $\mathrm{NO}$ produced was quite small at roughly $10 \%$ or less of the $\mathrm{NO}_{2}$. The $\mathrm{N}_{2} \mathrm{O}$ data are shown in Figure 10.

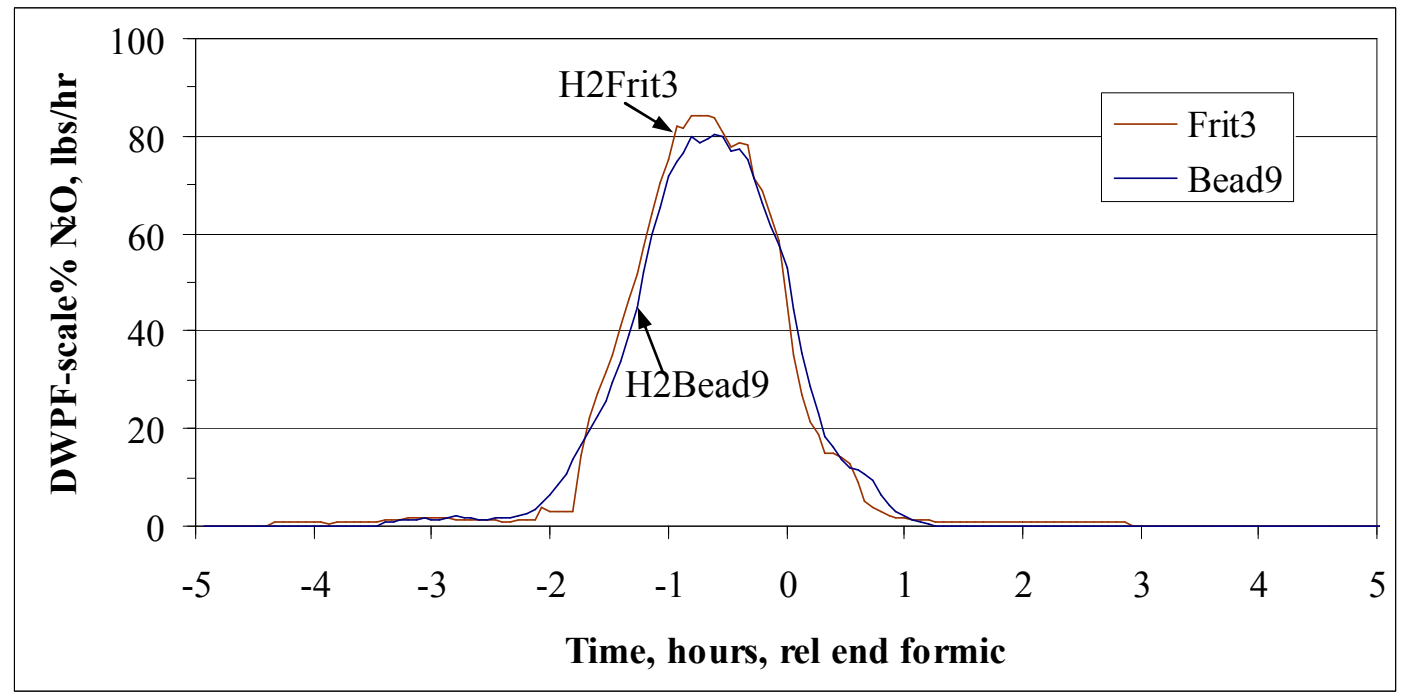

Figure 10. $\mathrm{N}_{2} \mathrm{O}$ generation at $0.2 \mathrm{wt} \% \mathrm{Ag}$ 
Because $\mathrm{N}_{2} \mathrm{O}$ evolution came later than the initial $\mathrm{CO}_{2}$ evolution, the reprocessed $\mathrm{H} 2 \mathrm{Frit} 3 \mathrm{~N}_{2} \mathrm{O}$ data and the H2Bead9 $\mathrm{N}_{2} \mathrm{O}$ data were quite comparable. Data for $\mathrm{N}_{2} \mathrm{O}$ and $\mathrm{CO}_{2}$ support the hypothesis that the He MKS was not significantly impacting the calculated DWPF-scale pounds per hour generation rates in these two runs.

Sampling was preferentially performed on runs with low catalytic activity to track the other major species as part of the investigation into SRAT chemistry. The next series of figures presents the dissolution versus time data for five individual elements. A composite low catalytic activity $\mathrm{pH}$ curve, taken from four low catalytic activity $\mathrm{pH}$ data sets averaged together, was superimposed over the dissolution data. Figure 11 presents the dissolution data for $\mathrm{Mg}$, which was the first major insoluble species to dissolve in the $\mathrm{ABC}$ simulant.

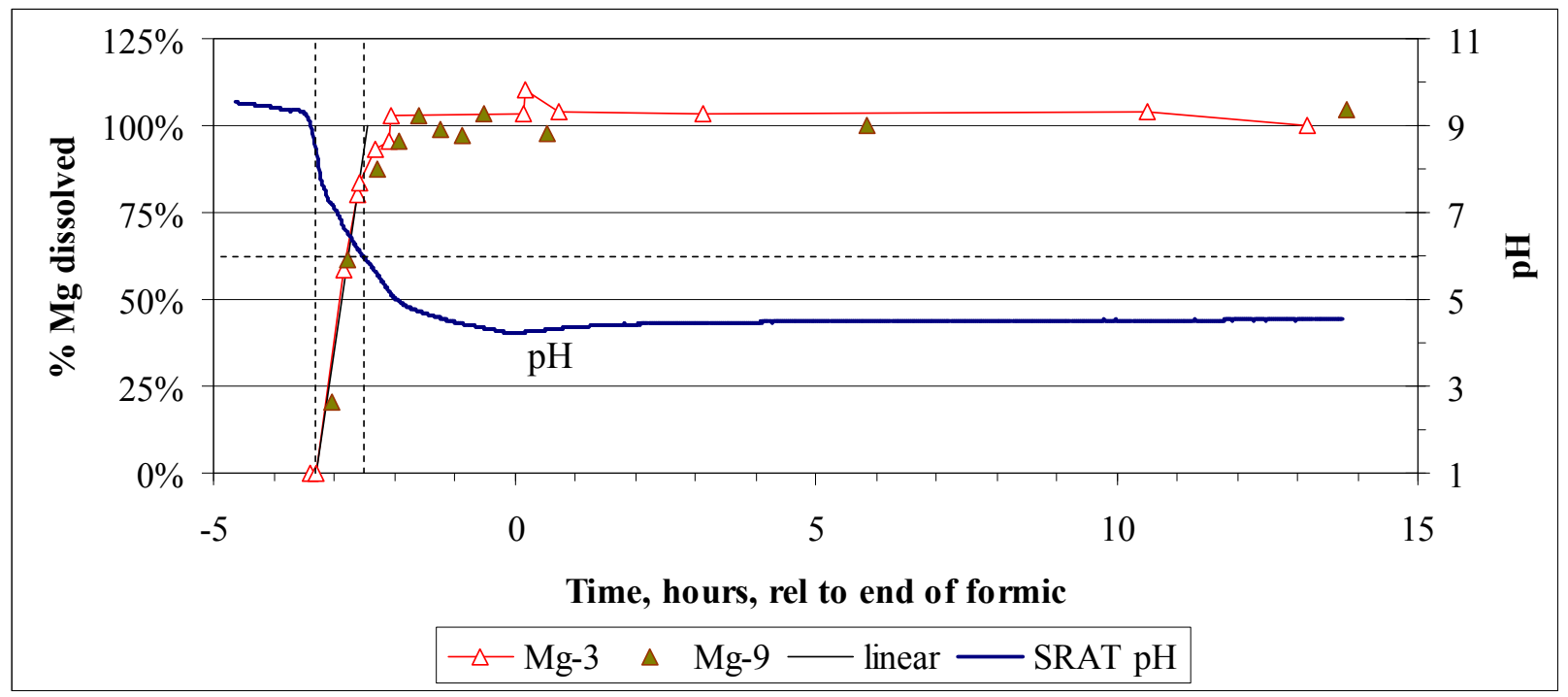

Figure 11. Mg dissolution at $0.2 \mathrm{wt} \% \mathrm{Ag}$

Magnesium dissolution started as the $\mathrm{pH}$ neared seven and was nearly complete before the $\mathrm{pH}$ had dropped below six. The maximum dissolution rate was about 2.3 moles/hour, or 4.6 moles hydroxide released per hour, since the $\mathrm{Mg}$ was present as $\mathrm{Mg}(\mathrm{OH})_{2}$. The acid addition rate was about 7.7 moles per hour which was adequate to support this reaction. The second major species to undergo significant dissolution was Ca, Figure 12. 
WSRC-STI-2008-00131

Revision 0

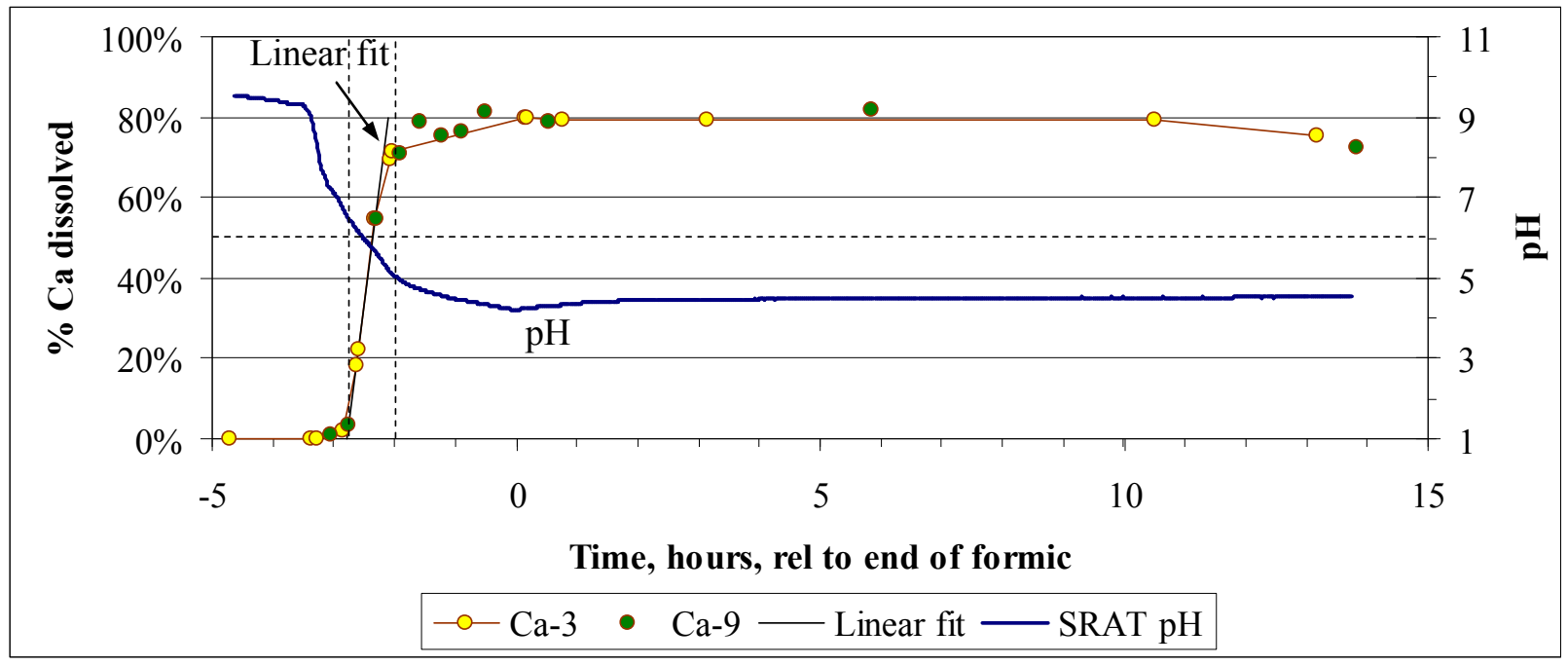

Figure 12. Ca dissolution at $0.2 \mathrm{wt} \% \mathrm{Ag}$

Calcium dissolution started as the $\mathrm{pH}$ fell near six and reached about $80 \%$ as the $\mathrm{pH}$ reached five. The dissolution was about 20 minutes behind the $\mathrm{Mg}$. The maximum rate was about 2.1 moles $\mathrm{Ca}^{+2}$ per hour. The dissolving calcium was primarily $\mathrm{CaCO}_{3}$, so the acid required to support $\mathrm{Ca}$ dissolution was up to about 4.3 moles per hour out of 7.7 moles per hour being fed. The data indicated competition between $\mathrm{Mg}$ and $\mathrm{Ca}$ for available acid during the end of $\mathrm{Mg}$ dissolution and beginning of $\mathrm{Ca}$ dissolution. $\mathrm{Mn}$ dissolution occurred primarily after $\mathrm{Mg}$ and $\mathrm{Ca}$ dissolution, Figure 13.

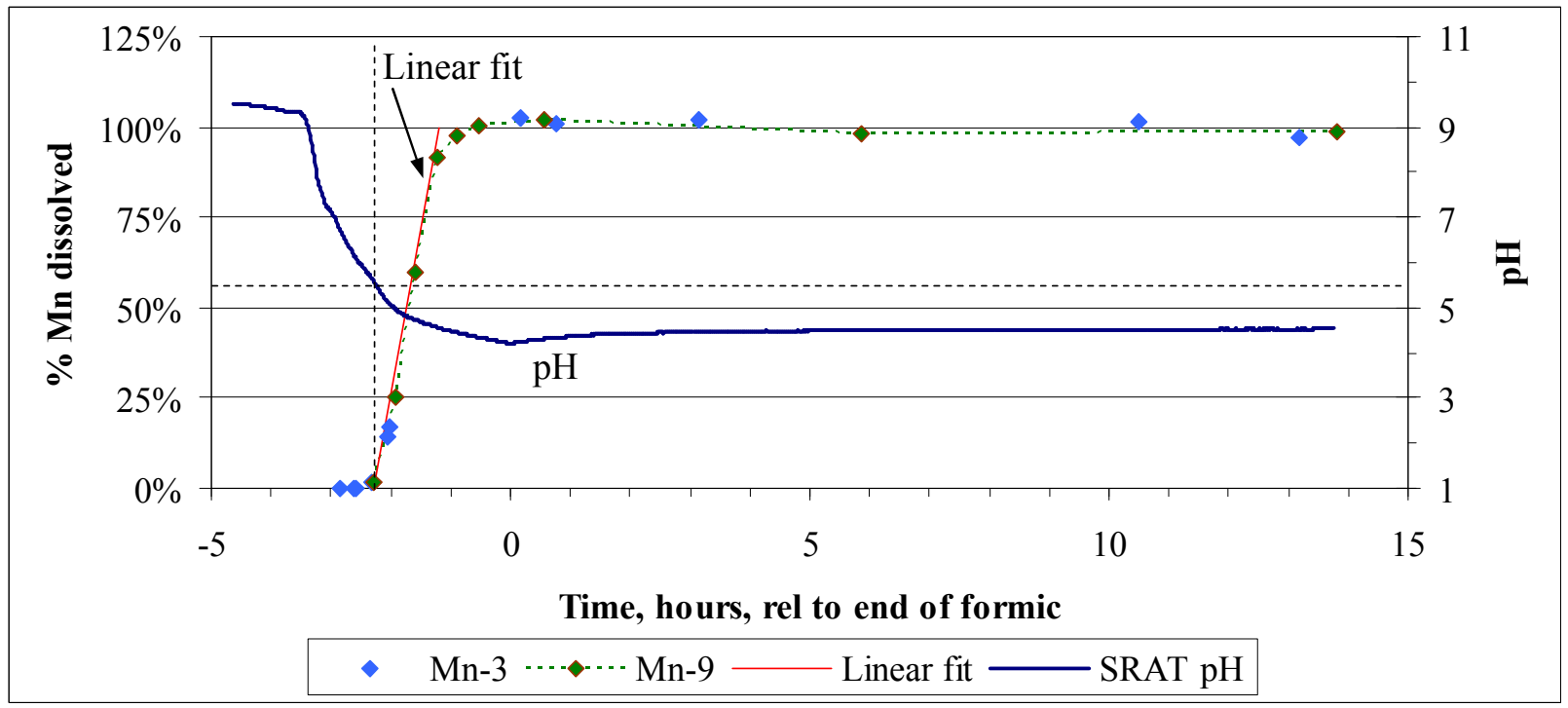

Figure 13. Mn dissolution at $0.2 \mathrm{wt} \% \mathrm{Ag}$

Manganese reduction/dissolution started as $\mathrm{pH}$ fell below about 5.5. The dissolution was about 30 minutes behind $\mathrm{Ca}$ initially and the two dissolutions only overlapped significantly for about 15 minutes. The maximum rate of reduction/dissolution was about 1.75 moles Mn per hour. The associated acid consumption was 5.3 moles per hour (at three moles acid per mole Mn reduced and dissolved) which was about two-thirds of the molar acid addition rate of $7.7 \mathrm{moles} / \mathrm{hr}$. Mn reduction started sooner and 
progressed faster in the $\mathrm{Ag}$ runs than in the Pd runs, perhaps due to Pd catalyzed nitrite destruction stealing acid away from $\mathrm{Mn}$ reduction in the $\mathrm{Pd}$ runs. Lesser amounts of $\mathrm{Ni}, \mathrm{Cu}$, and $\mathrm{Zn}$ were dissolved as well during these two runs. These results will be incorporated into the later discussions on SRAT chemistry in Section 5.0.

Data were obtained on anion concentrations during H2Frit3 to support the XAS samples. Some additional samples were targeted in $\mathrm{H} 2 \mathrm{Bead} 9$ to better define the period of nitrite destruction. Composite formate data from the two runs with $0.2 \mathrm{wt} \% \mathrm{Ag}$ are shown in Figure 14.

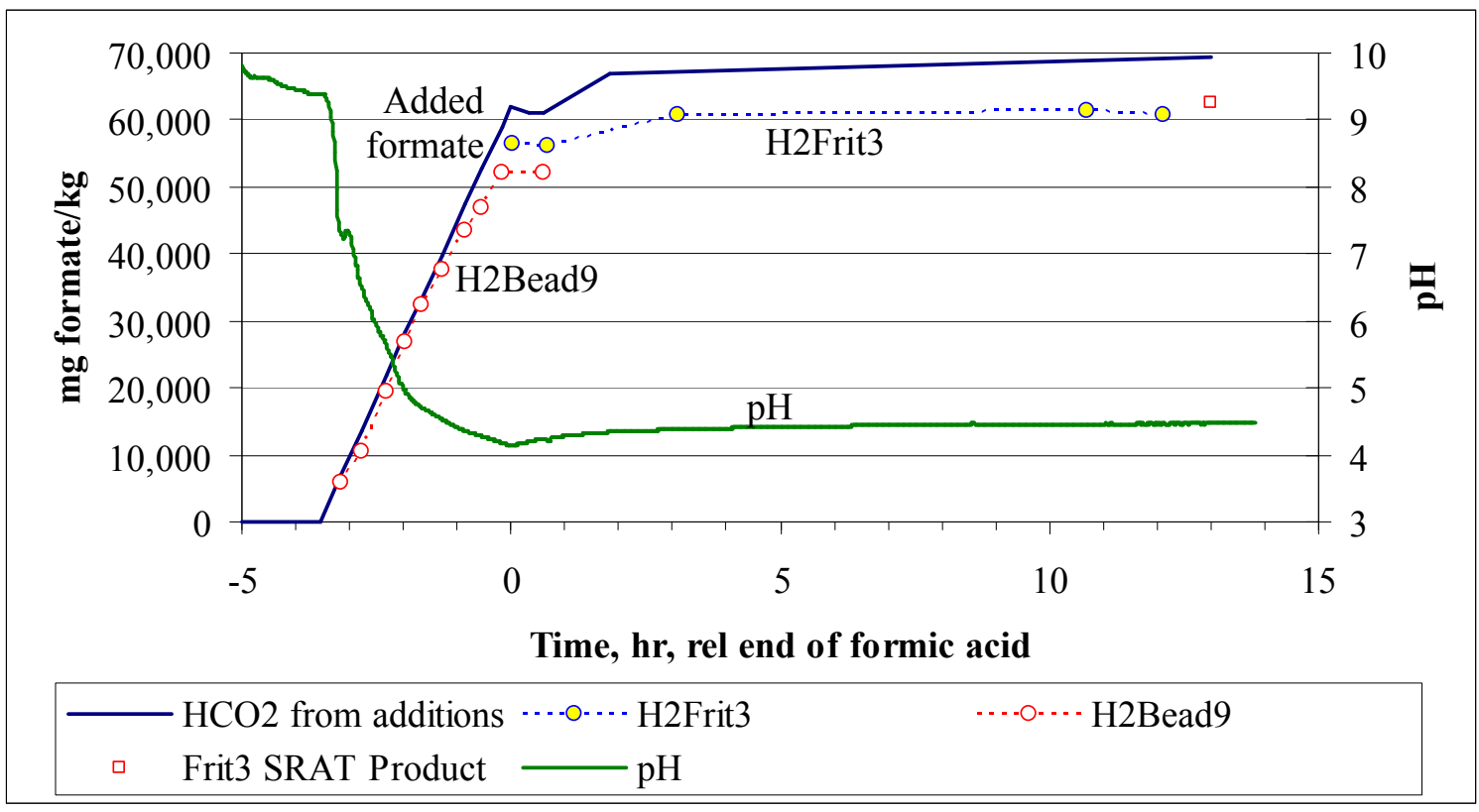

Figure 14. Formate concentration at $0.2 \mathrm{wt} \% \mathrm{Ag}$

The data are consistent with the $\mathrm{CO}_{2}$ generation rate profile that indicated little formate destruction after dewatering. Formate loss is indicated prior to the end of acid addition during the time that Mn reduction and nitrite destruction were occurring. There is an $8 \%$ offset in the analytical results near the end of acid addition for the two runs, but this is well within the expected range of uncertainty for IC data.

Nitrite-to-nitrate conversion was visible when plotting the measured nitrate concentrations versus the calculated concentration of the nitrates added to the system, Figure 15. 
WSRC-STI-2008-00131

Revision 0

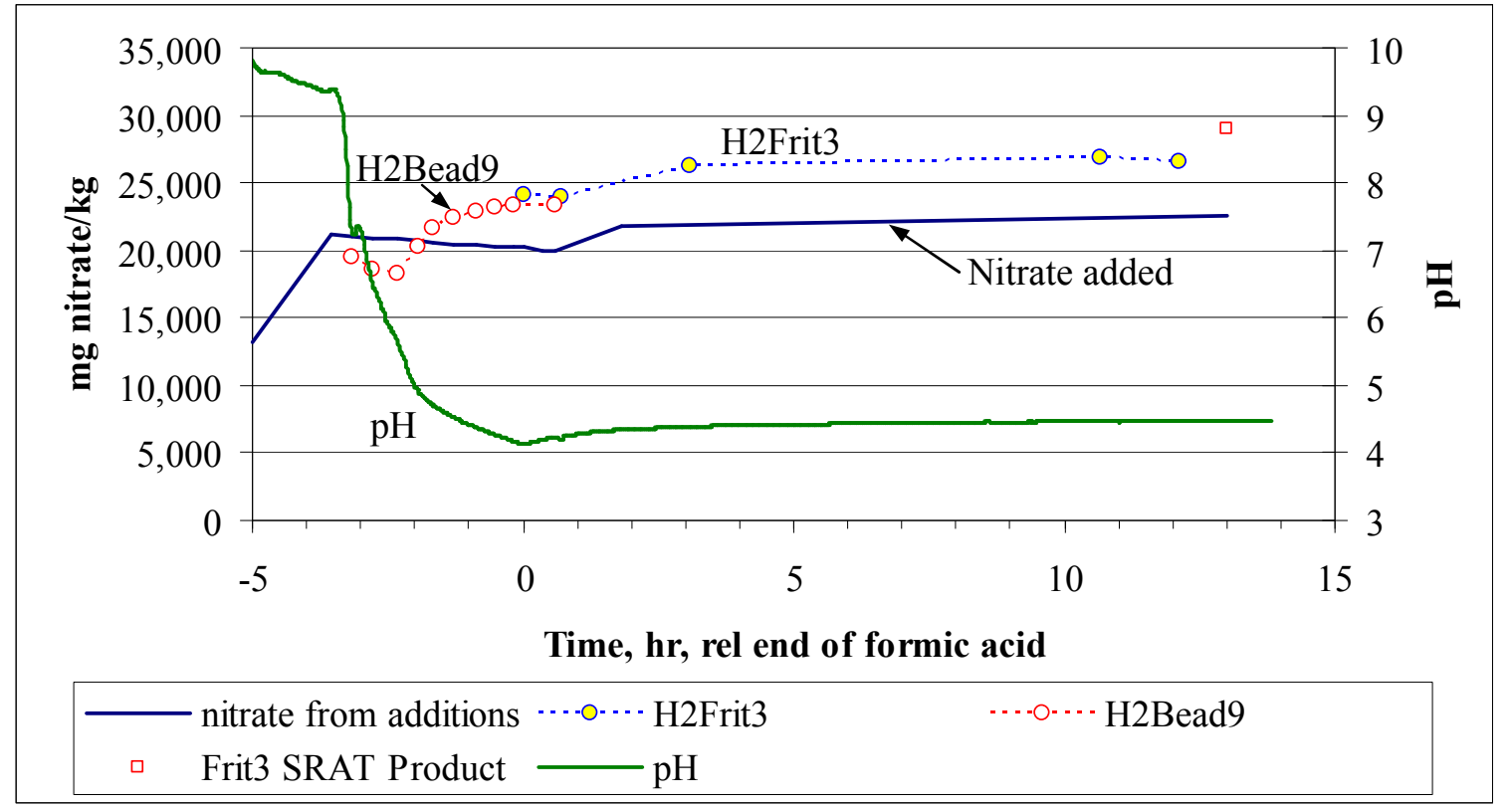

Figure 15. Nitrate concentration at $0.2 \mathrm{wt} \% \mathrm{Ag}$

The measured nitrate concentration showed a steady gain from -2 hours to +1 hours similar to the results with no noble metals. The corresponding nitrite ion data are shown in Figure 16.

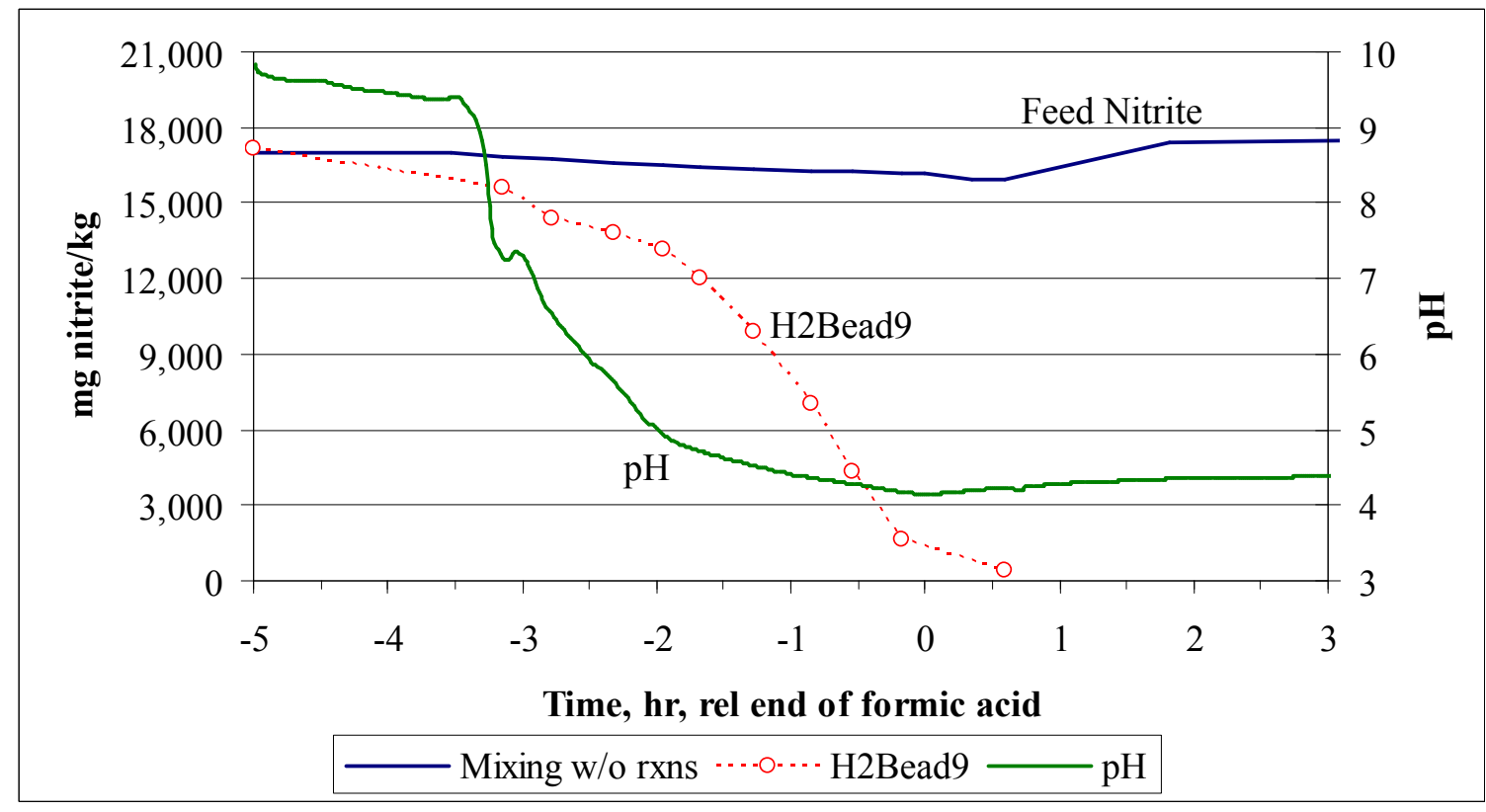

Figure 16. Nitrite ion concentration at $0.2 \mathrm{wt} \% \mathrm{Ag}$

Nitrite destruction started slowly, and then the rate increased about 1.5 hours prior to the end of acid addition. This time corresponds closely with the time that nearly $100 \%$ of the Mn had been reduced. It appears that nitrite destruction went slowly while $\mathrm{Mg}, \mathrm{Ca}$, and $\mathrm{Mn}$ were being dissolved (and using most 
of the fresh acid), and that the rate only increased once the dissolutions of the major soluble cations were complete.

Sufficient acid was added to essentially destroy nitrite prior to the end of acid addition. The final stages of nitrite destruction have a much different appearance when the acid addition is close to the minimum required for nitrite destruction. In those cases, the concentration of nitrite follows an approximately exponential decay (pseudo-first order decay) versus time during the rest of the SRAT cycle. This behavior was documented during tests supporting Sludge Batches 1A, 2, and 3.

The oxidation-reduction probe was present during acid addition in H2Bead9. Only manually logged readings from the ORP were available. These are shown in Figure 17.

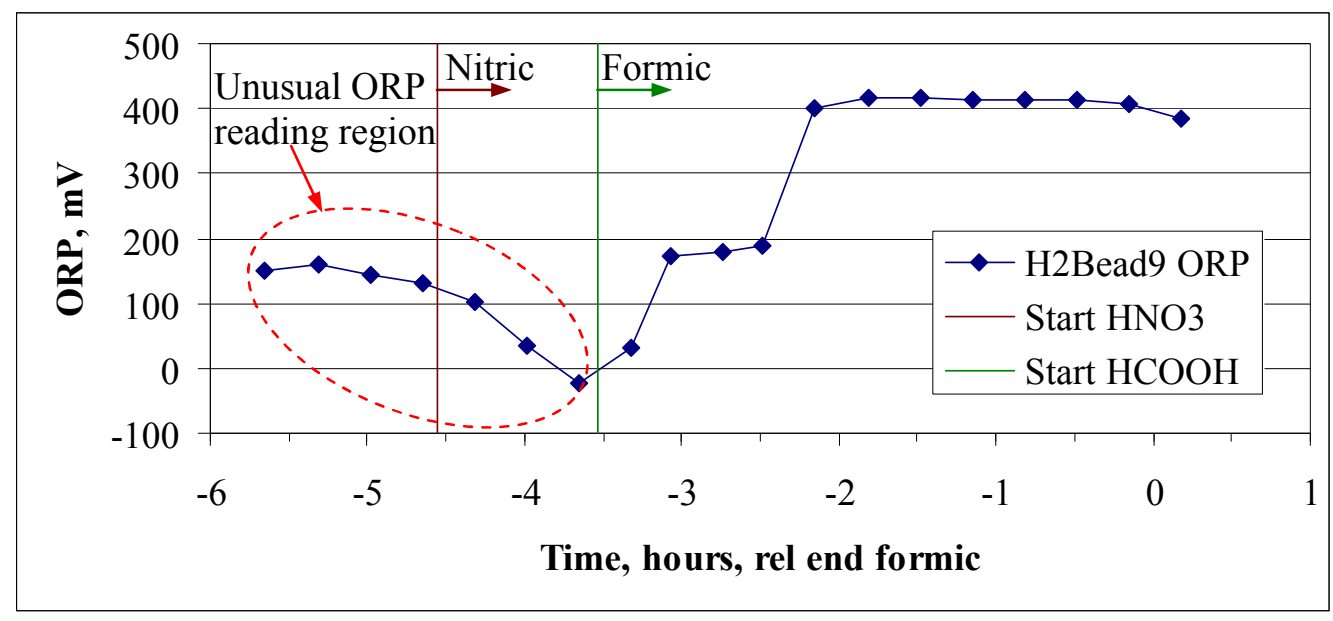

Figure 17. Oxidation-reduction potential at $0.2 \mathrm{wt} \% \mathrm{Ag}$

There are both similarities and differences between this set of ORP data and other ORP data sets presented for the other five runs that used the probe. The most obvious difference is that the initial ORP potential was not negative (oxidizing), and the potential barely went negative prior to the end of nitric acid addition. Subsequent ORP data from H2Bead9 look more or less like that from other runs, with the potential swinging into the positive $\mathrm{mV}$ (reducing) range shortly after the start of formic acid addition and climbing to $\sim 400 \mathrm{mV}$.

\subsubsection{Tests with Pd at 0.2 wt\%}

H2Frit4 and H2Bead15 were given an initial charge of $0.2 \mathrm{wt} \% \mathrm{Pd}$ in the trimmed sludge total solids. Data similar to that obtained with $0.2 \mathrm{wt} \% \mathrm{Ag}$ were obtained in these two runs. Silver, however, was seen as more nearly comparable to having no noble metals than was Pd. The palladium pair of runs showed more catalytic activity than the no noble metal and silver run pairs based on $\mathrm{CO}_{2}$ production (360-390 grams of $\mathrm{CO}_{2}$ ). There was still a markedly reduced attack rate on formate ion compared to the $\mathrm{Ru}$ and $\mathrm{Rh}$ catalyzed runs. The rate of $\mathrm{CO}_{2}$ generation is plotted as a function of time in Figure 18. 
WSRC-STI-2008-00131

Revision 0

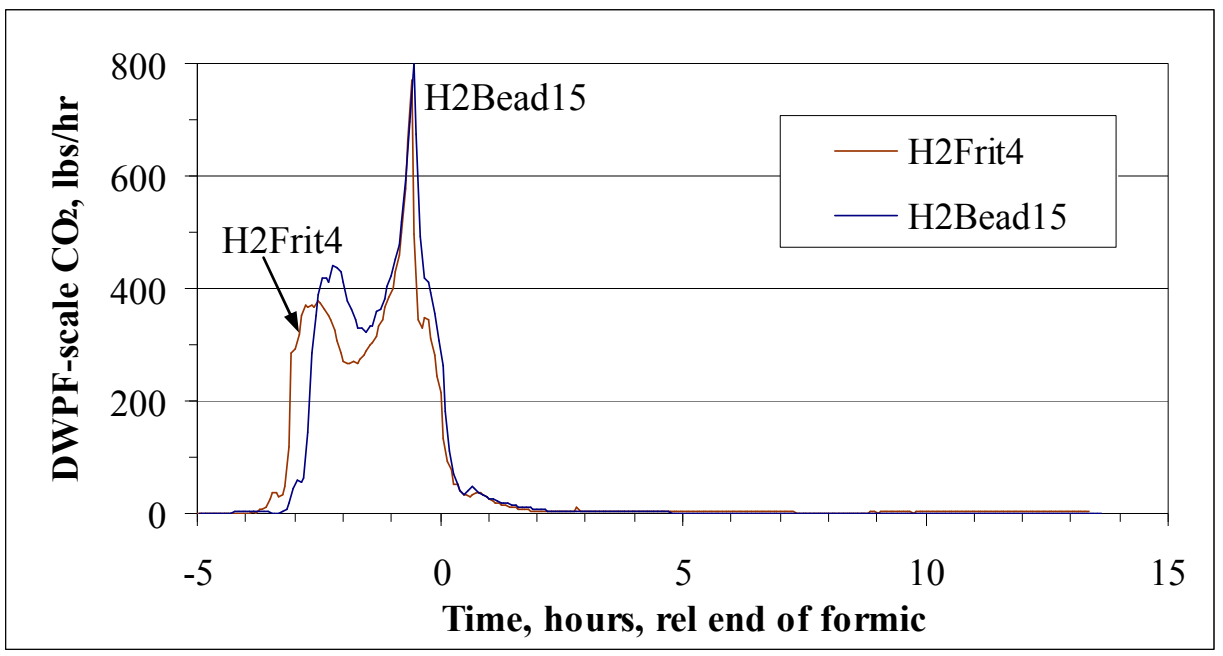

Figure 18. $\mathrm{CO}_{2}$ generation at $0.2 \mathrm{wt} \% \mathrm{Pd}$

The data were fairly well reproduced. Variations around -3 hours were attributed to the slightly different durations for formic acid addition, 3:47 in H2Frit4 and 3:21 in H2Bead15. The time difference was equivalent to an acid addition rate difference that caused the $\mathrm{H} 2 \mathrm{Frit} 4 \mathrm{CO}_{2}$ generation to start about 0.4 hours earlier than $\mathrm{H} 2 \mathrm{Bead} 15$ and to peak at a lower rate during the period of TIC destruction. Most of the $\mathrm{CO}_{2}$ was generated from TIC or during $\mathrm{Mn}$ reduction and nitrite destruction. These two runs had insignificant hydrogen generation during reflux with associated catalytic $\mathrm{CO}_{2}$ production of about 1-2 $\mathrm{lbs} / \mathrm{hr}$ (near the $\mathrm{CO}_{2}$ detection limit). The calculated $\mathrm{NO}$ and $\mathrm{NO}_{2}$ generation rates are given in Figure 19.

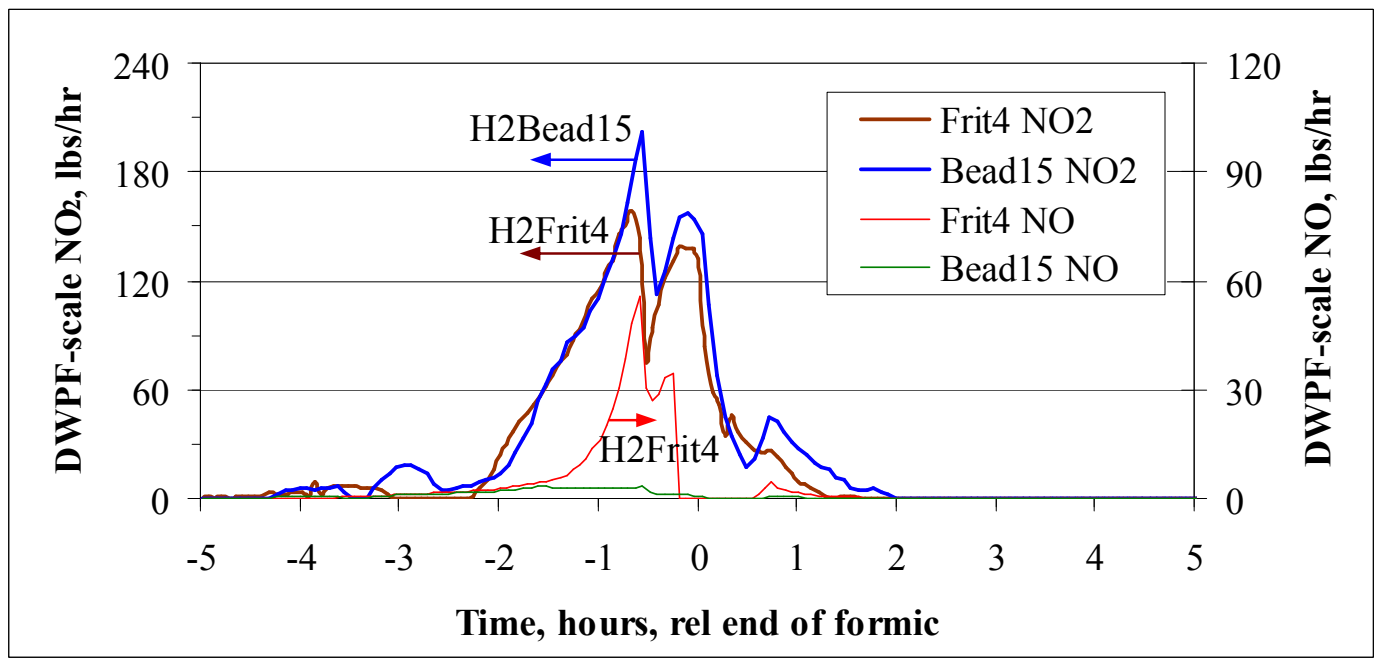

Figure 19. $\mathrm{NO}$ and $\mathrm{NO}_{2}$ generation rates at $0.2 \mathrm{wt} \% \mathrm{Pd}$

The $\mathrm{NO}_{2}$ data were very similar. The $\mathrm{NO}$ generation rates in $\mathrm{H} 2 \mathrm{Frit} 4$ were about eight times greater at the peak and five times greater overall than in $\mathrm{H} 2 \mathrm{Bead} 15$, but this seems to have been offset by reduced generation rates of $\mathrm{NO}_{2}$ between -1.5 and 0 hours. Both runs summed to total generations of 3.89 moles of combined $\mathrm{NO}+\mathrm{NO}_{2}$. The $\mathrm{N}_{2} \mathrm{O}$ generation rates are plotted in Figure 20. 
WSRC-STI-2008-00131

Revision 0

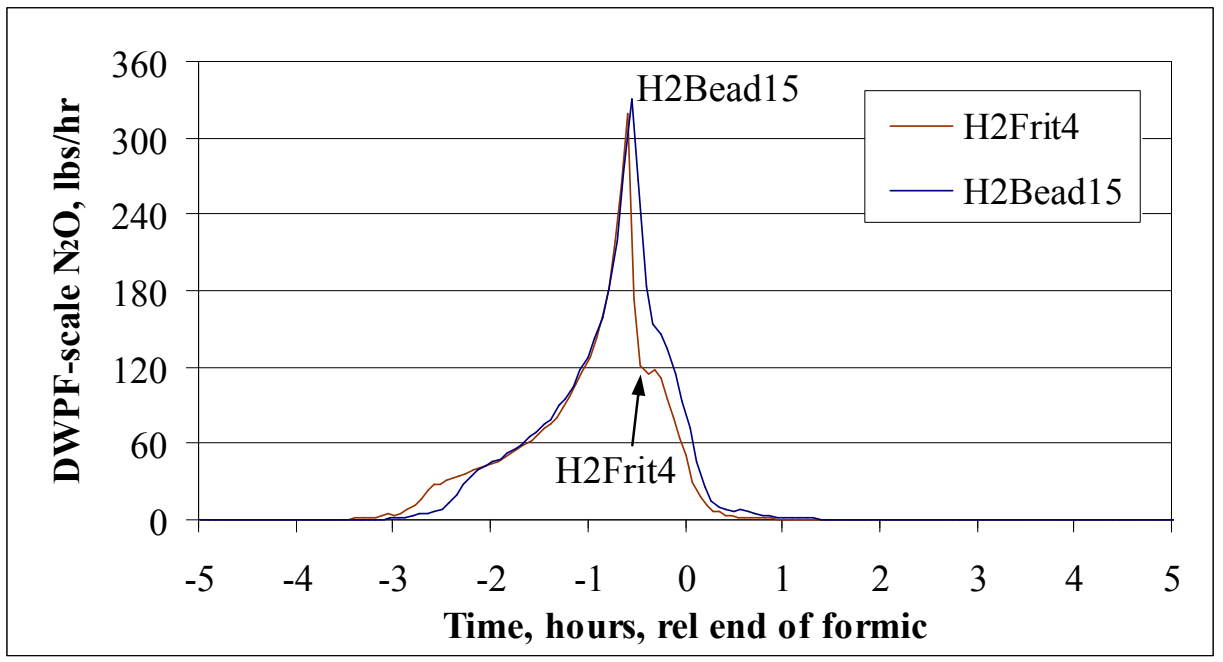

Figure 20. $\mathrm{N}_{2} \mathrm{O}$ generation at $0.2 \mathrm{wt} \% \mathrm{Pd}$

The $\mathrm{N}_{2} \mathrm{O}$ data were also virtually identical for these two runs. The overall off-gas data indicate that these two runs followed a nearly identical reaction sequence in their chemistry. The $\mathrm{N}_{2} \mathrm{O}$ production total was up to twice that in the other runs except for the pair at $0.2 \mathrm{wt} \% \mathrm{Rh}$, Section 3.3.2. From the data, it appears that $\mathrm{Pd}$ is catalyzing $\mathrm{N}_{2} \mathrm{O}$ formation.

More extensive sampling was performed on runs with low catalytic activity to track major species as part of the investigation into SRAT chemistry. The next series of figures presents the dissolution versus time data for three individual elements, $\mathrm{Mg}, \mathrm{Ca}$, and $\mathrm{Mn}$. Data for $\mathrm{Mg}$ are given in Figure 21.

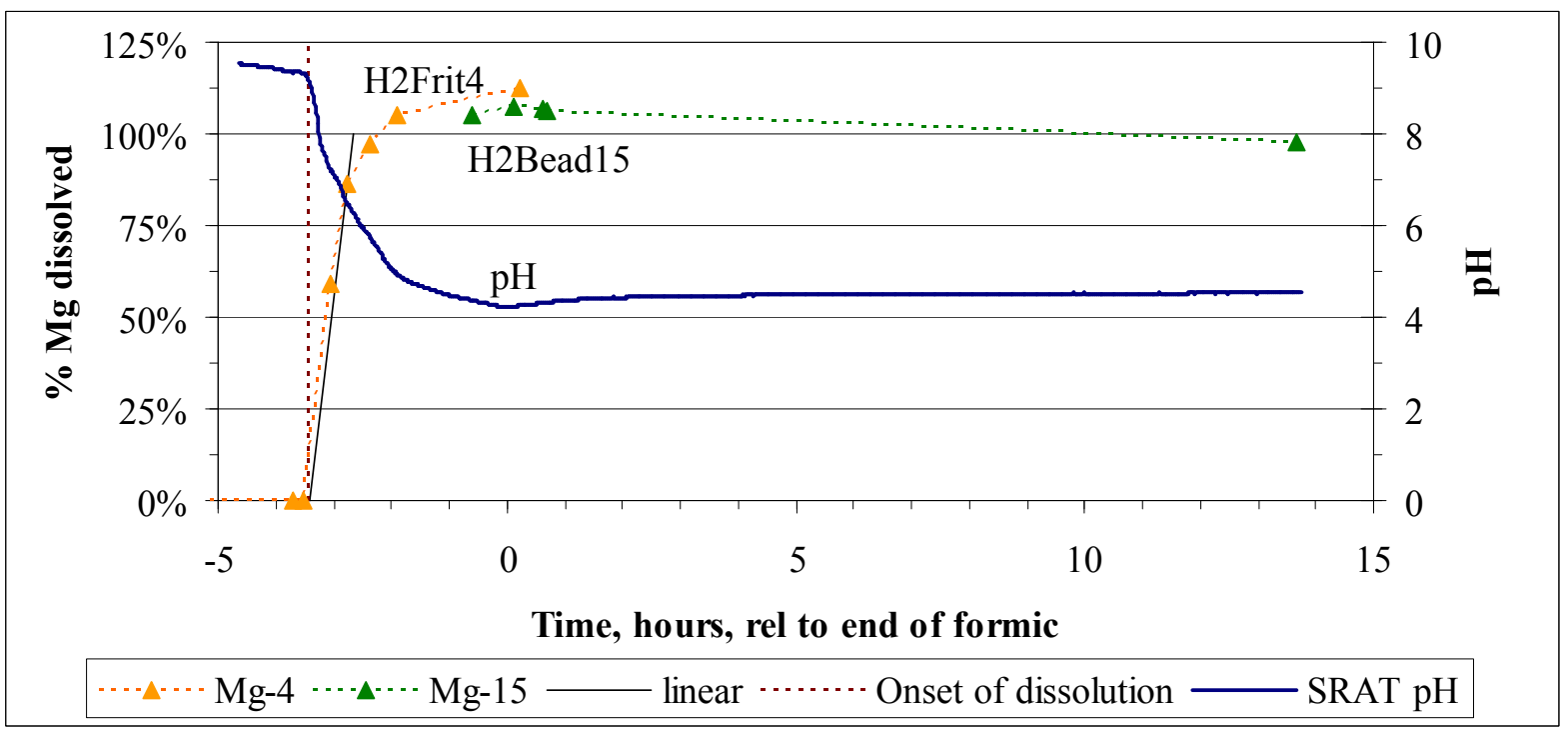

Figure 21. Mg dissolution at $0.2 \mathrm{wt} \% \mathrm{Pd}$

Magnesium dissolution started as the $\mathrm{pH}$ fell below about 7.5 and was nearly complete before the $\mathrm{pH}$ had dropped to six. The maximum dissolution rate was about $2.6 \mathrm{moles} / \mathrm{hour}$, or 5.2 moles hydroxide released per hour, since the $\mathrm{Mg}$ was present as $\mathrm{Mg}(\mathrm{OH})_{2}$. The acid addition rate was about 7.7 moles per 
hour which was adequate to support this reaction. Ca dissolution mostly followed $\mathrm{Mg}$ dissolution as was seen in the $0.2 \mathrm{wt} \% \mathrm{Ag}$ case, Figure 22.

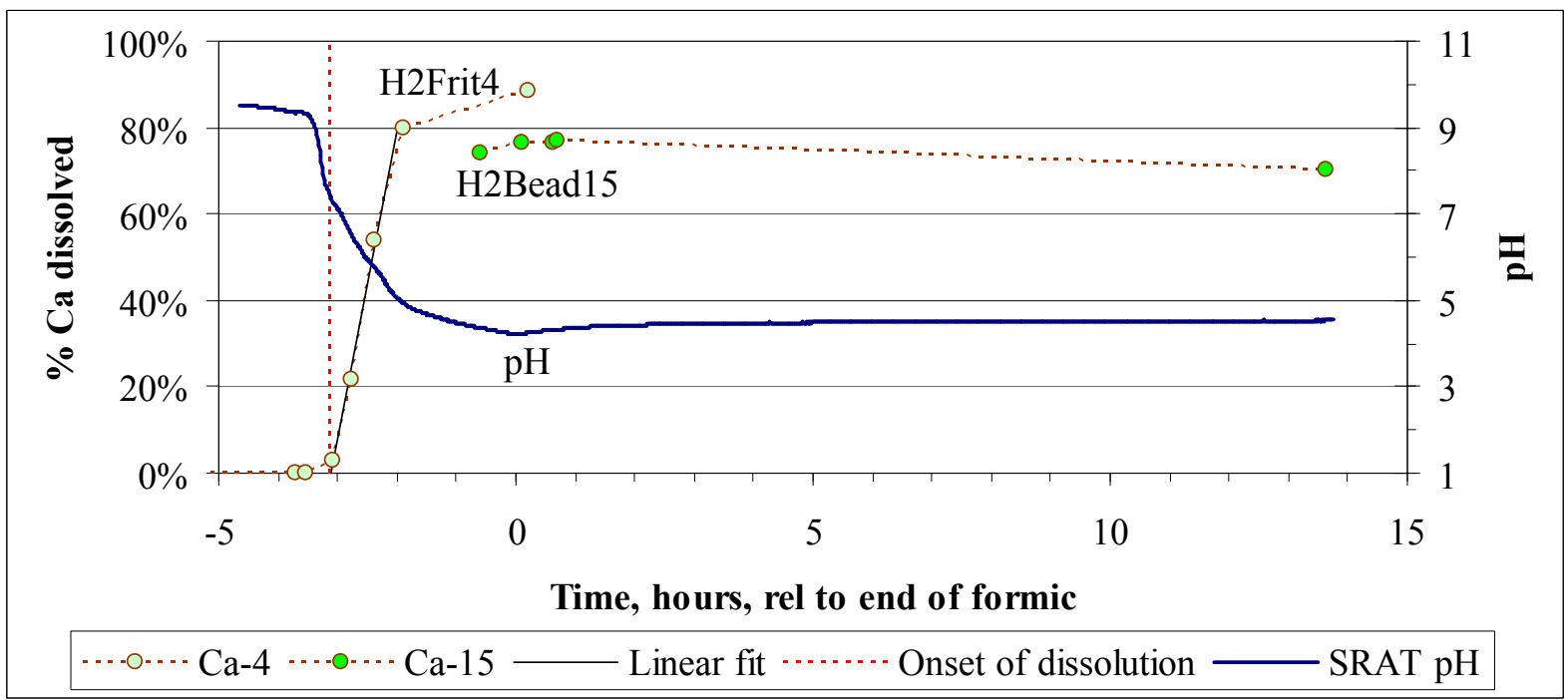

Figure 22. Ca dissolution at 0.2 wt\% Pd

Calcium dissolution started as $\mathrm{pH}$ fell below 6-7 and reached about $80 \%$ as the $\mathrm{pH}$ reached 5 . The dissolution lagged about 20 minutes behind $\mathrm{Mg}$. The maximum rate was about 2.1 moles $\mathrm{Ca}^{+2}$ per hour. The dissolving calcium was primarily $\mathrm{CaCO}_{3}$, so the acid required to support Ca dissolution was up to about 4.2 moles per hour out of 7.7 being fed. Competition between $\mathrm{Mg}$ and $\mathrm{Ca}$ for available acid was indicated during the end of $\mathrm{Mg}$ dissolution and beginning of $\mathrm{Ca}$ dissolution. Mn dissolution was detected toward the end of $\mathrm{Ca}$ dissolution. Mn results are given in Figure 23.

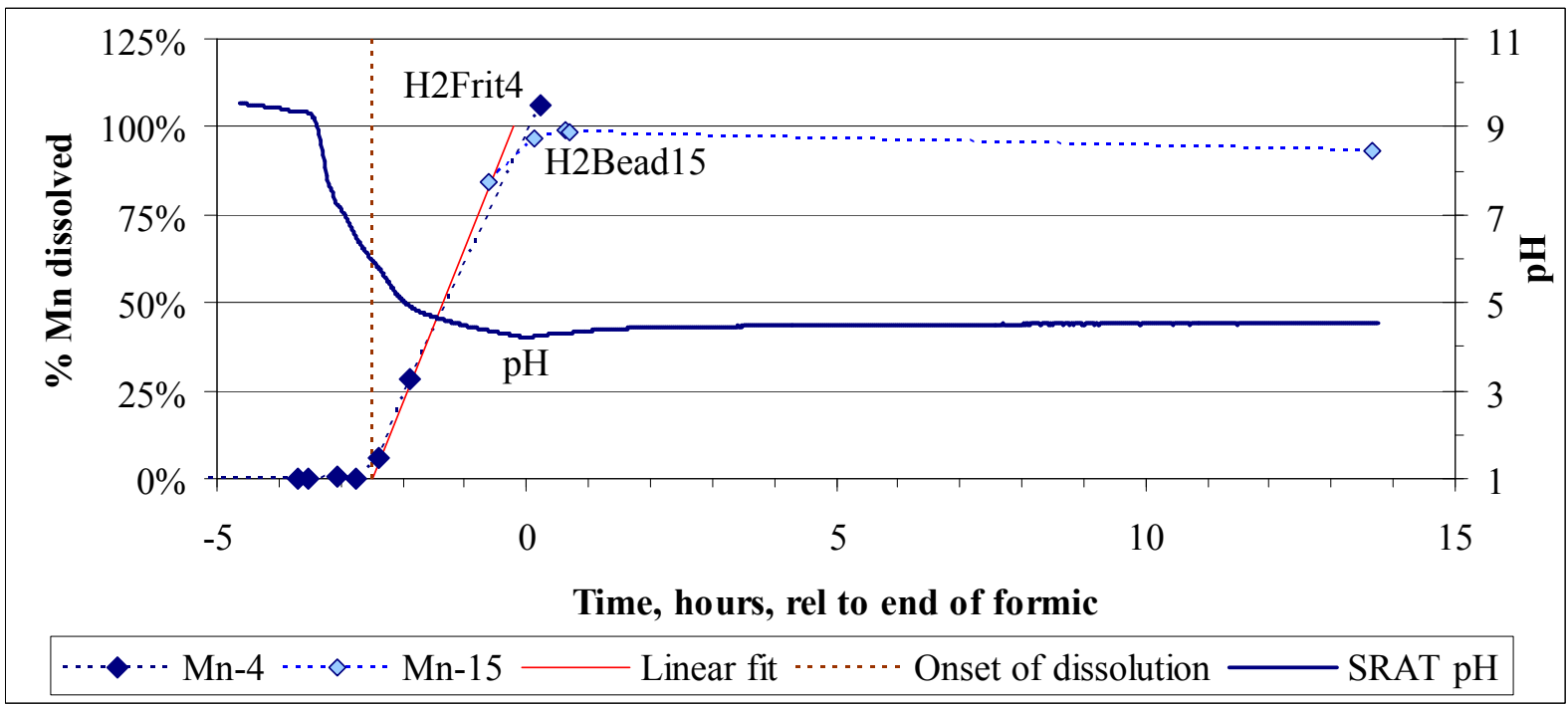

Figure 23. Mn dissolution at 0.2 wt \% Pd 
Manganese reduction/dissolution started as $\mathrm{pH}$ fell below six. The dissolution was about 35 minutes behind $\mathrm{Ca}$ initially. The maximum rate of reduction/dissolution was about 0.84 moles $\mathrm{Mn}$ per hour. The associated acid consumption was 2.51 moles per hour (at three moles acid per mole Mn reduced and dissolved) which was about one-third of the $7.7 \mathrm{moles} / \mathrm{hr}$ acid addition rate. Lesser amounts of $\mathrm{Ni}, \mathrm{Cu}$, and $\mathrm{Zn}$ were dissolved as well during these two runs. These results will be incorporated into later discussions on SRAT chemistry.

Anion concentration data were obtained during H2Frit4 in support of the XAS samples. Formate data are shown in Figure 24 compared to a theoretical curve for addition without destruction.

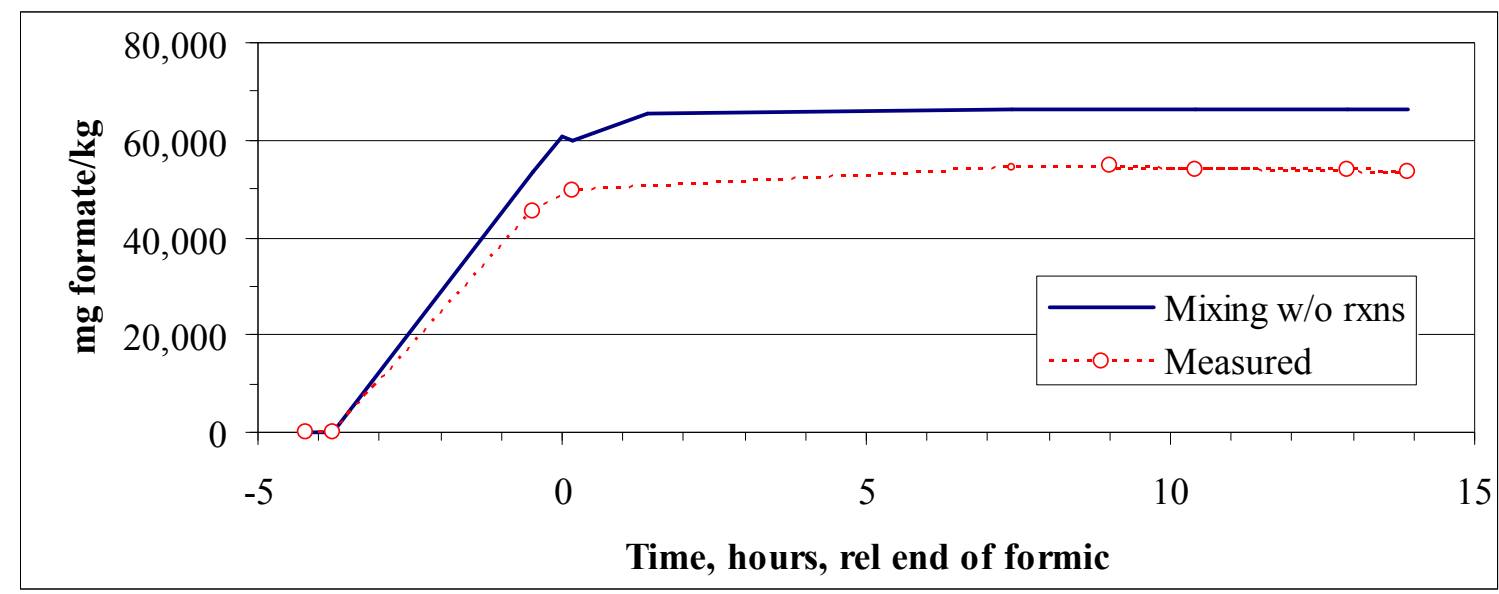

Figure 24. Formate concentration at $0.2 \mathrm{wt} \% \mathrm{Pd}$

The data are consistent with the $\mathrm{CO}_{2}$ generation rate profile that indicated little formate destruction after dewatering. Formate loss is indicated prior to the end of acid addition during the time that Mn reduction and nitrite destruction were occurring. H2Frit4 nitrate ion data are shown in Figure 25.

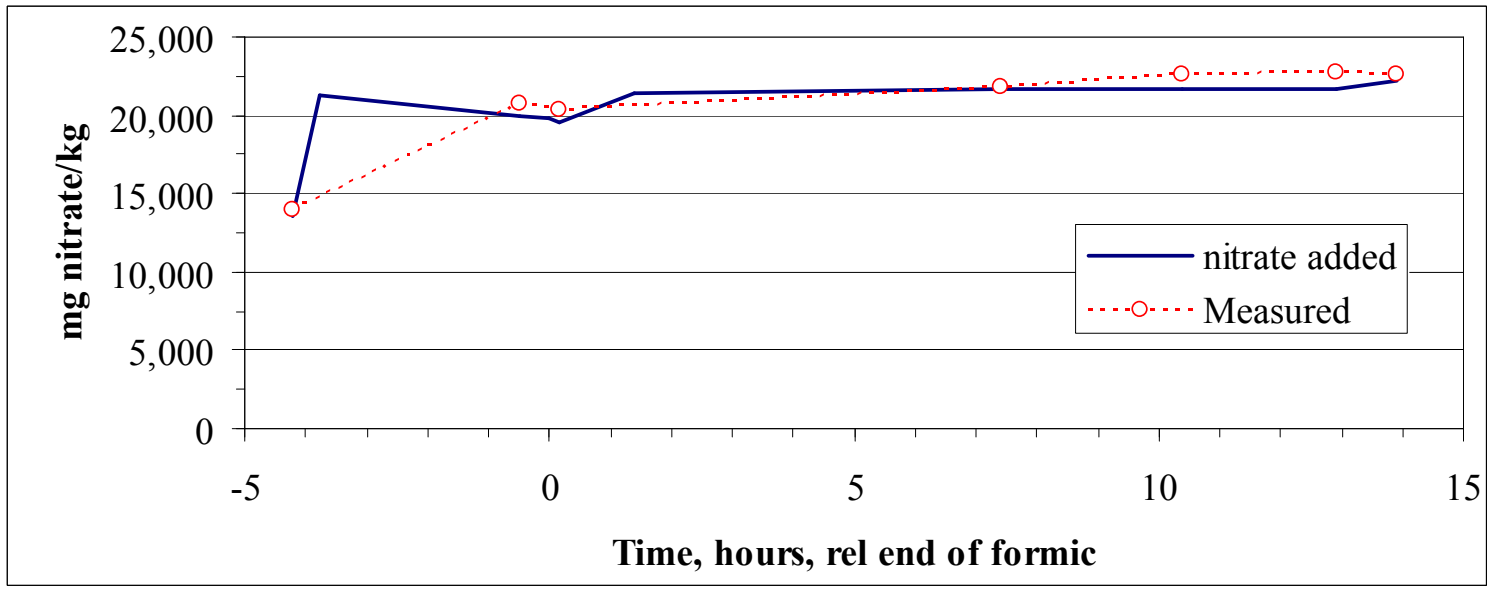

Figure 25. Nitrate concentration at $0.2 \mathrm{wt} \% \mathrm{Pd}$

The measured nitrate concentration closely followed the curve of nitrate added. The measured nitrate concentration in the presence of $0.2 \mathrm{wt} \% \mathrm{Ag}$ showed a steady gain from -2 hours to +1 hours unlike these results. Negligible nitrate gain from nitrite-to-nitrate conversion was indicated in the presence of Pd. 
Nitrate loss was not indicated during reflux. H2Bead15 SRAT product nitrate data supported the H2Frit4 data. Two nitrite values above the detection limit were also obtained (not on graph). These results show nitrite present at $3780 \mathrm{mg} / \mathrm{kg}$ about 30 minutes before the end of acid addition and at $462 \mathrm{mg} / \mathrm{kg}$ ten minutes after the end of acid addition. The Pd catalyzed conversion of nitrite to $\mathrm{N}_{2} \mathrm{O}$ may have reduced the ability of the system to convert nitrite to nitrate.

One set of oxidation-reduction probe data was obtained at $0.2 \mathrm{wt} \% \mathrm{Pd}$ on $\mathrm{H} 2 \mathrm{Bead} 15$. The measurements are shown in Figure 26. Electronic recording of the ORP data on the PC occurred until about 50 minutes short of the end of acid addition when recording switched to manual until the probe was removed shortly after the end of acid addition. No $\mathrm{pH}$ data were obtained during H2Bead15 per Section 2.3. Good $\mathrm{pH}$ data were obtained during H2Frit4, but they were not aligned in time with the ORP data from H2Bead15.

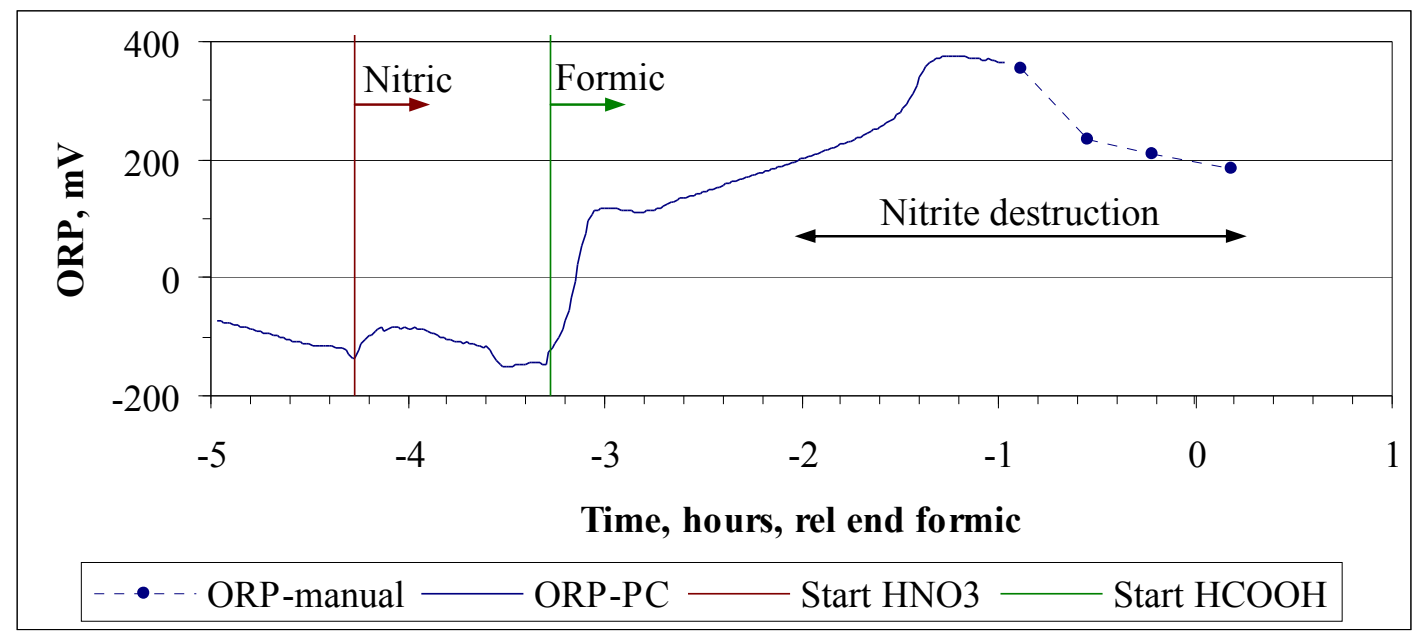

Figure 26. Oxidation-reduction potential at $0.2 \mathrm{wt} \% \mathrm{Pd}$

The ORP data follow trends seen in earlier ORP graphs in this report. The potential was initially oxidizing (negative), but shortly after the start of formic acid addition, the sign of the potential reversed. There was very little structure (peaks and valleys) in the period of high temporal resolution. The last data points indicate that the potential had fallen during the period with nitrite destruction and Mn reduction from -1 hour until the probe was removed. This drop seems to be consistent with partial consumption of the available reducing agent(s) by $\mathrm{Mn}$ and nitrite. The $\mathrm{pH}$ data from H2Frit4 are shown in Figure 27. These data indicate that the ORP potential probably reversed while the slurry was still above pH 7. Although $\mathrm{pH}$ and ORP are both millivolt measurements on the supernate in the SRAT slurry, the readings are clearly independent. The ORP data contains new information, such as the transition from oxidizing to reducing conditions. Whether ORP data can help to explain the onset of hydrogen generation or other phenomenon in the SRAT remains an open question. An ORP that can measure into the boiling period is needed to move forward on this front. 
WSRC-STI-2008-00131

Revision 0

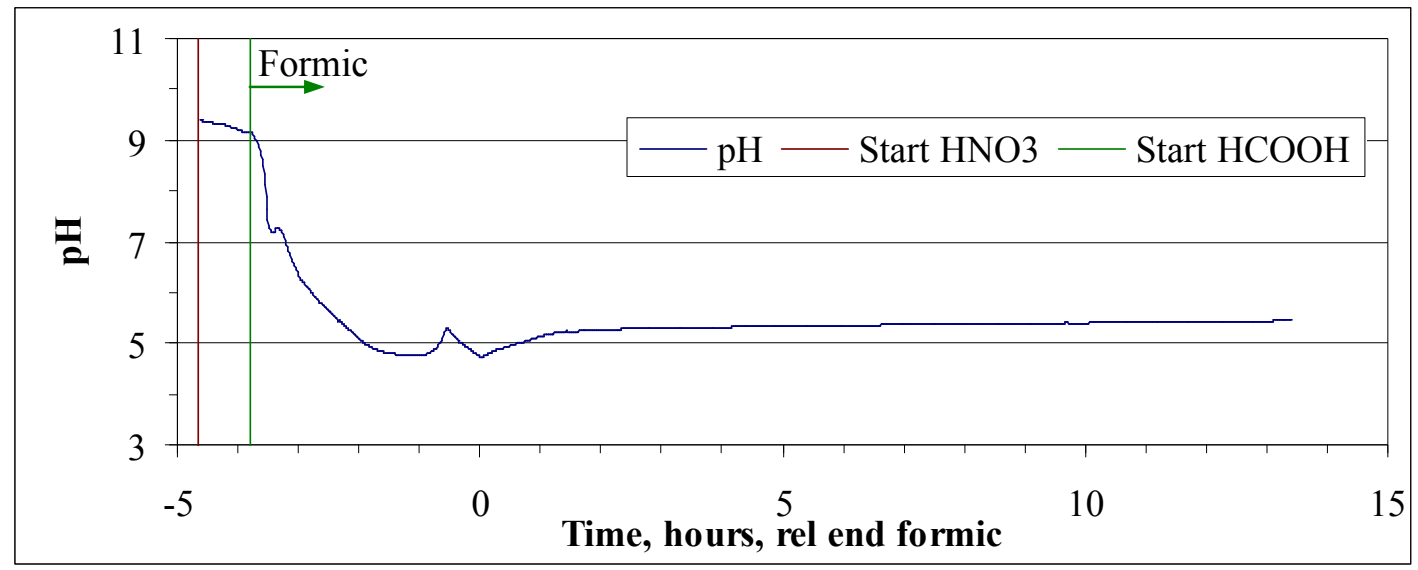

Figure 27. The pH versus time at 0.2 wt\% Pd (H2Frit4)

The H2Frit5 $\mathrm{pH}$ data were some of the best obtained during the bead-frit runs. The post-run probe checks in the standard buffers were all within about $0.2 \mathrm{pH}$ units of the nominal values. The general low level of catalytic activity led to only a mild increase in $\mathrm{pH}$ after acid addition from destruction of formic acid. The lower $\mathrm{pH}$ was consistent with the sustained high extents of dissolution of $\mathrm{Mn}, \mathrm{Mg}$, and $\mathrm{Ca}$ during reflux.

\subsection{Testing with $R u$ - moderate catalytic activity}

Five tests were performed with $\mathrm{Ru}$ in the absence of other noble metals. $\mathrm{Ru}$ was tested at 0.2 and 0.375 $\mathrm{wt} \%$ in two pairs of 22-L SRAT/SME runs. The fifth test was a 4-L SRAT run at $0.2 \mathrm{wt} \% \mathrm{Ru}$ along with $\mathrm{Hg}$. Ru showed significant catalytic activity for hydrogen generation, but it did not produce as high a maximum generation rate as corresponding systems with $\mathrm{Rh}$. The presence of $\mathrm{Hg}$ had no significant effect on the peak hydrogen generation rate, and it may have even promoted the onset of hydrogen generation to occur sooner.

\subsubsection{Tests with $\mathrm{Ru}$ at $0.2 \mathrm{wt} \%$ (no $\mathrm{Hg}$ )}

$\mathrm{H} 2 \mathrm{Frit} 2$ and $\mathrm{H} 2 \mathrm{Bead} 13$ were given an initial charge of $0.2 \mathrm{wt} \% \mathrm{Ru}$ in the trimmed sludge total solids. The $\mathrm{CO}_{2}$ generation rate is plotted as a function of time in Figure 28. 
WSRC-STI-2008-00131

Revision 0

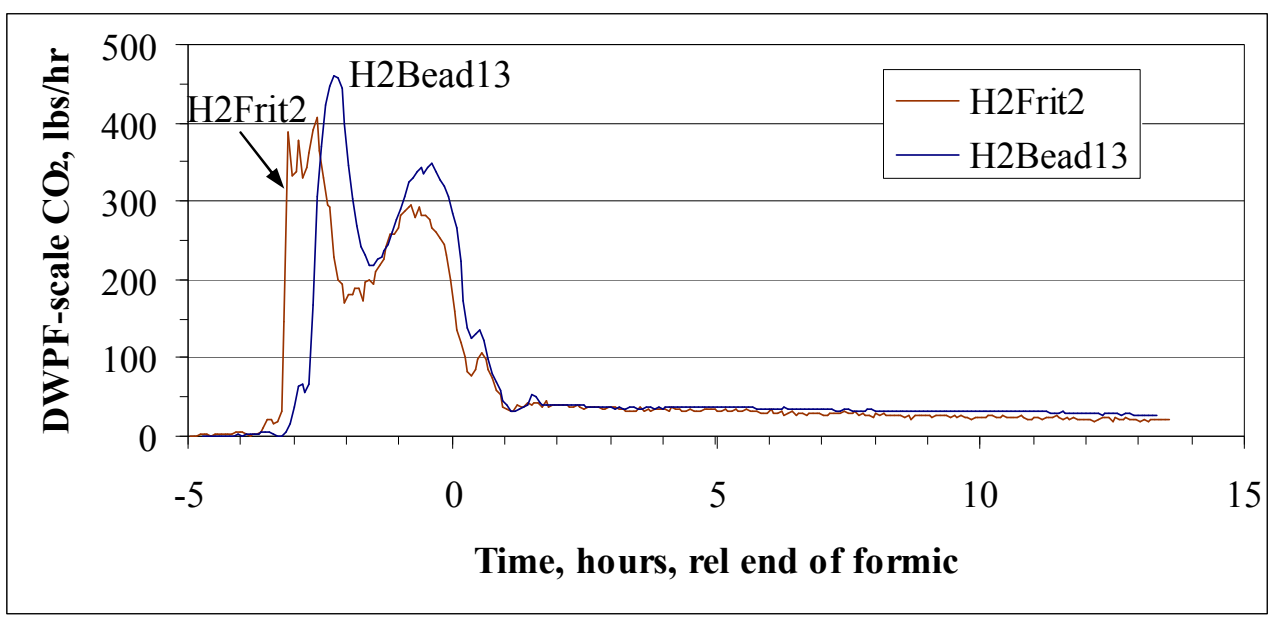

Figure 28. $\mathrm{CO}_{2}$ generation at $0.2 \mathrm{wt} \% \mathrm{Ru}$

Formic acid addition took 3:48 in H2Frit2 and 3:15 in $\mathrm{H} 2 \mathrm{Bead} 13$ causing the $\mathrm{CO}_{2}$ profile of $\mathrm{H} 2 \mathrm{Frit} 2$ to be spread over a longer period of time prior to the end of acid addition and reducing the generation rates which appear to be limited by the acid addition feed rate. The $\mathrm{NO}$ and $\mathrm{NO}_{2}$ generation rates are shown in Figure 29.

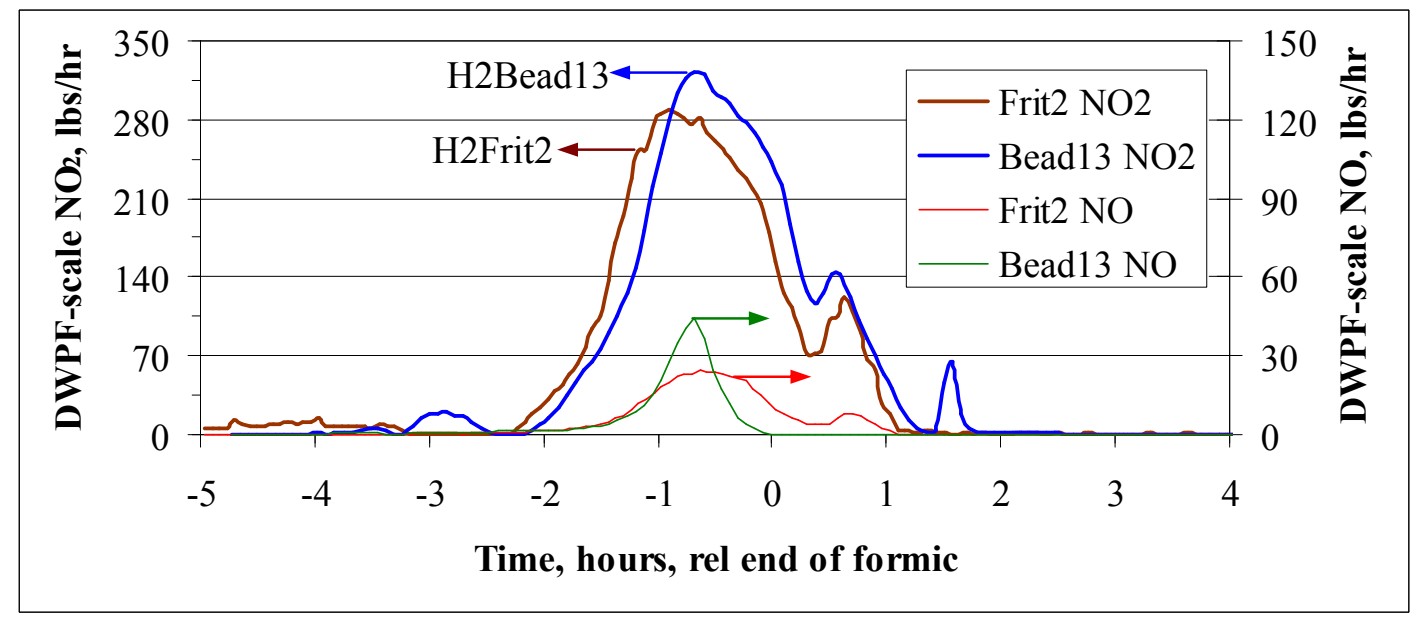

Figure 29. $\mathrm{NO}$ and $\mathrm{NO}_{2}$ generation at $0.2 \mathrm{wt} \% \mathrm{Ru}$

The agreement in $\mathrm{NO}_{2}$ data is fairly good after allowing for the longer acid addition in $\mathrm{H} 2 \mathrm{Frit} 2\left(\mathrm{NO}_{2}\right.$ data are broader and shallower as expected for a slower acid addition rate). Both runs used an Agilent 3000A $\mathrm{GC}$ with the same column-A temperature. NO generation in H2Frit2 continued past the end of acid addition, while the $\mathrm{NO}$ generation in $\mathrm{H} 2 \mathrm{Bead} 13$ stopped at the end of acid addition. Elimination of $\mathrm{NO}$ at the end of acid addition has been noted casually in previous SRAT simulations. It is not clear what, if anything, continuing NO generation past acid addition signifies, but the data show that it apparently does not happen reproducibly from the stand point of the timing of the $\mathrm{NO}$ release. The $\mathrm{N}_{2} \mathrm{O}$ data for the two runs are given in Figure 30. 
WSRC-STI-2008-00131

Revision 0

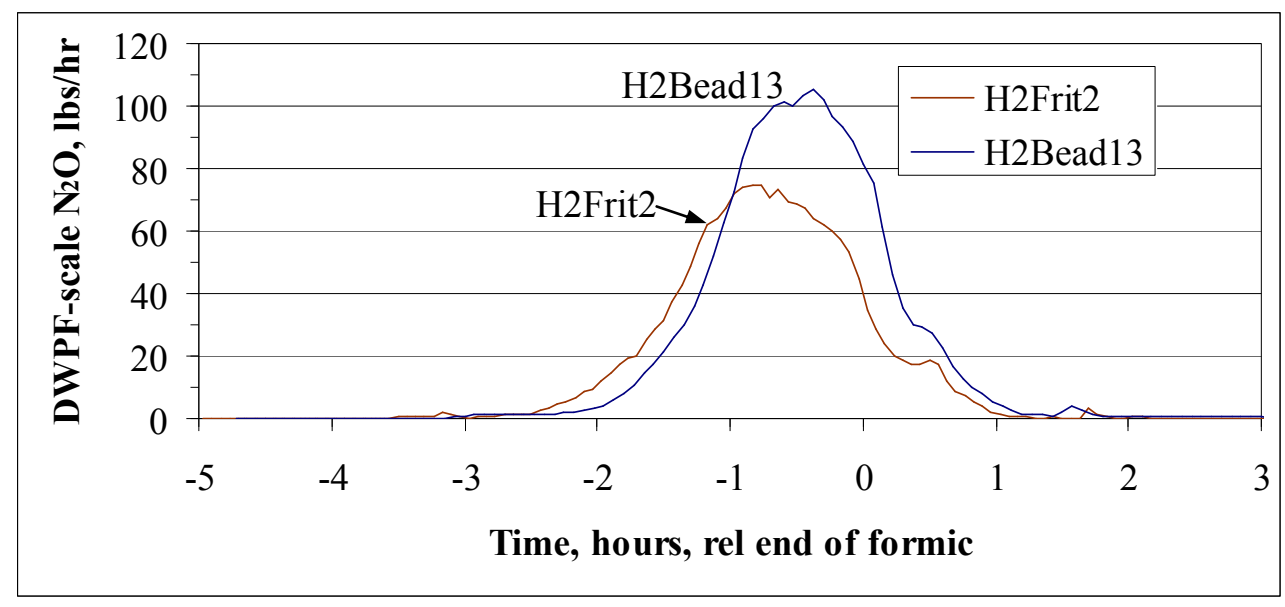

Figure 30. $\mathrm{N}_{2} \mathrm{O}$ generation at $0.2 \mathrm{wt} \% \mathrm{Ru}$

The data are fairly similar to the $\mathrm{NO}_{2}$ data, with the H2Frit2 data being broader and shallower than the $\mathrm{H} 2 \mathrm{Bead} 13$ data. The He concentration ran about $6 \%$ higher in $\mathrm{H} 2 \mathrm{Bead} 13$ than in $\mathrm{H} 2 \mathrm{Frit} 2$ even though the helium flow was set to $0.5 \mathrm{vol} \%$ of the nominal purge gas flow in both runs. An artificial $6 \% \mathrm{He}$ concentration difference could explain about half of the variation in generation rate between the two sets of curves for both the $\mathrm{CO}_{2}$ and oxides of nitrogen data, i.e. the results are probably being limited by the accuracy of the instrumentation used to make the measurements in the generation rate calculations.

Less process sampling was performed on the more catalytically active runs, because it was felt that data would be less applicable to normal sludges with the typical ranges of noble metal concentrations. Formate and nitrate ion concentration data were obtained on both runs (XAS samples in H2Frit2 and as potential support for $\mathrm{CO}_{2}$ absorption samples in $\mathrm{H} 2 \mathrm{Bead} 13$ ). The data primarily fall after acid addition during the period of hydrogen generation, which started at +1 hour. Curves showing the nominal concentration of added formate and nitrate are shown for comparison to the measured values. The formate data are given in Figure 31 compared to a curve of added formate assuming no destruction.

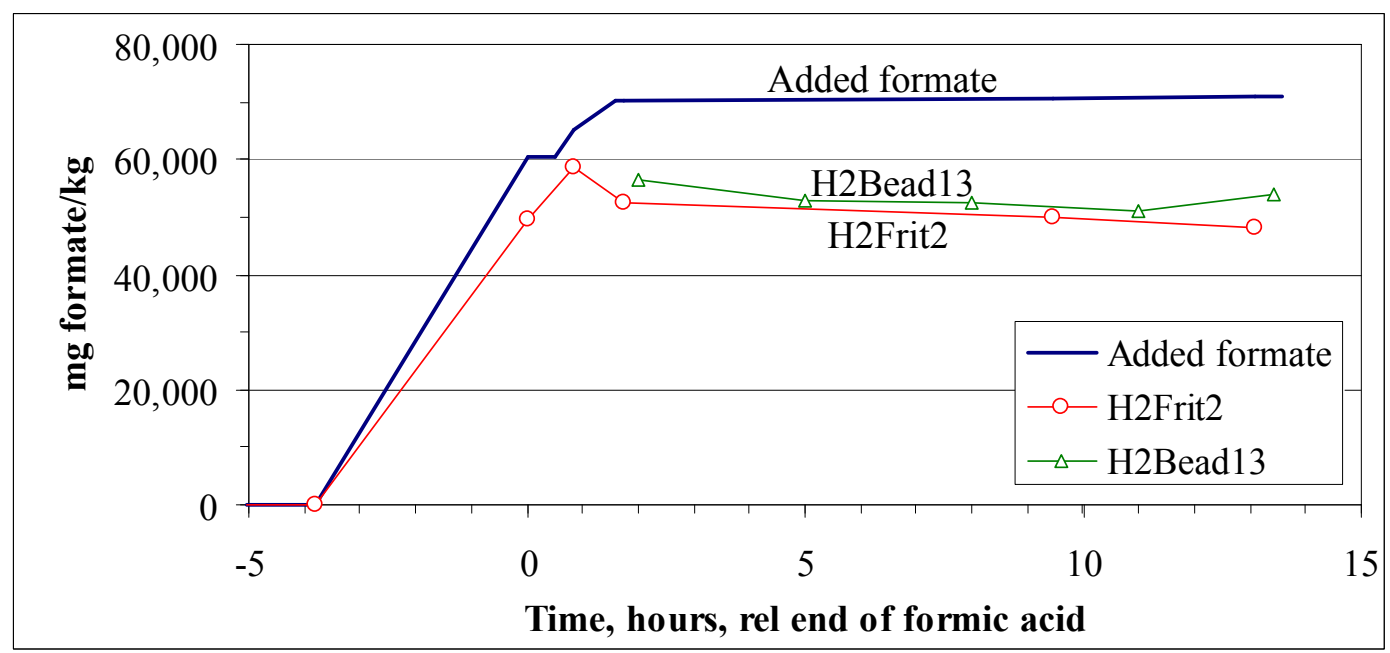

Figure 31. Formate ion concentrations at $0.2 \mathrm{wt} \% \mathrm{Ru}$ 
The period during acid addition was not covered by samples, since acid addition data were being targeted for other run pairs. Some formate loss was indicated in the H2Frit2 data before formic acid addition was completed as in runs discussed earlier (potentially associated with Mn reduction and nitrite destruction). A slow gradual loss in formate concentration occurred during reflux compared to the no reaction curve that showed a slow gradual increase in concentration as total slurry mass was lost during reflux. This loss was consistent with the increased loss of formate ion in the more active $\mathrm{Ru}$ runs compared to the low activity tests.

The nitrate ion concentration data are shown in Figure 32 compared to a theoretical curve showing the nitrate addition from nitric acid and the effect of dewatering that includes no nitrite-to-nitrate conversion.

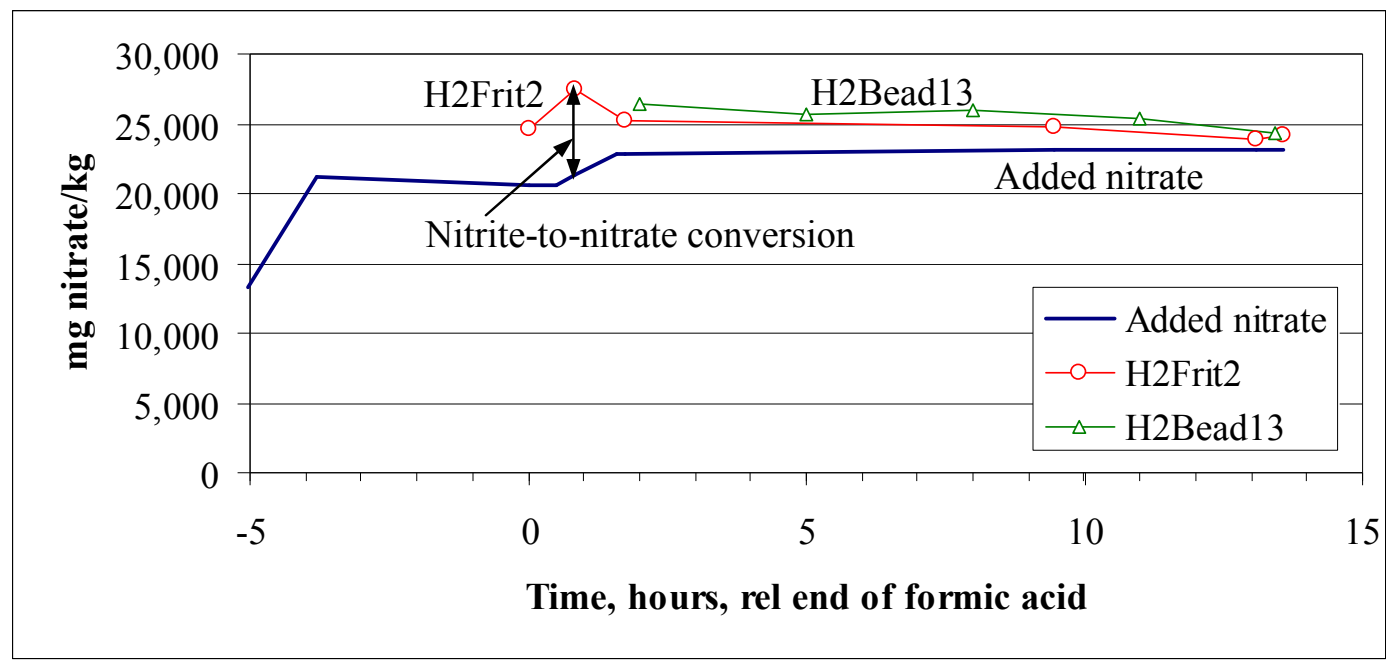

Figure 32. Nitrate ion concentration at $0.2 \mathrm{wt} \% \mathrm{Ru}$

The nitrate ion data went above the nominal concentrations due to significant nitrite-to-nitrate conversion near the end of formic acid addition. Following the period of maximum nitrate increase, the data for both runs show nitrate concentration falling back toward the nominal amount of nitrate added. Consequently, the overall SRAT nitrite-to-nitrate conversion for these two runs was just $6 \%$. The full set of data support the hypothesis that more than $6 \%$ of the nitrite was converted to nitrate and that a nitrate destruction reaction was occurring. The H2Bead13 SRAT product was checked for ammonium ion, and the concentration was $26 \mathrm{mg} / \mathrm{L}$ (required a sodium trap in order to quantify by cation chromatography due to the high sodium concentration and a sodium-ammonium ion interference).

A small quantity of cation supernate data were obtained in support of the H2Frit2 XAS samples. The calculated dissolution data for species that changed in some of the runs are shown in Figure 33. These species were $\mathrm{Mg}, \mathrm{Ca}, \mathrm{Mn}, \mathrm{Ni}$, and $\mathrm{Zn}$. 
WSRC-STI-2008-00131

Revision 0

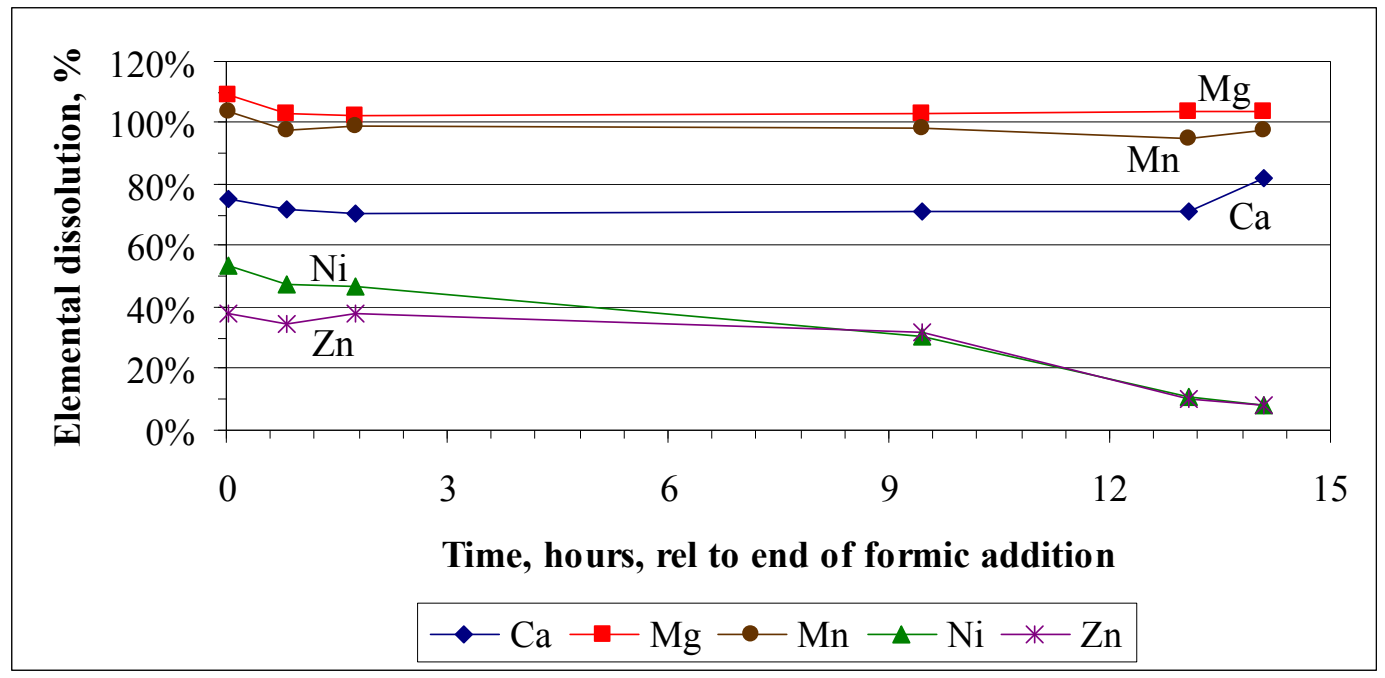

Figure 33. Elemental dissolution at $0.2 \mathrm{wt} \% \mathrm{Ru}$

Data were only obtained after acid addition except for the SRAT receipt sample in which none of the above five species were soluble. Precipitation of Ni and $\mathrm{Zn}$ appear to be consistent with past data on the impact of increasing $\mathrm{pH}$ on the solubility of these two elements in the SRAT. $\mathrm{Ca}, \mathrm{Mg}$, and $\mathrm{Mn}$ sustained their extent of dissolution into the SRAT product sample. As catalytic activity increased, $\mathrm{Ca}, \mathrm{Mg}$, and Mn were less able to sustain their extent of dissolution during reflux.

The experimental oxidation-reduction probe was used in both of the runs at $0.2 \mathrm{wt} \% \mathrm{Ru}$. One reason was to test the reproducibility of the ORP data. The results are shown in Figure 34.

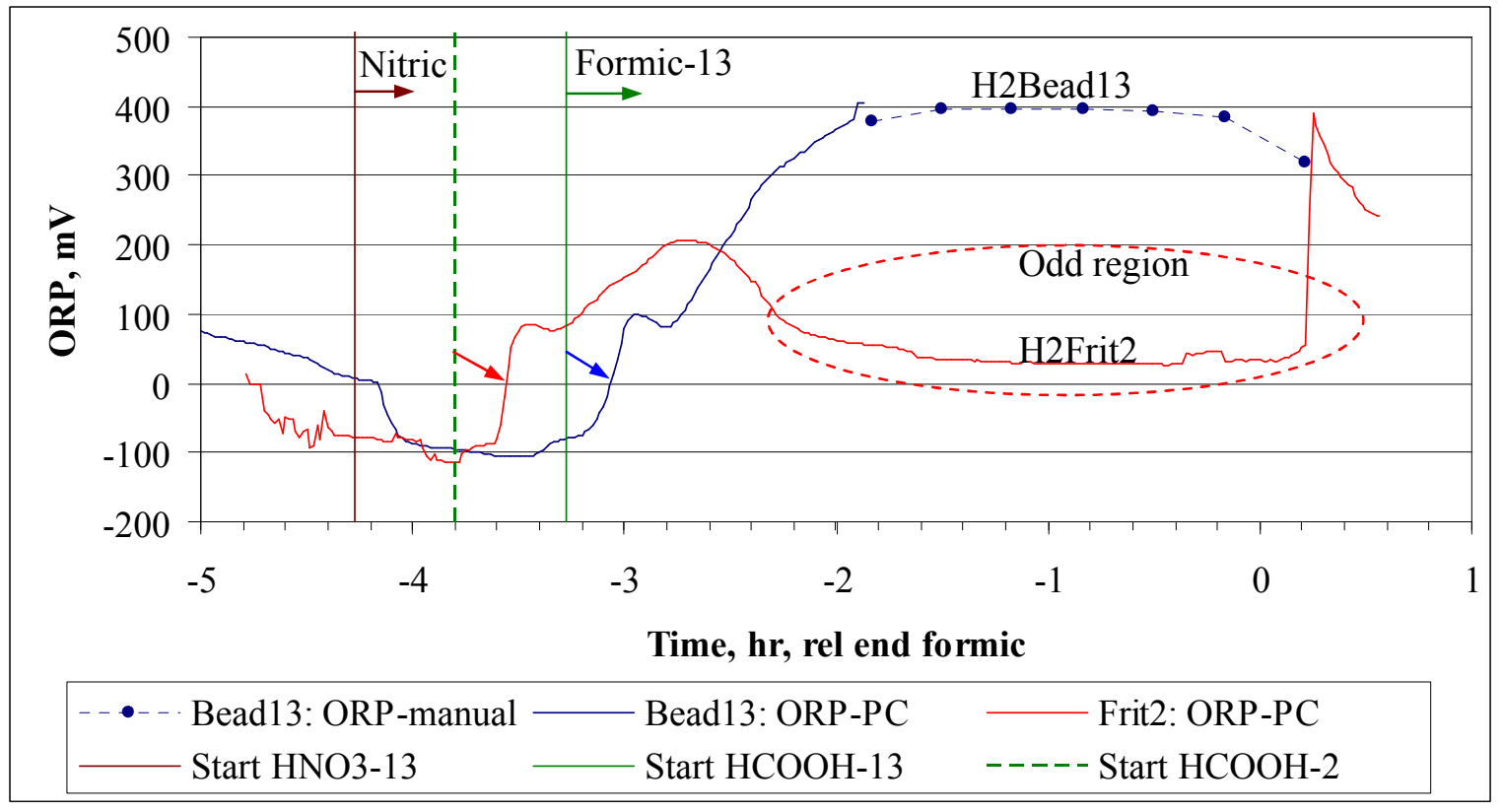

Figure 34. Oxidation-Reduction Potentials at 0.2 wt\% Ru 
The solid lines marking the start of nitric acid and formic acid addition are from H2Bead13. Formic acid addition started at -3.8 hours in H2Frit2 (dashed line closer to where the potential reversed). There was a change in sign shortly after formic acid addition started in both runs from oxidizing (negative $\mathrm{mV}$ ) to reducing (positive $\mathrm{mV}$ ). There was not much other obvious structure in the data. Reproducibility of the data seemed fairly good from the beginning of the SRAT until the potential had risen to about $200 \mathrm{mV}$ after adjusting for the different acid addition rates. After that the two curves diverged.

ORP data reproducibility was not good during the last two hours of formic acid addition for this pair. The H2Bead13 data for the last two hours of acid addition appear to be the ones consistent with readings from the other tests (strongly reducing). Something else may have happened in H2Frit2 that interfered with the probe (perhaps some kind of electrical interference; this was also the first run where the ORP was used. It was observed in prior runs that there was very little subsequent change to the ORP potential once it reached the neighborhood of $400 \mathrm{mV}$ during formic acid addition. Consequently, the PC data acquisition was switched over to the nitrate ISE with about two hours to go in formic acid addition during H2Bead13.)

\subsubsection{Tests with $\mathrm{Ru}$ at $0.375 \mathrm{wt} \%$}

$\mathrm{H} 2 \mathrm{Frit} 5$ and $\mathrm{H} 2 \mathrm{Bead} 12$ were charged with $0.375 \mathrm{wt} \% \mathrm{Ru}$ in the trimmed sludge total solids. The rate of $\mathrm{CO}_{2}$ generation is plotted as a function of time in Figure 35.

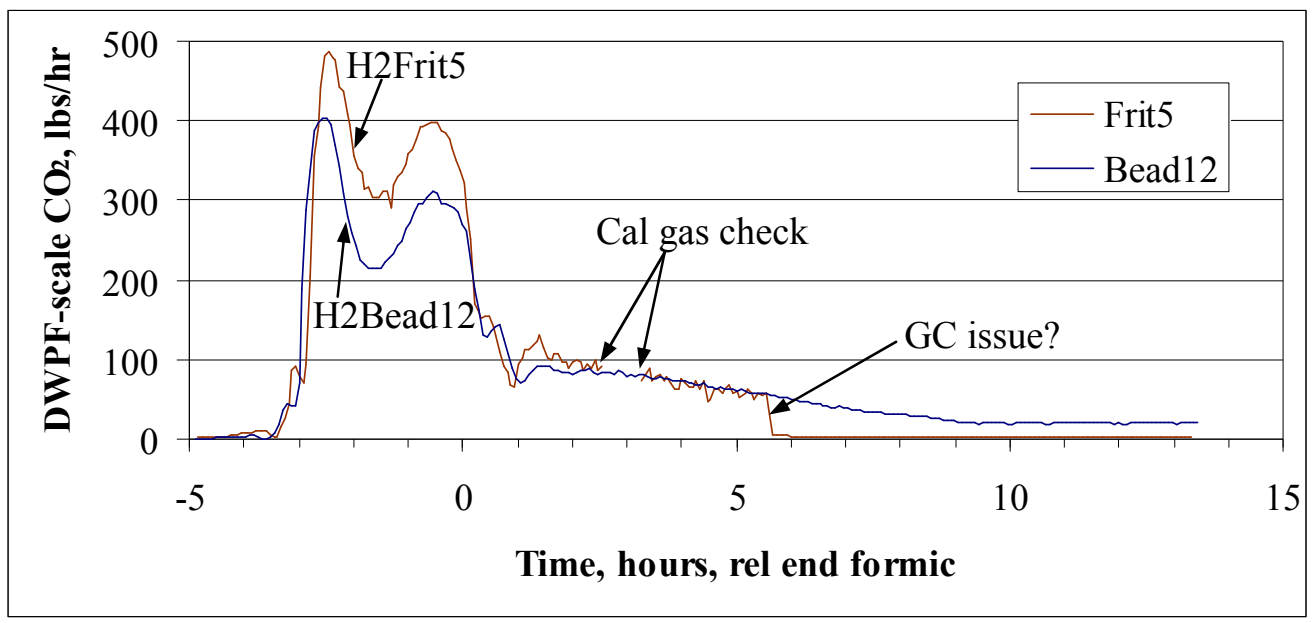

Figure 35. $\mathrm{CO}_{2}$ Generation at $0.375 \mathrm{wt} \%$

$\mathrm{H} 2 \mathrm{Frit5}$ was one of the runs that had some GC issues requiring more than normal reprocessing of the data. It appears that the drop in $\mathrm{CO}_{2}$ generation at 5.7 hours could not be adequately corrected. There was no matching drop in hydrogen generation rate at this time that would have signified a major change in catalytic activity (hydrogen data comes from a different column than $\mathrm{CO}_{2}$ ). H2Frit5 generation rate data has a gap between +2.3 and +3.0 hours where the $\mathrm{GC}$ was taken off-line for a cal gas check. $\mathrm{CO}_{2}$ data before and after that check agree well with each other and with H2Bead12.

Generation rate data for the oxides of nitrogen at DWPF-scale are given in Figure 36 and Figure 37. 
WSRC-STI-2008-00131

Revision 0

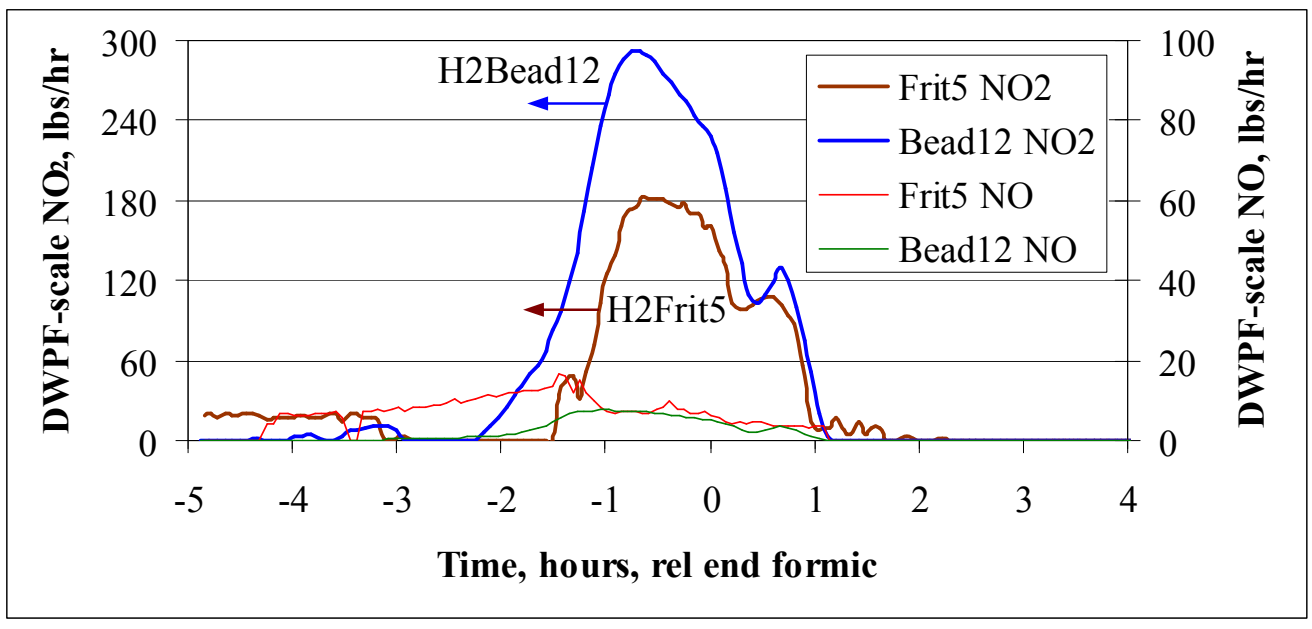

Figure 36. $\mathrm{NO}$ and $\mathrm{NO}_{2}$ generation at $0.375 \mathrm{wt} \% \mathrm{Ru}$

The $\mathrm{NO}_{2}$ data differ by more than the timing difference from a formic acid addition of 3:22 in H2Frit5 and 3:37 in H2Bead12. There were similarities and differences in the two NO traces, but the main conclusion was that neither run had very much $\mathrm{NO}$ generation. These $\mathrm{NO}$ and $\mathrm{NO}_{2}$ data come from an $\mathrm{M} 200 \mathrm{H}$ and a 3000A GC with somewhat different column operating temperatures and other settings, dimensions, etc. which apparently impacts the equilibria among the $\mathrm{NO}, \mathrm{NO}_{2}$, and $\mathrm{N}_{2} \mathrm{O}_{4}$ in the off-gas (the raw volume percent $\mathrm{NO}$ and $\mathrm{NO}_{2}$ data from the four runs with the $\mathrm{M} 200 \mathrm{H}$ GC seem generally less comparable than data from pairs where both runs used a 3000A GC, but this did not have a major impact on nitrogen species material balance calculations).

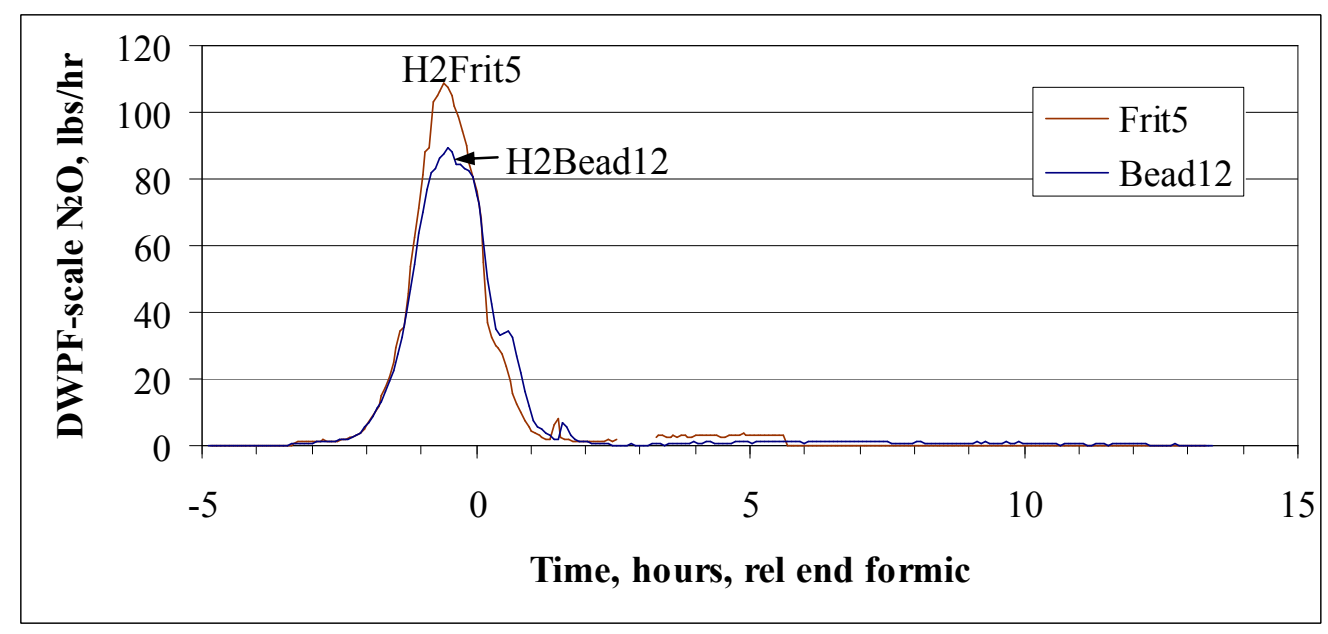

Figure 37. $\mathrm{N}_{2} \mathrm{O}$ generation at $0.375 \mathrm{wt} \% \mathrm{Ru}$

The $\mathrm{N}_{2} \mathrm{O}$ data showed excellent agreement considering some of the difficulties with the M200H GC. The $\mathrm{N}_{2} \mathrm{O}$ appeared when there were few GC issues, for example $\mathrm{N}_{2} \mathrm{O}$ generation was essentially nonexistent two hours after the end of acid addition when the cal gas check was made. The H2Frit5 $\mathrm{N}_{2} \mathrm{O}$ and $\mathrm{CO}_{2}$ peaks during acid addition were both higher than H2Bead12, which may be evidence for a slightly biased MKS controller on the He flow in one or both runs. 
The available data for formate ion concentration are given in Figure 38 compared to a nominal curve for formate addition without destruction.

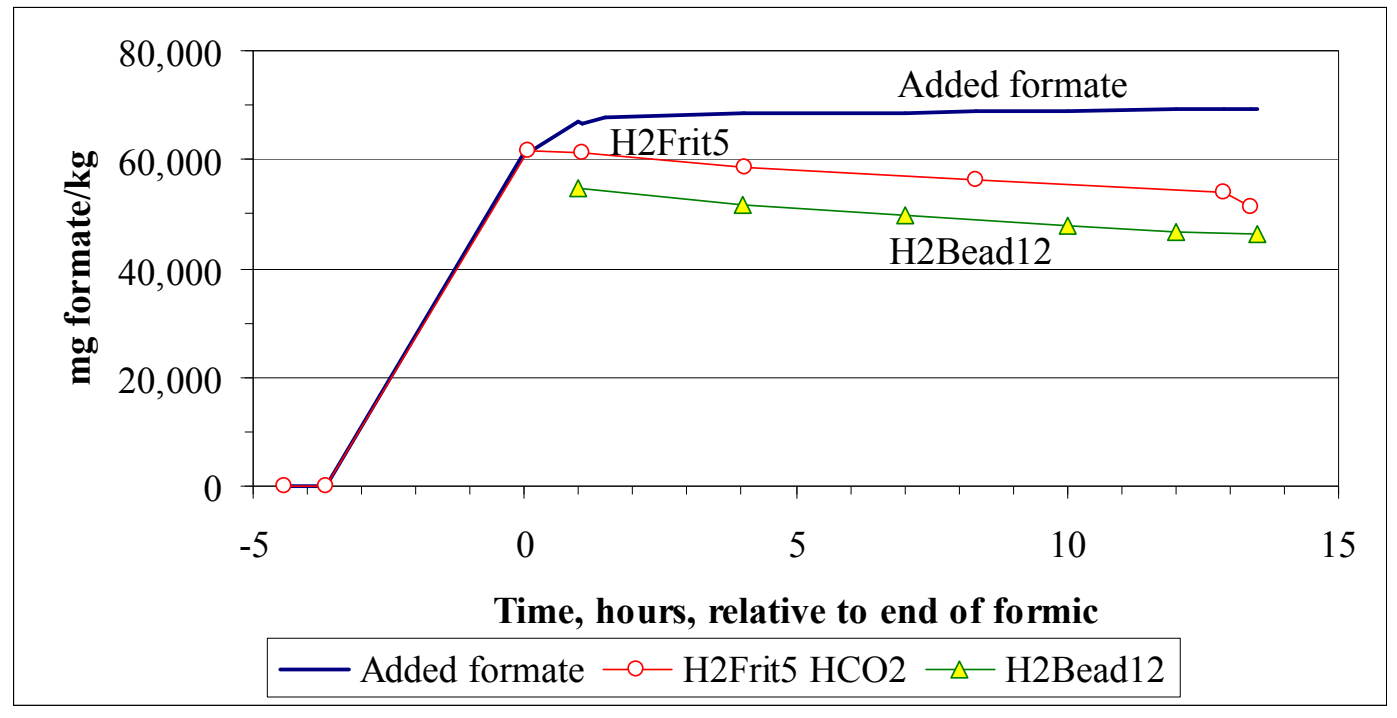

Figure 38. Formate ion concentration at $0.375 \mathrm{wt} \% \mathrm{Ru}$

The two traces of formate ion concentration during the period of hydrogen generation $(+1$ to +14 hours) were generally parallel, but the data from the two runs were off-set by about $7,000 \mathrm{mg} / \mathrm{kg}$. The historical accuracy of IC for formate is at least as good as $\pm 10 \%$. The implication is that one data set is a little high and/or the other is a little low if everything else was equal.

The corresponding nitrate ion results and $\mathrm{pH}$ data are given in Figure 39.

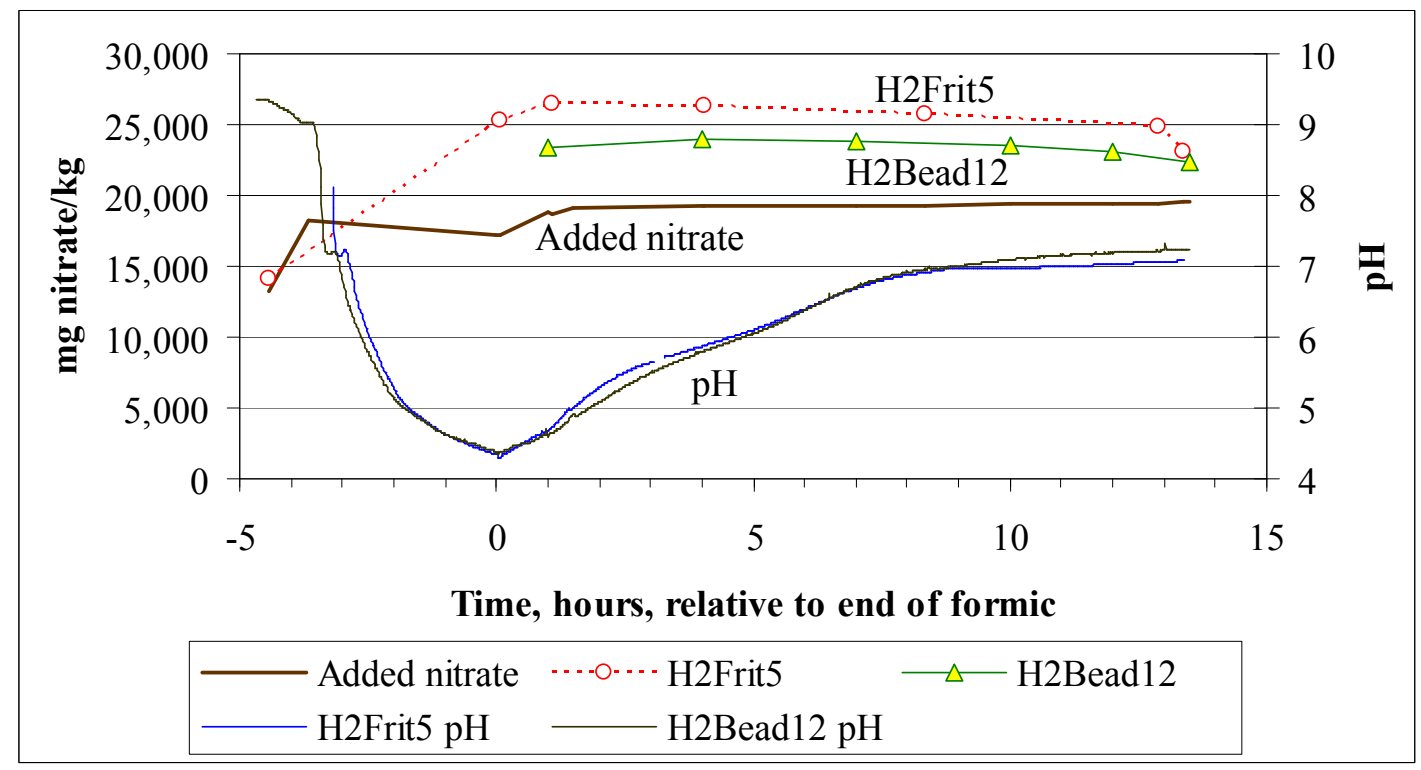

Figure 39. Nitrate ion concentration and $\mathrm{pH}$ at $0.375 \mathrm{wt} \% \mathrm{Ru}$ 
The nitrate data for H2Frit5 are about the same percent higher than the H2Bead12 data as the formate data were except in the SRAT product. The $\mathrm{pH}$ data agreed reasonably well. The probe in H2Frit5 read 5.62 in $\mathrm{pH} 4$ buffer after the SME cycle, and the H2Bead12 probe was broken at the end of the run, so the only check on the SRAT pH data was consistency in the two data sets. There were communication or ground fault issues in $\mathrm{H} 2 \mathrm{Frit5} \mathrm{pH}$ data logging during the early part of acid addition, so that $\mathrm{pH}$ data was not plotted.

The FAVC condensate and the SRAT product were checked for ammonium ion concentration. The FAVC condensate had $1,660 \mathrm{mg} / \mathrm{L}$ of ammonium ion. This concentration was smaller than in the samples from the three systems with $\mathrm{Rh}$ present. The SRAT product had $<25 \mathrm{mg} / \mathrm{L}$ of ammonium.

\subsubsection{Test with $\mathrm{Ru}$ at $0.2 \mathrm{wt} \%$ with $\mathrm{Hg}$}

A 4-L run bead-frit matching test (BFMT) with $\mathrm{Ru}$ at $0.2 \mathrm{wt} \%$ combined with $\mathrm{Hg}$ at $1.494 \mathrm{wt} \%$ was performed. Off-gas results are compared to the two matching $22-\mathrm{L}$ runs at $0.2 \mathrm{wt} \% \mathrm{Ru}$ without $\mathrm{Hg}$ from Section 3.2.1. Carbon dioxide data are given in Figure 40.

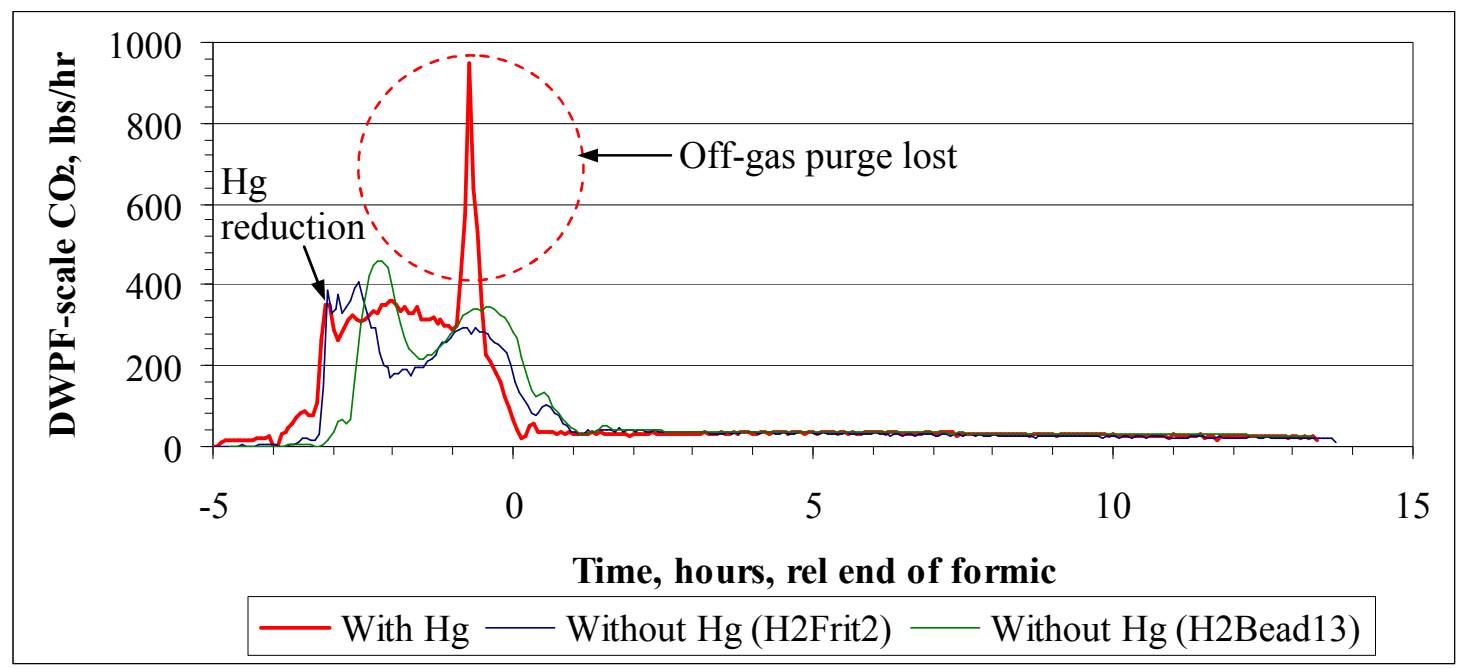

Figure 40. $\mathrm{CO}_{2}$ generation with and without $\mathrm{Hg}$ at $0.2 \mathrm{wt} \% \mathrm{Ru}$

There was a major process upset about one hour before the end of formic acid addition in the run with $\mathrm{Hg}$. A water slug accumulated in the air purge inlet line. For a period of time, the off-gases were not diluted by the normal flow of the air-He mixture and observed concentrations jumped considerably as seen by the tall red spike at -0.7 hours. Ignoring this aberration, the onset of significant $\mathrm{CO}_{2}$ was consistent with the two mercury-free runs and the rates during reflux were virtually identical (as were the hydrogen generation rates). It is believed that the small peak at about -3.2 hours for the $\mathrm{Hg}$ run coincides with the reduction of $\mathrm{Hg}$ based on data from other tests with this simulant. Differences between H2Frit2 and H2Bead 13 are due to small differences in the acid addition rates.

The broad valley between the predominantly TIC destruction based $\mathrm{CO}_{2}$ and the nitrite and $\mathrm{Mn}$ reduction based $\mathrm{CO}_{2}$ periods was not evident around -1.5 hours. It may be that the run was already starting to experience reduced air purges prior to the major upset, so this observation is not definitive on its own. The $\mathrm{CO}_{2}$ generation rate fell off faster near the end of acid addition than in the two no $\mathrm{Hg}$ runs perhaps due to more rapid nitrite destruction. The run with $\mathrm{Hg}$ also had an earlier initiation of hydrogen generation in the period of -0.5 to +1.0 hours which could be another sign of more rapid nitrite destruction. 
The oxides of nitrogen data are presented in Figure 41, Figure 42, and Figure 43 in equivalent DWPFscale $\mathrm{lbs} / \mathrm{hr}$. These also show the aberration at -0.7 hours, since this was the period of maximum nitrite destruction. The equivalent production of $\mathrm{NO}_{2}$ with $\mathrm{Hg}$ present was $290 \mathrm{~g}$ versus about $160 \mathrm{~g}$ in the two runs without $\mathrm{Hg}$. The $290 \mathrm{~g}$ of $\mathrm{NO}_{2}$ for the $\mathrm{Hg}$ test are an upper bound value due to the aberration in the middle of the peak generation period. Smoothing out the aberration dropped the value to $265 \mathrm{~g}$, which is still much more than $160 \mathrm{~g}$.

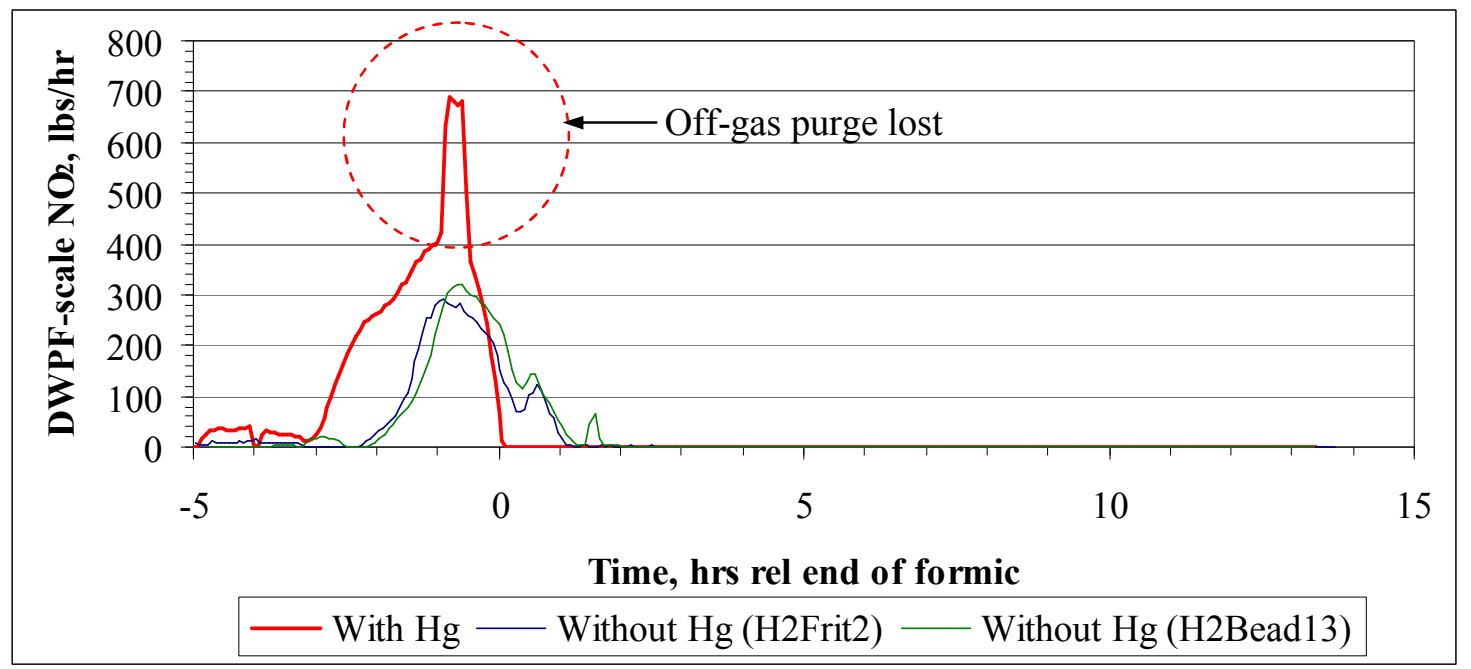

Figure 41. $\mathrm{NO}_{2}$ generation with and without $\mathrm{Hg}$ at $0.2 \mathrm{wt} \% \mathrm{Ru}$

The large early production of $\mathrm{NO}_{2}$ in the $-2 \mathrm{hr}$ to $-3 \mathrm{hr}$ period compared to the two runs without $\mathrm{Hg}$ is probably associated with the lack of a significant valley in the $\mathrm{CO}_{2}$ data during this time. Apparently this $\mathrm{NO}_{2}$ was being driven by the nitrite destruction reaction [6] in Section 2.4.4. Potentially, $\mathrm{Hg}$ was either catalyzing or promoting this nitrite destruction reaction in some fashion.

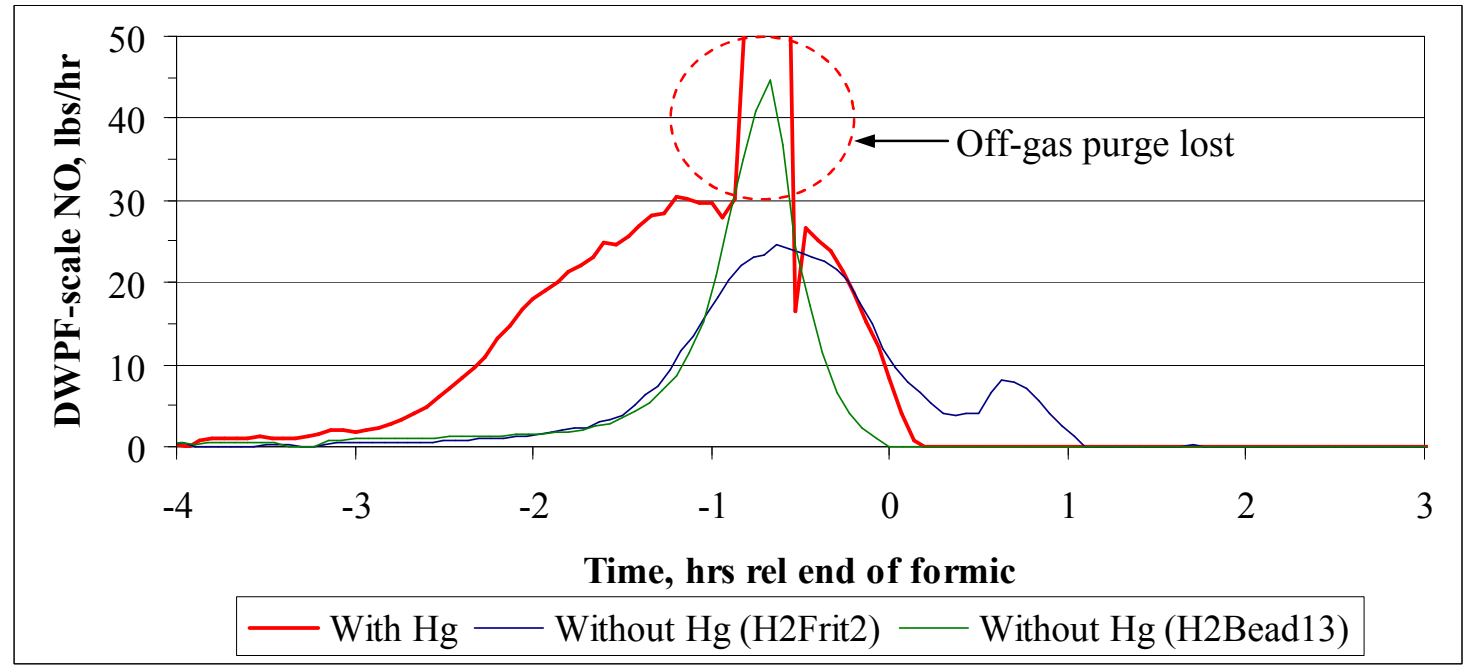

Figure 42. NO generation with and without $\mathrm{Hg}$ at $0.2 \mathrm{wt} \% \mathrm{Ru}$ 
The NO generation rate data were generally small compared to the $\mathrm{NO}_{2}$ generation rate data. The presence of mercury caused a small increase in NO from about $10 \mathrm{~g}$ to $30 \mathrm{~g}$ with $\mathrm{Hg}$ present. Off-setting the increases in $\mathrm{NO}$ and $\mathrm{NO}_{2}$ was a major decrease in $\mathrm{N}_{2} \mathrm{O}$ from $43 \mathrm{~g}$ to $7 \mathrm{~g}$, Figure 43.

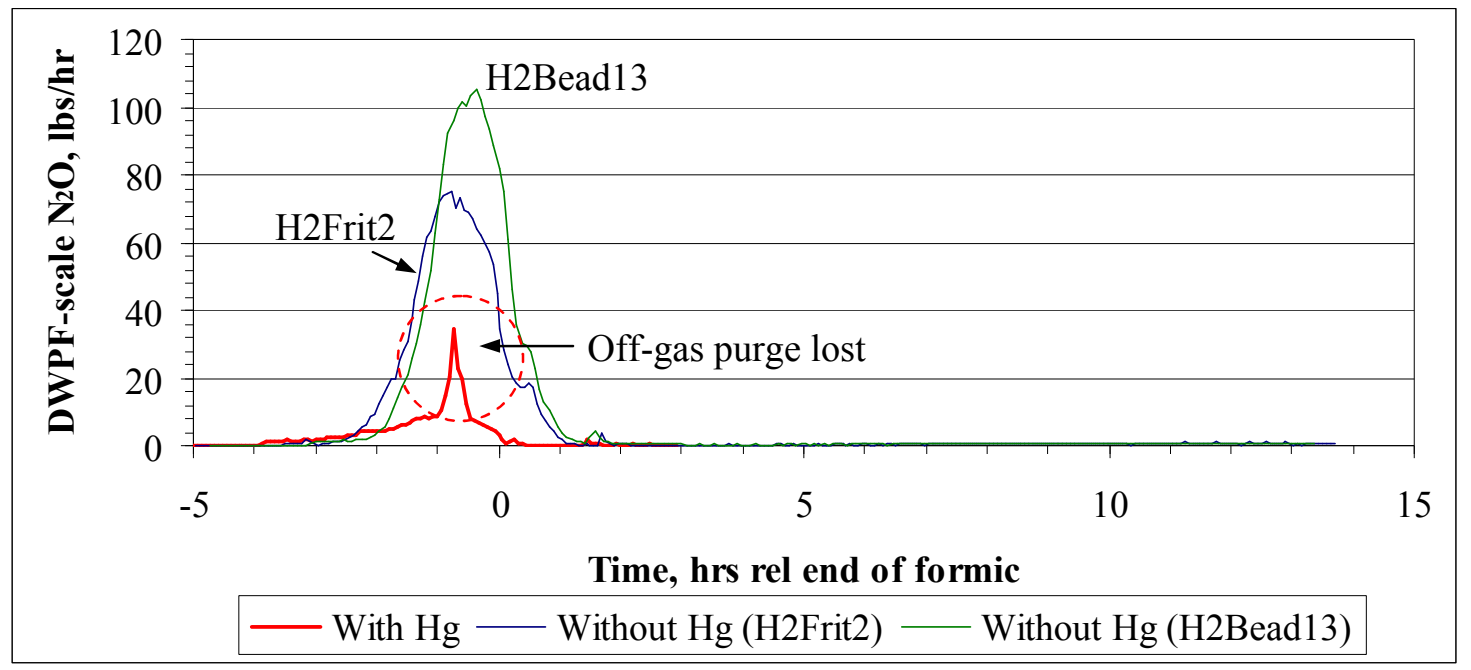

Figure 43. $\mathrm{N}_{2} \mathrm{O}$ generation with and without $\mathrm{Hg}$ at $0.2 \mathrm{wt} \% \mathrm{Ru}$

All three oxide of nitrogen graphs show that gas generation started sooner in the 4-L run with $\mathrm{Hg}$ and ended more abruptly following the end of acid addition. This might be due to an equipment configuration difference between the two lab scales. Presumably the decreased $\mathrm{N}_{2} \mathrm{O}$ production was caused by acceleration of the $\mathrm{NO}$ and $\mathrm{NO}_{2}$ forming reactions leaving less nitrite available to form $\mathrm{N}_{2} \mathrm{O}$. The other $\mathrm{Ru}$ run data do not suggest that $\mathrm{Ru}$ was catalyzing $\mathrm{N}_{2} \mathrm{O}$ formation in the absence of $\mathrm{Hg}$, so there should be no catalytic reaction for $\mathrm{Hg}$ to inhibit. Acceleration of nitrite destruction is also consistent with the earlier onset of hydrogen in the test with $\mathrm{Hg}$ and is also consistent with the earlier cutoffs in the $\mathrm{NO}_{\mathrm{x}}$ generation rates with $\mathrm{Hg}$.

The test with $\mathrm{Hg}$ had a net $25 \%$ nitrite-to-nitrate molar conversion from starting sludge to SRAT product compared to only $6 \%$ for the two runs without $\mathrm{Hg}$. Two possible reasons for the increase were identified. First, the attack on nitrite ion during and just after acid addition was very different with $\mathrm{Hg}$ added as shown by the impact on the three $\mathrm{NO}_{\mathrm{x}}$ species in the off-gas above. Second, there may not have been any significant attack on nitrate ion during boiling in the run with $\mathrm{Hg}$ added such as was seen in Figure 32 for $0.2 \mathrm{wt} \% \mathrm{Ru}$ as well as in Figure 39 for $0.375 \mathrm{wt} \% \mathrm{Ru}$.

A pH trace was obtained for the 4- $\mathrm{L}$ run with $\mathrm{Hg}$, Figure 44. Complete $\mathrm{pH}$ profiles were obtained for neither of the two 22-L matching runs, but a partial $\mathrm{pH}$ profile was obtained for H2Frit2. 


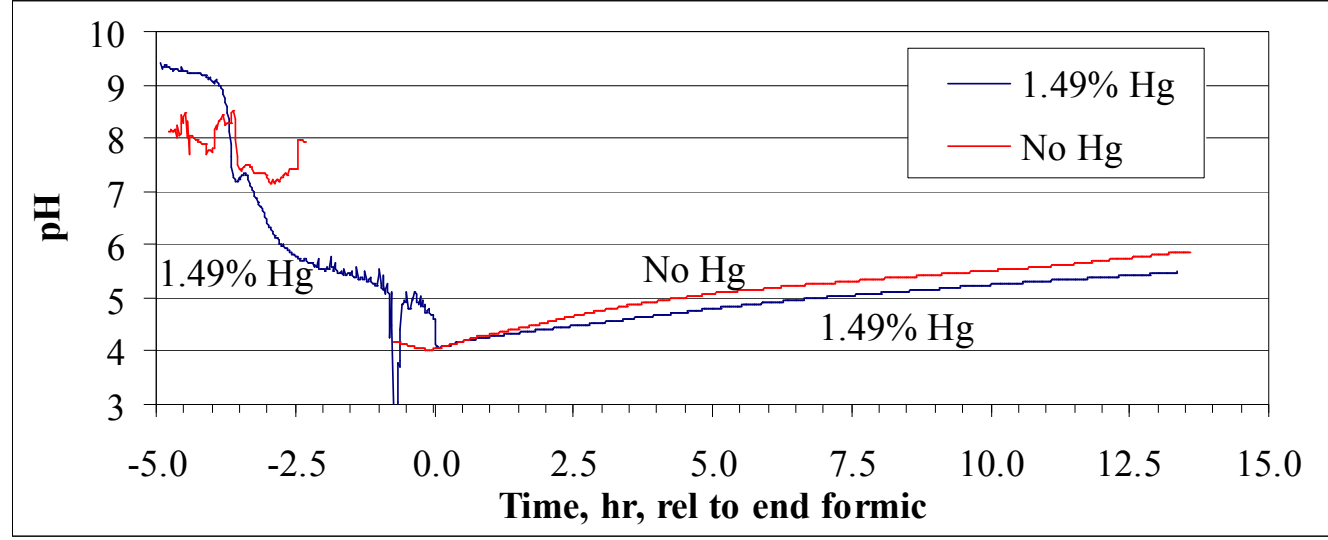

Figure 44. The pH data at $0.2 \mathrm{wt} \% \mathrm{Ru}$

The $\mathrm{pH}$ data from -5 to -2.5 hours for H2Frit 2 with no $\mathrm{Hg}$ may or may not have some value. The gap that follows was the time to condition, calibrate, and install a new $\mathrm{pH}$ probe. The air purge upset also impacted the $\mathrm{pH}$ reading for the run with $\mathrm{Hg}$ about 0.75 hours before the end of formic acid addition. The sharp downward-pointed spike in the run with $\mathrm{Hg}$ at -0.65 hours is an abnormality. The two $\mathrm{pH}$ profiles during boiling were fairly similar, as were the $\mathrm{H}_{2}$ and $\mathrm{CO}_{2}$ profiles.

Supernate cation data were obtained in support of the XAS samples as in other runs. These concentrations were converted into extent of dissolution as percent of the species in the supernate. Results for $\mathrm{Ca}, \mathrm{Mg}$, and $\mathrm{Mn}$ are shown in Figure 45.

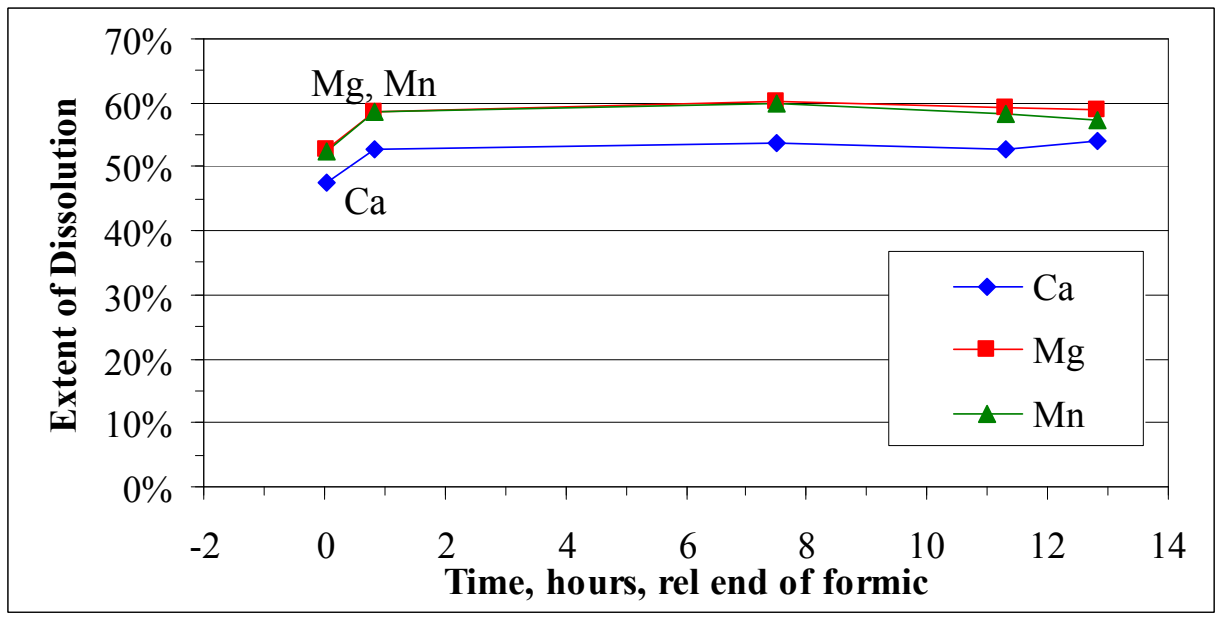

Figure 45. Cation dissolution with $\mathrm{Ru}$ and $\mathrm{Hg}$

Extent of dissolution of the three key elements was suppressed relative to the sixteen runs without $\mathrm{Hg}$. This suppression was not expected nor was it an artifact of the calculations. The raw reported concentrations were also 1000-3000 mg/L lower, e.g. Ca was reported at $2500 \mathrm{mg} / \mathrm{L}$ with $\mathrm{Hg}$ versus 4300 $\mathrm{mg} / \mathrm{L}$ without $\mathrm{Hg}$. The three cationic species behaved as if they were reaching maximum dissolution near the end of acid addition in that the extents of dissolution hit a plateau value that was sustained through the remainder of the SRAT. 
This run had significantly different nitrite destruction kinetics due to the presence of mercury, but it did not appear that this should be relevant to dissolving $\mathrm{Mg}(\mathrm{OH})_{2}, \mathrm{CaCO}_{3}$, etc. The $\mathrm{pH}$ data indicate that it was slightly lower in the run with $\mathrm{Hg}$ than the two bead-frit runs, which should have promoted dissolution of $\mathrm{Ca}$ and $\mathrm{Mg}$. Other run data, such as wt\% solids, are generally in the expected range. A problem with sampling or analysis is the likely explanation as to why the three cations apparently stopped dissolving at the end of acid addition or why they weren't more extensively dissolved. No data were found in other studies to support the validity of these results as significantly different from the no $\mathrm{Hg}$ data from the beadfrit runs.

\subsection{Testing with $\mathrm{Rh}$ - high catalytic activity}

Two pairs of 22L SRAT/SME runs were completed with two different concentrations of Rh. A 4L matching test to the $0.2 \mathrm{wt} \% \mathrm{Rh}$ run is planned for a future date and would include mercury at a concentration equal to that used in the $0.2 \mathrm{wt} \% \mathrm{Ru}$ run with mercury. The primary purpose of the run would be to give data on the mercury impact and to produce XAS samples for comparison to the Rh slurry samples without $\mathrm{Hg}$.

\subsubsection{Tests with $\mathrm{Rh}$ at $0.1 \mathrm{wt} \%$}

$\mathrm{H} 2 \mathrm{Frit} 6$ and $\mathrm{H} 2 \mathrm{Bead} 16$ were given an initial charge of $0.1 \mathrm{wt} \% \mathrm{Rh}$ in the trimmed sludge total solids. The $\mathrm{CO}_{2}$ generation rate is plotted as a function of time in Figure 46.

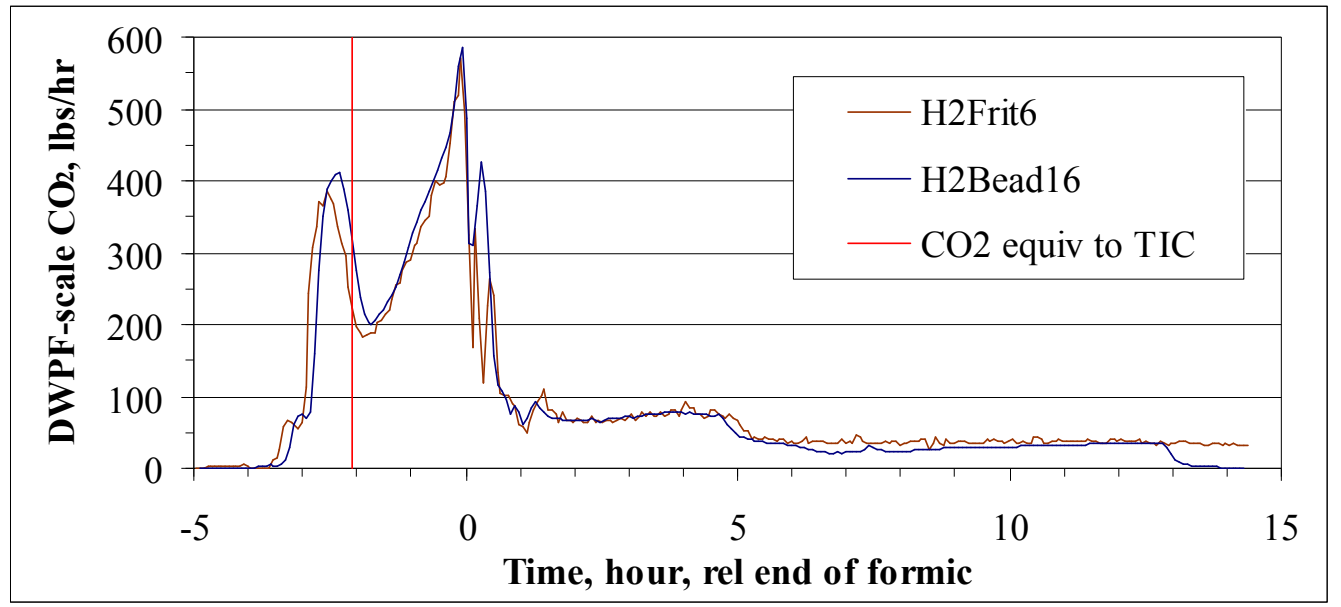

Figure 46. $\mathrm{CO}_{2}$ generation during SRAT processing at $0.1 \mathrm{wt} \% \mathrm{Rh}$

Both data sets came from an Agilent 3000A micro GC. The two $\mathrm{CO}_{2}$ data traces are very similar. H2Frit6 formic acid addition took 3:42, while H2Bead16 formic acid addition took 3:28. This small delta explains most of the observed differences (H2Frit6 profile slightly broader and shallower than H2Bead16). Total $\mathrm{CO}_{2}$ mass was also nearly identical, $476 \mathrm{~g}$ and $475 \mathrm{~g}$ for H2Frit6 and H2Bead16 respectively. The red vertical line indicates the time where the quantity of $\mathrm{CO}_{2}$ produced was sufficient to account for $1,350 \mathrm{mg} / \mathrm{kg}$ TIC in the starting slurry.

The generation of $\mathrm{NO}_{2}$ in the two runs was nearly identical as well. The results calculated from the oxygen consumption are shown in Figure 47 along with the NO data. 
WSRC-STI-2008-00131

Revision 0

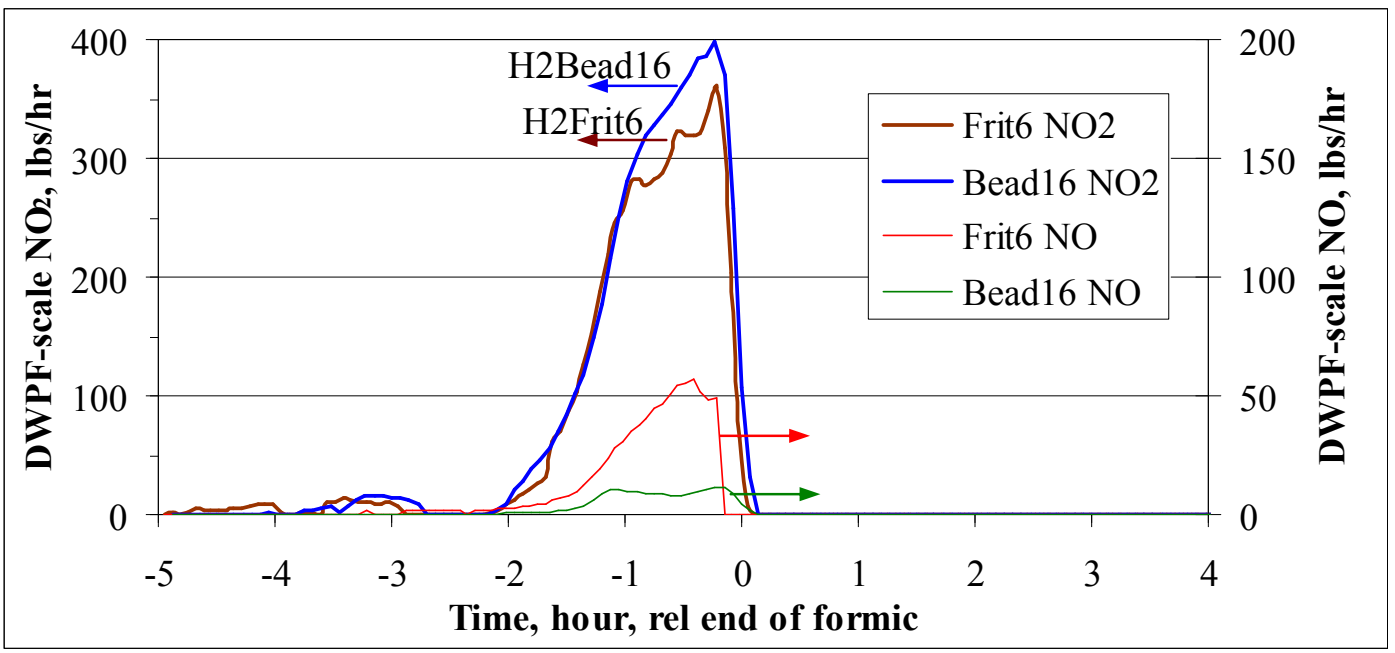

Figure 47. $\mathrm{NO}$ and $\mathrm{NO}_{2}$ Generation at $0.1 \mathrm{wt} \% \mathrm{Rh}$

The onset of NO generation was fairly similar, but H2Bead16 had a smaller peak than H2Frit6. The overall quantities of $\mathrm{NO}$ were much smaller than the quantities for $\mathrm{NO}_{2}$. The extra $\mathrm{NO}$ in $\mathrm{H} 2$ Frit6 relative to $\mathrm{H} 2 \mathrm{Bead} 16$ seemed to effectively offset the reduced $\mathrm{NO}_{2}$ at about the same time. The calculated sums of total $\mathrm{NO}+\mathrm{NO}_{2}$ were 2.68 moles $\mathrm{N}$ for $\mathrm{H} 2 \mathrm{Frit6}$ and 2.60 moles $\mathrm{N}$ for $\mathrm{H} 2 \mathrm{Bead} 10$ which are essentially identical within the likely measurement errors and assumptions made for the calculations. The off-gas data indicate that these two runs processed nearly identically through the SRAT cycle. The $\mathrm{N}_{2} \mathrm{O}$ generation occurred about the same time as $\mathrm{NO}_{2}$ and the results were very similar in terms of both general timing and magnitude, Figure 48.

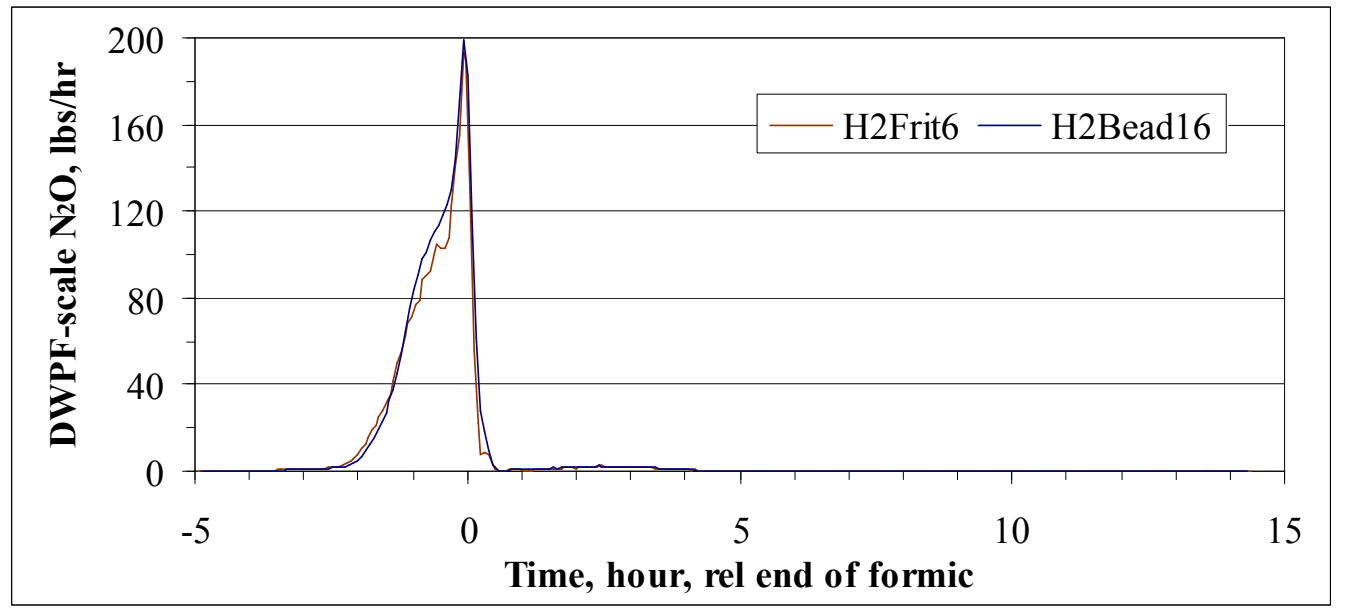

Figure 48. $\mathrm{N}_{2} \mathrm{O}$ generation at $0.1 \mathrm{wt} \% \mathrm{Rh}$

Sampling after dewatering was fairly limited until the SRAT product, since the $0.1 \mathrm{wt} \% \mathrm{Rh}$ runs were expected to be fairly active catalytically. Consequently, it was unclear how useful the data obtained in this period would be for explaining SRAT chemistry at more ordinary noble metal concentrations. Data for the formate ion concentration are shown in Figure 49. The two traces for nominal added formate start about 20 minutes apart but converge to the same curve at the end of acid addition, 0 hours. The two sets of data track their respective nominal addition curve during the majority of formic acid addition. 
WSRC-STI-2008-00131

Revision 0

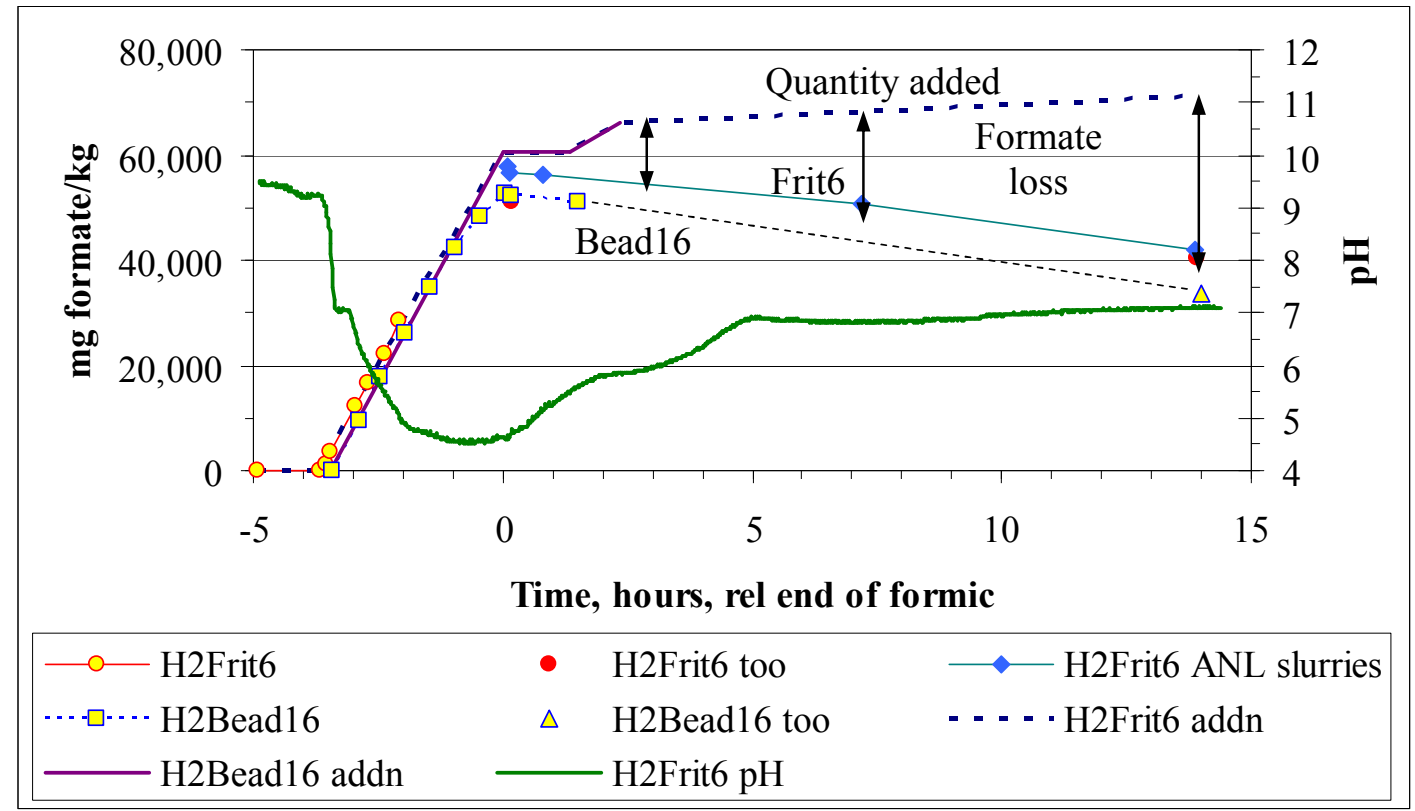

Figure 49. Formate changes at $0.1 \mathrm{wt} \% \mathrm{Rh}$

The "H2Frit6 too" and "H2Bead16 too" points at about +14 hours were unquenched SRAT product sample results that form part of the overall data set. Formate loss continued to increase during boiling until the end of the SRAT cycle by which time it had grown to 43-52\%. This is about double the formate loss in a typical run. The H2Frit6 ANL slurry samples (unquenched) were stored for eleven weeks before analysis by IC which may have impacted the results. The period around the end of formic acid addition is enlarged in Figure 50 to show details of the nominal formate additions versus the actual measurement profiles. 
WSRC-STI-2008-00131

Revision 0

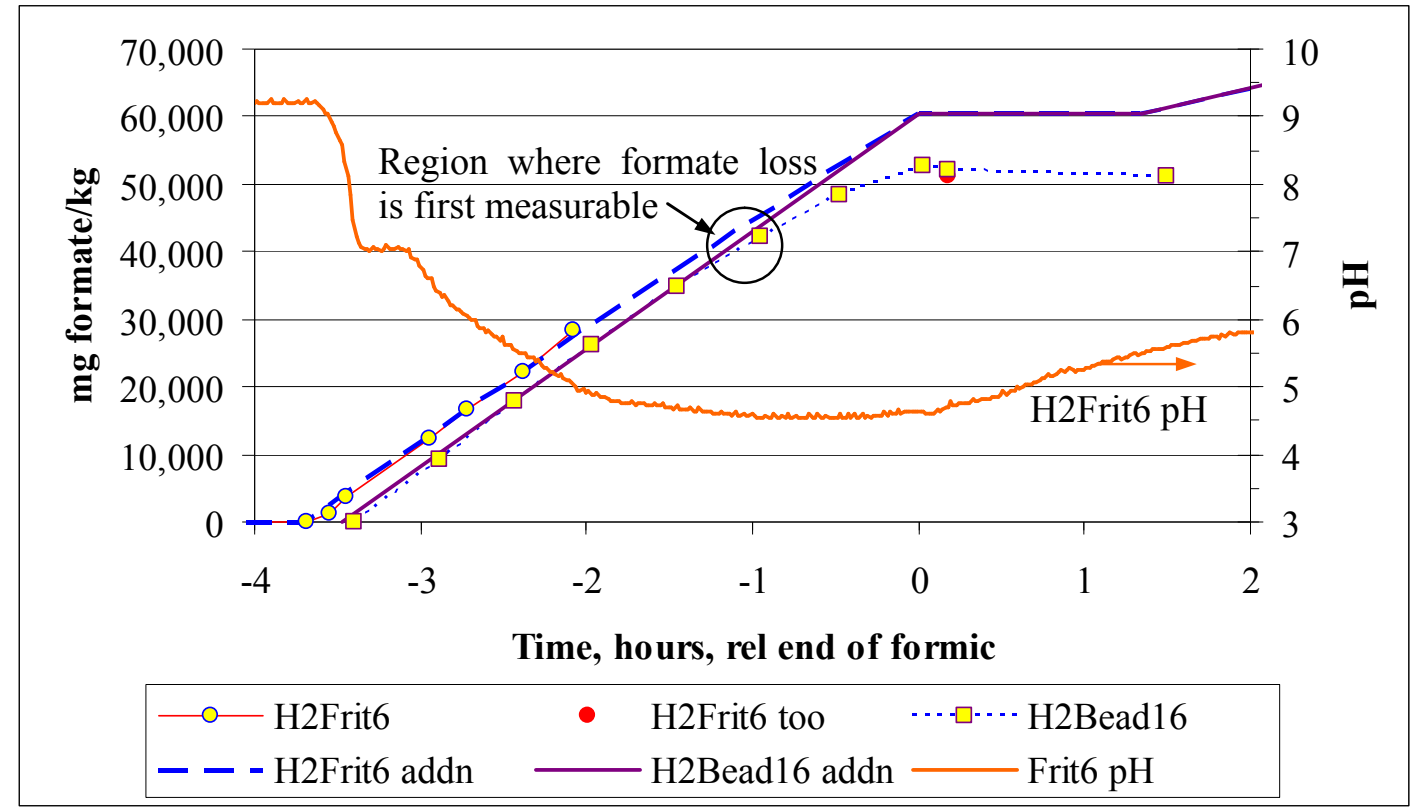

Figure 50. Detail of formate concentration during formic acid addition

Formate ion concentration closely tracked the two nominal addition rate curves indicating minimal losses during much of the formic acid addition period. This observation, however, seems to contradict the $\mathrm{CO}_{2}$ data that indicated that a second source of $\mathrm{CO}_{2}$ was needed by about -2.1 hours. Formate loss was seen before the end of acid addition, but it was most obvious in the last 1-1.5 hours. The SRAT pH was below 5 during most of this 1.5 hour period.

Relatively detailed information was also obtained about nitrite destruction during acid addition for these two runs, Figure 51. The sample data were compared to a hypothetical curve for the initial sludge nitrite concentration, adjusted for dilution by the nitric and formic acid additions, assuming no destruction of the nitrite was occurring. 
WSRC-STI-2008-00131

Revision 0

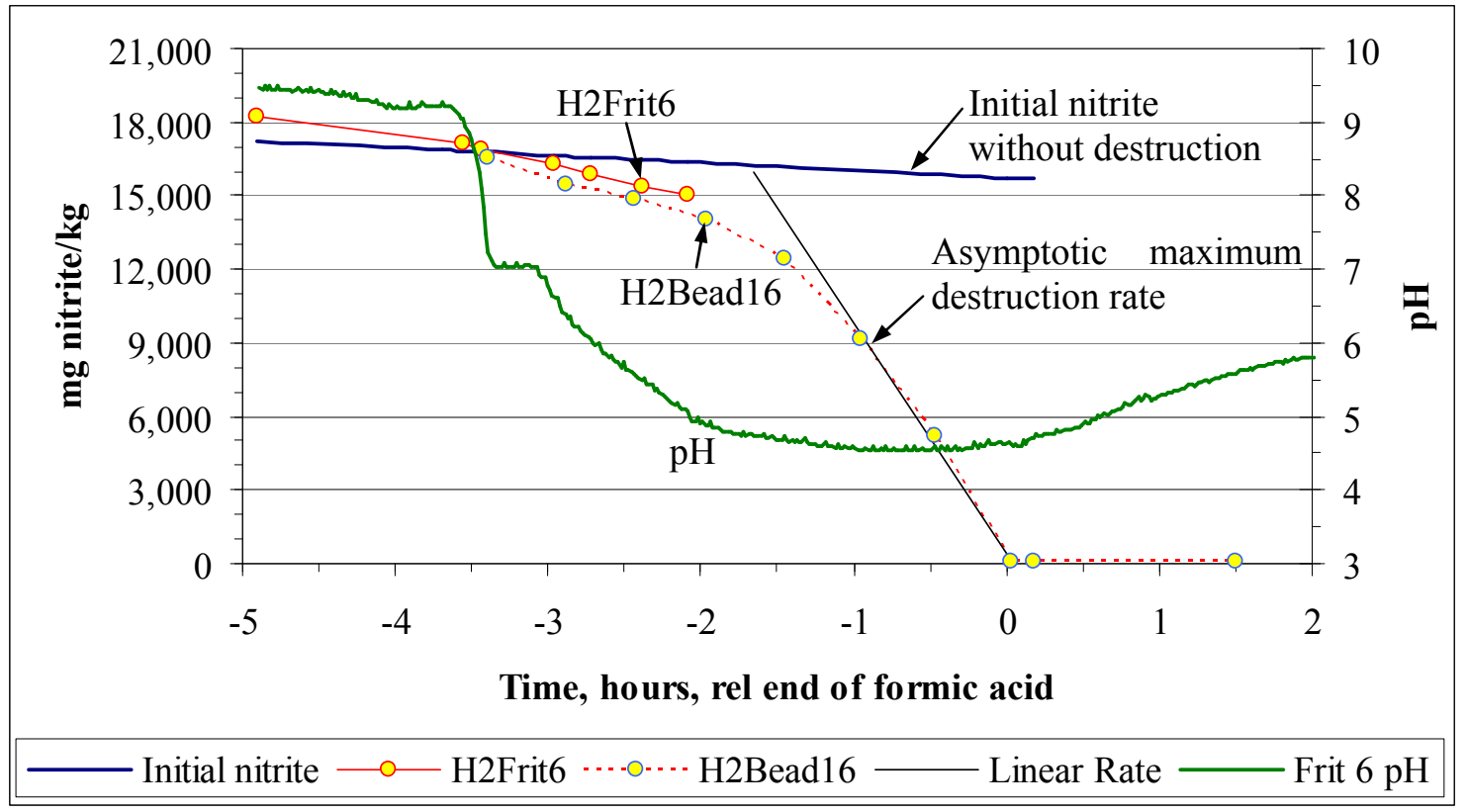

Figure 51. Nitrite destruction at $0.1 \mathrm{wt} \% \mathrm{Rh}$

The rate of nitrite destruction was quite variable during the last three hours of formic acid addition. It increased asymptotically to a rate of about 0.26 moles nitrite per hour per liter starting sludge relative to an acid addition rate of about 0.50 moles per hour per liter starting sludge. The matching set of nitrate ion concentration data are shown in Figure 52.

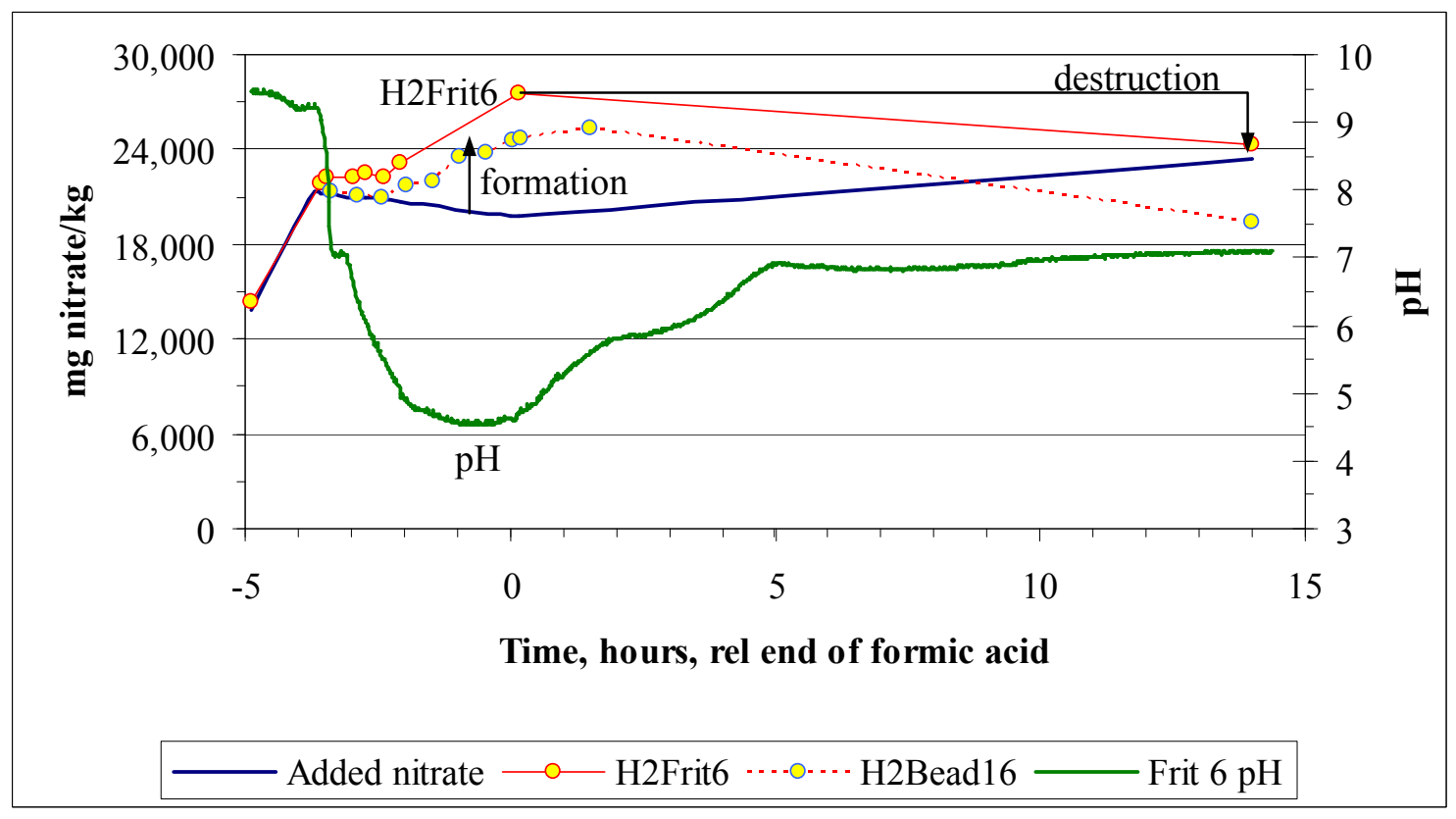

Figure 52. Nitrate formation and destruction at $0.1 \mathrm{wt} \% \mathrm{Rh}$ 
Nitrate was clearly forming near the end of acid addition in both runs, but there was a subsequent loss in nitrate during the period 2-14 hours after acid addition. Nitrate loss was seen in the $0.2 \mathrm{wt} \% \mathrm{Rh}$ runs as well, although data were not taken to show the initial nitrite-to-nitrate formation. H2Bead16 ended up with $-15 \%$ nitrite-to-nitrate conversion overall as the SRAT product nitrate fell below the nitrate added in the sludge, trim chemicals, and nitric acid.

Some cation data were obtained from the samples supporting the XAS work from H2Frit6. The pH rose quickly around the end of acid addition along with a brief period of intense hydrogen generation and formic acid destruction. After dissolving $\mathrm{Mn}, \mathrm{Mg}$, and $80 \%$ of the $\mathrm{Ca}$, these three cations began to reprecipitate during reflux, Figure 53.

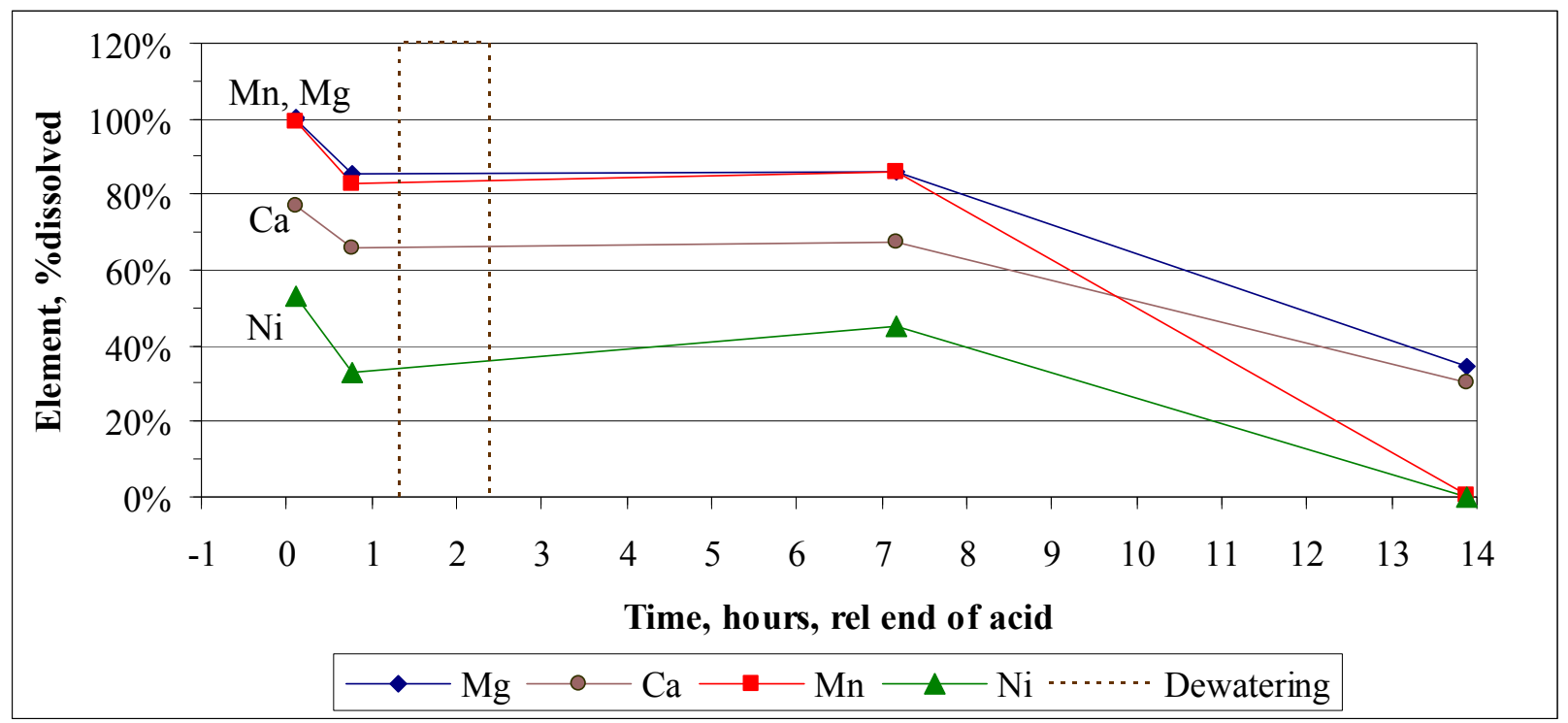

Figure 53. H2Frit6 Cation Precipitation

The initial extents of dissolution were comparable to the other runs. Nearly all of the Mn, about 2/3 of the $\mathrm{Mg}$, and over half of the dissolved $\mathrm{Ca}$ had reprecipitated by the end of the SRAT. Other smaller differences were seen between H2Frit6 and H2Bead16 in the SRAT product soluble cation data. Data on cation dissolution during acid addition were not taken during this pair of runs.

The FAVC condensate and the SRAT product were checked for ammonium ion concentration. The Bead 16 FAVC condensate had $50,000 \mathrm{mg} / \mathrm{L}$ of ammonium ion. This concentration was ten times higher than in the run with $0.2 \mathrm{wt} \% \mathrm{Rh}$. Ammonium generation may have occurred during reflux at a higher rate in the two $0.1 \mathrm{wt} \% \mathrm{Rh}$ runs just as hydrogen generation did, while the $0.2 \mathrm{wt} \% \mathrm{Rh}$ runs seemed to exhaust themselves shortly after the hydrogen peak. The Bead 16 SRAT product had $69 \mathrm{mg} / \mathrm{L}$ of ammonium ion.

The oxidation-reduction probe was mounted in the SRAT during H2Frit6 acid addition. The results are shown in Figure 54. 
WSRC-STI-2008-00131

Revision 0

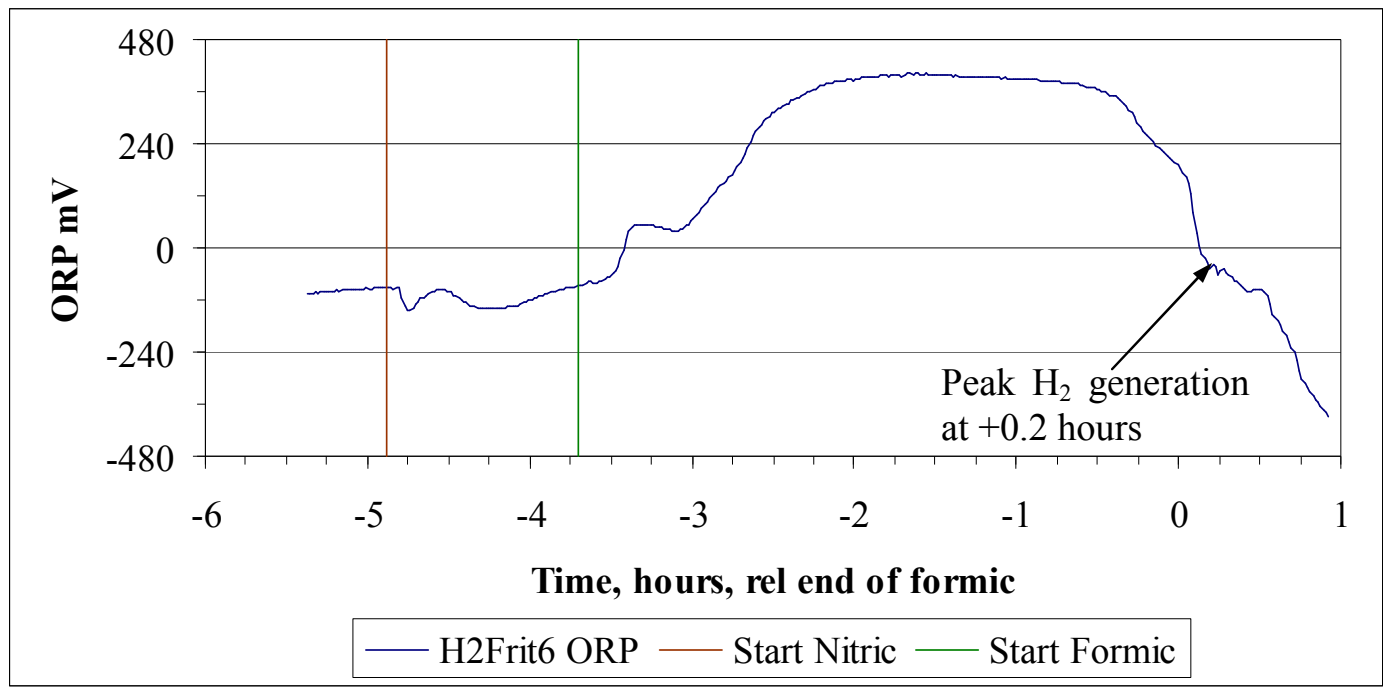

Figure 54. Oxidation-reduction potential at $0.1 \mathrm{wt} \% \mathrm{Rh}$

The probe read an oxidizing potential (negative $\mathrm{mV}$ ) during nitric acid addition and switched over to a reducing potential (positive $\mathrm{mV}$ ) shortly after the start of formic acid addition. A very large peak in hydrogen generation began to form near the end of formic acid addition (starting at -0.2 hours). Consequently, the SRAT was not taken to boiling until about an hour after the end of acid addition. This delay enabled the ORP to continue taking readings past the end of acid addition. The ORP potential fell steeply during this period of hydrogen generation. The SRAT switched back to oxidizing. Based on this data, it does not appear that the ORP potential would give much warning that a major hydrogen generation period was about to occur at the end of acid addition. While the potential did start dropping about twenty minutes before the end of acid addition, it is unclear whether the change would have been significant enough to halt acid addition in a lower noble metal SRAT. If the SRAT is truly oxidizing during hydrogen generation, then Mn could potentially convert back to the +4 oxidation state.

\subsubsection{Tests with $\mathrm{Rh}$ at $0.2 \mathrm{wt} \%$}

$\mathrm{H} 2 \mathrm{Frit} 1$ and H2Bead10 were given an initial charge of $0.2 \mathrm{wt} \% \mathrm{Rh}$ in the trimmed sludge total solids. Processing was generally similar, except that heat was taken off of $\mathrm{H} 2 \mathrm{Frit} 1$ following acid addition when hydrogen generation rates spiked, while $\mathrm{H} 2 \mathrm{Bead} 10$ was held at $93^{\circ} \mathrm{C}$ for an equivalent period. Hydrogen generation had dropped below the DWPF limit before either run was taken to boiling. Boiling was reached about 1.7 hours after the end of acid addition. Figure 55 and Figure 56 give elemental dissolution data for $\mathrm{Ca}, \mathrm{Mg}, \mathrm{Mn}$, and $\mathrm{Ni}$ along with $\mathrm{pH}$ data. 
WSRC-STI-2008-00131

Revision 0

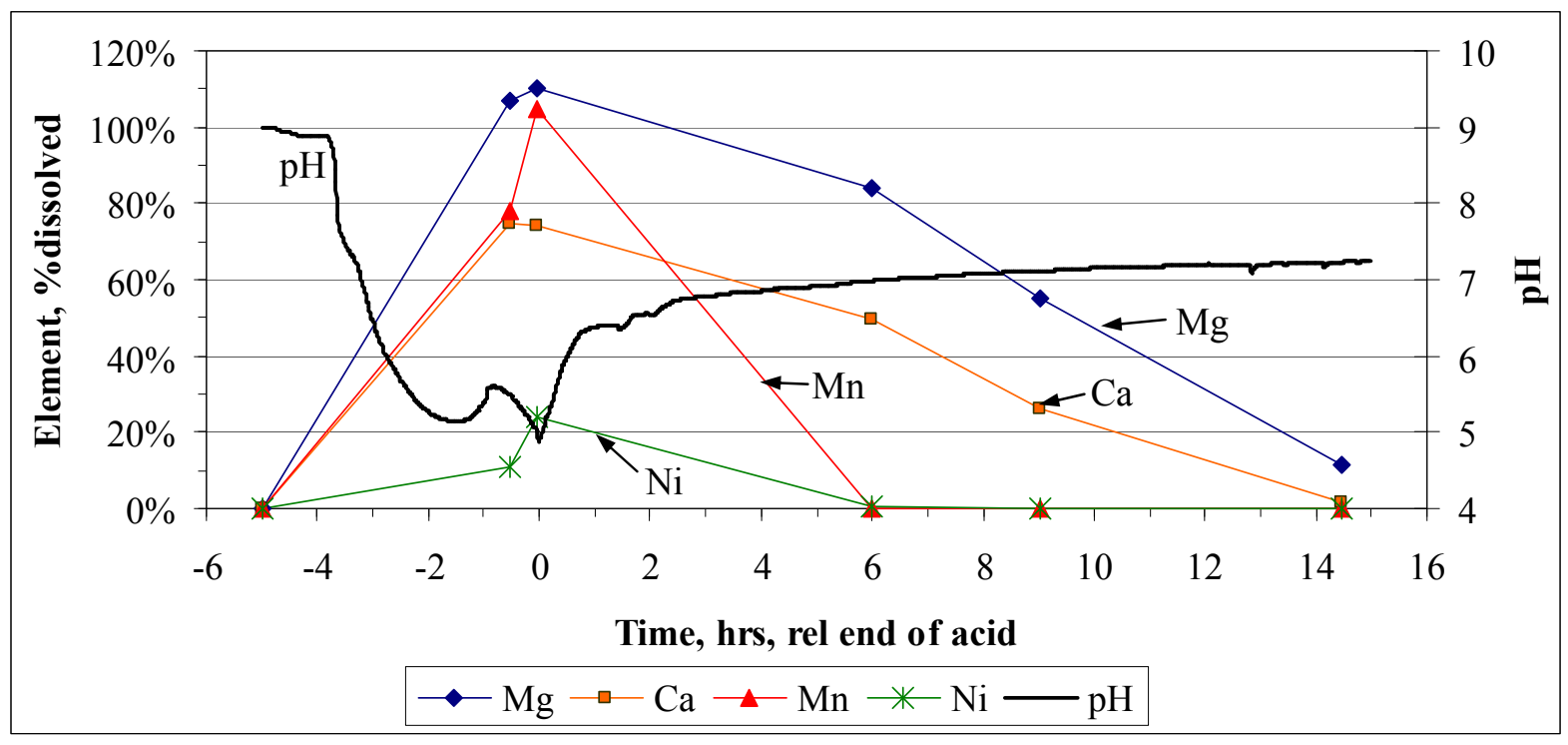

Figure 55. Elemental dissolution data at $0.2 \mathrm{wt} \% \mathrm{Rh}$ in H2Frit1

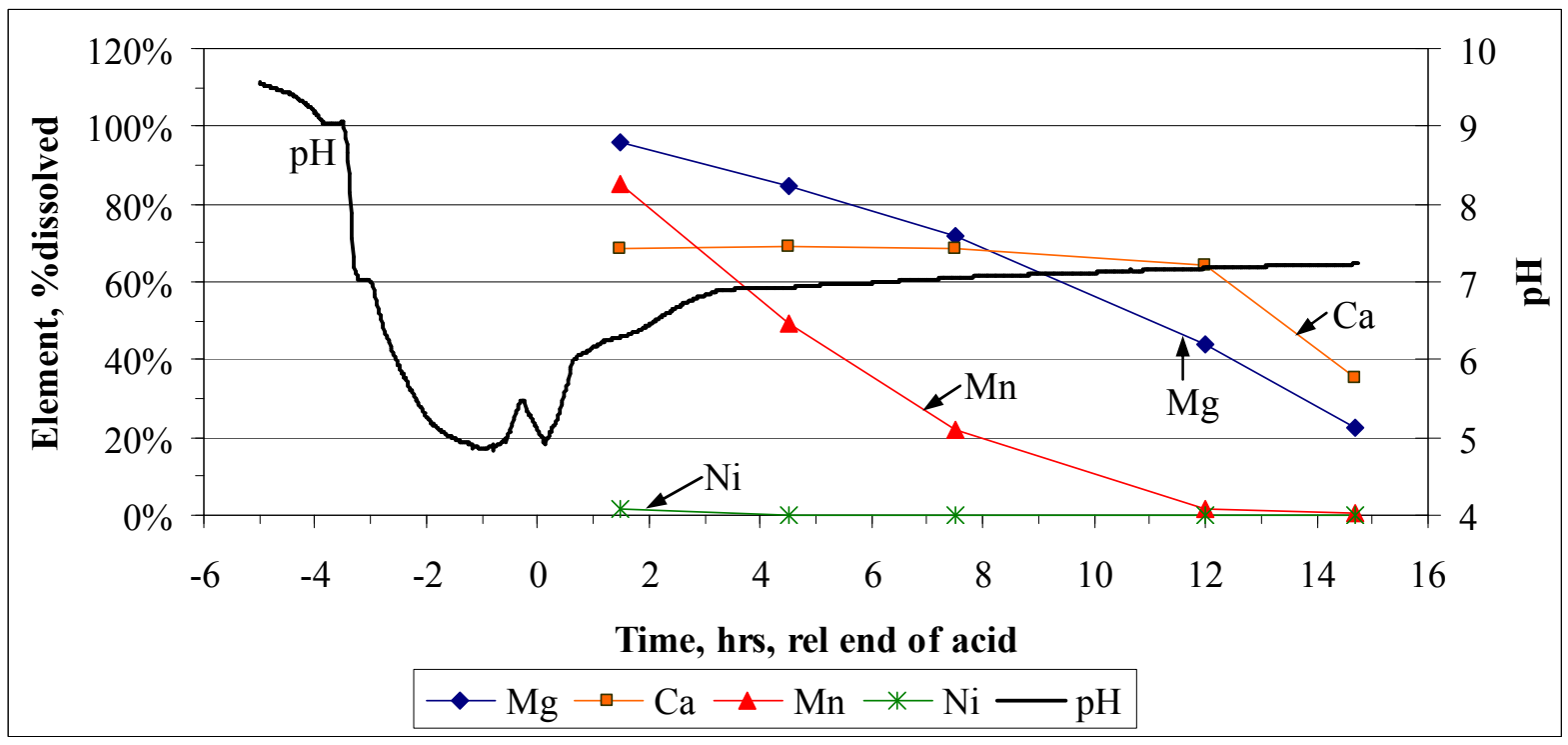

Figure 56. Elemental dissolution data at $0.2 \mathrm{wt} \% \mathrm{Rh}$ in $\mathrm{H} 2 \mathrm{Bead} 10$

The $\mathrm{pH}$ profile was fairly well reproduced in these two SRAT runs. The $\mathrm{pH}$ profile is typical of a run with a lot of catalytic activity in that there is a steady climb in $\mathrm{pH}$ following acid addition due to catalytic attack on the remaining formic acid with the final $\mathrm{pH}$ being above seven.

Total $\mathrm{Mg}(\mathrm{OH})_{2}$ dissolution, total $\mathrm{MnO}_{2}$ reduction, and partial Ca dissolution consistent with the full $71 \%$ of $\mathrm{Ca}$ present as $\mathrm{CaCO}_{3}$ in the simulant plus up to about $7-8 \%$ additional $\mathrm{Ca}$ occurred by the end of acid addition in both runs. Partial dissolution of $\mathrm{Ni}(\mathrm{OH})_{2}$ occurred with nickel dropping out of solution as soon as the $\mathrm{pH}$ rose above about 5. Mn precipitated out of the supernate on two offset curves but was essentially all back as insoluble solids by the end of the SRAT cycle. There were two very different curves for dissolved calcium concentration following initial dissolution. H2Bead10 retained a fairly high 
fraction of the $\mathrm{Ca}$ in solution until late in the reflux period, while H2Frit1 had most of the $\mathrm{Ca}$ reprecipitated by the end of the SRAT. The Mg data were reproduced fairly well. The data from these two runs do not show the actual sequence of cation dissolutions during acid addition (no samples during that time), but samples from other pairs of runs have that data.

Some of the differences in the curves for a given element may relate to the fact that the H2Frit1 samples were not analyzed until a month after the test. These samples sat as undecanted slurries until shortly before analysis. The $\mathrm{H} 2 \mathrm{Bead} 10$ supernates were separated from the insoluble solids immediately after the samples were taken from the SRAT vessel. Carbonates of $\mathrm{Ca}, \mathrm{Mg}$, and $\mathrm{Mn}$ are insoluble at near neutral $\mathrm{pH}$ 's. It is suspected that these species may have formed from absorbed carbonate produced from the carbon dioxide generated by catalytic attack on formate ion and formic acid molecules bubbling through the mildly acidic to mildly basic supernate. There is one additional hypothesis to explain the more rapid precipitation of $\mathrm{Mg}, \mathrm{Mn}$, and $\mathrm{Ca}$ in $\mathrm{H} 2 \mathrm{Frit} 1$ relative to $\mathrm{H} 2 \mathrm{Bead10}$. The absorption of the $\mathrm{CO}_{2}$ as a carbonate species may be mass transfer controlled. Something may have increased the rate of absorption in $\mathrm{H} 2 \mathrm{Frit1}$ relative to $\mathrm{H} 2 \mathrm{Bead10}$, such as better mixing profiles in the slurry. The ORP data from the 0.1 $\mathrm{wt} \% \mathrm{Rh}$ run suggested that the SRAT might revert to an oxidizing environment, which potentially means that the $\mathrm{Mn}^{2+}$ could reoxidize to $\mathrm{Mn}^{4+}$ and precipitate out as $\mathrm{MnO}_{2}$. The $0.2 \mathrm{wt} \% \mathrm{Rh}$ system, however, is probably less prototypical of ordinary SRAT cycles than the $0.1 \mathrm{wt} \% \mathrm{Rh}$ system.

The rate of $\mathrm{CO}_{2}$ generation is plotted as a function of time in Figure 57. The $\mathrm{M} 200 \mathrm{H}$ GC used for $\mathrm{H} 2 \mathrm{Frit} 1 \mathrm{had}$ some issues with the injection volume. Also, the near total absence of significant $\mathrm{CO}_{2}$ during the last ten hours of reflux in H2Frit1 was not considered to be credible.

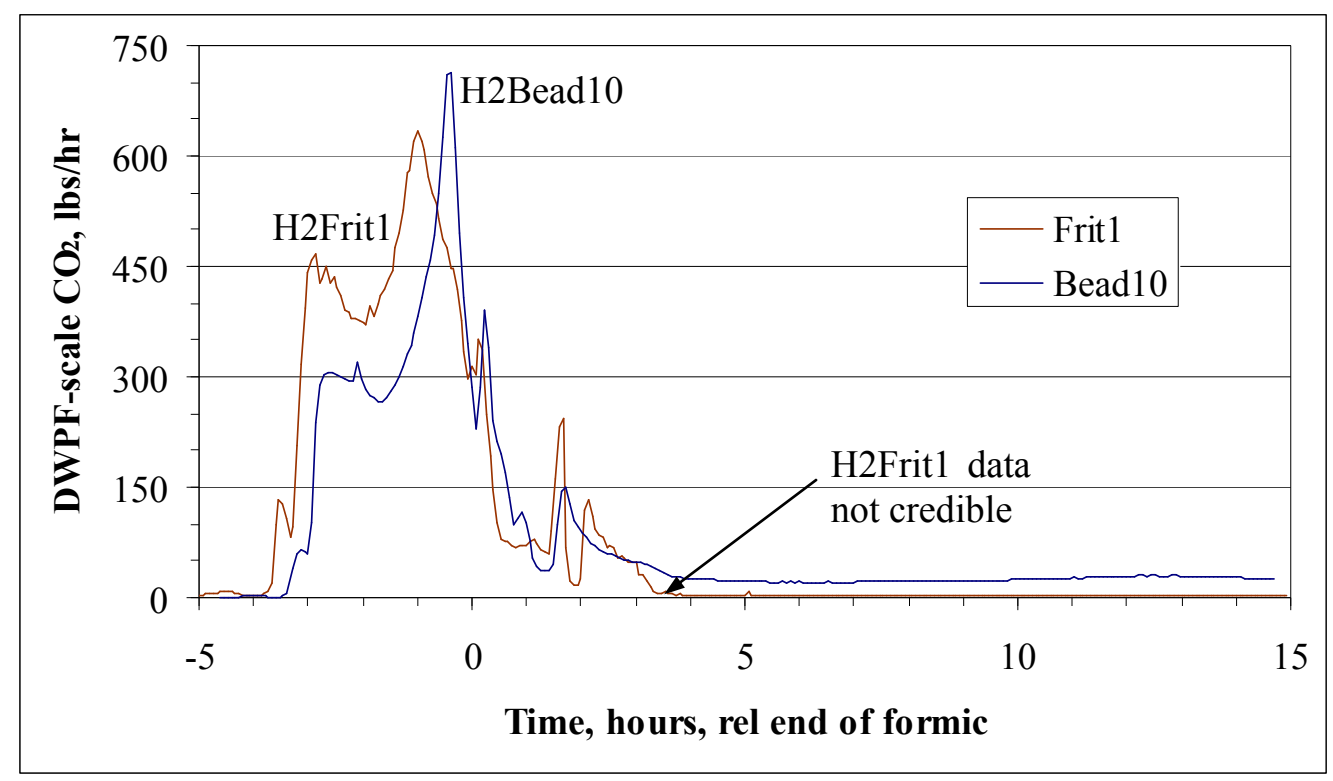

Figure 57. $\mathrm{CO}_{2}$ Generation at $0.2 \mathrm{wt} \% \mathrm{Rh}$

Formic acid addition took 3:53 for H2Frit1 and 3:33 for H2Bead10 causing the H2Frit1 results to be broader and generally shallower than the $\mathrm{H} 2 \mathrm{Bead} 10$ results during acid addition. The TIC-driven peak at -3 hours, however, was smaller in $\mathrm{H} 2 \mathrm{Bead} 10$. Total $\mathrm{CO}_{2}$ was $553 \mathrm{~g}$ for H2Frit1 and $525 \mathrm{~g}$ for H2Bead10 which is excellent agreement, and better than was expected from the two curves. The associated SRAT formate losses were $61 \%$ and $58 \%$ respectively. These losses are 2-3 times as high as typical formate loss percentages due to the high catalytic activity of $0.2 \mathrm{wt} \% \mathrm{Rh}$. 
Figure 58 gives the nitrous oxide generation data. The H2Fritl data is less sharp due to the slower formic acid addition rate, but is otherwise quite comparable.

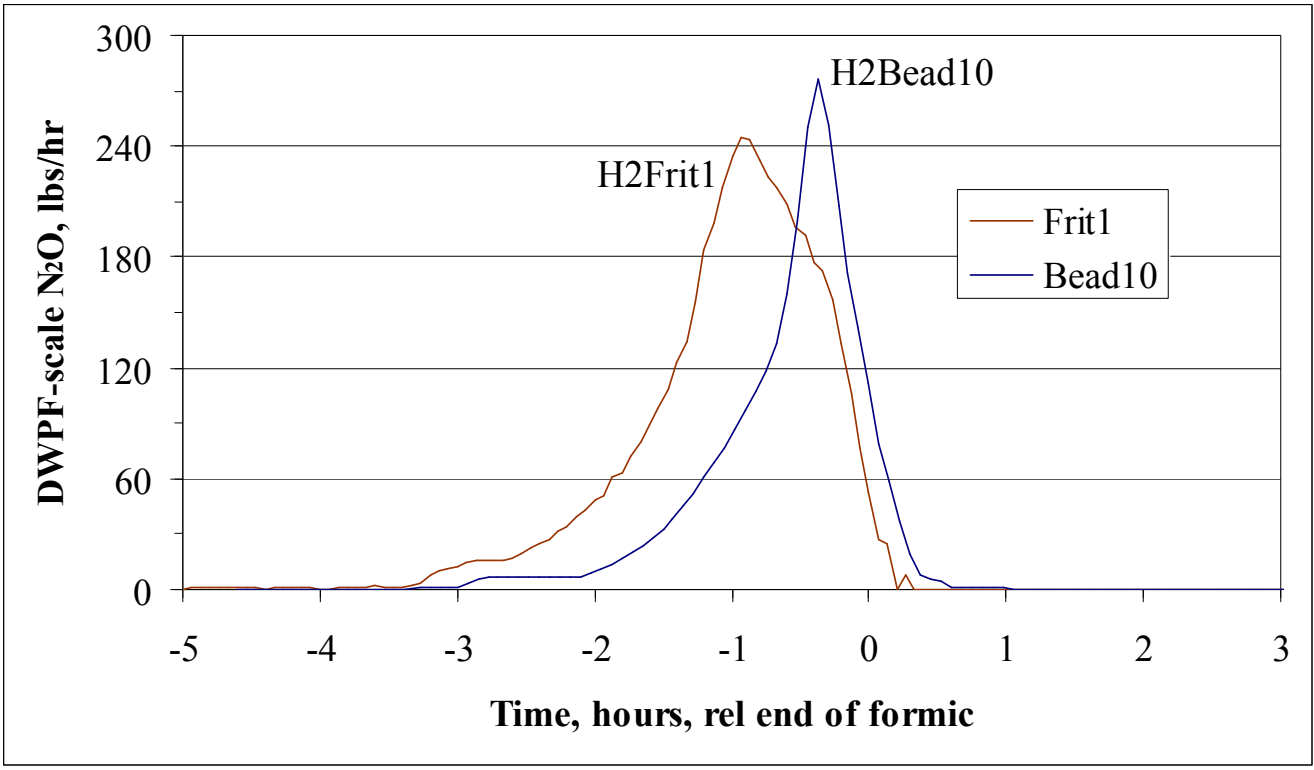

Figure 58. $\mathrm{N}_{2} \mathrm{O}$ generation at $0.2 \mathrm{wt} \% \mathrm{Rh}$

Total nitrous oxide was $101 \mathrm{~g}$ in H2Frit1 and $70 \mathrm{~g}$ in H2Bead10. Figure 59 gives the $\mathrm{NO}$ and $\mathrm{NO}_{2}$ generation data.

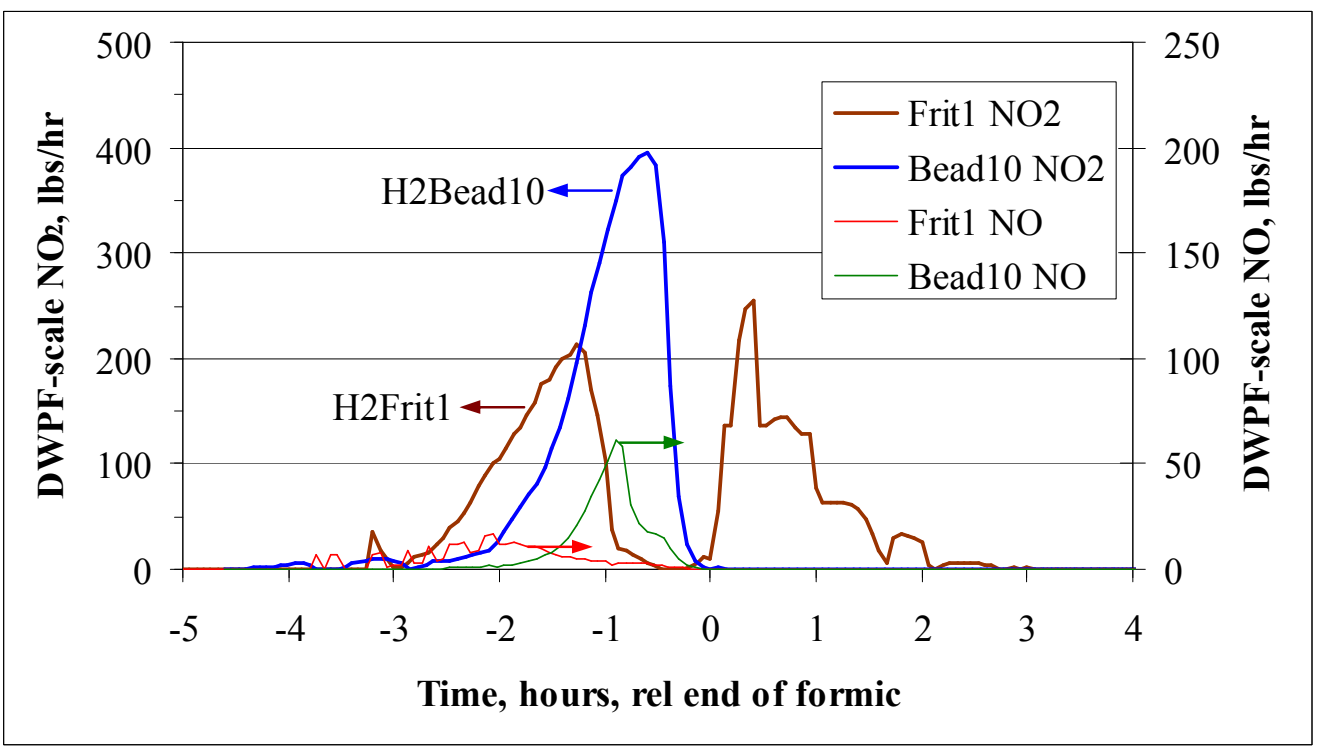

Figure 59. $\mathrm{NO}$ and $\mathrm{NO}_{2}$ generation at $0.2 \mathrm{wt} \% \mathrm{Rh}$

The dip in the H2Fritl data was not due to turning off the power to the heating mantle when hydrogen became difficult to control. This change occurred at +0.3 hours after formic acid addition was complete. The differences between the two traces may once again have to do with comparing $\mathrm{M} 200 \mathrm{H}$ GC data to 
3000A GC data and potential instrument specific variations in the approach to equilibrium existing between $\mathrm{NO}, \mathrm{NO}_{2}$, and $\mathrm{N}_{2} \mathrm{O}_{4}$. The $\mathrm{NO}$ data were also quite different. Data were also obtained on some of the major anions during these two runs. Formate data are shown in Figure 60 compared to the nominal formate addition curve without destruction.

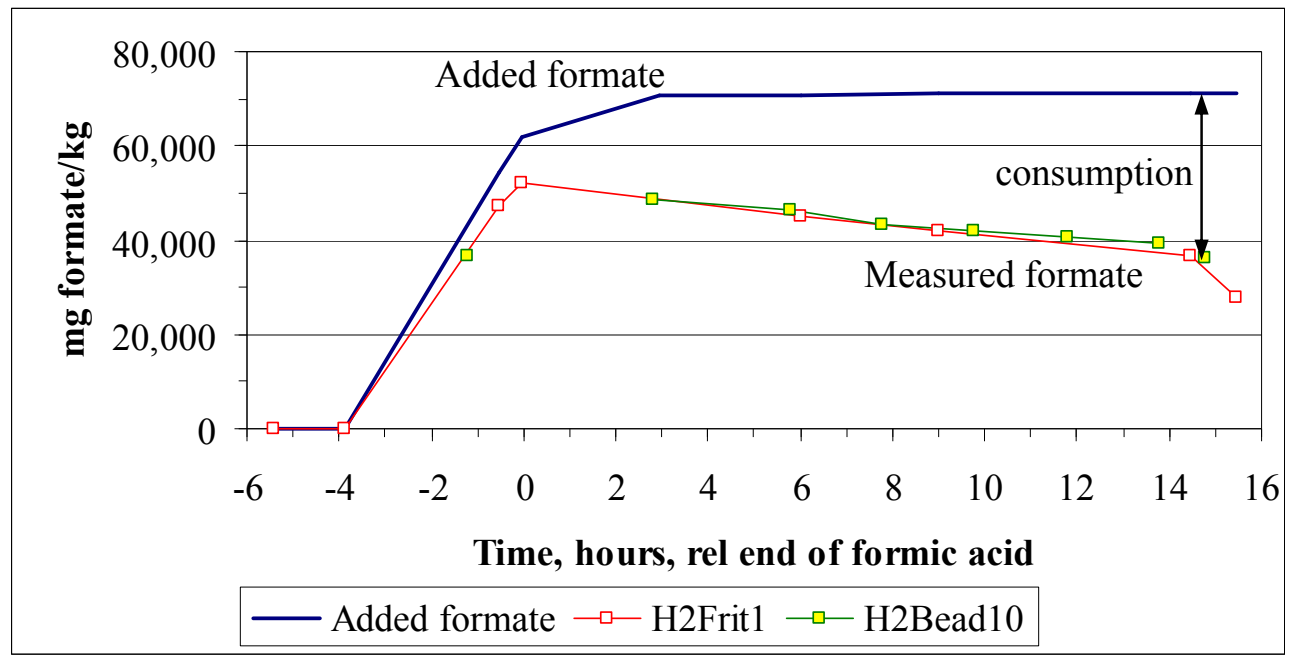

Figure 60. Formate consumption at $0.2 \mathrm{wt} \% \mathrm{Rh}$

The added formate curve shows H2Frit1 nominal formate as formic acid was added and concentrated during dewatering and the slow mass reduction leading to the SRAT product. The initial H2Bead10 data point at -1.2 hours is actually on the equivalent nominal curve for H2Bead10 (which was not shown to simplify the graph). Significant formate loss was only seen during the last hour of formic acid addition and later. Reproducibility of these data was excellent. The large formate loss in both runs was obvious from comparing the actual data at +14 hours to the matching amount of formate added as acid. The rate of loss, $0.3 \mathrm{~g} / \mathrm{min}$, was fairly constant from +1 hour to +14 hours. The $\mathrm{H} 2 \mathrm{Bead} 10 \mathrm{CO}_{2}$ generation rate data during this period were about $0.1 \mathrm{~g} / \mathrm{min}$, while the $\mathrm{H} 2 \mathrm{Frit} 1 \mathrm{CO}_{2}$ data were less than a tenth of that, i.e. not credible. The conclusion is that the ongoing formate destruction was only being partially translated into $\mathrm{CO}_{2}$ evolution. The ICP-AES data indicate that the precipitating elements may have been responsible for consuming the additional $\mathrm{CO}_{2}$ from decomposing formate.

The nitrate data from near the end of acid addition through the SRAT products are shown in Figure 61 along with a nominal curve for addition without reaction. 
WSRC-STI-2008-00131

Revision 0

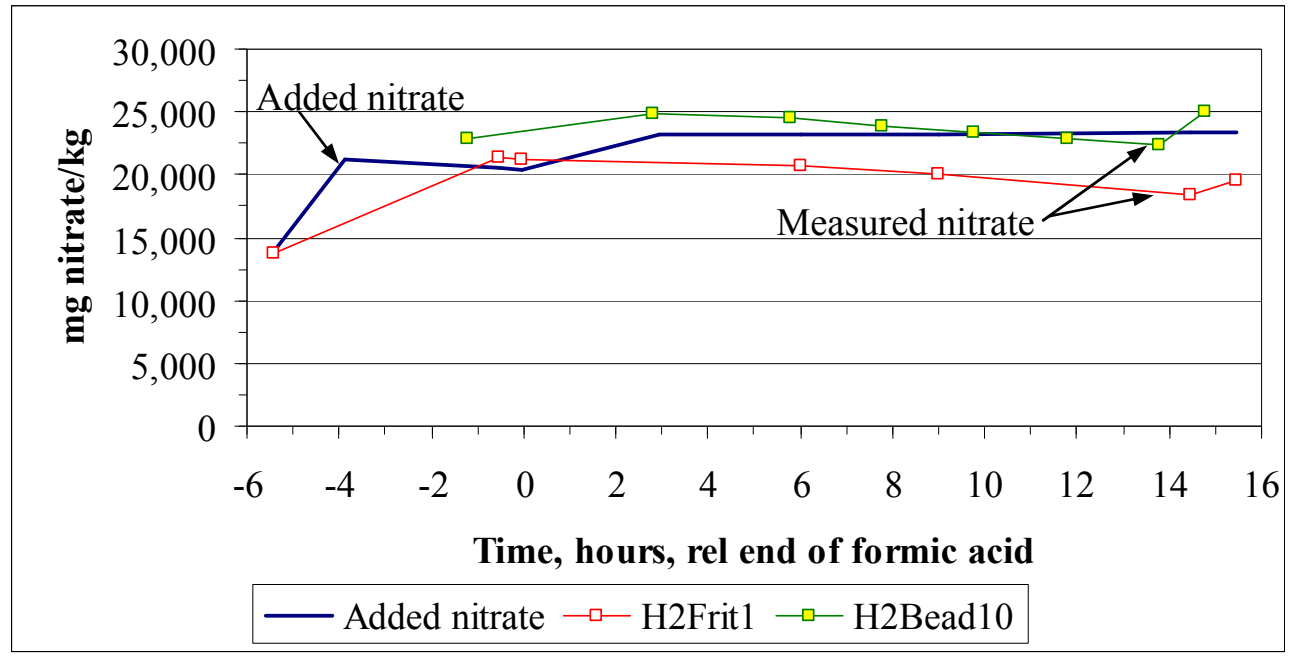

Figure 61. Nitrate concentration at $0.2 \mathrm{wt} \% \mathrm{Rh}$

The two data traces for nitrate generally parallel each other with a constant offset. Both indicate potential destruction of up to $10 \%$ of the maximum nitrate concentrations. The run offset may be due to sampling or instrument issues rather than to differences in processing chemistry. H2Fritl failed to make nitrate from nitrite according to the data, and that makes that data more suspect than the H2Bead10 data. The overall nitrite-to-nitrate conversion for H2Frit1 was $-15 \%$, since there was less nitrate in the SRAT product than was added. The overall $\mathrm{H} 2 \mathrm{Bead} 10$ result was $+4.9 \%$. These results were not interpreted to mean that nitrite did not convert to nitrate during acid addition. It appears that nitrate was actually destroyed sometime after acid addition, as seen in other run pairs, perhaps during the formation of ammonium ion. There was a point of maximum nitrate concentration associated with nitrite-to-nitrate conversion during nitrite destruction.

The FAVC condensate and the SRAT product were checked for ammonium ion concentration. The Bead10 FAVC condensate had 4,800 mg/L of ammonium ion. The Bead10 SRAT product had 98 mg/L.

\subsection{Testing with all noble metals combined}

H2Frit8 and H2Bead14 were given an initial charge of $0.1 \mathrm{wt} \% \mathrm{Ag}, \mathrm{Pd}$, and $\mathrm{Rh}$ in the trimmed sludge total solids along with $\mathrm{Ru}$ at $0.375 \mathrm{wt} \%$. In a sense, these runs are a bounding case for noble metals in SRS sludge given the unusually high noble metal concentrations and the fission yield ratio of $\mathrm{Ru}$ to $\mathrm{Rh}$ in the initial make-up. The rate of $\mathrm{CO}_{2}$ generation is plotted as a function of time in Figure 62. A vertical line marking when the mass of $\mathrm{CO}_{2}$ produced was sufficient to account for $100 \%$ destruction of the carbonate basis in the feed is also shown. It fell in a generally similar location in all of the 22-L tests (on the down-slope after the first significant maximum). 
WSRC-STI-2008-00131

Revision 0

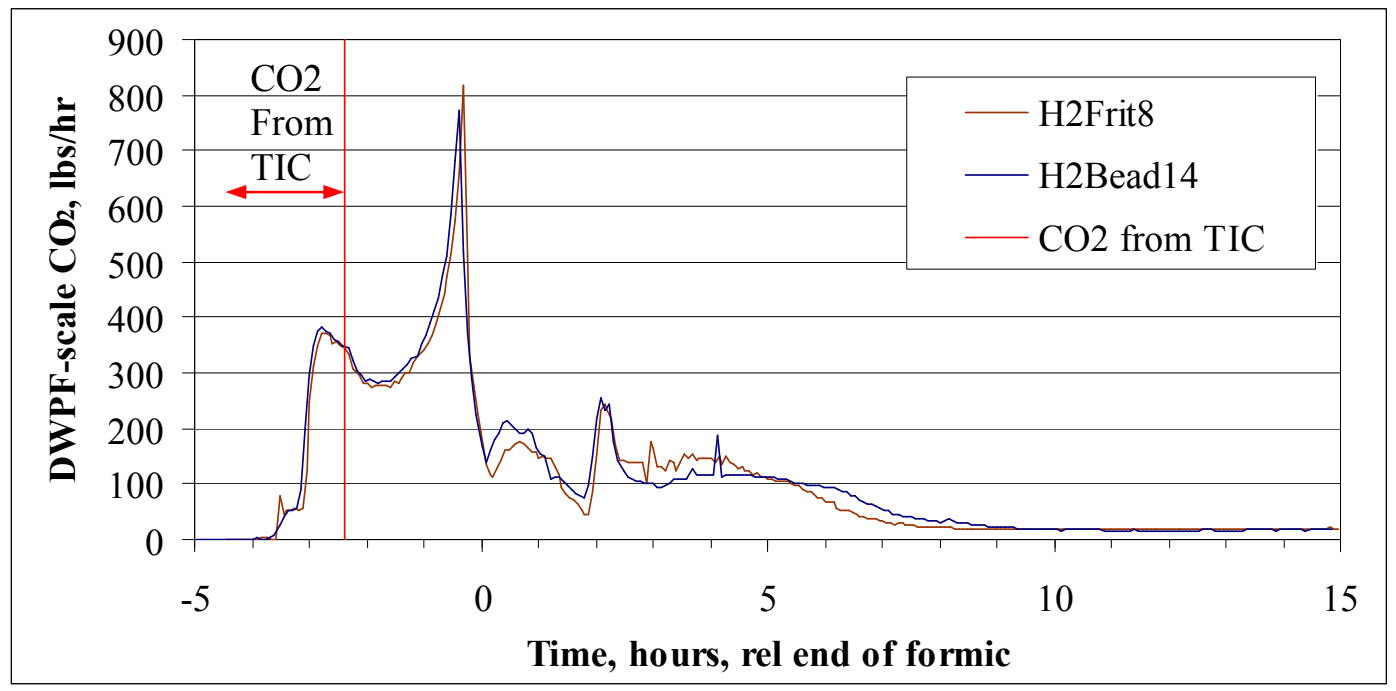

Figure 62. Rh dissolution during processing with all noble metals

The two sets of $\mathrm{CO}_{2}$ data were nearly identical. Four significant maxima were reproduced at $-3,-0.5$, +0.7 , and +2.2 hours. Integrated $\mathrm{CO}_{2}$ masses of $624 \mathrm{~g}$ and $656 \mathrm{~g}$ for $\mathrm{H} 2 \mathrm{Frit} 8$ and $\mathrm{H} 2 \mathrm{Bead} 14$ were within $5 \%$. The total mass was well above the $85 \mathrm{~g}$ from TIC destruction. The $\mathrm{CO}_{2}$ data resemble the $0.1 \mathrm{wt} \%$ $\mathrm{Rh}$ case without the other three noble metals, except that the new results show an even sharper peak just prior to the end of formic acid addition. This peak may be the combined effect of $\mathrm{Rh}$ and Pd catalyzed $\mathrm{N}_{2} \mathrm{O}$ formation. The two all noble metal data sets generally tracked through dewatering and reflux with minimal differences. These data indicate that much of the processing chemistry must have been fairly well reproduced in the two runs.

The $\mathrm{NO}$ and $\mathrm{NO}_{2}$ generation rate data for these two runs are shown in Figure 63.

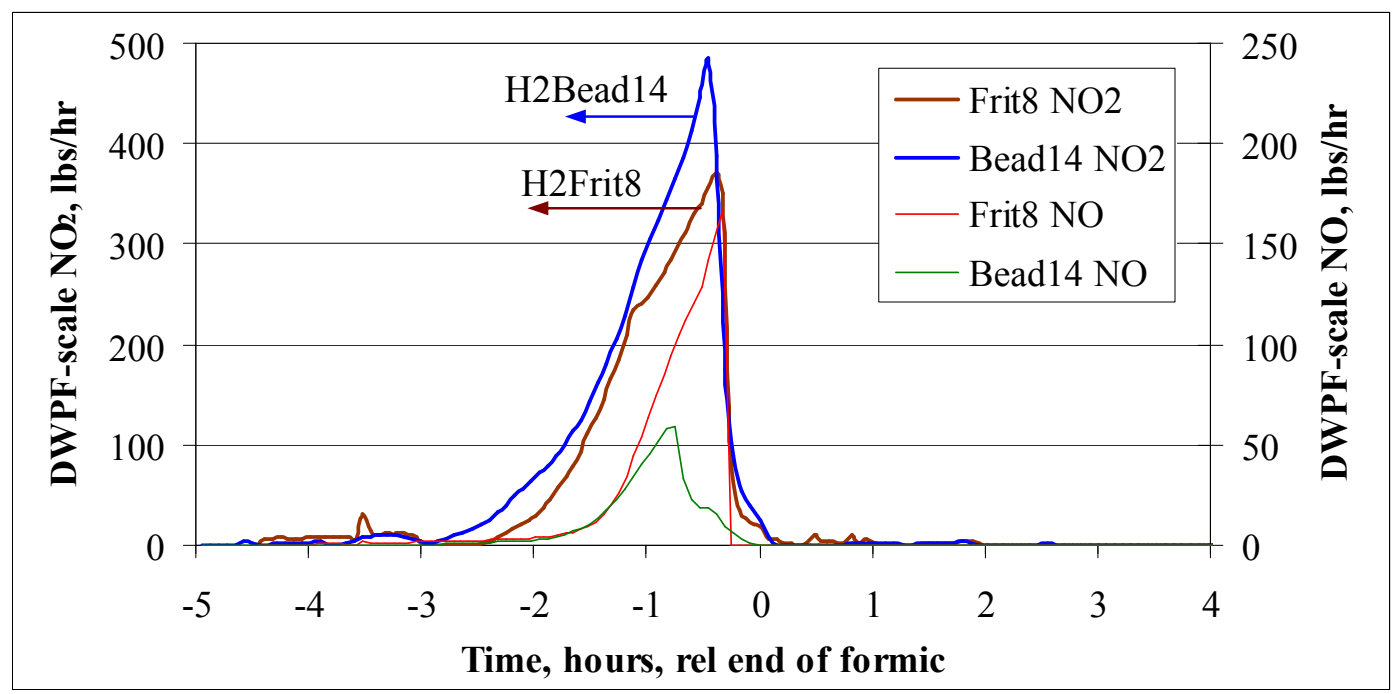

Figure 63. $\mathrm{NO}$ and $\mathrm{NO}_{2}$ generation at $0.1 \mathrm{wt} \% \mathrm{Rh}$ with other noble metals 
Here is another instance where the additional $100 \mathrm{lbs} / \mathrm{hr}$ NO made in H2Frit8 compared to H2Bead14 appears to be nearly balanced by an equivalent reduction of about $130 \mathrm{lbs} / \mathrm{hr}$ in the $\mathrm{NO}_{2}$ made by $\mathrm{H} 2 \mathrm{Frit}$. The two totals of $\mathrm{NO}+\mathrm{NO}_{2}$ produced in the two runs were 3.56 and 3.52 moles respectively. The data sets for $\mathrm{N}_{2} \mathrm{O}$ are given in Figure 64.

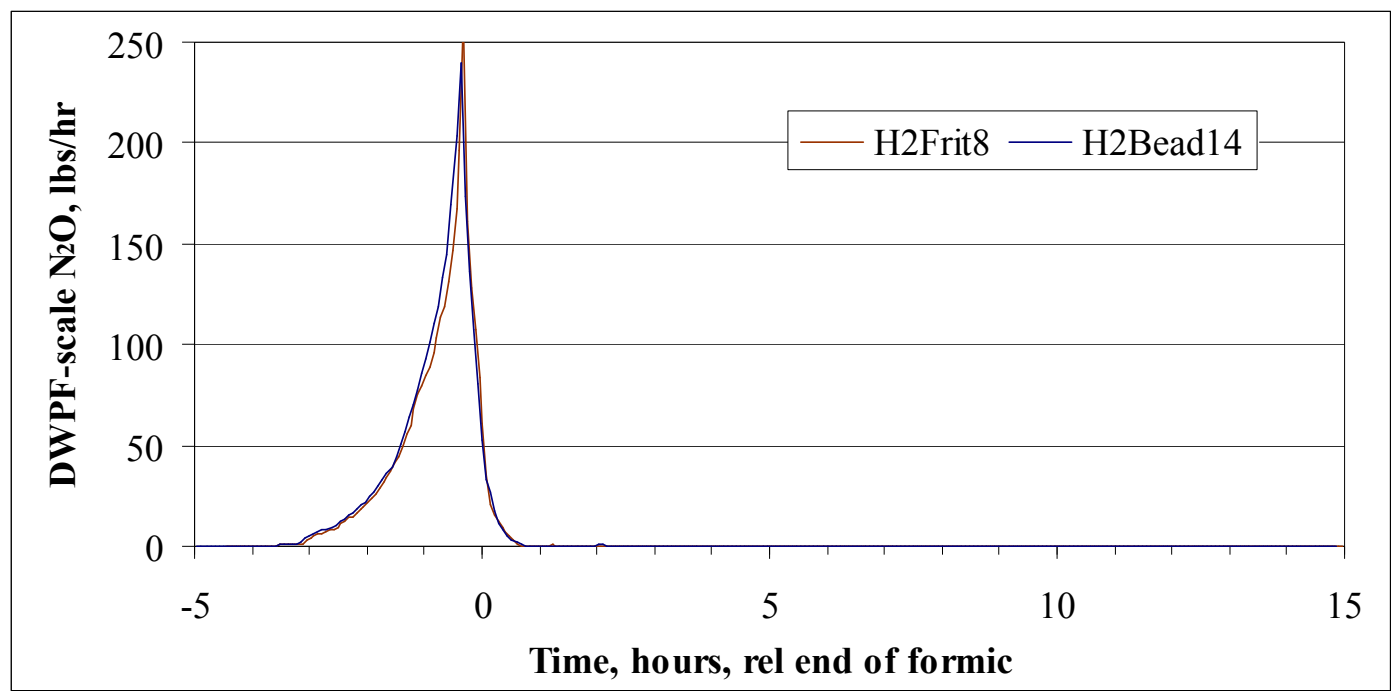

Figure 64. $\mathrm{N}_{2} \mathrm{O}$ generation at $0.1 \mathrm{wt} \% \mathrm{Rh}$ with other noble metals

The $\mathrm{N}_{2} \mathrm{O}$ data are virtually identical. The spike matches one in the $\mathrm{CO}_{2}$ data. $\mathrm{H} 2 \mathrm{Frit} 8$ and $\mathrm{H} 2 \mathrm{Bead} 14$ had virtually identical $\mathrm{CO}_{2}, \mathrm{~N}_{2} \mathrm{O}$, and $\mathrm{NO}+\mathrm{NO}_{2}$ generation rate profiles, which implies that the chemistry occurring in these two runs was also nearly identical. Data on formate ion concentration shows that these two runs were extreme in terms of formate destruction, Figure 65.

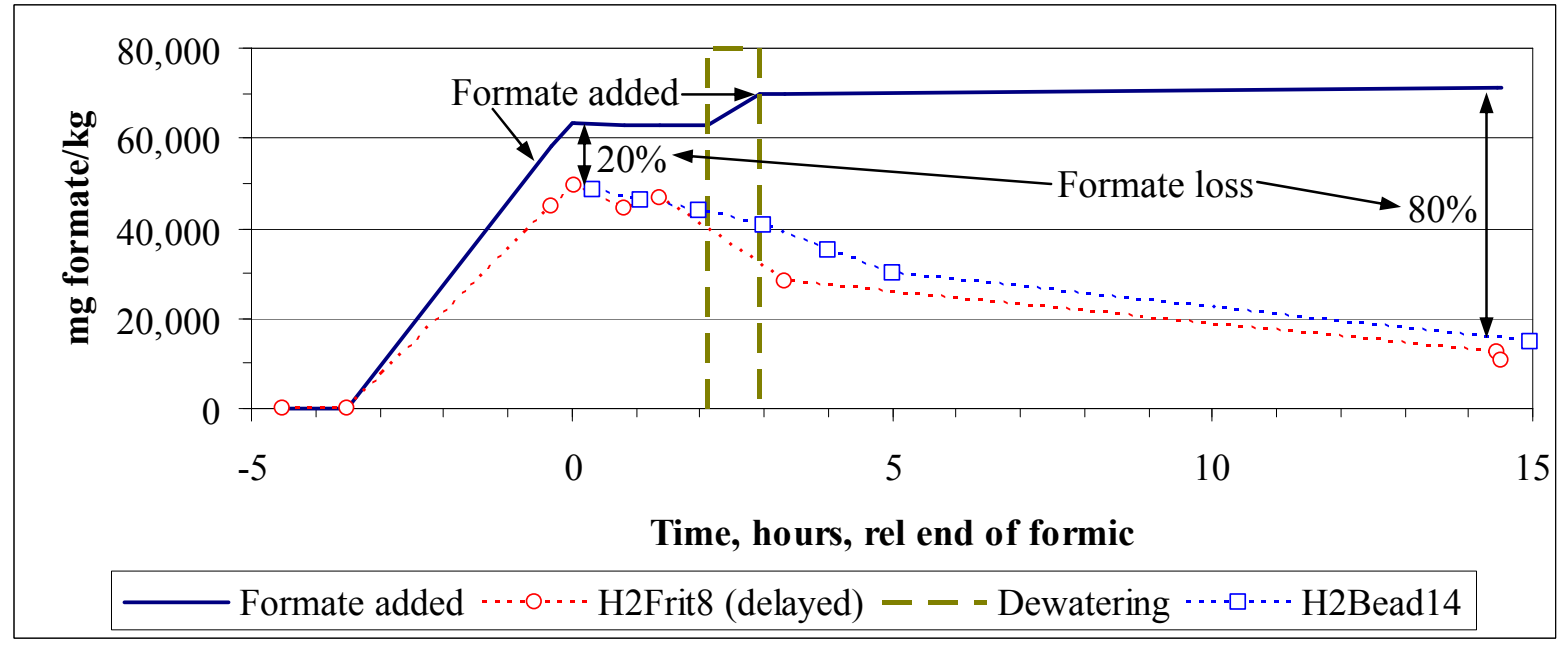

Figure 65. Formate changes at $0.1 \mathrm{wt} \% \mathrm{Rh}$ with other noble metals

Formate was nearly $20 \%$ destroyed before formic acid addition was complete, and the final calculated formate losses were $85 \%$ and $79 \%$ for $\mathrm{H} 2 \mathrm{Frit} 8$ and $\mathrm{H} 2 \mathrm{Bead} 14$ respectively. The relationship between formate concentration and hydrogen generation is shown in Figure 66. 


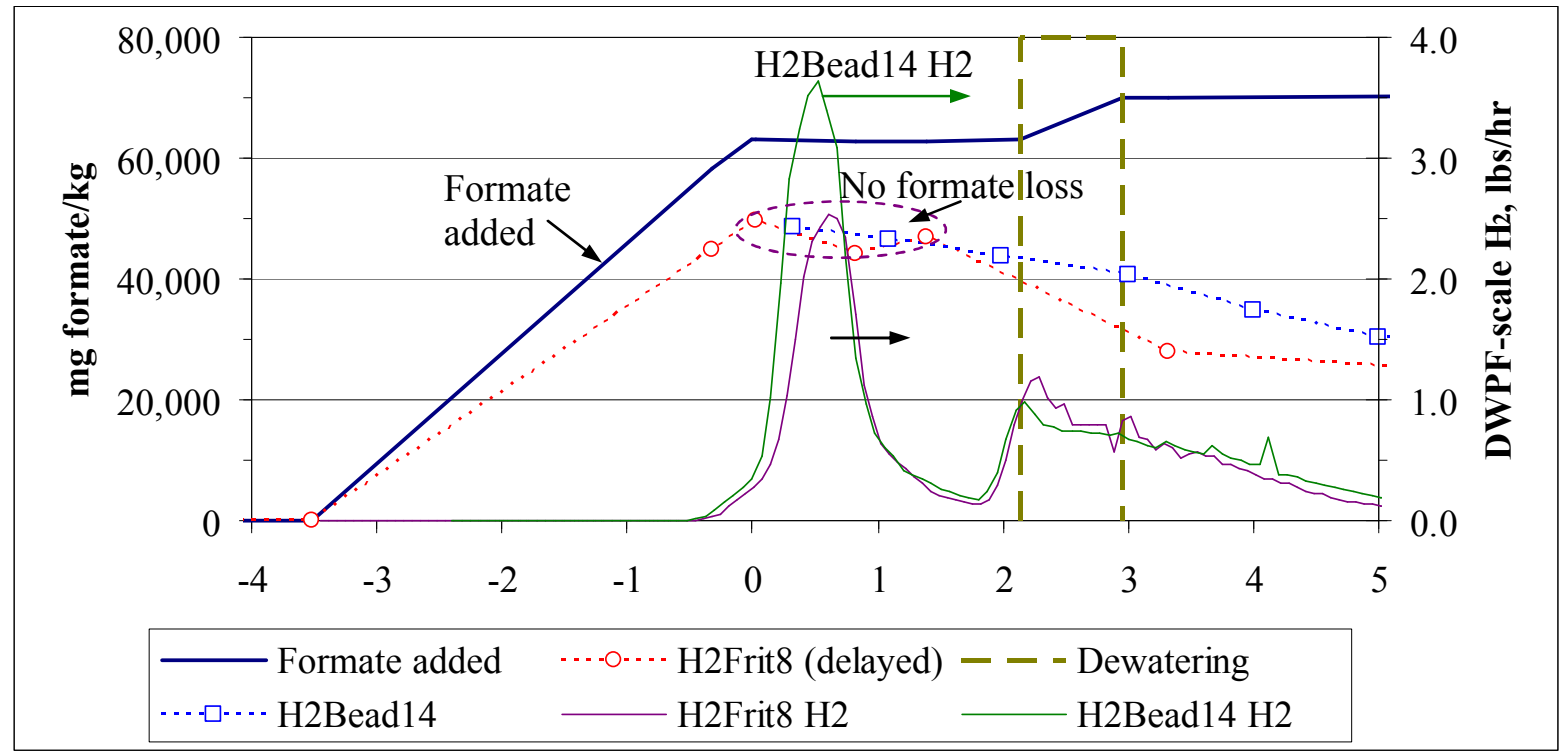

Figure 66. Formate and hydrogen with all noble metals

The primary hydrogen generation rate maxima at +0.5 hours were $4-6$ times the DWPF SRAT limit. In spite of the relative magnitude of the two maxima compared to ordinary SRAT flowsheet tests, there was only a small loss in measured formate ion concentration during this period. The loss in the formate reactant does not seem to be sufficient to account for the large drop in hydrogen generation rate, but it is consistent with the amount of formate destroyed in making the hydrogen. Nitrate ion concentration also exhibited some extreme behavior during these two runs, Figure 67.

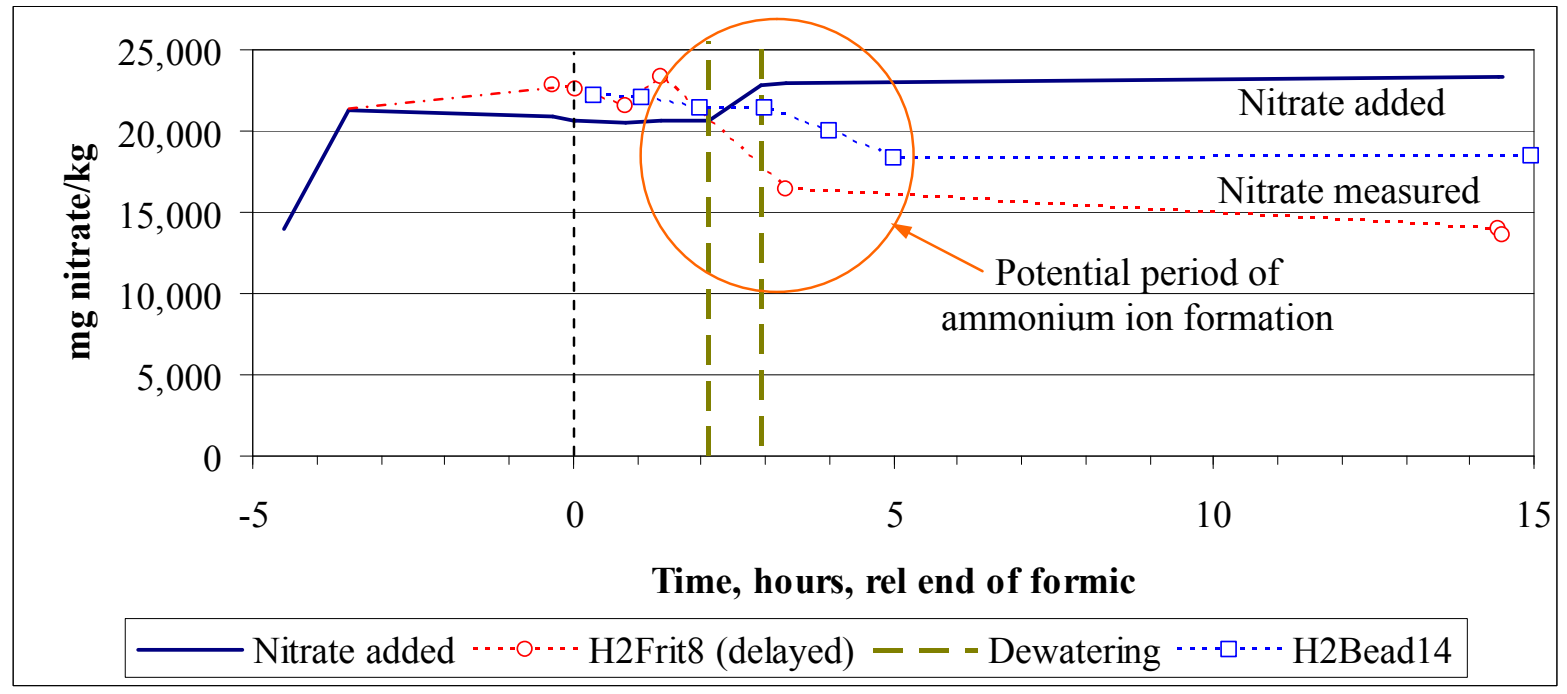

Figure 67. Nitrate concentration at $0.1 \mathrm{wt} \% \mathrm{Rh}$ with other noble metals

After an initial gain in nitrate concentration around the end of acid addition, some reaction(s) began which consumed nitrate ion. Production of $\mathrm{NO}, \mathrm{NO}_{2}$, and $\mathrm{N}_{2} \mathrm{O}$ appeared to have stopped by +0.5 hours which was before the primary nitrate loss occurred. Both runs had a negative overall SRAT nitrite-to- 
nitrate conversion due to subsequent nitrate destruction. Reproducibility of the IC data was not as good as for the GC data, but the GC data suggest that the runs were more similar than the IC anion data indicates. A result of $1,440 \mathrm{mg} / \mathrm{kg}$ ammonium was reported on the H2Frit8 SRAT product and a result of $193 \mathrm{mg} / \mathrm{L}$ was reported on the H2Bead14 SRAT product. Different approaches were taken in obtaining these two IC cation results, but the potential impact on the reported ammonium ion concentration is not known. The FAVC condensate accumulated during the H2Bead14 SRAT cycle had a reported 47,600 $\mathrm{mg} / \mathrm{L}$ of ammonium ion. It appears that some of the destroyed nitrate was converted into ammonium ion.

The $\mathrm{pH}$ data for these runs was problematic. $\mathrm{H} 2 \mathrm{Bead} 14$ started with a used $\mathrm{pH}$ probe that was several $\mathrm{pH}$ units out of calibration by the end of the SME cycle, while H2Frit8 had communication problems between the probe and the PC data acquisition system. Such $\mathrm{pH}$ data as could be salvaged from the manually logged sheets and eventually from the data acquisition system for H2Frit8 were integrated together and are given in Figure 68.

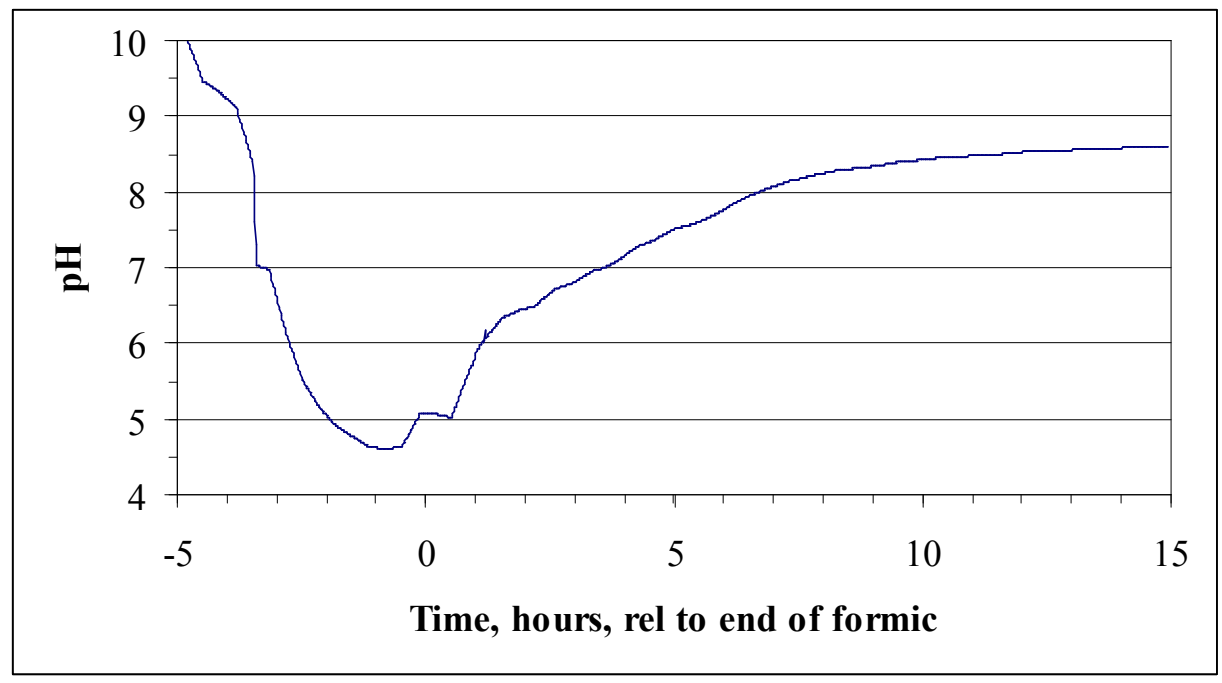

Figure 68. The pH data for $\mathrm{H} 2 \mathrm{Frit8}$ with all noble metals

The $\mathrm{pH}$ data through the end of acid addition and into dewatering are not that unlike the data for $0.1 \mathrm{wt} \%$ $\mathrm{Rh}$ without other noble metals. The drift to higher $\mathrm{pH}$ 's during boiling, however, ended at about $\mathrm{pH} 8.5$ by the end of reflux.

\subsection{Closing Remarks on SRAT Data}

Very significant differences were observed in the eight pairs of runs as well as in the one run with $\mathrm{Hg}$. In spite of the differences there were also some significant similarities such as nitrite destruction by shortly after the end of acid addition, extensive dissolution of $\mathrm{Mg}$ and $\mathrm{Ca}$ during the middle of acid addition along with the destruction of carbonate, and the delaying of significant formate destruction until near the final hour of acid addition. Some cationic species $(\mathrm{Ni}, \mathrm{Zn}, \mathrm{Cu})$ with strongly $\mathrm{pH}$ dependent solubilities showed a range of maximum solubility during the SRAT indicative of both the $\mathrm{pH}$ dependence and what appeared to be a rate limited dissolution of the insoluble hydroxide starting form that prevented complete dissolution even when the $\mathrm{pH}$ may have been low enough to allow it.

The analysis of chemistry during acid addition was complicated by the variability of the MasterFlex pumps feeding the formic acid. The pumps gave a small range of formic acid addition times, but the range was enough to distort some of the off-gas generation rate profiles. Converting the time axis into a 
WSRC-STI-2008-00131

Revision 0

moles of acid added axis would eliminate this effect. Plots were made for Section 5.0 where the SRAT data was broken down into a chemical reaction timeline.

Data reproducibility did not appear to be a major issue between the runs in any given pair; however the performance of the M200H GC did not appear to be generally comparable to the 3000A GC's. The $\mathrm{M} 200 \mathrm{H}$ unit is older and was clearly verging on some sort of mechanical failure during the four oddnumbered frit runs. Even the better quality $\mathrm{M} 200 \mathrm{H}$ data appeared to be noisier than equivalent 3000A data, which could signify a failing or fluctuating injection system and/or detector. 
WSRC-STI-2008-00131

Revision 0

This page intentionally left blank. 


\subsection{Summary of SRAT and SME Product Properties}

The main purpose of the sixteen 22-L SRAT/SME simulations was the preparation of eight SME products with regular frit 418 and eight matching SME products with beaded frit 418 for comparison tests. This section presents the measured properties of the sixteen SRAT and SME products, summarizes calculated anion conversion factors, and gives the results of some material balance calculations across the entire SRAT cycle.

Since the eight frit SME products are to be blended together, as are the eight bead SME products, it was relevant to project what the average noble metal concentrations of a composite starting sludge would have been, i.e. if the eight differently trimmed starting sludges had been combined prior to SRAT processing. The resulting noble metal concentrations were calculated and incorporated into Table 6 along with some selected data from previous sludge batches.

Table 6. Composite Blend Sludge Noble Metal Concentrations

\begin{tabular}{|l|c|c|c|c|}
\hline & $\mathrm{Ag}$ & $\mathrm{Pd}$ & $\mathrm{Rh}$ & $\mathrm{Ru}$ \\
\hline Bead-frit blend, wt $\%$ & 0.0375 & 0.0375 & 0.0500 & 0.1188 \\
\hline Sludge Batch $4, \mathrm{wt} \%$ & 0.0099 & 0.0012 & 0.0084 & 0.0313 \\
\hline Sludge Batch $3, \mathrm{wt} \%$ & 0.0100 & 0.0012 & 0.0074 & 0.0340 \\
\hline Sludge Batch $2, \mathrm{wt} \%$ & 0.0106 & 0.0009 & 0.0078 & 0.0332 \\
\hline HM design basis, wt\% & 0.0140 & 0.0790 & 0.0380 & 0.2170 \\
\hline
\end{tabular}

The table shows that, although individual runs had noble metal concentrations that were more than an order of magnitude larger than recent sludge batches, the resulting overall blend of noble metals corresponded to more mildly elevated concentrations, except for palladium. Also, the relative fission yield gives $\mathrm{Ru}>\mathrm{Rh}>\mathrm{Pd}$, and this general ranking was retained in the composite blend.

\subsection{SRAT Product Data and Results}

The sixteen 22-L SRAT products were sampled, calcined at $1100^{\circ} \mathrm{C}$, and analyzed for elemental composition. The next two tables give the results for the frit run products, Table 7 , and the bead run products, Table 8 . 
WSRC-STI-2008-00131

Revision 0

Table 7. Calcined Elemental wt\% of Frit SRAT Products

\begin{tabular}{|l|c|c|c|c|c|c|c|c|}
\hline & H2Frit1 & H2Frit2 & H2Frit3 & H2Frit4 & H2Frit5 & H2Frit6 & H2Frit7 & H2Frit8 \\
\hline $\mathrm{Al}$ & 16.0 & 16.1 & 15.9 & 15.8 & 15.7 & 15.5 & 15.7 & 15.5 \\
\hline $\mathrm{Ba}$ & 0.225 & 0.225 & 0.225 & 0.224 & 0.224 & 0.222 & 0.220 & 0.210 \\
\hline $\mathrm{Ca}$ & 2.66 & 2.62 & 2.38 & 2.39 & 2.37 & 2.40 & 2.66 & 2.64 \\
\hline $\mathrm{Cr}$ & 0.187 & 0.158 & 0.161 & 0.157 & 0.165 & 0.153 & 0.150 & 0.147 \\
\hline $\mathrm{Cu}$ & 0.089 & 0.053 & 0.086 & 0.072 & 0.096 & 0.084 & 0.090 & 0.088 \\
\hline $\mathrm{Fe}$ & 22.6 & 22.2 & 22.6 & 22.2 & 21.5 & 20.8 & 21.1 & 21.3 \\
\hline $\mathrm{K}$ & 0.221 & 0.196 & 0.250 & 0.254 & 0.166 & 0.233 & 0.272 & 0.201 \\
\hline $\mathrm{Mg}$ & 1.85 & 1.79 & 1.82 & 1.80 & 1.56 & 1.61 & 1.54 & 1.60 \\
\hline $\mathrm{Mn}$ & 4.00 & 3.88 & 3.93 & 3.87 & 3.79 & 3.74 & 3.58 & 3.69 \\
\hline $\mathrm{Na}$ & 12.9 & 12.9 & 13.2 & 13.0 & 12.3 & 12.5 & 13.7 & 12.7 \\
\hline $\mathrm{Ni}$ & 0.91 & 1.02 & 1.03 & 1.02 & 0.91 & 0.89 & 0.83 & 0.83 \\
\hline $\mathrm{P}$ & 0.028 & 0.028 & 0.030 & 0.036 & 0.042 & 0.044 & 0.039 & 0.040 \\
\hline $\mathrm{Pb}$ & 0.037 & 0.054 & 0.058 & 0.051 & 0.054 & 0.039 & 0.051 & 0.044 \\
\hline $\mathrm{S}$ & 0.310 & 0.320 & 0.318 & 0.305 & 0.282 & 0.273 & 0.294 & 0.284 \\
\hline $\mathrm{Si}$ & 1.88 & 1.75 & 1.80 & 1.77 & 1.76 & 1.67 & 1.64 & 1.66 \\
\hline $\mathrm{Ti}$ & 0.019 & 0.019 & 0.020 & 0.019 & 0.019 & 0.018 & 0.018 & 0.021 \\
\hline $\mathrm{Zn}$ & 0.218 & 0.220 & 0.223 & 0.220 & 0.220 & 0.209 & 0.211 & 0.203 \\
\hline $\mathrm{Zr}$ & 0.458 & 0.466 & 0.472 & 0.352 & 0.485 & 0.494 & 0.463 & 0.467 \\
\hline
\end{tabular}

Table 8. Calcined Elemental wt\% of Bead SRAT Products

\begin{tabular}{|l|c|c|c|c|c|c|c|c|}
\hline & Bead9 & Bead10 & Bead11 & Bead12 & Bead13 & Bead14 & Bead15 & Bead16 \\
\hline $\mathrm{Al}$ & 15.8 & 15.9 & 16.0 & 15.9 & 15.8 & 16.0 & 15.5 & 15.7 \\
\hline $\mathrm{Ba}$ & 0.211 & 0.205 & 0.200 & 0.203 & 0.201 & 0.205 & 0.205 & 0.202 \\
\hline $\mathrm{Ca}$ & 2.34 & 2.34 & 2.41 & 2.44 & 2.40 & 2.47 & 2.43 & 2.44 \\
\hline $\mathrm{Cr}$ & 0.152 & 0.144 & 0.145 & 0.145 & 0.146 & 0.150 & 0.148 & 0.145 \\
\hline $\mathrm{Cu}$ & 0.054 & 0.078 & 0.085 & 0.066 & 0.148 & 0.153 & 0.080 & 0.081 \\
\hline $\mathrm{Fe}$ & 22.3 & 22.4 & 22.3 & 22.6 & 23.0 & 23.0 & 22.7 & 22.8 \\
\hline $\mathrm{K}$ & 0.241 & 0.223 & 0.243 & 0.157 & 0.186 & 0.131 & 0.240 & 0.232 \\
\hline $\mathrm{Mg}$ & 1.81 & 1.86 & 1.84 & 1.84 & 1.89 & 1.93 & 1.88 & 1.90 \\
\hline $\mathrm{Mn}$ & 3.86 & 3.95 & 3.89 & 3.96 & 4.01 & 4.10 & 3.98 & 4.08 \\
\hline $\mathrm{Na}$ & 13.2 & 13.0 & 13.6 & 12.9 & 13.3 & 12.8 & 13.9 & 13.3 \\
\hline $\mathrm{Ni}$ & 1.01 & 1.02 & 1.02 & 1.03 & 1.06 & 1.06 & 1.05 & 1.05 \\
\hline $\mathrm{Pb}$ & 0.027 & $<0.02$ & 0.025 & $<0.02$ & 0.022 & 0.029 & 0.030 & $<0.02$ \\
\hline $\mathrm{S}$ & 0.299 & 0.290 & 0.285 & 0.286 & 0.283 & 0.282 & 0.292 & 0.271 \\
\hline $\mathrm{Si}$ & 1.78 & 1.76 & 1.77 & 1.76 & 1.78 & 1.81 & 1.79 & 1.80 \\
\hline $\mathrm{Ti}$ & 0.018 & 0.017 & 0.017 & 0.017 & 0.017 & 0.017 & 0.017 & 0.017 \\
\hline $\mathrm{Zn}$ & 0.204 & 0.200 & 0.194 & 0.198 & 0.197 & 0.201 & 0.198 & 0.195 \\
\hline $\mathrm{Zr}$ & 0.463 & 0.440 & 0.455 & 0.457 & 0.446 & 0.470 & 0.470 & 0.468 \\
\hline
\end{tabular}

SRAT products were also analyzed for wt $\%$ solids, density, and anion concentrations. The next two tables present the results for the eight frit runs, Table 9, and eight bead runs, Table 10. 
WSRC-STI-2008-00131

Revision 0

Table 9. Solids and Anion Data for Frit SRAT Products

\begin{tabular}{|l|c|c|c|c|c|c|c|c|}
\hline & Frit1 & Frit2 & Frit3 & Frit4 & Frit5 & Frit6 & Frit7 & Frit8 \\
\hline $\mathrm{wt} \% \mathrm{TS}$ & $24.4 \%$ & $25.7 \%$ & $26.2 \%$ & $25.8 \%$ & $25.1 \%$ & $24.8 \%$ & $25.8 \%$ & $23.7 \%$ \\
\hline $\mathrm{wt} \% \mathrm{IS}$ & $16.7 \%$ & $14.6 \%$ & $15.0 \%$ & $15.0 \%$ & $15.5 \%$ & $16.3 \%$ & $14.5 \%$ & $17.6 \%$ \\
\hline $\mathrm{wt} \% \mathrm{SS}$ & $7.7 \%$ & $11.1 \%$ & $11.2 \%$ & $10.8 \%$ & $9.5 \%$ & $8.5 \%$ & $11.2 \%$ & $6.1 \%$ \\
\hline $\mathrm{wt} \% \mathrm{CS}$ & $16.2 \%$ & $16.1 \%$ & $16.0 \%$ & $16.2 \%$ & $15.9 \%$ & $16.1 \%$ & $15.8 \%$ & $16.0 \%$ \\
\hline Slurry, g/mL & 1.177 & 1.181 & 1.173 & 1.182 & 1.178 & 1.158 & 1.184 & 1.164 \\
\hline Supernate, $\mathrm{g} / \mathrm{mL}$ & 1.054 & 1.085 & 1.093 & 1.086 & 1.076 & 1.062 & 1.091 & 1.056 \\
\hline Formate, $\mathrm{mg} / \mathrm{kg}$ & 27,800 & 31,200 & 60,100 & 54,600 & 51,400 & 40,500 & 60,200 & 10,600 \\
\hline Nitrate. $\mathrm{mg} / \mathrm{kg}$ & 19,600 & 24,200 & 26,100 & 22,300 & 23,200 & 24,400 & 27,000 & 13,600 \\
\hline Chloride, $\mathrm{mg} / \mathrm{kg}$ & 400 & 820 & 250 & 340 & 1310 & 370 & 320 & 1350 \\
\hline Oxalate, $\mathrm{mg} / \mathrm{kg}$ & 130 & 120 & 1500 & 820 & $<100$ & $<100$ & 530 & 730 \\
\hline
\end{tabular}

Table 10. Solids and Anion Data for Bead SRAT Products

\begin{tabular}{|l|c|c|c|c|c|c|c|c|}
\hline & Bead9 & Bead10 & Bead11 & Bead12 & Bead13 & Bead14 & Bead15 & Bead16 \\
\hline $\mathrm{wt} \% \mathrm{TS}$ & $26.0 \%$ & $24.7 \%$ & $25.9 \%$ & $25.1 \%$ & $25.2 \%$ & $24.0 \%$ & $25.1 \%$ & $24.6 \%$ \\
\hline $\mathrm{wt} \% \mathrm{IS}$ & $15.0 \%$ & $16.7 \%$ & $14.5 \%$ & $15.8 \%$ & $15.1 \%$ & $17.9 \%$ & $14.5 \%$ & $16.4 \%$ \\
\hline $\mathrm{wt} \% \mathrm{SS}$ & $11.0 \%$ & $8.0 \%$ & $11.3 \%$ & $9.4 \%$ & $10.1 \%$ & $6.2 \%$ & $10.6 \%$ & $8.2 \%$ \\
\hline $\mathrm{wt} \% \mathrm{CS}$ & $15.8 \%$ & $16.0 \%$ & $15.8 \%$ & $15.8 \%$ & $15.6 \%$ & $16.0 \%$ & $14.9 \%$ & $15.9 \%$ \\
\hline Density, $\mathrm{g} / \mathrm{mL}$ & 1.19 & 1.17 & 1.19 & 1.17 & 1.18 & 1.17 & 1.17 & 1.17 \\
\hline Formate, $\mathrm{mg} / \mathrm{kg}$ & 62,450 & 36,300 & 65,050 & 46,150 & 53,850 & 14,850 & 53,400 & 33,650 \\
\hline Nitrate. $\mathrm{mg} / \mathrm{kg}$ & 29,000 & 25,000 & 22,350 & 22,350 & 24,300 & 18,400 & 21,500 & 19,450 \\
\hline Chloride, $\mathrm{mg} / \mathrm{kg}$ & 304 & 433 & 383 & 1,430 & 987 & 1,430 & 355 & 380 \\
\hline Oxalate, $\mathrm{mg} / \mathrm{kg}$ & 1,061 & $<100$ & 1,925 & $<1000$ & $<1000$ & $<1000$ & $<1000$ & $<1000$ \\
\hline
\end{tabular}

Supernate density was not measured for the bead SRAT products, since a single reasonable value was available from the frit SRAT products for each case. That was all that was needed to perform solubility calculations for each starting noble metal composition. Chloride ion provided a way to track the samples from the three pairs of runs with $\mathrm{RuCl}_{3}$ additions.

\subsection{SME Product Data and Results}

SME product ICP-AES data for calcined elementals at $1100^{\circ} \mathrm{C}$ for the eight runs with frit 418 are given in Table 11. 
WSRC-STI-2008-00131

Revision 0

Table 11. Calcined Elemental wt\% of Frit SME Products

\begin{tabular}{|l|c|c|c|c|c|c|c|c|}
\hline & H2Frit1 & H2Frit2 & H2Frit3. & H2Frit4 & H2Frit5 & H2Frit6 & H2Frit7 & H2Frit8 \\
\hline $\mathrm{Al}$ & 5.83 & 5.92 & 5.85 & 5.75 & 5.67 & 5.58 & 5.73 & 5.71 \\
\hline $\mathrm{B}$ & 1.35 & 1.37 & 1.35 & 1.37 & 1.35 & 1.37 & 1.33 & 1.43 \\
\hline $\mathrm{Ba}$ & 0.083 & 0.084 & 0.084 & 0.083 & 0.083 & 0.082 & 0.083 & 0.080 \\
\hline $\mathrm{Ca}$ & 0.818 & 0.816 & 0.840 & 0.833 & 0.793 & 0.789 & 0.798 & 0.777 \\
\hline $\mathrm{Cr}$ & 0.065 & 0.066 & 0.073 & 0.060 & 0.067 & 0.067 & 0.065 & 0.064 \\
\hline $\mathrm{Cu}$ & 0.041 & 0.068 & 0.041 & 0.037 & 0.043 & 0.036 & 0.045 & 0.044 \\
\hline $\mathrm{Fe}$ & 7.95 & 8.05 & 8.09 & 8.03 & 7.83 & 7.78 & 7.43 & 8.04 \\
\hline $\mathrm{K}$ & n.a. & 0.129 & 0.137 & 0.148 & 0.131 & 0.135 & 0.140 & 0.147 \\
\hline $\mathrm{Li}$ & 2.23 & 2.23 & 2.20 & 2.22 & 2.14 & 2.14 & 2.22 & 2.24 \\
\hline $\mathrm{Mg}$ & 0.603 & 0.625 & 0.619 & 0.607 & 0.606 & 0.580 & 0.591 & 0.582 \\
\hline $\mathrm{Mn}$ & 1.39 & 1.41 & 1.38 & 1.42 & 1.26 & 1.27 & 1.18 & 1.23 \\
\hline $\mathrm{Na}$ & 8.55 & 8.48 & 8.71 & 8.84 & 8.59 & 8.48 & 8.71 & 8.83 \\
\hline $\mathrm{Ni}$ & 0.324 & 0.339 & 0.323 & 0.319 & 0.322 & 0.312 & 0.315 & 0.319 \\
\hline $\mathrm{P}$ & 0.014 & 0.014 & 0.014 & 0.016 & 0.018 & 0.018 & 0.019 & 0.016 \\
\hline $\mathrm{Pb}$ & 0.029 & 0.030 & 0.033 & 0.027 & 0.028 & 0.027 & 0.026 & 0.024 \\
\hline $\mathrm{S}$ & 0.101 & 0.106 & 0.105 & 0.096 & 0.092 & 0.097 & 0.092 & 0.088 \\
\hline $\mathrm{Si}$ & 23.95 & 24 & 24.1 & 24.2 & 23.5 & 23.65 & 23.85 & 24.4 \\
\hline $\mathrm{Ti}$ & 0.045 & 0.048 & 0.043 & 0.045 & 0.043 & 0.043 & 0.043 & 0.042 \\
\hline $\mathrm{Zn}$ & 0.081 & 0.079 & 0.079 & 0.082 & 0.078 & 0.077 & 0.084 & 0.075 \\
\hline $\mathrm{Zr}$ & 0.265 & 0.276 & 0.265 & 0.265 & 0.269 & 0.256 & 0.261 & 0.255 \\
\hline
\end{tabular}

SME product ICP-AES data for calcined elementals at $1100^{\circ} \mathrm{C}$ for the eight runs with bead 410 are given in Table 12. 
WSRC-STI-2008-00131

Revision 0

Table 12. Calcined Elemental wt\% of Bead SME Products

\begin{tabular}{|l|c|c|c|c|c|c|c|c|}
\hline & Bead9 & Bead10 & Bead11 & Bead12 & Bead13 & Bead14 & Bead15 & Bead16 \\
\hline $\mathrm{Al}$ & 5.70 & 5.81 & 5.78 & 5.75 & 5.73 & 5.47 & 5.61 & 5.72 \\
\hline $\mathrm{B}$ & 1.38 & 1.36 & 1.31 & 1.35 & 1.34 & 1.29 & 1.36 & 1.29 \\
\hline $\mathrm{Ba}$ & 0.075 & 0.073 & 0.073 & 0.072 & 0.072 & 0.072 & 0.074 & 0.070 \\
\hline $\mathrm{Ca}$ & 0.755 & 0.777 & 0.753 & 0.765 & 0.878 & 0.902 & 0.869 & 0.892 \\
\hline $\mathrm{Cr}$ & 0.061 & 0.060 & 0.061 & 0.059 & 0.059 & 0.059 & 0.061 & 0.060 \\
\hline $\mathrm{Cu}$ & 0.030 & 0.036 & 0.045 & 0.031 & 0.054 & 0.053 & 0.040 & 0.042 \\
\hline $\mathrm{Fe}$ & 7.93 & 7.89 & 8.04 & 8.04 & 8.06 & 8.26 & 8.05 & 8.05 \\
\hline $\mathrm{K}$ & 0.129 & 0.132 & 0.128 & 0.127 & 0.131 & 0.158 & 0.127 & 0.136 \\
\hline $\mathrm{Li}$ & 2.20 & 2.25 & 2.18 & 2.23 & 2.21 & 2.15 & 2.21 & 2.21 \\
\hline $\mathrm{Mg}$ & 0.637 & 0.644 & 0.633 & 0.658 & 0.658 & 0.682 & 0.657 & 0.663 \\
\hline $\mathrm{Mn}$ & 1.39 & 1.41 & 1.39 & 1.43 & 1.44 & 1.45 & 1.40 & 1.44 \\
\hline $\mathrm{Na}$ & 8.39 & 8.65 & 8.52 & 8.38 & 8.63 & 8.92 & 8.76 & 8.85 \\
\hline $\mathrm{Ni}$ & 0.368 & 0.374 & 0.370 & 0.377 & 0.378 & 0.383 & 0.375 & 0.378 \\
\hline $\mathrm{Pb}$ & 0.024 & 0.023 & 0.023 & 0.023 & 0.023 & 0.022 & 0.022 & \\
\hline $\mathrm{S}$ & 0.078 & 0.075 & 0.088 & 0.086 & 0.095 & 0.087 & 0.096 & 0.091 \\
\hline $\mathrm{Si}$ & 24.2 & 24.3 & 24.1 & 24.5 & 24.7 & 24.5 & 23.3 & 22.7 \\
\hline $\mathrm{Ti}$ & 0.037 & 0.036 & 0.035 & 0.036 & 0.036 & 0.036 & 0.036 & 0.035 \\
\hline $\mathrm{Zn}$ & 0.072 & 0.071 & 0.070 & 0.069 & 0.068 & 0.069 & 0.070 & 0.068 \\
\hline $\mathrm{Zr}$ & 0.246 & 0.241 & 0.240 & 0.242 & 0.241 & 0.242 & 0.238 & 0.232 \\
\hline
\end{tabular}

Samples of SME product were analyzed for wt $\%$ solids, density, and anion concentration. The next two tables present results for the frit runs, Table 13, and bead runs, Table 14.

Table 13. Solids and Anion Data for Frit SME Products

\begin{tabular}{|l|c|c|c|c|c|c|c|c|}
\hline & Frit1 & Frit2 & Frit3 & Frit4 & Frit5 & Frit6 & Frit7 & Frit8 \\
\hline $\mathrm{wt} \% \mathrm{TS}$ & $47.3 \%$ & $49.8 \%$ & $50.0 \%$ & $49.9 \%$ & $49.1 \%$ & $48.6 \%$ & $49.7 \%$ & $48.2 \%$ \\
\hline $\mathrm{wt} \% \mathrm{IS}$ & $41.0 \%$ & $40.1 \%$ & $39.3 \%$ & $39.8 \%$ & $41.5 \%$ & $41.0 \%$ & $39.4 \%$ & $43.1 \%$ \\
\hline $\mathrm{wt} \% \mathrm{SS}$ & $6.3 \%$ & $9.7 \%$ & $10.7 \%$ & $10.1 \%$ & $7.6 \%$ & $7.6 \%$ & $10.3 \%$ & $5.2 \%$ \\
\hline $\mathrm{wt} \% \mathrm{CS}$ & $40.2 \%$ & $41.2 \%$ & $40.7 \%$ & $41.0 \%$ & $41.4 \%$ & $40.7 \%$ & $40.4 \%$ & $41.7 \%$ \\
\hline Slurry, g/mL & 1.387 & 1.412 & 1.411 & 1.410 & 1.391 & 1.413 & 1.406 & 1.419 \\
\hline Supernate, $\mathrm{g} / \mathrm{mL}$ & 1.065 & 1.094 & 1.121 & 1.114 & 1.086 & 1.077 & 1.119 & 1.078 \\
\hline Formate, $\mathrm{mg} / \mathrm{kg}$ & 30,000 & 32,900 & 56,200 & 51,600 & 32,600 & 40,000 & 54,300 & 2,680 \\
\hline Nitrate. $\mathrm{mg} / \mathrm{kg}$ & 14,700 & 20,200 & 23,200 & 19,700 & 18,300 & 18,100 & 21,000 & 7,900 \\
\hline Chloride, $\mathrm{mg} / \mathrm{kg}$ & $<100$ & $<100$ & 250 & 300 & 330 & 1140 & 280 & 1110 \\
\hline Oxalate, $\mathrm{mg} / \mathrm{kg}$ & $<100$ & $<100$ & 1450 & 1010 & 110 & 110 & 630 & 730 \\
\hline
\end{tabular}


WSRC-STI-2008-00131

Revision 0

Table 14. Solids and Anion Data for Bead SME Products

\begin{tabular}{|l|c|c|c|c|c|c|c|c|}
\hline & Bead9 & Bead10 & Bead11 & Bead12 & Bead13 & Bead14 & Bead15 & Bead16 \\
\hline wt\% TS & $51.8 \%$ & $48.5 \%$ & $58.6 \%$ & $48.7 \%$ & $49.5 \%$ & $48.1 \%$ & $49.1 \%$ & $48.6 \%$ \\
\hline wt\% IS & $42.7 \%$ & $41.7 \%$ & $50.1 \%$ & $41.0 \%$ & $40.5 \%$ & $43.0 \%$ & $39.4 \%$ & $41.3 \%$ \\
\hline wt\% SS & $9.1 \%$ & $6.8 \%$ & $8.5 \%$ & $7.7 \%$ & $9.0 \%$ & $5.1 \%$ & $9.7 \%$ & $7.3 \%$ \\
\hline wt\% CS & $40.1 \%$ & $41.0 \%$ & $40.3 \%$ & $40.7 \%$ & $41.0 \%$ & $41.6 \%$ & $40.4 \%$ & $41.0 \%$ \\
\hline Density, $\mathrm{g} / \mathrm{mL}$ & 1.397 & 1.418 & 1.381 & 1.394 & 1.411 & 1.409 & 1.389 & 1.404 \\
\hline Formate, $\mathrm{mg} / \mathrm{kg}$ & 57,200 & 30,700 & 65,100 & 36,900 & 47,600 & 6,810 & 50,500 & 27,800 \\
\hline Nitrate. $\mathrm{mg} / \mathrm{kg}$ & 26,100 & 21,000 & 24,200 & 18,100 & 21,200 & 10,400 & 19,300 & 16,300 \\
\hline Chloride, $\mathrm{mg} / \mathrm{kg}$ & 270 & 400 & 340 & 1220 & 880 & 1270 & 340 & 350 \\
\hline Oxalate, $\mathrm{mg} / \mathrm{kg}$ & 1070 & $<100$ & 1950 & $<1000$ & $<1000$ & $<1000$ & $<1000$ & $<1000$ \\
\hline
\end{tabular}

Chloride ion was again useful for tracking the three pairs of runs with $\mathrm{RuCl}_{3}$ additions. The SRAT and SME product sample results were put into the acid calculation spreadsheet. The initial estimates for formate loss, nitrate loss, nitrite-to-nitrate conversion, wt $\%$ solids, mass of antifoam added, SRAT dewatered condensate mass, SME product mass, etc. were adjusted to match the actual measured results. This process produced corrected values for nitrite-to-nitrate conversion in the SRAT, formate loss in the SRAT, formate loss in the SME, and nitrate loss in the SME. These results are given in Table 15.

Table 15. Calculated Overall SRAT and SME Anion Conversions

\begin{tabular}{|l|l|c|c|c|c|}
\hline Run & Noble Metal Loading & $\begin{array}{c}\text { SRAT } \\
\text { Formate } \\
\text { Loss, } \%\end{array}$ & $\begin{array}{c}\text { SRAT } \\
\text { Nitrite to } \\
\text { Nitrate, } \%\end{array}$ & $\begin{array}{c}\text { SME } \\
\text { Formate } \\
\text { Loss, } \%\end{array}$ & $\begin{array}{c}\text { SME } \\
\text { Nitrate } \\
\text { Loss, } \%\end{array}$ \\
\hline H2Frit1 & $0.2 \% \mathrm{Rh}$ & 61 & -15 & -10 & 12 \\
\hline H2Bead10 & $0.2 \% \mathrm{Rh}$ & 58 & 5 & 1 & 5 \\
\hline H2Frit2 & $0.2 \% \mathrm{Ru}$ & 31 & 6 & 29 & 6 \\
\hline H2Bead13 & $0.2 \% \mathrm{Ru}$ & 23 & 6 & 8 & 3 \\
\hline BFMT1 & $0.2 \% \mathrm{Ru}+1.4943 \% \mathrm{Hg}$ & 26 & 26 & - & - \\
\hline H2Frit3 & $0.2 \% \mathrm{Ag}$ & 13 & 15 & 1 & 0 \\
\hline H2Bead9 & $0.2 \% \mathrm{Ag}$ & 10 & 26 & 3 & -6 \\
\hline H2Frit4 & $0.2 \% \mathrm{Pd}$ & 22 & -2 & 1 & 0 \\
\hline H2Bead15 & $0.2 \% \mathrm{Pd}$ & 23 & -5 & 1 & -1 \\
\hline H2Frit5 & $0.375 \% \mathrm{Ru}$ & 26 & 2 & 18 & 11 \\
\hline H2Bead12 & $0.375 \% \mathrm{Ru}$ & 34 & -2 & 16 & 8 \\
\hline H2Frit6 & $0.1 \% \mathrm{Rh}$ & 43 & 4 & 17 & 15 \\
\hline H2Bead16 & $0.1 \% \mathrm{Rh}$ & 52 & -15 & 17 & 5 \\
\hline H2Frit7 & No noble metals & 13 & 18 & 6 & 13 \\
\hline H2Bead11 & No noble metals & 6 & -1 & 3 & -21 \\
\hline H2Frit8 & $0.1 \% \mathrm{Pd}, \mathrm{Rh}, \mathrm{Ag}, 0.375 \% \mathrm{Ru}$ & 85 & -40 & 79 & 34 \\
\hline H2Bead14 & $0.1 \% \mathrm{Pd}, \mathrm{Rh}, \mathrm{Ag}, 0.375 \% \mathrm{Ru}$ & 79 & -20 & 59 & 36 \\
\hline
\end{tabular}

- H2Frit1 - used average of SRAT product and 11.5 hour reflux formate results.

- H2Frit5 and 6 SME raw IC results were switched based on the chloride analyses (hi Cl with $\mathrm{Ru}$ )

- H2Bead11 - calculated nitrite-to-nitrate conversion and SME nitrate loss values are suspect 
Error propagation analysis assuming $10 \%$ uncertainties on IC results indicates that the individual values in the table are probably only accurate to about one significant figure ( $\pm 10 \%$ absolute), e.g. $26 \%$ and $34 \%$ are both essentially $30 \pm 10 \%$. In that context, most of the pairs were successful reproductions of the same values. Also, it is safe to conclude that $59 \%$ formate loss at $0.2 \mathrm{wt} \% \mathrm{Rh}$ was different from a $26 \%$ formate loss at $0.2 \mathrm{wt} \% \mathrm{Ru}$. Calculations were reported to two digits, since the acid calculation estimates are typically made with two digit values. The table includes results from the 4-L bead-frit matching test, BFMT1.

The availability of pairs of runs with multiple samples allowed for a comparison of the reproducibility of the calculated anion shifts. The GC data presented in Section 3.0 indicated that the processing chemistry within each pair was being fairly well reproduced with respect to the major off-gas species. Therefore, it was expected that the anion chemistry should also be well reproduced. The only exception to the statement that Table 15 contains the raw results of the anion calculations is that several suspect SRAT product IC results from the eight frit runs were cross-checked against samples pulled earlier. When the projected results from these samples were a better match to the corresponding bead run result than the SRAT product results, the frit run anion calculations were based on an average of the reported SRAT product value and the 30 minutes before end of SRAT value. Otherwise, the anion calculations were based solely on the SRAT product anion results. This approach was justified by the off-gas data, and by the fact that some anion data came from caustic quenched samples which presumably froze the reactions, while the SRAT products were not caustic quenched and some product samples did not get analyzed for over four weeks (so reactions could have been proceeding slowly in the sample bottle).

H2Bead11 is an example of what can happen without duplicate independent sample results (the samples 30 minutes before the end of the SRAT for the eight bead runs were archived). The calculated SRAT nitrite-to-nitrate conversion was $-0.6 \%$ compared to $18.3 \%$ in H2Frit7, while the SME nitrate loss was $-21.4 \%$ (a SME nitrate gain when no nitrate was added). It is more likely that the nitrate gain occurred in the SRAT from nitrite-to-nitrate conversion than that nitrate was formed in the SME during H2Bead11. One inaccurate result for SRAT product nitrate ion concentration can cause both the SRAT nitrite-tonitrate conversion and SME nitrate loss to be off. It is normal to have a few suspect analytical results in a study of this size. The H2Frit7 results are probably more representative of what happened in the two no noble metal runs than the H2Bead11 result. No such ready explanation is available for the variations in the H2Frit6-H2Bead16 pair of nitrite-to-nitrate conversion and SME formate and nitrate loss values which all differed by $10 \%$ or more from each other.

\subsection{SRAT Material Balances}

Overall material balances were constructed to ensure that subsequent species material balances on nitrogen and carbon containing species would not be compromised by poor slurry masses. The various balances were used selectively during the construction of the SRAT chemistry timeline and during investigations into the quantities of acid consumed by different reactions, Section 5.0. The masses of the inlet streams to the SRAT vessel are summarized in Table 16. 
Table 16. Summary of SRAT Inlet Masses

\begin{tabular}{|l|c|c|l|c|c|}
\hline & $\begin{array}{c}\text { Trimmed } \\
\text { sludge, }\end{array}$ & $\begin{array}{c}\text { Nitric } \\
\text { Acid, g }\end{array}$ & $\begin{array}{c}\text { Formic } \\
\text { Acid, g }\end{array}$ & $\begin{array}{c}\text { Antifoam } \\
\text { g }\end{array}$ & $\begin{array}{c}\text { Total } \\
\text { In, g }\end{array}$ \\
\hline H2Frit1 & $17,678.93$ & 270.83 & 1327.08 & 282.24 & $19,559.08$ \\
\hline H2Frit2 & $17,541.15$ & 292.67 & 1318.03 & 280.57 & $19,432.42$ \\
\hline H2Frit3 & $17,539.67$ & 285.6 & 1321.0 & 279.92 & $19,426.19$ \\
\hline H2Frit4 & $17,576.08$ & 278.59 & 1323.81 & 280.56 & $19,459.04$ \\
\hline H2Frit5 & $17,559.19$ & 294.41 & 1317.84 & 280.32 & $19,451.76$ \\
\hline H2Frit6 & $17,588.77$ & 282.52 & 1322.72 & 281.00 & $19,475.01$ \\
\hline H2Frit7 & $17,524.96$ & 293.27 & 1318.31 & 279.74 & $19,416.28$ \\
\hline H2Frit8 & $17,617.75$ & 272.49 & 1301.06 & 281.22 & $19,472.52$ \\
\hline H2Bead9 & $17,538.85$ & 286.77 & 1320.9 & 279.92 & $19,426.44$ \\
\hline H2Bead10 & $17,678.98$ & 271.54 & 1327.45 & 282.14 & $19,560.11$ \\
\hline H2Bead11 & $17,527.94$ & 293.1 & 1316.9 & 279.64 & $19,417.58$ \\
\hline H2Bead12 & $17,560.78$ & 294.19 & 1316.9 & 280.20 & $19,452.07$ \\
\hline H2Bead13 & $17,544.18$ & 293.37 & 1316.7 & 279.95 & $19,434.20$ \\
\hline H2Bead14 & $17,609.58$ & 272.3 & 1327.1 & 281.12 & $19,490.10$ \\
\hline H2Bead15 & $17,574.38$ & 279.55 & 1323.4 & 280.46 & $19,457.79$ \\
\hline H2Bead16 & $17,587.71$ & 282.9 & 1321.7 & 280.90 & $19,473.21$ \\
\hline
\end{tabular}

Trimmed sludge includes $\mathrm{ABC}$ sludge simulant, noble metal trim chemicals, and rinse water. The starting basis was after the SRAT receipt sample was pulled. Water used to rinse the two acid feed lines was also included in the trimmed sludge column. This was typically $25 \mathrm{~g}$ for each line. Nitric acid, formic acid, and antifoam masses include the water associated with their solutions.

In the outlet mass summary, Table 17, condensate includes the SRAT dewatering condensate, accumulated FAVC condensate, and the net gain/loss between the pre-run and post-run MWWT masses. Off-gas includes the integrated sums of the five non-condensable off-gases, $\mathrm{CO}_{2}, \mathrm{H}_{2}, \mathrm{~N}_{2} \mathrm{O}, \mathrm{NO}_{2}$, and $\mathrm{NO}$. The SRAT product mass is estimated. The estimate was made on a pre-SRAT product sample basis, and then the mass of SRAT product samples was subtracted. The estimate assumed that there should be a significantly larger unexplained mass loss in the 16 hour long SRAT than in the seven hour long SME (only about four at boiling) assuming that the primary source of unexplained mass loss was water vapor loss through small leaks. The unexplained SME loss was typically held to about $30-40 \mathrm{~g}$, while the SRAT loss was typically about $400 \mathrm{~g}$. Moisture loss in the off-gas exiting the FAVC is calculated to be sufficiently small to be ignored based on the vapor pressure of water at $5^{\circ} \mathrm{C}$. 
Table 17. Summary of SRAT Outlet Masses

\begin{tabular}{|l|c|c|c|c|c|c|}
\hline & $\begin{array}{c}\text { Condensate } \\
\mathrm{g}\end{array}$ & $\begin{array}{c}\text { Samples } \\
\mathrm{g}\end{array}$ & $\begin{array}{c}\text { Off-gas, } \\
\mathrm{g}\end{array}$ & $\begin{array}{c}\text { Product } \\
\mathrm{g}\end{array}$ & $\begin{array}{c}\text { Total } \\
\text { Out, } \mathrm{g}\end{array}$ & $\begin{array}{c}\text { (in-out)/ } \\
\text { in }\end{array}$ \\
\hline H2Frit1 & 1869.55 & 699.9 & 793 & $15,700.10$ & $19,062.55$ & $2.54 \%$ \\
\hline H2Frit2 & 1771.51 & 664.65 & 593 & $16,035.35$ & $19,064.51$ & $1.89 \%$ \\
\hline H2Frit3 & 1808.65 & 810.58 & 371 & $16,139.43$ & $19,129.66$ & $1.53 \%$ \\
\hline H2Frit4 & 1843.70 & 777.54 & 529 & $16,022.46$ & $19,172.70$ & $1.47 \%$ \\
\hline H2Frit5 & 1917.31 & 679.78 & 620 & $16,085.22$ & $19,302.31$ & $0.77 \%$ \\
\hline H2Frit6 & 1944.45 & 747.13 & 727 & $15,602.88$ & $19,021.46$ & $2.33 \%$ \\
\hline H2Frit7 & 1784.78 & 665.78 & 437 & $16,194.22$ & $19,081.78$ & $1.72 \%$ \\
\hline H2Frit8 & 1738.90 & 1072.21 & 834 & $15,317.79$ & $18,962.90$ & $2.62 \%$ \\
\hline H2Bead9 & 1813.06 & 902.64 & 462 & $15,917.36$ & $19,095.06$ & $1.71 \%$ \\
\hline H2Bead10 & 1919.57 & 862.56 & 724 & $15,237.44$ & $18,743.57$ & $4.17 \%$ \\
\hline H2Bead11 & 1810.97 & 747.25 & 437 & $16,112.75$ & $19,107.97$ & $1.59 \%$ \\
\hline H2Bead12 & 1787.97 & 857.90 & 684 & $15,857.10$ & $19,186.97$ & $1.36 \%$ \\
\hline H2Bead13 & 1679.38 & 878.3 & 645 & $15,813.48$ & $19,016.16$ & $2.15 \%$ \\
\hline H2Bead14 & 1703.87 & 882.66 & 874 & $15,537.34$ & $18,997.87$ & $2.53 \%$ \\
\hline H2Bead15 & 1719.94 & 708.64 & 562 & $16,141.37$ & $19,131.95$ & $1.67 \%$ \\
\hline H2Bead16 & 1810.88 & 830.46 & 722 & $15,669.54$ & $19,032.88$ & $2.26 \%$ \\
\hline
\end{tabular}

The given outlet off-gas mass for $\mathrm{H} 2 \mathrm{Frit} 7$ is actually the value from the matching run, $\mathrm{H} 2 \mathrm{Bead} 11$, since a significant portion of the $\mathrm{H} 2$ Frit7 $\mathrm{CO}_{2}$ and $\mathrm{NO}_{\mathrm{x}}$ data were lost due to $\mathrm{GC}$ issues. Only $\mathrm{H} 2 \mathrm{Bead} 10$ had an overall mass balance closure worse than 3\%. The missing mass between SRAT inlet and outlet was equivalent to approximately $0.4 \mathrm{~g} /$ minute during the processing time above $90^{\circ} \mathrm{C}$. This loss rate is equivalent to about $2 \%$ of the nominal boil-up rate of $25 \mathrm{~g} /$ minute. It appears that the SME mass loss could have been taken to be in the 80-90 g range based on the average SRAT loss rate instead of in the 30-40 g range. Then all of the material balances could have been fine tuned through another iteration of the estimated SRAT product mass. This would have changed the estimated SRAT product mass by less than a half percent. The closure percentages would all have remained positive, i.e. they were not randomly distributed about zero and would not subsequently become randomly distributed about zero. Quantities derived from the SRAT product mass, such as the SRAT product formate mass, already have potential uncertainties of $\pm 10 \%$ from the analytical concentration measurements, so there was little to be gained in downstream calculations by further fine tuning to remove $0.5 \%$ errors and this was deemed unnecessary.

SRAT anion results were combined with MWWT, FAVC, and dewatered condensate IC results, and with $\mathrm{GC}$ results for $\mathrm{NO}, \mathrm{NO}_{2}$, and $\mathrm{N}_{2} \mathrm{O}$ to perform more in-depth nitrogen balances on the runs, Table 18. The nitrogen balances are in terms of moles nitrogen from each species. The $\mathrm{NO}_{2}$ values contain any dimerized gas present as $\mathrm{N}_{2} \mathrm{O}_{4}$ with the understanding that one mole of $\mathrm{N}_{2} \mathrm{O}_{4}$ was equivalent to two moles of $\mathrm{NO}_{2}$. The balance does not include nitrogen gas itself which appears to be totally inert during SRAT processing (moles $\mathrm{N}_{2}$ in = moles $\mathrm{N}_{2}$ out was assumed). It is possible, however, that some $\mathrm{N}_{2}$ might be formed during nitrite destruction.

The SRAT reactions forming the oxides of nitrogen primarily occurred in what will be defined as Period 3 of the SRAT cycle in Section 5.3, but there was still a declining concentration in the off-gas GC readings for up to an hour after acid addition was complete, i.e. into Period 4. 
Table 18. Detailed Molar Nitrogen Species Balance

\begin{tabular}{|c|c|c|c|c|c|c|c|}
\hline Run & Noble Metals & $\begin{array}{l}\text { Sludge } \\
\mathrm{NO}_{2}^{-} \text {in }\end{array}$ & $\begin{array}{l}\text { Sludge } \\
\mathrm{NO}_{3}^{-} \text {in }\end{array}$ & $\begin{array}{l}\mathrm{HNO}_{3} \\
\text { added }\end{array}$ & $\begin{array}{l}\text { Total } \\
\mathrm{N} \text { in }\end{array}$ & $\begin{array}{c}\text { (in- } \\
\text { out)/in }\end{array}$ & $\begin{array}{r}\mathrm{NH}_{4}^{+} \\
\text {out }\end{array}$ \\
\hline H2Frit1 & $0.2 \% \mathrm{Rh}$ & 6.61 & 3.99 & 2.18 & 12.78 & $-1 \%$ & - \\
\hline H2Bead10 & $0.2 \% \mathrm{Rh}$ & 6.61 & 3.99 & 2.18 & 12.78 & $-1 \%$ & 0.08 \\
\hline H2Frit2 & $0.2 \% \mathrm{Ru}$ & 6.61 & 3.76 & 2.35 & 12.72 & $3 \%$ & - \\
\hline H2Bead13 & $0.2 \% \mathrm{Ru}$ & 6.61 & 3.76 & 2.35 & 12.72 & $-2 \%$ & 0.02 \\
\hline BFMT1 & $0.2 \% \mathrm{Ru}+\mathrm{Hg}$ & 6.67 & 3.80 & 2.57 & 13.04 & $-15 \%$ & - \\
\hline H2Frit3 & $0.2 \% \mathrm{Ag}$ & 6.61 & 3.84 & 2.30 & 12.75 & $7 \%$ & - \\
\hline H2Bead9 & $0.2 \% \mathrm{Ag}$ & 6.61 & 3.84 & 2.30 & 12.75 & $-8 \%$ & - \\
\hline H2Frit4 & $0.2 \% \mathrm{Pd}$ & 6.61 & 3.91 & 2.24 & 12.76 & $8 \%$ & - \\
\hline H2Bead15 & $0.2 \% \mathrm{Pd}$ & 6.61 & 3.91 & 2.24 & 12.76 & $6 \%$ & - \\
\hline H2Frit5 & $0.375 \% \mathrm{Ru}$ & 6.61 & 3.76 & 2.36 & 12.73 & $14 \%$ & - \\
\hline H2Bead12 & $0.375 \% \mathrm{Ru}$ & 6.61 & 3.76 & 2.36 & 12.73 & $4 \%$ & 0.02 \\
\hline H2Frit6 & $0.1 \% \mathrm{Rh}$ & 6.61 & 3.88 & 2.27 & 12.76 & $4 \%$ & - \\
\hline H2Bead16 & $0.1 \% \mathrm{Rh}$ & 6.61 & 3.88 & 2.27 & 12.76 & $10 \%$ & 0.05 \\
\hline H2Frit7 & None & 6.61 & 3.76 & 2.35 & 12.72 & $6 \%$ & - \\
\hline H2Bead11 & None & 6.61 & 3.76 & 2.35 & 12.72 & $10 \%$ & - \\
\hline H2Frit8 & All & 6.61 & 3.99 & 2.19 & 12.79 & $10 \%$ & 1.32 \\
\hline H2Bead14 & All & 6.61 & 3.99 & 2.18 & 12.78 & $8 \%$ & 0.15 \\
\hline Run & Noble Metals & $\begin{array}{c}\mathrm{NO}_{2} \\
\text { off-gas }\end{array}$ & $\begin{array}{c}\mathrm{N}_{2} \mathrm{O} \\
\text { off-gas }\end{array}$ & $\begin{array}{c}\text { NO } \\
\text { off-gas }\end{array}$ & $\begin{array}{c}\text { Product } \\
\mathrm{NO}_{3}{ }^{-}\end{array}$ & $\begin{array}{c}\text { Conden } \\
\text {-sates }\end{array}$ & $\begin{array}{l}\text { Total } \\
\mathrm{N} \text { out }\end{array}$ \\
\hline H2Frit1 & $0.2 \% \mathrm{Rh}$ & 2.74 & 4.59 & 0.21 & 5.17 & $>0.23$ & $>12.9$ \\
\hline H2Bead10 & $0.2 \% \mathrm{Rh}$ & 2.55 & 3.06 & 0.36 & 6.49 & 0.32 & 12.9 \\
\hline H2Frit2 & $0.2 \% \mathrm{Ru}$ & 3.26 & 1.73 & 0.33 & 6.48 & 0.53 & 12.3 \\
\hline H2Bead13 & $0.2 \% \mathrm{Ru}$ & 3.54 & 2.11 & 0.27 & 6.54 & 0.56 & 13.0 \\
\hline BFMT1 & $0.2 \% \mathrm{Ru}+\mathrm{Hg}$ & 5.70 & 0.33 & 0.93 & 7.27 & 0.75 & 15.0 \\
\hline H2Frit3 & $0.2 \% \mathrm{Ag}$ & 2.41 & 1.73 & 0.37 & 7.12 & 0.30 & 11.9 \\
\hline H2Bead9 & $0.2 \% \mathrm{Ag}$ & 3.46 & 1.64 & 0.43 & 7.87 & 0.37 & 13.8 \\
\hline H2Frit4 & $0.2 \% \mathrm{Pd}$ & 1.59 & 3.54 & 0.35 & 6.03 & 0.30 & 11.8 \\
\hline H2Bead15 & $0.2 \% \mathrm{Pd}$ & 1.88 & 3.82 & 0.07 & 5.84 & 0.35 & 12.0 \\
\hline H2Frit5 & $0.375 \% \mathrm{Ru}$ & 1.65 & 2.32 & 0.42 & 6.25 & 0.31 & 11.0 \\
\hline H2Bead12 & $0.375 \% \mathrm{Ru}$ & 3.32 & 2.12 & 0.15 & 6.02 & 0.56 & 12.2 \\
\hline H2Frit6 & $0.1 \% \mathrm{Rh}$ & 2.65 & 2.41 & 0.51 & 6.40 & $(0.22)$ & 12.2 \\
\hline H2Bead16 & $0.1 \% \mathrm{Rh}$ & 2.97 & 2.47 & 0.13 & 5.18 & 0.63 & 11.5 \\
\hline H2Frit7 & None & 1.72 & $? 1.76$ & 0.17 & 7.32 & 0.35 & $? 12.0$ \\
\hline H2Bead11 & None & 3.09 & 1.76 & 0.05 & 6.08 & 0.48 & 11.5 \\
\hline H2Frit8 & All & 2.52 & 2.73 & 1.04 & 3.63 & $(0.22)$ & 11.5 \\
\hline H2Bead14 & All & 3.10 & 2.73 & 0.42 & 4.87 & 0.54 & 11.8 \\
\hline
\end{tabular}

Overall, the quality of the nitrogen balances seemed very acceptable based on the magnitude of the percent closure of (in-out)/in, which was always less than 15\% and frequently less than $10 \%$ for the sixteen 22-L runs. The errors were larger than the overall material balance closure errors, but this was expected once the random uncertainty of analytical measurements was combined with the material balance uncertainty. The poorest closure came on the 4-L BFMT1 test, but this run lost air purge during 
nitrite destruction. Consequently, the calculated outlet gas moles may have been overstated. There were also some issues with seemingly high nitrate measurements during this time period.

There was a statistically significant difference between the average closure error of $+4.8 \%$ and $0 \%$ at the $95 \%$ confidence level for the sixteen $22-\mathrm{L}$ runs. This implies that the outgoing nitrogen species were being systematically undercounted in these data. A small bias low in the SRAT product nitrate ion concentrations would easily explain this. An alternative explanation is the formation of some molecular nitrogen during processing.

$\mathrm{H} 2$ Frit7 $\mathrm{N}_{2} \mathrm{O}$ was taken from the $\mathrm{H} 2 \mathrm{Bead} 11$ test, since the relevant $\mathrm{GC}$ data were lost. H2Frit6 and H2Frit8 SRAT condensate nitrogen moles are probably off low by about 0.3-0.4 moles, since there was no ammonium ion measure corresponding to the ones in $\mathrm{H} 2 \mathrm{Bead} 16$ and $\mathrm{H} 2 \mathrm{Bead14}$. Ammonium ion was at $50,000 \mathrm{mg} / \mathrm{L}$ in the FAVC condensates of the two bead runs that were checked. Several likely bead SRAT products were checked for ammonium ion after ammonium was reported in the all noble metal frit run product, H2Frit8. A sodium ion trap was used during the bead run sample analyses to reduce the interference between sodium and ammonium in the SRAT products. This trap was not used during H2Frit8 sample analysis, and it was not needed for the FAVC samples, which did not have the sodium interference.

A carbon species balance was similarly constructed. This balance ignored oxalate, since it is difficult to draw insoluble oxalate into the supernate for IC analysis. Oxalate can be catalytically reduced to formate ion. There were about 0.5 moles of oxalate in the initial sludge charge, or $2 \%$ of the typical inlet carbon content. The carbon balance also ignored the carbon in the antifoam molecules, which were assumed to be inert during processing (inert for antifoam meaning that they didn't break down into formate or $\mathrm{CO}_{2}$, but could have broken down into simpler organo-silane fragments). Inlet TIC for the SRAT was calculated assuming $1350 \mathrm{mg} / \mathrm{kg}$ for the $\mathrm{ABC}$ simulant - the adopted calculation basis. TIC data for SRAT product slurries were available for five bead runs that had significant $\mathrm{pH}$ rise after acid addition. The bead run TIC mole results were also used for the matching frit runs, since the quantities were not trivial. The SRAT product TIC results had a high degree of analytical uncertainty, and they are given with only a single significant figure. Table 19 gives the raw calculated moles of carbon for the various streams entering and leaving the SRAT. Values are given to the hundredths place for the purpose of summing them without additional round-off error accumulation, but not all of these digits represent significant figures in some columns such as "Product $\mathrm{HCO}_{2}$ ' out" which has at most two significant figures. 
WSRC-STI-2008-00131

Revision 0

Table 19. Moles of Carbon Balances

\begin{tabular}{|l|c|c|c|c|c|c|c|}
\hline Run & $\begin{array}{c}\text { Noble } \\
\text { Metals }\end{array}$ & $\begin{array}{c}\text { Sludge } \\
\text { TIC } \\
\text { in }\end{array}$ & $\begin{array}{c}\text { Formic } \\
\text { Acid } \\
\text { in }\end{array}$ & $\begin{array}{c}\mathrm{CO}_{2} \\
\text { In off- } \\
\text { gas }\end{array}$ & $\begin{array}{c}\text { Product } \\
\mathrm{HCO}_{2}^{-} \\
\text {out }\end{array}$ & $\begin{array}{c}\text { Conden } \\
\text { sates } \\
\text { out }\end{array}$ & $\begin{array}{c}\text { Product } \\
\text { TIC out }\end{array}$ \\
\hline H2Frit1 & $0.2 \% \mathrm{Rh}$ & 1.90 & 26.01 & 12.57 & 10.13 & 0.01 & 6 \\
\hline H2Bead10 & $0.2 \% \mathrm{Rh}$ & 1.90 & 26.02 & 11.93 & 10.98 & 0.01 & 6 \\
\hline H2Frit2 & $0.2 \% \mathrm{Ru}$ & 1.90 & 25.83 & 8.86 & 17.76 & 0.16 & 1 \\
\hline H2Bead13 & $0.2 \% \mathrm{Ru}$ & 1.90 & 25.81 & 9.63 & 19.97 & 0.30 & 1 \\
\hline BFMT1 & $\mathrm{Ru}+\mathrm{Hg}$ & 1.90 & 27.15 & 10.39 & 20.22 & 0.13 & - \\
\hline H2Frit3 & $0.2 \% \mathrm{Ag}$ & 1.90 & 25.89 & 4.70 & 22.63 & 0.28 & - \\
\hline H2Bead9 & $0.2 \% \mathrm{Ag}$ & 1.90 & 25.89 & 5.74 & 23.34 & 0.34 & - \\
\hline H2Frit4 & $0.2 \% \mathrm{Pd}$ & 1.90 & 25.95 & 8.23 & 20.38 & 0.04 & - \\
\hline H2Bead15 & $0.2 \% \mathrm{Pd}$ & 1.90 & 25.94 & 8.76 & 19.99 & 0.05 & - \\
\hline H2Frit5 & $0.375 \% \mathrm{Ru}$ & 1.90 & 25.83 & 10.82 & 19.11 & 0.14 & 3 \\
\hline H2Bead12 & $0.375 \% \mathrm{Ru}$ & 1.90 & 25.81 & 10.79 & 17.14 & 0.14 & 3 \\
\hline H2Frit6 & $0.1 \% \mathrm{Rh}$ & 1.90 & 25.92 & 12.04 & 14.65 & 0.01 & 4 \\
\hline H2Bead16 & $0.1 \% \mathrm{Rh}$ & 1.90 & 25.90 & 11.85 & 12.34 & 0.02 & 4 \\
\hline H2Frit7 & None & 1.90 & 25.84 & 5.75 & 22.54 & 0.20 & - \\
\hline H2Bead11 & None & 1.90 & 25.81 & 5.75 & 24.37 & 0.43 & - \\
\hline H2Frit8 & All & 1.90 & 25.50 & 14.18 & 3.88 & 0.00 & 7 \\
\hline H2Bead14 & All & 1.90 & 26.01 & 14.87 & 5.42 & 0.00 & 7 \\
\hline
\end{tabular}

The individual inlet and outlet terms in Table 19 were combined and compared to determine the percent closures of the seventeen carbon material balances, Table 20 . Fourteen runs closed to within $10 \%$ using \{(in-out)/in\} as the closure measure and rounding the error to the nearest whole integer percent. 
Table 20. Carbon Balance Closures

\begin{tabular}{|l|c|c|c|c|}
\hline Run & $\begin{array}{c}\text { Noble } \\
\text { Metals }\end{array}$ & $\begin{array}{c}\text { SRAT } \\
\text { Total IN }\end{array}$ & $\begin{array}{c}\text { SRAT } \\
\text { Total OUT }\end{array}$ & $\begin{array}{c}\text { (in-out)/in } \\
* 100 \%\end{array}$ \\
\hline H2Frit1 & $0.2 \% \mathrm{Rh}$ & 27.91 & 28.71 & $-2.9 \%$ \\
\hline H2Bead10 & $0.2 \% \mathrm{Rh}$ & 27.92 & 28.92 & $-3.6 \%$ \\
\hline H2Frit2 & $0.2 \% \mathrm{Ru}$ & 27.73 & 27.78 & $-0.2 \%$ \\
\hline H2Bead13 & $0.2 \% \mathrm{Ru}$ & 27.71 & 30.90 & $-11.5 \%$ \\
\hline BFMT1 & $0.2 \% \mathrm{Ru}+\mathrm{Hg}$ & 29.05 & 30.74 & $-5.8 \%$ \\
\hline H2Frit3 & $0.2 \% \mathrm{Ag}$ & 27.79 & 27.61 & $0.6 \%$ \\
\hline H2Bead9 & $0.2 \% \mathrm{Ag}$ & 27.79 & 29.42 & $-5.9 \%$ \\
\hline H2Frit4 & $0.2 \% \mathrm{Pd}$ & 27.85 & 28.65 & $-2.9 \%$ \\
\hline H2Bead15 & $0.2 \% \mathrm{Pd}$ & 27.84 & 28.80 & $-3.4 \%$ \\
\hline H2Frit5 & $0.375 \% \mathrm{Ru}$ & 27.73 & 33.07 & $-19.3 \%$ \\
\hline H2Bead12 & $0.375 \% \mathrm{Ru}$ & 27.71 & 31.07 & $-12.1 \%$ \\
\hline H2Frit6 & $0.1 \% \mathrm{Rh}$ & 27.82 & 30.70 & $-10.4 \%$ \\
\hline H2Bead16 & $0.1 \% \mathrm{Rh}$ & 27.80 & 28.21 & $-1.5 \%$ \\
\hline H2Frit7 & None & 27.74 & 28.49 & $-2.7 \%$ \\
\hline H2Bead11 & None & 27.71 & 30.55 & $-10.2 \%$ \\
\hline H2Frit8 & All & 27.40 & 25.06 & $8.5 \%$ \\
\hline H2Bead14 & All & 27.91 & 27.29 & $2.2 \%$ \\
\hline
\end{tabular}

As mentioned earlier, $\mathrm{H} 2 \mathrm{Frit} 7 \mathrm{CO}_{2}$ was taken from the $\mathrm{H} 2 \mathrm{Bead} 11 \mathrm{GC}$ data due to incomplete $\mathrm{GC}$ coverage of H2Frit7. H2Frit1 condensate out carbon was taken from H2Bead10 data, since the H2Frit1 dewatering sample was misplaced. Measured SRAT product formate IC data was balanced against other comparable SRAT formate data, and a reasonable mean value was assigned consistent with the balance of the data. SRAT condensate formate included dewatered mass, FAVC mass, and net MWWT mass, but virtually all of the carbon was lost as formate in the dewatered condensate following acid addition. Most FAVC and end of SRAT MWWT samples had much lower formate concentrations than the dewatered condensate as well as considerably smaller total masses to multiply them by to get the total carbon in them.

The outlet carbon total averaged about $5 \%$ more than the inlet carbon total, or about 1.3 moles more. Five of the eight pairs had larger variations in the IC concentration-based formate out term than 1.3 moles. There were several other possible reasons for closure issues, including uncertainty in the feed TIC concentration of about \pm 1 mole and neglecting possible conversion of oxalate or antifoam to $\mathrm{CO}_{2}$. The carbon material balance closures easily met expectations given the number of terms and sources of error.

Successful closure of the material balances was a prerequisite for some of the work in developing the SRAT chemistry timeline, and in evaluating the causes of acid consumption. Specialized species balance calculations were performed a few times during the investigations into the SRAT chemistry timeline and acid consumption in Section 5.0. These balances were performed for nitrogen and/or carbon from the starting sludge to an intermediate point in the SRAT cycle instead of to the SRAT product. 
WSRC-STI-2008-00131

Revision 0

This page intentionally left blank. 


\subsection{Development of SRAT Chemistry Timeline}

The SRAT cycle was divided into five sequential periods, Periods 1-5. The first three periods were during acid addition. The divisions between periods were selected to coincide with a significant shift in the observable chemistry. The last two periods were dewatering and reflux. Sample and off-gas data along with basic chemistry were used to describe what occurred during each period. The descriptions were fairly universal to the extent that the noble metals did not impact the chemistry. Once the noble metals began to impact the chemistry, however, the various SRAT systems evolved in unique ways. This uniqueness as a function of noble metal loading was apparent from the graphical data presented in Section 3.0 and the anion conversions and material balance data presented in Section 4.0.

\subsection{Period 1: Initial Sludge Neutralized to pH 7.4 (0-16.6\% total acid)}

The moles of acid added per liter of sludge during Period 1 were virtually identical to the measured base equivalents at $\mathrm{pH} 7$ by cold titration. The acid added by the end of Period 1 averaged $16.6 \%$ of the total moles of acid over the sixteen 22-L runs with a standard deviation of $2.8 \%$. The acid included all of the nitric acid $(8.1 \%$ of the total on average) plus some of the formic acid ( $8.5 \%$ of the total acid). Virtually all of the acid consumption reactions occurred in the supernate based on the lack of changes in the supernate cation sample data (almost nothing dissolved or precipitated). The main reactions in Period 1 included the following where $\mathrm{HA}$ represents either $\mathrm{HNO}_{3}$ or $\mathrm{HCOOH}$ :

$$
\begin{aligned}
& \mathrm{NaOH}+\mathrm{HA} \rightarrow \mathrm{NaA}+\mathrm{H}_{2} \mathrm{O} \\
& \mathrm{Na}_{2} \mathrm{CO}_{3}+\mathrm{HA} \rightarrow \mathrm{NaA}+\mathrm{NaHCO}_{3} \\
& 2 \mathrm{NaAlO}_{2}+2 \mathrm{HA} \rightarrow \mathrm{Al}_{2} \mathrm{O}_{3}(\text { ins })+\mathrm{H}_{2} \mathrm{O}
\end{aligned}
$$

The supernate $\mathrm{Al}$ concentration fell from $535 \mathrm{mg} / \mathrm{L}$ to $9 \mathrm{mg} / \mathrm{L}$. The aluminum may have formed $\mathrm{Al}(\mathrm{OH})_{3}$ instead of $\mathrm{Al}_{2} \mathrm{O}_{3}$. This would not affect acid consumption. Off-gas observations indicated that small amounts of carbon dioxide formation occurred:

$$
\mathrm{NaHCO}_{3}+\mathrm{HA} \rightarrow \mathrm{NaA}+\mathrm{CO}_{2}+\mathrm{H}_{2} \mathrm{O}
$$

This reaction can occur in the regions where the acid drops first contact the slurry and the $\mathrm{pH}$ is lower than in the bulk slurry. IC data indicated negligible nitrite destruction. ICP-AES data indicated negligible dissolution of any major insoluble cations in the feed. TIC data were inconclusive as to whether a significant loss of inorganic carbon had occurred. Analysis of supernate from the diluted cold auto-titration to $\mathrm{pH}$ seven showed about $15-20 \%$ of the calcium became soluble, but this did not appear to have occurred during Period 1 of the SRAT. In Period 2, Mg dissolved before Ca, but negligible $\mathrm{Mg}$ was observed in the cold auto-titration supernate. (It is possible that the small amounts of $\mathrm{CO}_{2}$ formation detected were formed as acid droplets struck the slurry creating locally low $\mathrm{pH}$ regions in which some of the $\mathrm{CaCO}_{3}$ was converted to $\mathrm{Ca}^{2+}$ and $\mathrm{CO}_{2}$. Subsequently, the $\mathrm{Ca}^{2+}$ reprecipitated in the $93^{\circ} \mathrm{C}$ SRAT but not in the $25^{\circ} \mathrm{C}$ auto-titration due to the temperature and dilution differences.)

\subsection{Period 2: pH 7.4 to pH 5.1 (16.6-50\% total acid)}

The moles of acid added during Period 2 were nearly identical to the acid required to dissolve insoluble $\mathrm{Mg}(\mathrm{OH})_{2}, \mathrm{CaCO}_{3}, \mathrm{Ca}(\mathrm{OH})_{2}$, and to partially $(25 \%)$ dissolve/reduce $\mathrm{MnO}_{2}$ to $\mathrm{Mn}^{2+}$. Acid addition reached $50 \%$ of the total acid quantity. The acid split through the end of Period 2 was $8.1 \%$ from nitric acid and $41.9 \%$ from formic acid. The SRAT pH fell to 5.06 with a standard deviation of 0.17 based on data from eleven runs with reliable $\mathrm{pH}$ readings. 
The carbonate from calcium was converted to carbon dioxide, along with the final destruction of supernate carbonate/bicarbonate from sodium to carbon dioxide. Not all calcium was present in the simulant as $\mathrm{CaCO}_{3}$. The current best recipe calculation was that $71.1 \%$ of the $\mathrm{Ca}$ was added as $\mathrm{CaCO}_{3}$ ( $16.1 \%$ was oxalate, $9.5 \%$ was sulfate, and $3.3 \%$ was phosphate). Relatively soluble $\mathrm{CaSO}_{4}$ may have converted to $\mathrm{Ca}(\mathrm{OH})_{2}$ or $\mathrm{CaCO}_{3}$ prior to processing, while $\mathrm{CaC}_{2} \mathrm{O}_{4}$ and $\mathrm{Ca}_{3}\left(\mathrm{PO}_{4}\right)_{2}$ probably remained insoluble throughout the run. Cation dissolution data indicate that $\mathrm{Ca}$ solubility reached a maximum of about $80 \%$, which exceeds the $\mathrm{CaCO}_{3}$ in the recipe but is close to the $\mathrm{CaCO}_{3}+\mathrm{CaSO}_{4}$ in the recipe.

TIC data indicate that carbonate had disappeared by the end of Period 2. This conclusion can be supported regardless of the actual quantitative values for TIC, which showed considerable uncertainty. Several sets of TIC data covering Period 2 were obtained with this simulant. The GC data indicate that a molar quantity of $\mathrm{CO}_{2}$ equivalent to $1,350 \mathrm{mg} \mathrm{TIC} / \mathrm{kg}$ was produced by the time that $43 \%$ of the total acid was added. The $\mathrm{CO}_{2}$ data are consistent with $100 \%$ TIC destruction plus a fairly small amount of formate destruction $(<5 \%)$ by the end of Period 2 (or else there was potentially more TIC in the feed than was assumed or less $\mathrm{CO}_{2}$ than was calculated). Final TIC destruction corresponded closely with calcium dissolution in time. Both of these changes were observed near the end of $\mathrm{Mg}(\mathrm{OH})_{2}$ dissolution and the beginning of $\mathrm{MnO}_{2}$ reduction, i.e. the dissolution reactions of $\mathrm{Mg}, \mathrm{Ca}$, and $\mathrm{Mn}$ were nearly in series but there was some overlap at the beginnings and endings.

Only very small quantities of $\mathrm{NO}_{\mathrm{x}}$ were seen in the Period 2 off-gas, and IC data indicated that most of the initial nitrite was still present at the end of Period 2. Nitrous acid, $\mathrm{HNO}_{2},(\mathrm{pK}=5.22)$ is a stronger acid than carbonic acid, $\mathrm{H}_{2} \mathrm{CO}_{3},(\mathrm{pK}=6.38)$. Generation of nitrous acid from nitrite ions is only expected to occur after all bicarbonate ions have been converted to $\mathrm{CO}_{2}$. Virtually no formate ions were destroyed during Period 2. This was determined by comparing the increase in formate ion concentration measured by IC with the predicted concentration based on the formic acid addition rate and calculated slurry mass. Linear formate accumulation was evident on a number of the formate concentration versus time plots in Section 3.0. Formate attack on nitrite ion was not indicated during Period 2. A small decrease in formate ion relative to the predicted rate of increase was observed in the IC data near the end of Period 2 and coincided in time with the initial partial reduction of $\mathrm{Mn}$. The main reactions during Period 2 appeared to be these, where $\mathrm{HA}$ was either $\mathrm{HNO}_{3}$ or $\mathrm{HCOOH}$ :

$$
\begin{aligned}
& \mathrm{Mg}(\mathrm{OH})_{2}+2 \mathrm{HA} \rightarrow \mathrm{MgA}_{2}+2 \mathrm{H}_{2} \mathrm{O} \\
& \mathrm{CaCO}_{3}+2 \mathrm{HA} \rightarrow \mathrm{CaA}_{2}+\mathrm{CO}_{2}+\mathrm{H}_{2} \mathrm{O} \\
& \mathrm{Ca}(\mathrm{OH})_{2}+2 \mathrm{HA} \rightarrow \mathrm{CaA}_{2}+2 \mathrm{H}_{2} \mathrm{O} \\
& \mathrm{MnO}_{2}+\mathrm{HCOOH}+2 \mathrm{HA} \rightarrow \mathrm{MnA}_{2}+\mathrm{CO}_{2}+2 \mathrm{H}_{2} \mathrm{O}
\end{aligned}
$$

Solubility data indicate that $\mathrm{CaCO}_{3}$ is the preferred species over $\mathrm{Ca}(\mathrm{OH})_{2}$ in the presence of dissolved carbonate. The rates of the above dissolution reactions were measured from the slopes of the supernate cation data. The rates indicated that nearly all of the acid being added was being consumed by these four reactions, i.e. the progress of these reactions was being controlled by the acid addition rate (two gallons per minute at DWPF-scale). The bead-frit matching test with $\mathrm{Hg}$ showed smaller extents of $\mathrm{Ca}$ and $\mathrm{Mg}$ dissolution than was seen in the select data from certain 22-L bead-frit runs, but there are some questions about the accuracy of the results. Data from supporting tests with the same simulant in the $\mathrm{Rh}-\mathrm{Ru}-\mathrm{Hg}$ matrix study indicate that the reduction of mercury occurred as the $\mathrm{pH}$ initially fell to seven over about a twenty minute interval included in Period 2 and probably nearly immediately after Period $1 .^{12}$ Mercury reduction probably either preceded or paralleled the dissolution of $\mathrm{Mg}(\mathrm{OH})_{2}$. 
Noble metal dissolution was also in progress during Period 2, but the impact on acid consumption was minimal. Pd solubility peaked at about the end of Period 2 at nearly $100 \%$. Rh and Ru dissolution began at $20-25 \%$ total acid, but the maximum supernate concentration did not come until roughly all of the total acid was added (end of Period 3). Extensive data on noble metal dissolution were presented in the companion report on noble metal chemistry and hydrogen generation. ${ }^{9}$

The initial peak in $\mathrm{CO}_{2}$ production has frequently been attributed to carbonate destruction. That hypothesis was critically evaluated with the data obtained in the bead-frit runs. Cumulative data on carbonate loss as a function of acid added was constructed and fit with a sigmoidal function, Figure 69. Most data are from H2Bead9, but some data from H2Sim1 were translated to an equivalent time basis (using moles acid added per liter) and included as well. H2Sim1 was documented as part of the preliminary characterization of $\mathrm{ABC}$ simulant processing. ${ }^{7}$

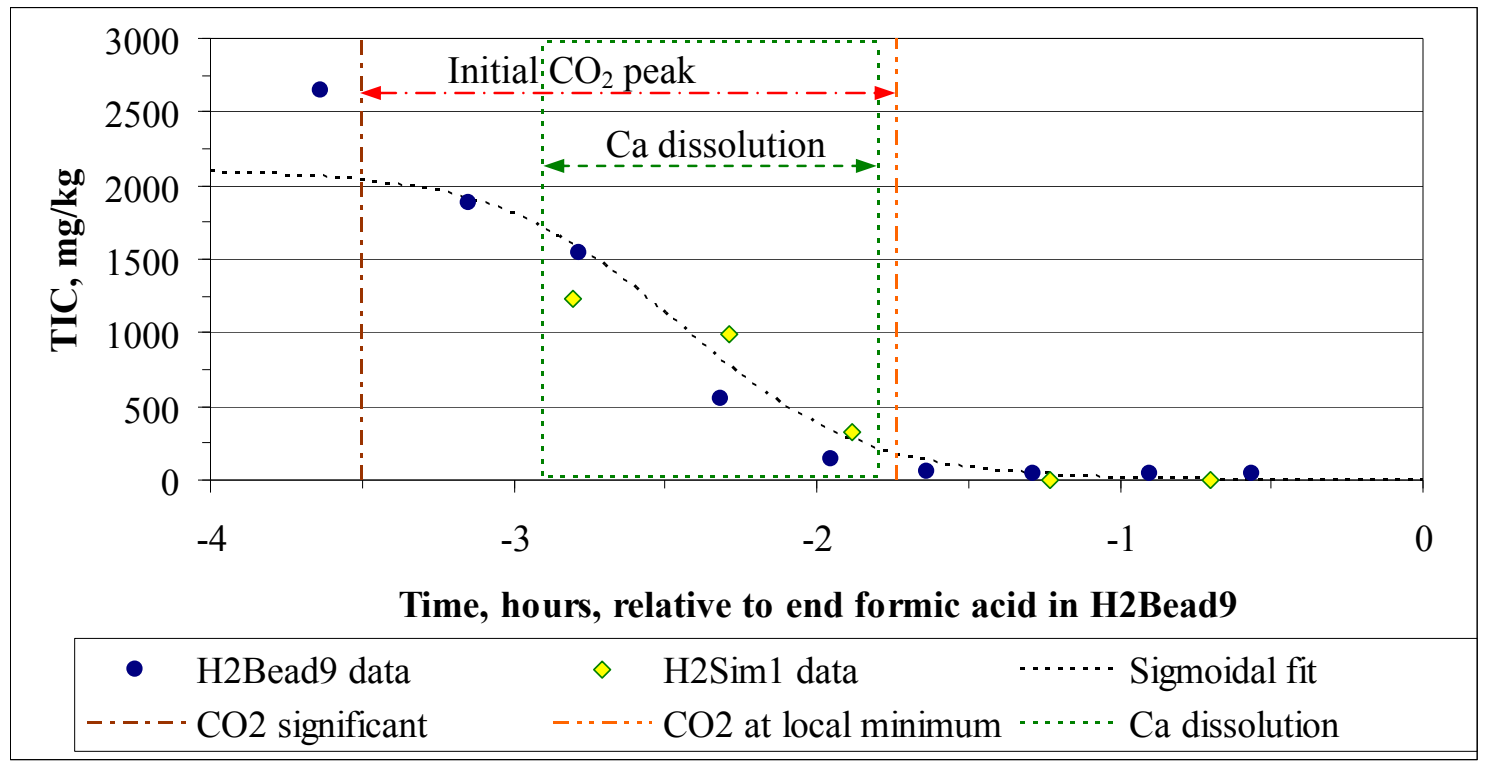

Figure 69. TIC concentration versus time

The TIC destruction sigmoidal function was of the form:

$$
\text { TIC }=\frac{2100 \mathrm{mg} / \mathrm{kg}}{1+e^{-u}}, u=\frac{t-2.45 \text { hours }}{0.3 \text { hours }}
$$

The three parameters were not entirely freely chosen. The $2,100 \mathrm{mg} / \mathrm{kg}$ represents the apparent initial concentration at the onset of TIC destruction, and the 2.45 hours represents the time of $50 \%$ destruction. The 0.3 hours adjusts the abruptness of the transition from 2,100 to $0 \mathrm{mg} / \mathrm{kg}$ and is the one truly adjustable parameter.

The $\mathrm{CO}_{2}$ generation rate data from $\mathrm{H} 2 \mathrm{Bead} 9$ during acid addition were taken and partitioned into two normal probability functions. The partitioning took the form of the sum of two distinct Gaussian distributions:

$$
g \mathrm{CO}_{2} / \min =1.95 * e^{-0.5 u^{2}}+1.4 * e^{-0.5 v^{2}}, v=\frac{t-0.65 \text { hours }}{0.8 \text { hours }}
$$




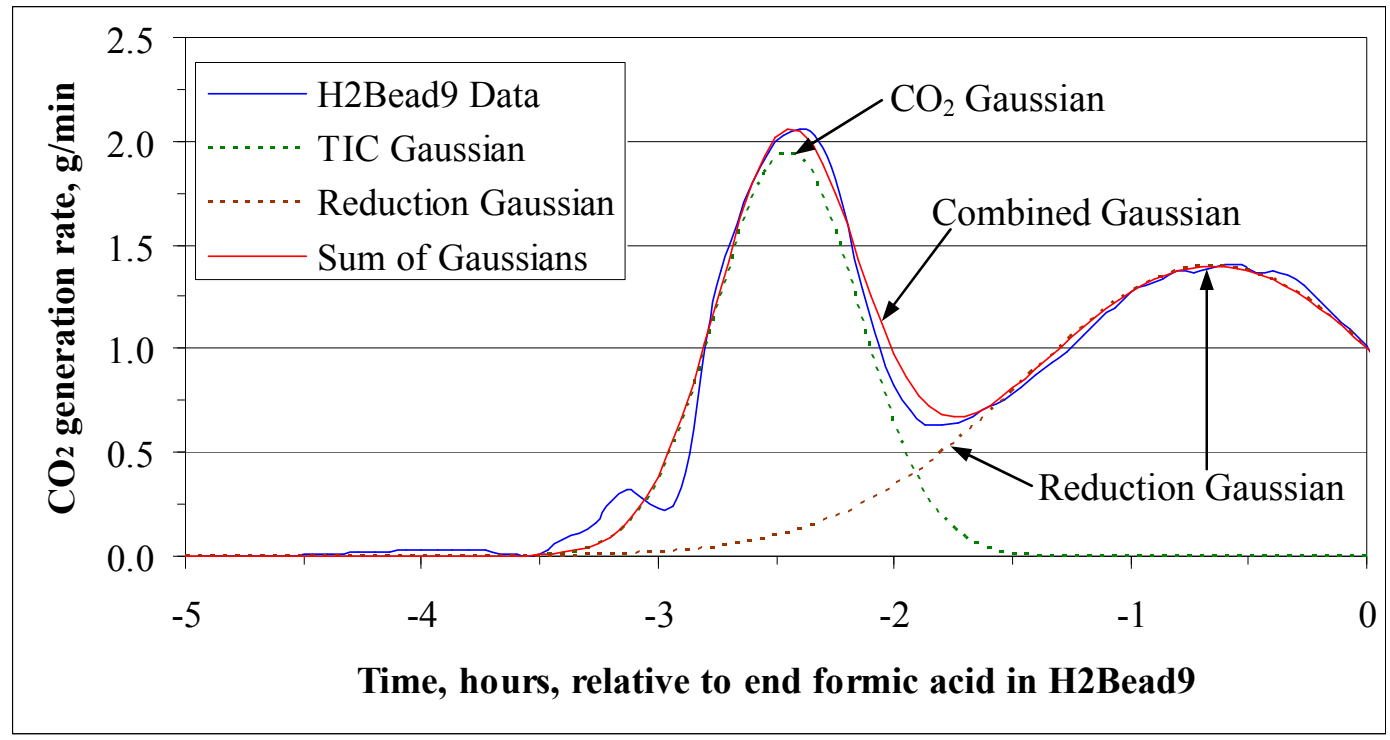

Figure 70. Partitioning of $\mathrm{H} 2 \mathrm{Bead} 9 \mathrm{CO}_{2}$

The same normalized variable, $\mathrm{u}$, was used to fit the first peak in $\mathrm{CO}_{2}$ generation that was used to describe the TIC destruction data. The second variable, $\mathrm{v}$, describes the $\mathrm{CO}_{2}$ produced by reduction reactions on $\mathrm{Mn}$ and nitrite ion. The two variables $\mathrm{u}$ and $\mathrm{v}$ are associated with the variances, or breadths, of the two Gaussian distributions shown. Although this approach to correlating the two phenomena is empirical, the fact that a variable of the form, $\mathrm{u}$, could be found that described both the TIC destruction profile and the $\mathrm{CO}_{2}$ generation rate profile should satisfactorily establish that the first big peak in $\mathrm{CO}_{2}$ generation is due to carbonate destruction. (Note that the integral of a normal probability function produces a sigmoidal-shaped function as the cumulative probability distribution.)

A molar acid balance through the midpoint of acid addition at 22-L run scale (14.41 L untrimmed sludge) provided the information in Table 21 and closed to within $2 \%$.

Table 21. Acid Used Through Period 2

\begin{tabular}{|l|c|}
\hline Term & Moles of acid \\
\hline Acid added at $50 \%$ total & 14.09 \\
\hline Titrated base equivalents neutralized & 4.52 \\
\hline $\mathrm{Mg}(\mathrm{OH})_{2}$ base neutralized & 3.91 \\
\hline $\mathrm{CaCO}_{3}$ base neutralized (at $80 \%$ of total $\left.\mathrm{Ca}\right)$ & 3.03 \\
\hline Mn reduced (at $25 \%$ total $\mathrm{Mn}$ ) & 1.44 \\
\hline Soluble TIC (as bicarbonate) destroyed & 0.94 \\
\hline Total acid accounted for by individual terms & 13.84 \\
\hline
\end{tabular}

Soluble TIC was calculated from the supernate TIC of the untrimmed sludge. It was assumed that the soluble TIC was 100\% bicarbonate on average at the start of Period 2 (after addition of acid to consume the base equivalents). Literature titration curves of $\mathrm{Na}_{2} \mathrm{CO}_{3}$ support the assumption that $\mathrm{pH} 7$ is about midway between the two equivalence points with respect to the quantity of acid required to convert the 
carbonate ion to bicarbonate to carbon dioxide. $\mathrm{CaCO}_{3}$ could have been set to $71 \%$ instead of $80 \%$ of the total $\mathrm{Ca}$, reducing that term from 3.03 moles to 2.69 moles, and the total to 13.50 . The rest of the terms are fairly certain (speciation of $\mathrm{Mg}$ is also known from the simulant preparation recipe in this case, but if it were present as an insoluble carbonate instead, then that would have no impact on the moles of acid required to dissolve it).

\subsection{Period 3: pH 5 to the End of Acid Addition}

The amount of acid added during Period 3 exceeded the quantity required to complete Mn dissolution and nitrite destruction. Initial 4-L testing achieved nitrite destruction to $<1,000 \mathrm{mg} / \mathrm{kg}$ in the SRAT product with less than $80 \%$ of the total acid added in the $22-\mathrm{L}_{\text {runs. }}{ }^{7}$ Nevertheless, $22-\mathrm{L}$ data from some of the bead-frit tests had 100\% acid consumption by the end of the SRAT cycle (SRAT product $\mathrm{pH}>7$ ). Analysis of off-gas and supernate data from the eight 22-L starting systems indicated that the chemistry diverged to some extent during Period 3. The reactions that occurred were not identical in all cases. All eight pairs did achieve essentially 100\% nitrite destruction and $100 \%$ Mn dissolution at or near the end of acid addition.

The $\mathrm{pH}$ at the end of acid addition varied considerably. The SRAT $\mathrm{pH}$ went to its minimum value at the end of Period 3 in the eight runs with $\mathrm{Ru}$ alone, Ag alone, or no noble metals. The four runs with $\mathrm{Rh}$ alone and two runs with $\mathrm{Pd}$ alone had a minimum in $\mathrm{pH}$ during Period 3 after which the $\mathrm{pH}$ began rising in spite of continuing acid addition. The Pd runs reversed a second time and began to fall with acid at the very end of acid addition. The two all noble metal runs reached $\mathrm{pH} 4.6$ about $60 \%$ of the way through Period 3, but the $\mathrm{pH}$ had risen back to 5.1 by the end of acid addition (the $\mathrm{pH}$ at the start of Period 3).

\subsubsection{Destruction of nitrite}

The major acid consuming reaction during Period 3 was nitrite destruction. Mn reduction was next in significance. A total of 6.6 moles of nitrite were destroyed during Period 3, while the completion of Mn reduction by formic acid (75\%, after $25 \%$ reduction in Period 2$)$ required 4.3 moles of additional acid. The data from the initial 4-L study indicated that nitrite destruction averaged about 1-1.1 moles of acid per mole nitrite destroyed. ${ }^{7}$ Therefore, reducing the remaining Mn and destroying nitrite consumed approximately 10.9-11.6 moles of the 14.1 moles of acid added during Period 3 unless the nitrite demand changed significantly. This acid range from $\mathrm{Mn}$ and nitrite destruction, taken with the potential presence of 5.6 moles of excess acid, would seem to more than account for the balance of the actual acid addition in these runs. Note that the lowest acid 4-L run achieved nitrite destruction, but only had about $63 \% \mathrm{Mn}$ reduction by the end of the run. Process samples from the bead-frit runs during Period 3 showed that nitrite destruction and $\mathrm{Mn}$ reduction were in direct competition for available acid during Period 3; in other words, they were parallel reactions.

The analysis of Period 3 chemistry by material balance on nitrogen-containing species was further complicated by the analysis of data for nitrite, nitrate, and the gaseous oxides of nitrogen produced from the eight pairs. The only possible conclusion from the data was that both the rate and end result of nitrite destruction were impacted by the noble metal contents. The end result of nitrite destruction is the distribution of nitrogen among the various product species (nitrate, $\mathrm{NO}_{\mathrm{x}}$, ammonium ion, etc.). There were matching variations in the quantity of $\mathrm{CO}_{2}$ produced through the end of Period 3. These changes confirmed that formic acid reduction of nitrite varied significantly from system to system. Another complicating factor in tracking nitrite and nitrate destruction was the presence of ammonium ion in the SRAT product and in the SRAT FAVC condensate of certain catalytically active cases.

The first sign that nitrite destruction was varying came from the SRAT product analyses. The anion data were used to update the acid calculation spreadsheet with corrected values for formate loss, nitrite-tonitrate conversion, etc., Table 15 in Section 4.2. These measures varied considerably with trim 
composition. The second indication of variation came from the tabulated values of individual quantities in the nitrogen species balances, Table 18 in Section 4.3. Significant reproducible variations were occurring in individual terms. The $\mathrm{NO}, \mathrm{NO}_{2}$, and $\mathrm{N}_{2} \mathrm{O}$ were primarily produced in Period 3 with some continuation into Period 4. Agreement of the $\mathrm{N}_{2} \mathrm{O}$ values within a pair was generally fairly good in the seven cases where a comparison was possible. The NO values agreed somewhat within a pair, but the main factor relevant to the nitrogen balance was that the NO contribution was typically less than $4 \%$ of the total nitrogen leaving the system. Reasonable agreement was obtained for the $\mathrm{NO}_{2}$ values of the even numbered frit runs with their matching bead runs. Currently the $\mathrm{NO}_{2}$ values for $\mathrm{H} 2 \mathrm{Frit} 3$, 5, and 7 are considered suspect due to general issues with the GC that was used on the four odd-numbered frit runs.

Results for $\mathrm{N}_{2} \mathrm{O}$ will be discussed first of the three $\mathrm{GC} \mathrm{NO}_{x}$ gases, since this gas was directly determined by a calibrated GC, while assumptions and calculations were needed to estimate the $\mathrm{NO}$ and $\mathrm{NO}_{2}$ values. Although the numbers say much the same thing, Figure 71 shows more clearly the impact of noble metals on $\mathrm{N}_{2} \mathrm{O}$ generation. The figure was limited to the four runs at identical $0.2 \mathrm{wt} \%$ noble metal loading plus the baseline no noble metal case for simplicity.

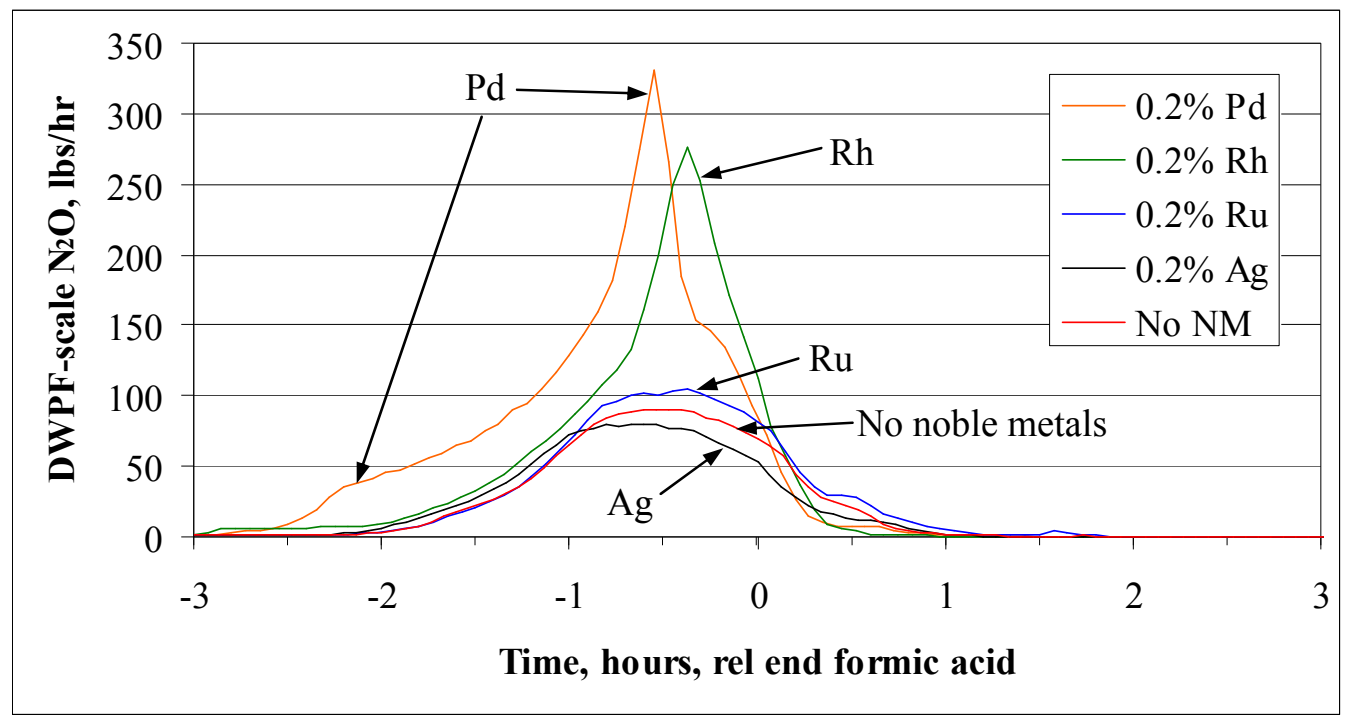

Figure 71. Noble metal impact on $\mathrm{N}_{2} \mathrm{O}$

Palladium was the most effective catalyst for $\mathrm{N}_{2} \mathrm{O}$ formation of the four noble metals under these SRAT processing conditions. Data presented in the parallel hydrogen report show that Pd dissolved sooner and left solution sooner than $\mathrm{Rh}$ and $\mathrm{Ru}$, which seems consistent with $\mathrm{Pd}$ driven $\mathrm{N}_{2} \mathrm{O}$ generation starting and peaking sooner than the other cases. Rhodium produced slightly less $\mathrm{N}_{2} \mathrm{O}$ than $\mathrm{Pd}$, while the other three cases in Figure 71 were arguably about the same (while the three peak areas integrate to slightly different quantities, the generally similar shape, timing, etc. of the $\mathrm{Ru}, \mathrm{Ag}$, and no noble metal curves suggests that the differences could be attributed to analytical errors. Data from the $0.375 \mathrm{wt} \% \mathrm{Ru}$ run confirmed that $\mathrm{Ru}$ was a weak catalyst for $\mathrm{N}_{2} \mathrm{O}$ production. $\mathrm{N}_{2} \mathrm{O}$ production was high in the all noble metal run with 0.1 $\mathrm{wt} \% \mathrm{Pd}$ and $\mathrm{Rh}$. The all noble metal pair was the third highest in terms of total $\mathrm{N}_{2} \mathrm{O}$ formation after the $0.2 \mathrm{wt} \% \mathrm{Pd}$ pair and $0.2 \mathrm{wt} \% \mathrm{Rh}$ pair. The addition of $\mathrm{Hg}$ greatly suppressed $\mathrm{N}_{2} \mathrm{O}$ production in the case of $0.2 \mathrm{wt} \% \mathrm{Ru}$ as the only noble metal, Figure 43, page 43.

Palladium is a known catalyst for hydrogen generation, and $\mathrm{Pd}$ is clearly catalytically active for $\mathrm{N}_{2} \mathrm{O}$ production, so hydrogen could also be forming in parallel with nitrite destruction. Hydrogen did not become detectable in the downstream off-gas during the two Pd runs until about -0.8 hours or as the $\mathrm{N}_{2} \mathrm{O}$ 
peaked and began to fall. Palladium is also a room temperature hydrogenation catalyst for destruction of nitrite ion. ${ }^{13,14}$ Reaction products include $\mathrm{N}_{2}, \mathrm{NH}_{3}, \mathrm{NO}$, and hydroxide ions. It is possible that hydrogen production due to $\mathrm{Pd}$ is consumed by nitrite ion hydrogenation until the nitrite ion concentration is driven below a concentration that permits some of it to escape into the off-gas system. Confirmation of this reaction had seemed unlikely, since the $\mathrm{N}_{2}$ produced would be a small fraction of the air purge $\mathrm{N}_{2}$, the NO would be lost in the NO being produced from reactions [5] and [6] in Section 2.4.4, and detection of ammonium ion in the slurry could be attributed to other reactions. At $0.2 \mathrm{wt} \% \mathrm{Pd}$, however, it appears that the production of base associated with the hydrogenation reaction, but with none of the other nitrite destruction reactions in Section 2.4.4, may have been detected, Figure 72.

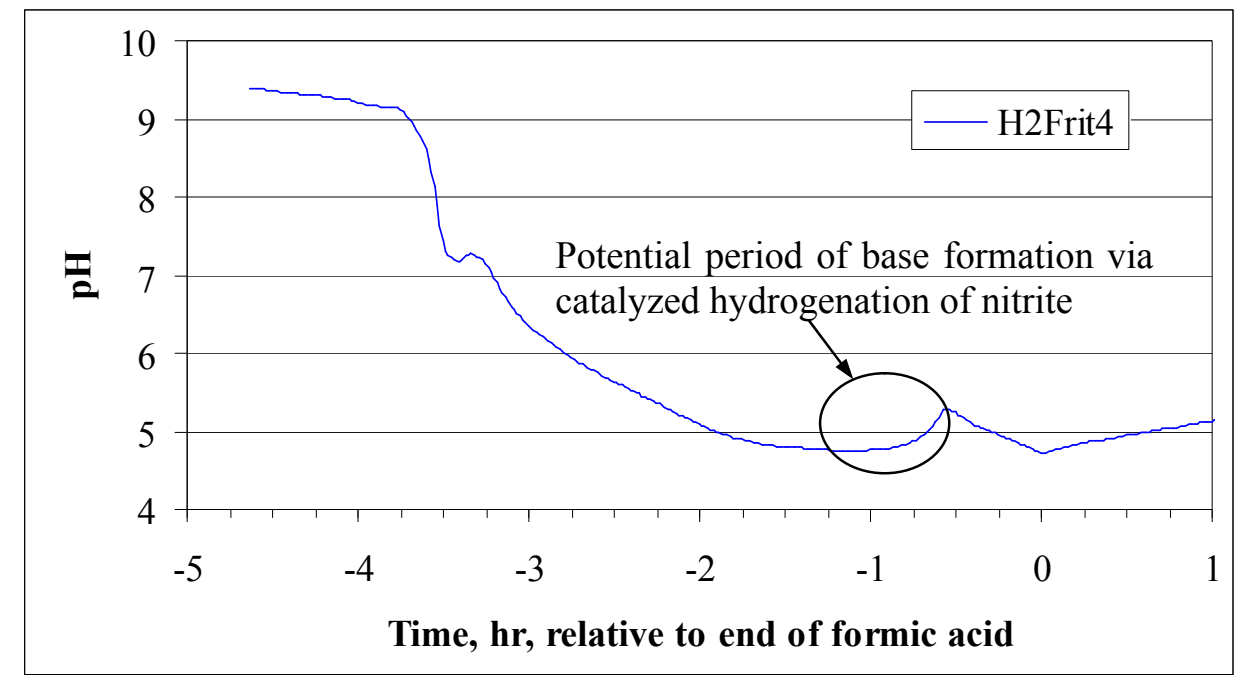

Figure 72. Profile of $\mathrm{pH}$ with $0.2 \mathrm{wt} \% \mathrm{Pd}$

Although small changes in $\mathrm{N}_{2}$ are difficult to detect, the air and helium purge flows are controlled very precisely and the ratio of $\mathrm{N}_{2} / \mathrm{He}$ fed to the SRAT should be constant. In addition to that, both gases are measured on the A column of the GC, so small variations in the injection volume should bias both gases by about the same amount. Therefore, a graph was prepared of the ratio of $\mathrm{N}_{2} / \mathrm{He}$ during nitrite destruction for the two runs with $0.2 \mathrm{wt} \% \mathrm{Pd}$, Figure 73. 
WSRC-STI-2008-00131

Revision 0

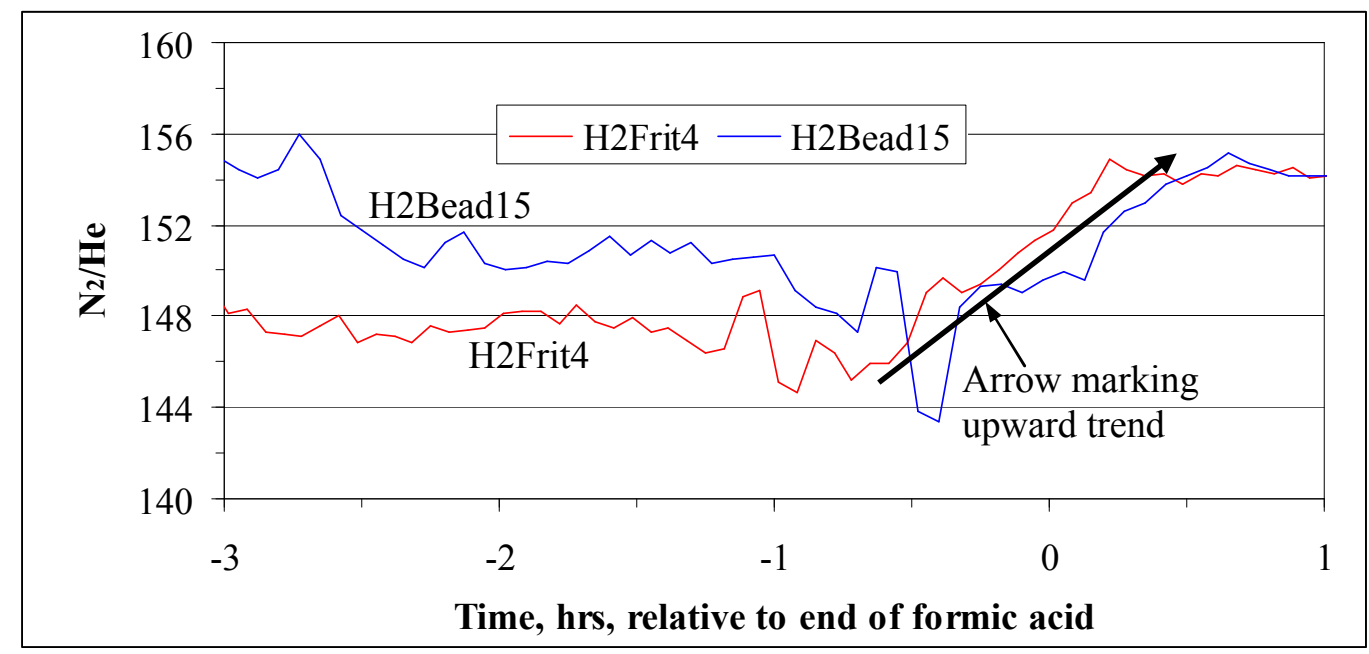

Figure 73. Test for $\mathrm{N}_{2}$ generation with $0.2 \mathrm{wt} \% \mathrm{Pd}$

Both sets of data show a slowly increasing ratio of $\mathrm{N}_{2}$ to He during the last 45-50 minutes of formic acid addition up until about the start of boiling 30 minutes later that could be due to hydrogenation of nitrite ion to $\mathrm{N}_{2}$. The trend (arrow) is close to the noise level of the data, but it did appear to occur at the same time in both runs. The rise in $\mathrm{N}_{2} / \mathrm{He}$ comes immediately after the period of rising $\mathrm{pH}$. This is consistent with proposed multi-step mechanisms for nitrite hydrogenation and the dynamics of the measurements involved. The proposed kinetics proceeds by adsorption of nitrite ion onto $\mathrm{Pd}$, liberation of one of the nitrite oxygen atoms as hydroxide and formation of adsorbed NO, liberation of the second nitrite oxygen atom and combination of two nitrogen atoms to form $\mathrm{N}_{2}$, and finally desorption of the $\mathrm{N}_{2}$ molecule. In addition to the fact that the $\mathrm{N}_{2}$ liberation occurs later in the reaction sequence than the liberation of hydroxide ion, the $\mathrm{pH}$ probe was giving a real time measurement of the slurry $\mathrm{pH}$. The off-gas GC data, however, are about ten minutes behind real time. So the rising $\mathrm{N}_{2} / \mathrm{He}$ data probably partially overlap the rising $\mathrm{pH}$ data as expected for sequential reactions. Desorption of the NO intermediate prior to $\mathrm{N}_{2}$ formation at SRAT processing temperatures may help to explain why the impact of this reaction on the available process analytical measures is difficult to observe.

The $\mathrm{pH}$ and $\mathrm{N}_{2} / \mathrm{He}$ data appear to be the strongest evidence to date for a potential hydrogenation reaction of nitrite ion during the SRAT. The simultaneity of the appearance of hydrogen relative to the peak in $\mathrm{N}_{2} \mathrm{O}$ is shown in Figure 74. The onset of hydrogen and the drop in $\mathrm{N}_{2} \mathrm{O}$ coincide with the start of the rise in $\mathrm{N}_{2} / \mathrm{He}$. 
WSRC-STI-2008-00131

Revision 0

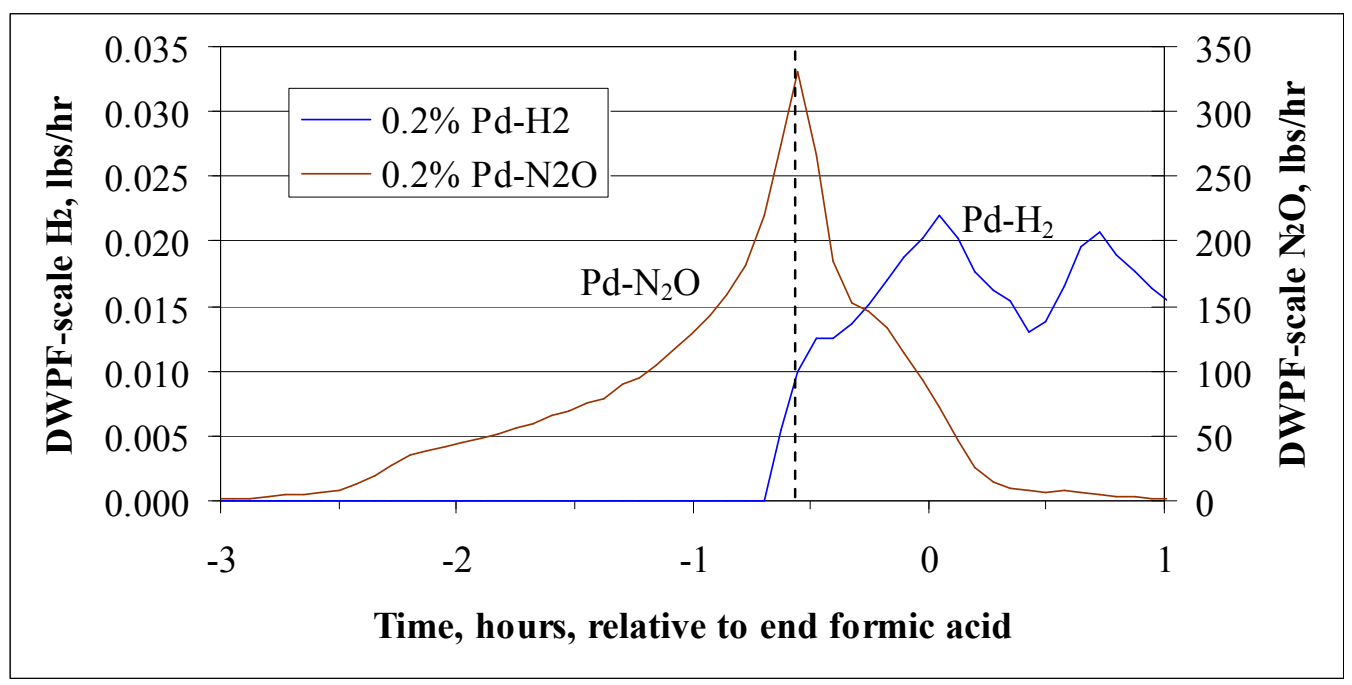

Figure 74. Hydrogen and $\mathrm{N}_{2} \mathrm{O}$ at $0.2 \mathrm{wt} \% \mathrm{Pd}$

Palladium may not be acting alone in SRAT runs with all noble metals. Other noble metals were reported to be catalysts for hydrogenation of nitrite in the technical journal articles. The $\mathrm{pH}$ was also rising in the $\mathrm{Rh}$ runs near the end of nitrite destruction, although this may have been due to the high rate of catalytic formic acid destruction rather than to hydrogenation of nitrite ion. Hydrogenation of nitrate, however, is more difficult than nitrite. Currently, bimetallic catalysts of copper and Pd are being developed to destroy nitrate in aqueous systems, since noble metals alone are ineffective on nitrate. ${ }^{15}$ Catalytic hydrogenation of nitrate to $\mathrm{N}_{2}$ and ammonium ion does not seem likely to be part of the SRAT chemistry, although it cannot be ruled out since the precise route(s) to SRAT product ammonium ion have not been established.

$\mathrm{N}_{2} \mathrm{O}$ production in the silver and no noble metal runs was about 1.7 moles, or only half the total of the 0.2 wt $\%$ Pd runs. $\mathrm{N}_{2} \mathrm{O}$ production at $0.2 \mathrm{wt} \% \mathrm{Ru}$ was not much higher at 1.9 moles average and increased only to 2.2 moles at $0.375 \mathrm{wt} \% \mathrm{Ru}$. The additional increase in $\mathrm{N}_{2} \mathrm{O}$ from no $\mathrm{Ru}$ to $0.2 \mathrm{wt} \% \mathrm{Ru}$ to 0.375 $\mathrm{wt} \% \mathrm{Ru}$ seemed to be roughly proportional to the increase in $\mathrm{Ru}$ content. Therefore, $\mathrm{Ru}$ may be a weak catalyst for $\mathrm{N}_{2} \mathrm{O}$ generation in the sludge system rather than a non-catalyst. The data indicate that silver was not a significant catalyst for $\mathrm{N}_{2} \mathrm{O}$ production. The $\mathrm{N}_{2} \mathrm{O}$ results from the $\mathrm{Rh}$ runs were intermediate between the Pd case and the other results. The first conclusion from these data is that the combined effects of $\mathrm{Pd}-\mathrm{Rh}-\mathrm{Ru}$ on nitrite destruction will be to increase $\mathrm{N}_{2} \mathrm{O}$ production as the total noble metal concentration increases when everything else is equal. The second conclusion is that the relative contribution to $\mathrm{N}_{2} \mathrm{O}$ formation ranks $\mathrm{Pd}>\mathrm{Rh}>\mathrm{Ru}>\mathrm{Ag} \approx 0$ for equivalent mass loadings. Associated with $\mathrm{N}_{2} \mathrm{O}$ production was a stoichiometric loss of formate ion, acid, and formation of $\mathrm{CO}_{2}$. Mercury impacts $\mathrm{N}_{2} \mathrm{O}$ production, but more data are needed from other systems to define the $\mathrm{Hg}$ impact in detail.

The no noble metal run case produced 5.75 moles of $\mathrm{CO}_{2}$ overall. Virtually none of this came after nitrite destruction (no catalysts to attack formate after all reduction reactions were complete). The minimum quantity of theoretical $\mathrm{CO}_{2}$ production associated with TIC destruction, $100 \% \mathrm{Mn}$ reduction, and the smallest $\mathrm{N}_{2} \mathrm{O}$ production in Table 18 per the reactions in Section 2.4 gave 5.65 moles of $\mathrm{CO}_{2}$. The minimum quantity of $\mathrm{CO}_{2}$ production came in the no noble metal run, the two runs with silver, and perhaps in H2Frit2 (all about 40 grams plus uncertainty). The no noble metal run and two runs with $\mathrm{Ag}$ are taken as being virtually inactive catalytically with respect to formate destruction to $\mathrm{CO}_{2}$ plus either hydrogen or water. 
The third conclusion is that the nitrite destruction reaction [6], or equivalently reaction [8], in Section 2.4 .4 appears to be $\sim 100 \%$ catalytically driven. This reaction is the formic acid reduction of nitrite to NO and $\mathrm{CO}_{2}$. This conclusion was based on the repeated absence of any unexplained $\mathrm{CO}_{2}$ formation in the catalytically inactive runs after accounting for TIC destruction, Mn reduction, and $\mathrm{N}_{2} \mathrm{O}$ formation using the numbers in the nitrogen and carbon balances. The fourth conclusion is that the relative contribution to $\mathrm{NO}$ formation by catalytic reduction with formic acid ranks $\mathrm{Rh} \approx \mathrm{Pd}>\mathrm{Ru}>\mathrm{Ag} \approx 0$ for equivalent loadings. This ranking applies to reaction [6] in Section 2.4.4.

Table 22 shows the theoretical contributions to $\mathrm{CO}_{2}$ production from TIC destruction, Mn reduction, and $\mathrm{N}_{2} \mathrm{O}$ generation, and how the sum of these compares to the total measured $\mathrm{CO}_{2}$ produced through the approximate end of $\mathrm{NO}_{\mathrm{x}}$ generation. Either run pair average values or best case values were used to calculate the $\mathrm{CO}_{2}$ production and the stoichiometric $\mathrm{CO}_{2}$ from $\mathrm{N}_{2} \mathrm{O}$ generation, depending on the perceived magnitude of $\mathrm{GC}$ issues. $\left(\mathrm{NO}_{\mathrm{x}}\right.$ generation and associated $\mathrm{CO}_{2}$ production continued 0.2-1.2 hours past the end of Period 3 depending on the system, but this discussion fits better here than under Period 4.)

Table 22. Contributions to $\mathrm{CO}_{2}$ through end of $\mathrm{NO}_{x}$

\begin{tabular}{|l|c|c|c|c|c|}
\hline & $\begin{array}{c}\mathrm{TIC} \\
\mathrm{g} \mathrm{CO}_{2}\end{array}$ & $\begin{array}{c}\mathrm{Mn} \\
\mathrm{g} \mathrm{CO}_{2}\end{array}$ & $\begin{array}{c}\mathrm{N}_{2} \mathrm{O} \\
\mathrm{g} \mathrm{CO}_{2}\end{array}$ & $\begin{array}{c}\text { Sum } \\
\mathrm{g} \mathrm{CO}_{2}\end{array}$ & $\begin{array}{c}\text { Total } \\
\text { made }\end{array}$ \\
\hline $0.2 \mathrm{wt} \% \mathrm{Rh}$ & 88 & 85 & 136 & 309 & 360 \\
\hline $0.2 \mathrm{wt} \% \mathrm{Ru}$ & 88 & 85 & 84 & 257 & 290 \\
\hline $0.2 \mathrm{wt} \% \mathrm{Ag}$ & 88 & 85 & 75 & 248 & 240 \\
\hline $0.2 \mathrm{wt} \% \mathrm{Pd}$ & 88 & 85 & 163 & 336 & 360 \\
\hline $0.375 \mathrm{wt} \% \mathrm{Ru}$ & 88 & 85 & 97 & 270 & 340 \\
\hline $0.1 \mathrm{wt} \% \mathrm{Rh}$ & 88 & 85 & 107 & 280 & 320 \\
\hline No noble metals & 88 & 85 & 79 & 252 & 250 \\
\hline All noble metals & 88 & 85 & 120 & 293 & 360 \\
\hline
\end{tabular}

The results show that there generally was significant excess $\mathrm{CO}_{2}$ production (35-70 g) above that from the three terms given in the table when an active catalyst was present $(\mathrm{Pd}, \mathrm{Rh}$, and/or $\mathrm{Ru})$. The difference in $\mathrm{CO}_{2}$ between total made and the sum of the three listed contributions was used to estimate an upper bound for nitrite destruction via reaction [6] or [8], though the results could be subject to the small difference of large numbers phenomenon resulting in relatively large uncertainties. Even with perfect accuracy for $\mathrm{N}_{2} \mathrm{O}$ and $\mathrm{CO}_{2}$ masses, the difference would include not only $\mathrm{CO}_{2}$ from $\mathrm{NO}$ formation but also $\mathrm{CO}_{2}$ associated with the onset of hydrogen generation which overlapped the end of $\mathrm{NO}_{\mathrm{x}}$ formation during Period 4 for most runs except the Ru runs.

\subsubsection{Implications of nitrite destruction data for acid consumption}

The above partitioning of destroyed nitrite moles gave average coefficients for the stoichiometric acid requirement for nitrite in the eight cases ranging from 1.0-1.6 moles acid/mole nitrite. The higher numbers were in the more catalytically active systems (including the $0.2 \% \mathrm{Pd}$ case which was particularly active during nitrite destruction if not for hydrogen production). The lower numbers were in the no noble metal and $0.2 \% \mathrm{Ag}$ system. No further attempt was made to partition the nitrite destruction data among the three parallel paths, such as was done in the initial simulant study. ${ }^{7}$ The main reason was the low overall nitrite-to-nitrate conversion in the runs that produced ammonium ion by destroying nitrate. Ammonium ion formation complicated the nitrogen balance analysis. 
For the silver runs and no noble metal runs, where no excess $\mathrm{CO}_{2}$ was indicated, the nitrite destruction was presumably limited to just two reaction paths, [5] and [7]. For these two systems, about $26 \%$ of the nitrite converted to $\mathrm{N}_{2} \mathrm{O}$ via [7] and $74 \%$ converted to nitrate plus $2 \mathrm{NO}$ via [5]. This partition implies that the nitrite-to-nitrate conversion should have been $74 \% / 3 \approx 25 \%$. The three plausible nitrite-to-nitrate conversion values for these four runs from Table 15 were 15,26 , and $18 \%$, all $\pm 10 \%$, which were deemed consistent with $25 \%$ deduced from the off-gas data (H2Bead11 SRAT product nitrate had issues discussed earlier). The calculated stoichiometric coefficient for nitrite destruction for the no noble metal and Ag runs was the weighted sum of $25 \%$ times two plus $75 \%$ times two-thirds, or 1.0 moles acid per mole nitrite.

The fifth conclusion was that in the absence of $\mathrm{Hg}$, the destruction of nitrite ion requires at least one mole of acid per mole of nitrite. This parallel calculation of acid consumption supports the derived nitrite destruction coefficients for these two cases. Reconciling the nitrite-to-nitrate conversion results in the other six cases was not possible due to the unknown extent of nitrate to ammonium conversion.

The sixth definitive conclusion from the nitrogen species balances was that the coefficient for nitrite in the stoichiometric acid equation should be a function of sludge composition rather than a constant. The range of calculated coefficients was not enormous, however, given the bounding concentrations of noble metals tested. Therefore, it is arguably sufficient to use a reasonable average constant or a bounding constant for more moderate noble metal concentrations. The initial simulant testing, ${ }^{7}$ which included mercury and more typical noble metal concentrations, produced coefficients in the 1.0-1.2 moles acid per mole nitrite range. These coefficients overlap with the range of results from the sixteen bead-frit runs and align more closely with the less catalytically active systems as would be expected.

An earlier evaluation of the DWPF acid equation for high oxalate $(>10,000 \mathrm{mg} / \mathrm{kg})$ systems derived a coefficient of $1.95 \mathrm{moles}$ acid/mole nitrite. This equation, however, absorbed most of the uncertainty in acid consumption into the various terms, e.g. base equivalents was multiplied by $1.47{ }^{16}$ Factoring the implicit $147 \%$ stoichiometric factor out of the individual coefficients gives the more realistic coefficient for nitrite destruction of 1.33 moles acid per mole nitrite. This coefficient is also well within the range of values seen in the bead-frit runs. The corrected SB3 high oxalate equation term may be further overstated, due to potential statistical correlations between the acid requirement for Mn reduction and nitrite destruction in the model data that were used to derive the high oxalate acid equation. It appears that a coefficient of 1.15 moles acid per mole nitrite would describe most of the historically available data with an uncertainty of about $\pm 15 \%$, and a value of 1.1 moles acid per mole nitrite is recommended as reasonable in order to keep the coefficient slightly biased toward the conservative end of the range. A value of $1.0 \mathrm{moles}$ acid/mole nitrite would be even more conservative and would be more appropriate for estimating a minimum quantity of acid required, i.e. a lower bound for acid consumed during nitrite destruction in the presence of noble metal catalysts at nominal SRS waste ranges.

Historical data on near minimum acid requirements for nitrite destruction have been collected into a small statistical database. A preliminary acid requirement model was developed before the latest data were available, but after the significance of $\mathrm{Mg}$ dissolution at $\mathrm{pH}$ 's below seven was recognized. The model assumed nitrite destruction to less than $1,000 \mathrm{mg} / \mathrm{kg}$ in the SRAT product, $50 \%$ reduction of $\mathrm{Mn}$, and a 60:40 split between soluble and insoluble carbonates with one mole acid per mole soluble carbonate and two moles acid per mole insoluble carbonate combined into a weighted average coefficient of 1.4 moles acid per mole total slurry TIC. The assumption on soluble and insoluble carbonates was necessary due to limited data on supernate TIC.

The ability of a preliminary model to explain the observed minimum acid requirement on data from SB1SB4 is shown in Figure 75. Data from high oxalate systems were excluded from the analysis due to the 
complex effect of oxalate on titration results, acid consumption, and SRAT chemistry. All terms in the equation are in moles of species per liter of sludge slurry, e.g. Base Equivalents is moles of equivalent hydroxide ion per liter of sludge slurry.

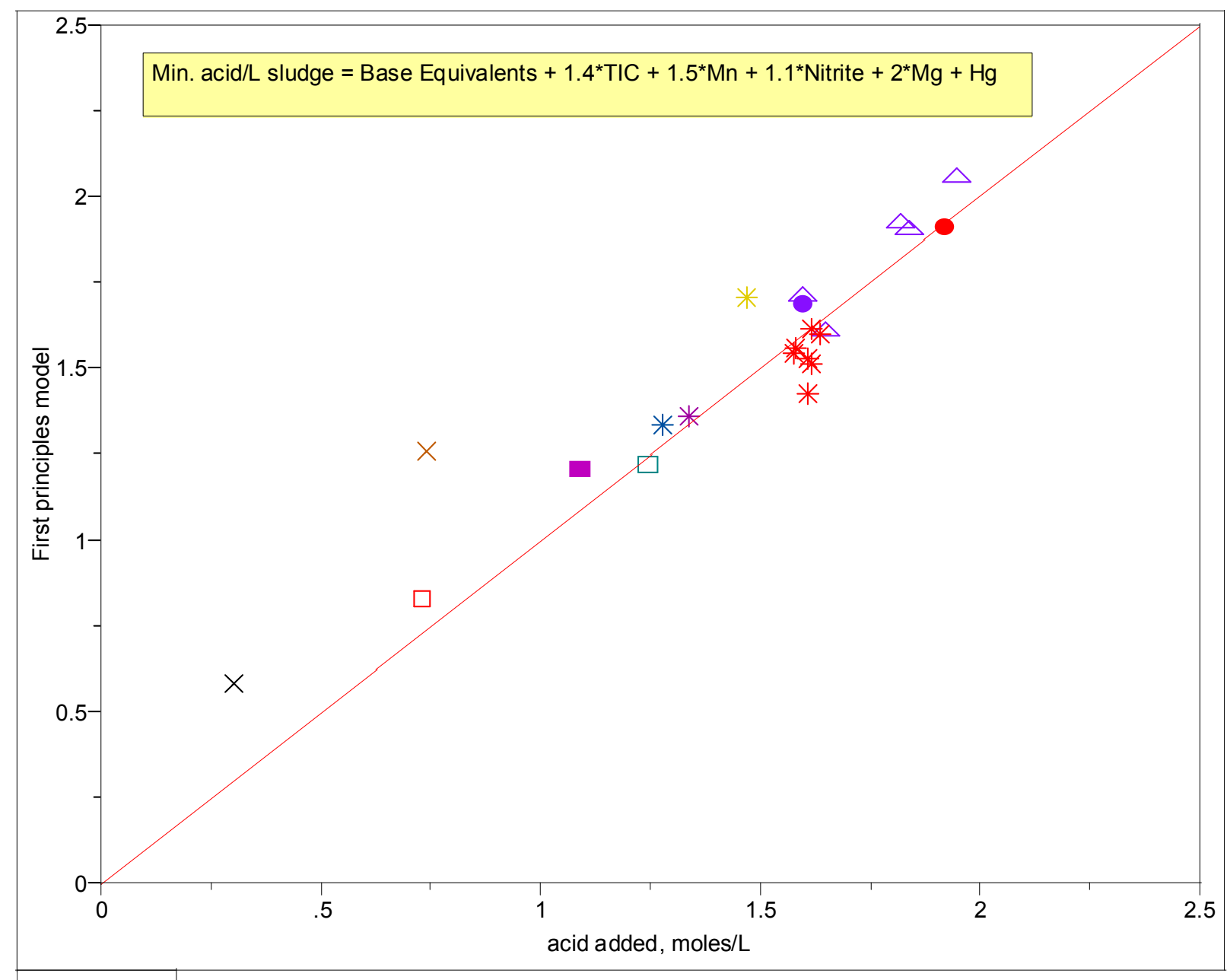

Figure 75. Comparison of minimum acid data versus model equation

This figure was generated using the JMP statistical platform after constructing a hypothetical linear model for acid consumption. On this graph, a point below the $45^{\circ}$ line represents a system with a minimum acid requirement above that calculated by the model. The agreement between model and most of the experimental data can be seen to be quite good qualitatively. More will be said about this model and potential revisions to it in the rest of this section. This model is fundamentally first principles in nature and not the result of a regression analysis. There is no stoichiometric factor adjusting the model, i.e. the model is taken at $100 \%$. The model equation is subject to the assumptions about soluble versus insoluble TIC and that nitrite destruction can be completed before $\mathrm{Mn}$ is more than 50\% reduced. The main reason for introducing this graph here was to show that a coefficient of 1.1 moles acid per mole nitrite worked well in explaining historical data on minimum acid requirements.

Data obtained in the bead-frit study suggest several potential improvements to the postulated model equation for the stoichiometric acid requirement. First, the insoluble TIC in this study, and apparently in coprecipitated simulant studies and in Cells runs with real waste, is primarily associated with the 
dissolution of carbonates of $\mathrm{Mg}$ and $\mathrm{Ca}$. In the traditional simulants used exclusively prior to SB4 as well as in the bead-frit study, $\mathrm{Mg}$ and $\mathrm{Ca}$ were introduced as $100 \% \mathrm{Mg}(\mathrm{OH})_{2}$ and $\mathrm{CaCO}_{3}$. In coprecipitated simulants, the $\mathrm{Ca}$ can also precipitate as $\mathrm{Ca}(\mathrm{OH})_{2}$ which is more soluble than $\mathrm{Mg}(\mathrm{OH})_{2}$. A subsequent carbonate strike following caustic precipitation during simulant preparation tends to scavenge residual soluble $\mathrm{Mg}, \mathrm{Ca}$, etc. as carbonates. Historical SRAT sample data from all three types of systems show extensive dissolution of both $\mathrm{Mg}$ and $\mathrm{Ca}$ in the SRAT product supernate. Small quantities of other species that dissolve, and may have been present as carbonates, have been neglected to a first approximation.

Having the new first principles term of the form $2 *(\mathrm{Mg}+\mathrm{Ca})$ in the stoichiometric acid equation could replace the need to measure slurry TIC. Such a term would also cover the acid consumed in dissolving either species as a hydroxide instead of as a carbonate. This part of acid consumption is missed by the base equivalents titration to $\mathrm{pH}$ seven, and it is not picked up by the other terms in the current DWPF acid equation. The measurement of slurry TIC could be replaced by a measurement of soluble TIC multiplied by a coefficient of about one mole acid per mole soluble TIC (the other mole of acid required to destroy soluble TIC is approximately picked up during the base equivalents titration). The measurement of soluble TIC is simpler than the measurement of insoluble TIC due to solids plugging the sample lines. This proposed change would not only better capture the actual acid consumers, but it should also reduce the uncertainty in the calculated acid requirement due to slurry TIC measurement variability.

Manganese reduction presents a choice as to how to include a suitable goal for it in the acid requirement model. Using a factor of three moles acid per mole Mn would put in the acid needed to get $100 \%$ reduction from +4 to +2 . There is, however, no requirement for the DWPF SRAT to achieve $100 \% \mathrm{Mn}$ reduction. Mn reduction overlaps nitrite destruction and competes with it for acid after $\mathrm{Mg}$ and $\mathrm{Ca}$ dissolution. Some of the data seem to indicate that $100 \% \mathrm{Mn}$ reduction can be achieved before nitrite destruction is completed, but closer scrutiny shows that the speed of nitrite destruction is being impacted by the noble metal and mercury concentrations. As the catalytic activity of the noble metals goes up, nitrite destruction uses more of the available acid, and $\mathrm{Mn}$ reduction uses what is left over, i.e. takes longer. The choice of a coefficient of three moles acid per mole Mn would tend to ensure that both $\mathrm{Mn}$ reduction and adequate nitrite destruction occur simultaneously. Other species, such as $\mathrm{Ni}(\mathrm{OH})_{2}$, also begin to compete for the available acid during Mn reduction. These contributions to acid consumption, though not particularly large, are not accounted for in the stoichiometric acid consumption equation. Acid consumption by these lesser reactions reduces the potential rate of accumulation of excess acid in the latter stages of acid addition. Consequently, less acid remains for hydrogen generation than expected based on the major reactions alone as $\mathrm{Mn}$ reduction and nitrite destruction are nearing completion.

Summarizing, the following issues appear to exist with the current stoichiometric acid equation being used by DWPF and SRNL compared to the chemistry observed in Periods 1-3:

- Nitrite destruction consumes more than 0.75 moles acid per mole nitrite.

- Mn reduction often consumes more than 1.2 moles acid per mole Mn.

- $\mathrm{Ca}$ and $\mathrm{Mg}$ dissolution involves significant acid consumption that is not in the current equation.

- Slurry TIC partially double counts titratable supernate carbonate, but this is insufficient to offset the three undercounted quantities above.

The result of the preceding discussion on acid requirements and potential model improvements led to the following proposed revised form of the first principles stoichiometric acid equation:

$$
\frac{\text { moles acid }}{L \text { slurry }}=\text { base equivalents }+ \text { soluble TIC }+1.1 * \text { nitrite }+2 *(C a+M g)+H g+A^{*} M n
$$


The current DWPF equation uses $\mathrm{A}=1.2$, or $40 \%$ reduction. Mn driven acid consumption is not always evident in the SRAT product supernate. Some of the systems tested previously, as well as in the bead-frit study, have subsequent partial or total $\mathrm{Mn}$ precipitation during reflux. The $\mathrm{pH}$ seven base equivalents term was retained, since it seems to have captured the acid consumption in Period 1. Insoluble TIC was eliminated from the proposed equation. Its effect, however, is still present in the terms for $\mathrm{Ca}$ and $\mathrm{Mg}$. Soluble TIC disappeared in Period 2 along with insoluble TIC. The coefficient on soluble TIC was changed from two to one to eliminate double counting the acid required for carbonate destruction. This is the result of titration studies that show that the base equivalents titration picks up the first of the two moles of acid required to destroy soluble carbonate. The chemistry of mercury reduction is well established, and virtually none of the simulant mercury participates in the base equivalents titration.

A potential practical issue exists with the new $\mathrm{Ca}$ and $\mathrm{Mg}$ term. Certain anions, e.g. oxalate or phosphate, bound to these two cations can apparently resist dissolution and would not necessarily require acid even if they did dissolve. To the extent that slurry $\mathrm{Mg}$ and $\mathrm{Ca}$ are tied up in comparatively insoluble forms, the coefficient of two on this term would tend to overstate the acid required. This situation was the case with the $\mathrm{ABC}$ blend simulant used in the bead-frit runs, where $\mathrm{Ca}$ dissolution peaked short of $80 \%$. The total $\mathrm{Ca}$ in the simulant, however, included additions of reagent grade $\mathrm{Ca}_{3}\left(\mathrm{PO}_{4}\right)_{2}$ and $\mathrm{CaC}_{2} \mathrm{O}_{4}$. That is, the recipe forced potentially insoluble forms to be present, and this may not be consistent with the speciation in real waste. A quick review of selected historical Shielded Cells and coprecipitated simulant data seemed to indicate that it was easier to get nearly complete dissolution of $\mathrm{Ca}$ than $\mathrm{Mg}$, rather than vice versa as seen here with traditional $\mathrm{ABC}$ simulant. This observation supports the hypothesis that $\mathrm{Ca}$ and $\mathrm{Mg}$ speciation was not perfectly matched between the two types of simulants or between simulant and real waste, but that the coprecipitated simulants are probably closer to real waste with respect to $\mathrm{Ca}$ and $\mathrm{Mg}$ than the traditional simulants.

\subsubsection{Nitrite converted to $\mathrm{NO}, \mathrm{NO}_{2}$, and $\mathrm{N}_{2} \mathrm{O}_{4}$}

As discussed in Section 3.0, the sum of $\mathrm{NO}$ plus $\mathrm{NO}_{2}$ produced was often more directly comparable within the $\mathrm{GC}$ data for a given pair of matched runs than the moles of either gas individually. The current understanding is that $\mathrm{NO}$ is produced during nitrite destruction and that $\mathrm{NO}_{2}$ is produced when the $\mathrm{NO}$ interacts with oxygen in the purge air. The two gases share a common origin in the sludge during processing, and only the sum is relevant to analyzing the nitrogen balance data to get at the partitioning of the nitrite destruction among the parallel paths.

Figure 76 presents the oxygen loss derived $\mathrm{NO}_{2}\left(+\mathrm{N}_{2} \mathrm{O}_{4}\right)$ generation rates versus the four noble metals at equal loading plus the no noble metal baseline. 


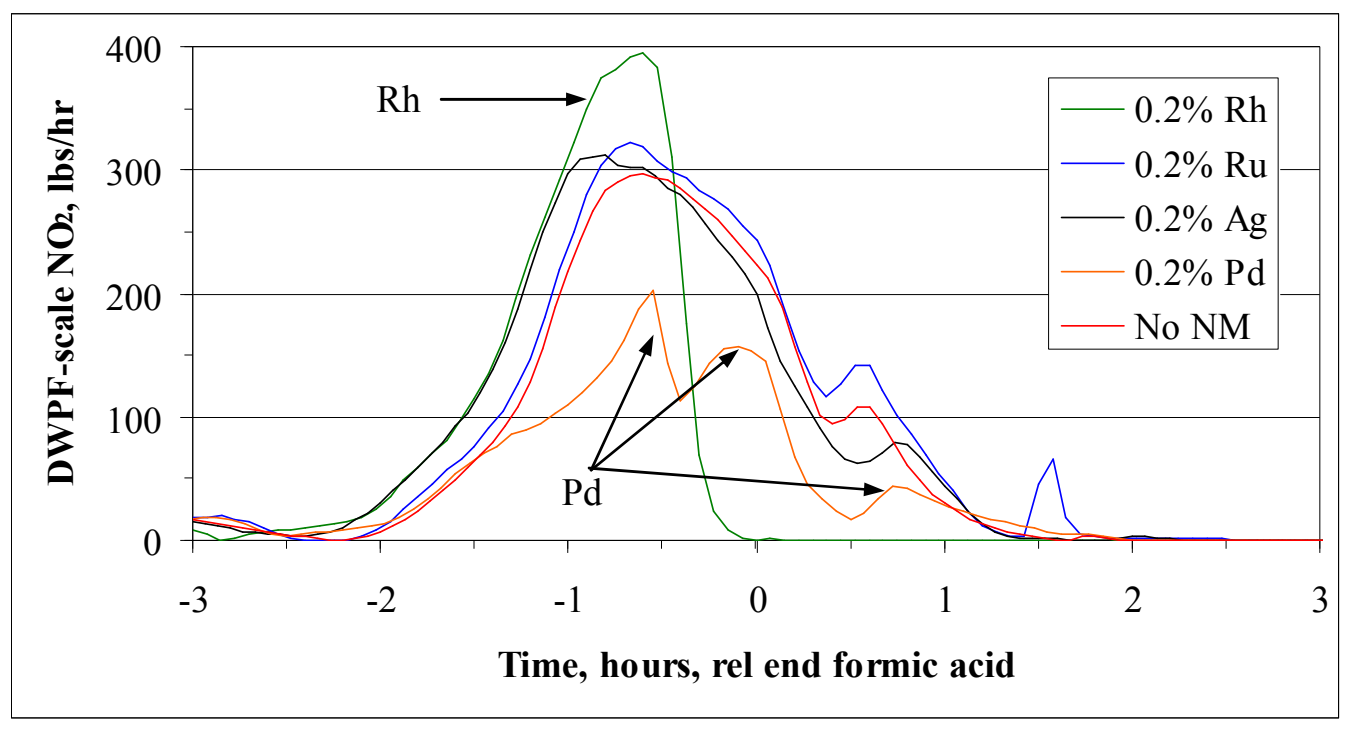

Figure 76. $\mathrm{NO}_{2}$ (and $\mathrm{N}_{2} \mathrm{O}_{4}$ ) as a function of noble metal

These data share a feature with the corresponding set of curves for $\mathrm{N}_{2} \mathrm{O}$. In both cases the data for the systems with $\mathrm{Rh}$ and $\mathrm{Pd}$ stood out from the other three sets. The Pd trace looks particularly unusual and contains a lot of structure. The peak at +0.75 hours is due to the onset of boiling. The remaining structure in the $\mathrm{Pd}$ trace is not due to $\mathrm{GC}$ issues. Two nearly identical traces of $\mathrm{NO}_{2}$ versus time were obtained from the two runs with $0.2 \mathrm{wt} \% \mathrm{Pd}$, Figure 19. The tests with $\mathrm{Rh}$ achieved significant nitrite destruction early and began hydrogen generation prior to the end of formic acid addition. That is apparent in the $\mathrm{NO}_{2}$ data more than in the $\mathrm{N}_{2} \mathrm{O}$ data, which persisted slightly into the time after the end of acid addition. It is possible that nearly all of the $\mathrm{NO}_{2}$ in the off-gas entering the SRAT condenser and FAVC can be absorbed into the aqueous condensate once the concentration falls below some critical number. MWWT data from the nitrate ISE, Appendix A, certainly support a rapid increase in nitrate ion concentration near the end of acid addition and start of dewatering. Since two different nitrite destruction reactions, [5] and [6] in Section 2.4.4, produce NO, these data by themselves are more useful for showing trends than analyzing nitrite destruction.

Rh appeared to catalyze some NO formation, while Pd appeared to inhibit it. The Pd catalyzed formation of $\mathrm{N}_{2} \mathrm{O}$ may be sufficient to explain the reduced $\mathrm{NO}_{2}$, since less nitrite remained for $\mathrm{NO}$ formation than in the other cases. $\mathrm{Rh}$, however, catalyzed both $\mathrm{N}_{2} \mathrm{O}$ and $\mathrm{NO}$ formation, which should negatively impact nitrite-to-nitrate conversion. The four $\mathrm{Rh}$ runs had negligible net nitrite-to-nitrate conversion during the SRAT cycle, but these runs also had some eventual nitrate to ammonium conversion during the SRAT cycle which obscured the nitrite-to-nitrate conversion during Period 3. Intermediate samples indicate that there was some nitrite-to-nitrate conversion in Period 3, and then a subsequent loss of nitrate during SRAT boiling. By the end of the SRAT cycle, the nitrate made from nitrite had been offset by nitrate losses, and the calculation of net nitrite-to-nitrate conversion was very small, or even negative.

It might be reasonable to expect that the ratio of $\mathrm{NO} / \mathrm{NO}_{2}$ would stay nearly constant, if equilibrium prevailed in the gas phase and if oxygen concentration was constant, $\mathrm{K}_{\mathrm{eq}}=\left[\mathrm{NO}_{2}\right]^{2} /\left[\mathrm{O}_{2}\right][\mathrm{NO}]^{2}$. The concentration of oxygen, however, did not stay even approximately constant during nitrite destruction. Therefore, it was not surprising that the ratio of $\mathrm{NO} / \mathrm{NO}_{2}$ formed in the different run pairs varied. A ratio of about $1: 19$ was expected at $85^{\circ} \mathrm{C}$ (close to the $\mathrm{GC}$ column temperature), but as $\mathrm{O}_{2}$ declined, $\mathrm{NO}$ had to increase to offset the effect. The $\mathrm{NO} / \mathrm{NO}_{2}$ ratios that could be formed from the numbers in Table 18 
would show considerable variation (issues with NO calibration), but a majority lay in the range of 1:5 to 1:15 which seems generally reasonable.

\subsubsection{Cations during Period 3}

Changes were also noted in the cation dissolution extents during Period 3. Several initially insoluble lesser cations achieved partial solubility, including $\mathrm{Ni}, \mathrm{Cu}$, and $\mathrm{Zn}$. About $40 \%$ of $\mathrm{Zn}, 35 \%$ of $\mathrm{Ni}$, and $30 \%$ of $\mathrm{Cu}$ entered solution by the end of Period 3 based on relatively limited data and with considerable variability among the differently trimmed run pairs. The solubility of these three cations appeared to be very sensitive to $\mathrm{pH}$, and, as discussed earlier, the $\mathrm{pH}$ during Period 3 reached a minimum and in some cases began rising before the end of Period 3. Pd began to reprecipitate during Period 3 without an increase in $\mathrm{pH}$ in the $\mathrm{Pd}$ runs. $\mathrm{Rh}$ reached its maximum concentration in the supernate and was actively precipitating at the end of Period 3. Ru also continued to dissolve and precipitate through the end of acid addition. ( $\mathrm{Ru}$ data indicate the sequential formation and loss of two soluble forms via a series of dissolution and precipitation reactions.)

The formation of $\mathrm{H}_{2}$ from Pd catalyzed destruction of formic acid started in Period 3 and peaked near the end of Period 3. The $\mathrm{Ru}$ runs did not have $\mathrm{H}_{2}$ formation during Period 3. The Rh runs started $\mathrm{H}_{2}$ formation in Period 3, but the peak came after acid addition ended at this stoichiometric factor. There was a very small amount of $\mathrm{H}_{2}$ formation in one $\mathrm{Ag}$ run near the end of Period 3.

\subsubsection{Reaction timeline for acid addition}

The data presented in Section 3.0 contain a lot of information on reactions occurring during acid addition in the SRAT cycle. Certain samples were targeted into certain run pairs to avoid potential issues that might be linked to enhanced catalytic activity of the high $\mathrm{Rh}$ and $\mathrm{Ru}$ concentrations. This section brings together a composite picture of the five major reactions between the supernate acid and the insoluble solids and nitrite ion. The major reactions were the following:

- Dissolution of $\mathrm{Mg}$

- Dissolution of $70-80 \%$ of $\mathrm{Ca}$

- Destruction of TIC

- Destruction of nitrite

- Dissolution/reduction of Mn

The data during acid addition were collected and combined. The reactant concentrations were normalized to a $100 \%$ basis, e.g. $100 \%$ for $\mathrm{Mg}$ equaled $100 \%$ of the total slurry $\mathrm{Mg}$ in the supernate and $100 \%$ for TIC meant $100 \%$ of the initial TIC present. So, TIC and nitrite started at $100 \%$ and went to $0 \%$, while $\mathrm{Mg}, \mathrm{Ca}$, and $\mathrm{Mn}$ started at $0 \%$ and went to $80-100 \%$ in solution. Each of the five reactions was fitted to a sigmoidal function to connect the raw data. The composite results are shown in Figure 77. 
WSRC-STI-2008-00131

Revision 0

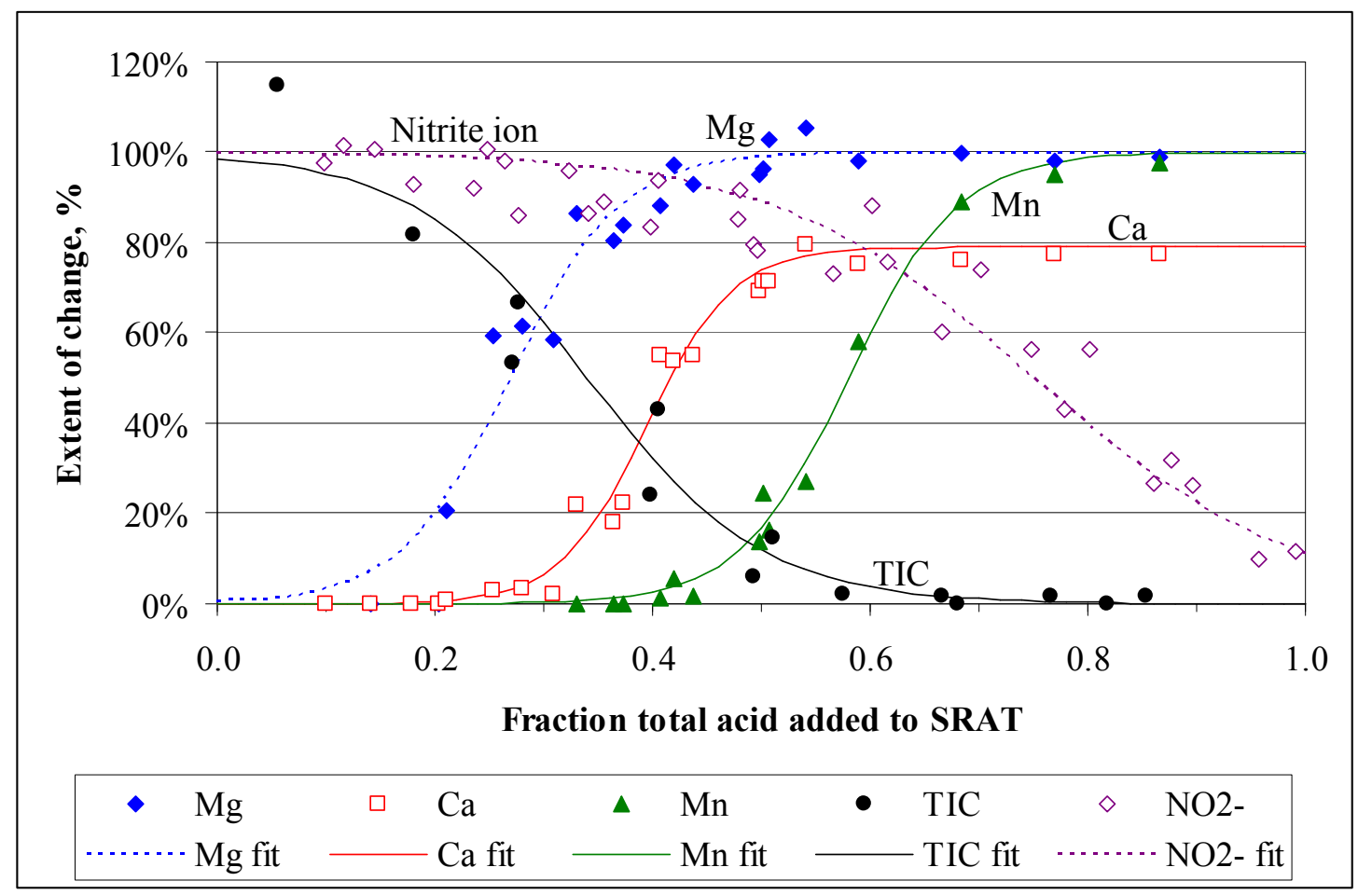

Figure 77. Major reaction timeline with raw data

Nitrite data has the most scatter due to the effects of the different catalysts on nitrite destruction paths. The visual reaction timeline is easier to look at without the raw data superimposed on the fits. A second version without the sample data is given in Figure 78.

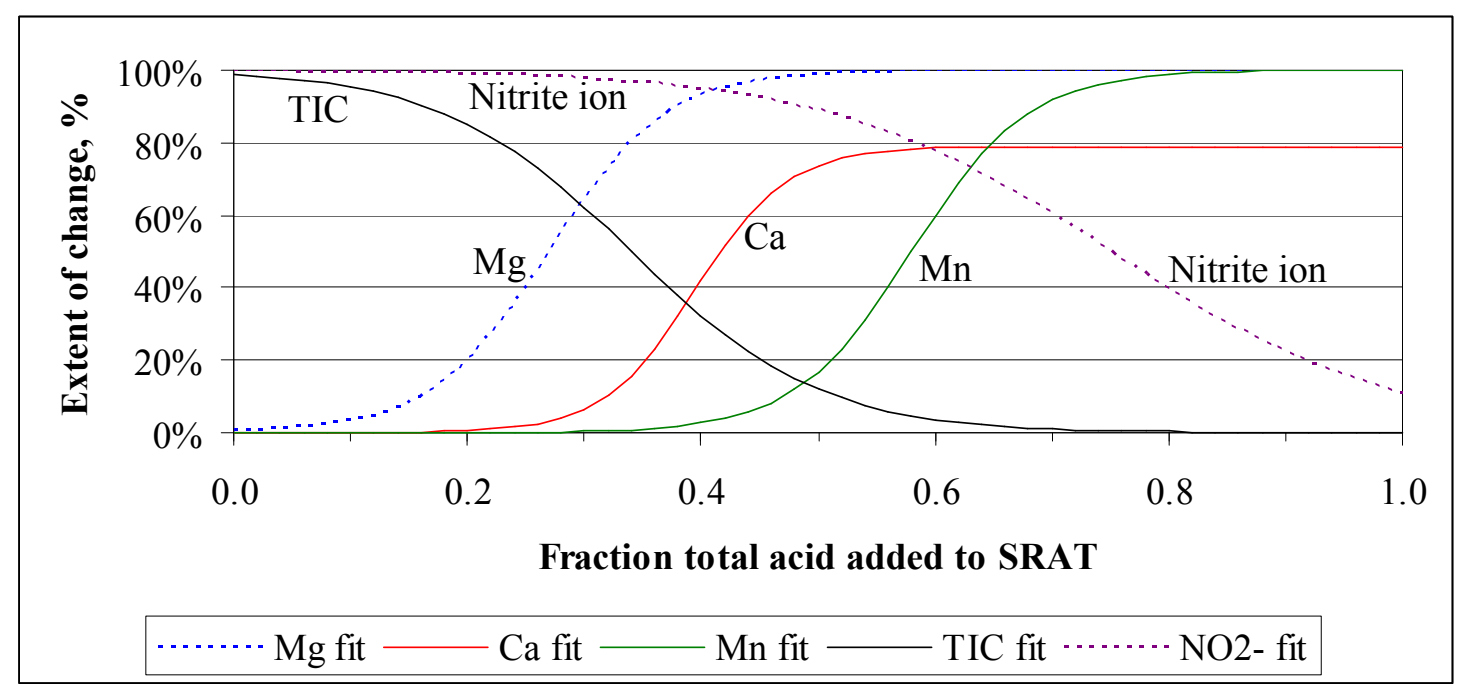

Figure 78. Major reaction timeline without raw data

As discussed above, there is overlap between the three major cation dissolutions. TIC destruction and Ca dissolution are clearly occurring from some of the same acid addition. Nitrite destruction was the slowest 
of the five reactions at this stoichiometry and sludge composition based on the available data. In the eight bead-frit systems, $100 \% \mathrm{Mn}$ reduction occurred before nitrite was destroyed.

Other reactions occurred near the end of Period 3. These had a less universal appearance and included the formation of nitrate from nitrite, the reductive destruction of formate by $\mathrm{Mn}$ and nitrite, and the partial dissolution of some additional lower concentration cations such as $\mathrm{Ni}, \mathrm{Cu}$, and $\mathrm{Zn}$. These reactions varied significantly from case to case unlike the five major reactions. The raw data concerning these reactions were presented in Sections 3.1 to 3.4, and expanded on in the section above concerning nitrite destruction.

Period 3 was the dominant period for off-gas generation. Figure 79 shows the combined generation rates of $\mathrm{H}_{2}, \mathrm{CO}_{2}, \mathrm{NO}, \mathrm{NO}_{2}$, and $\mathrm{N}_{2} \mathrm{O}$ as a function of time. Data were taken from the eight bead runs. The locations of the divisions between Periods 1 and 2 and between Periods 2 and 3 are approximate, since the acid addition rates were slightly different in the eight runs. A division between Periods 4 and 5 was not shown on the graph, since this division moved considerably depending on hydrogen generation.

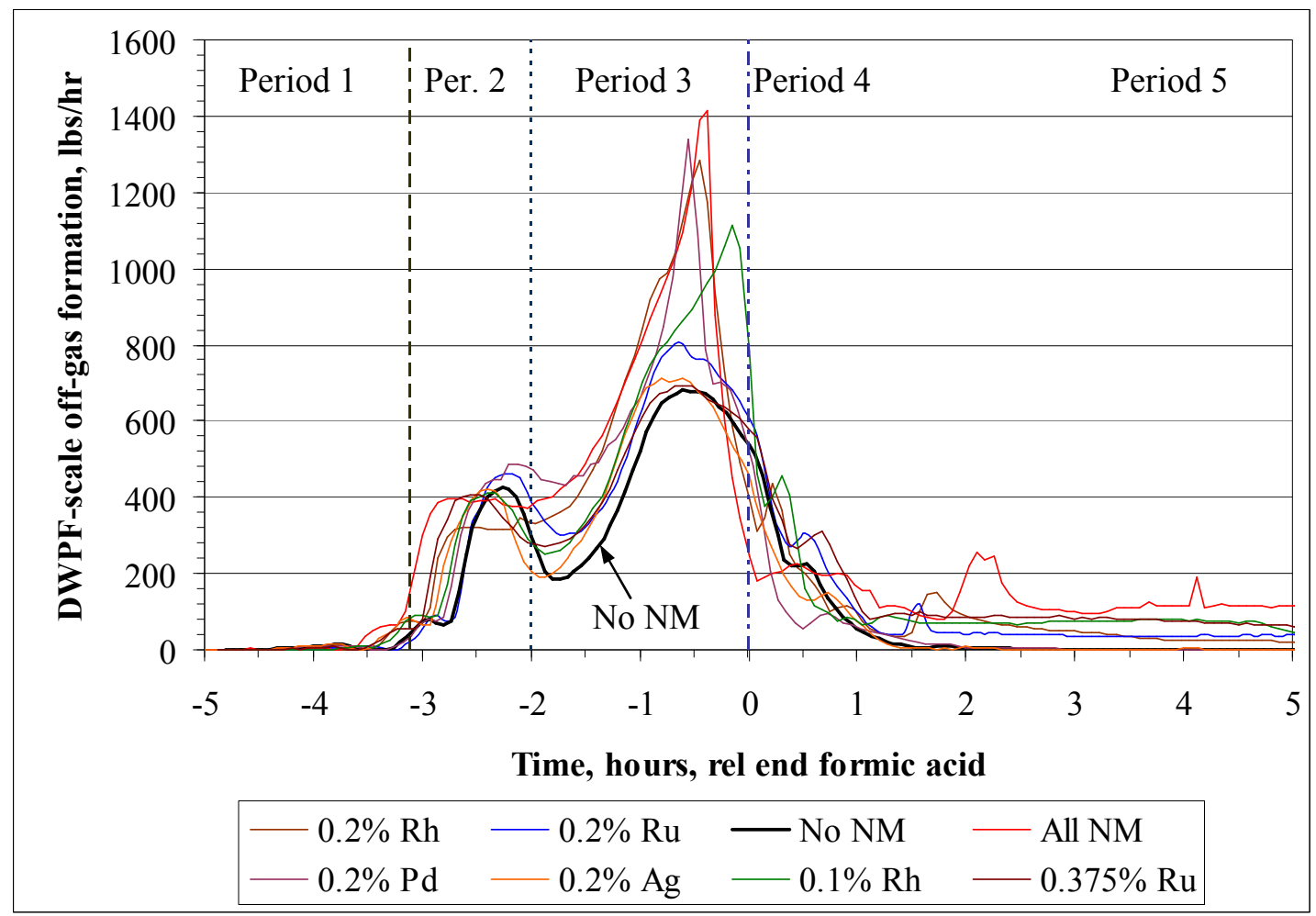

Figure 79. Overall off-gas generation rates

It is readily apparent from Figure 79 that Period 3 had both the most off-gas generation and the maximum cumulative off-gas generation rates. The no noble metal case (bold black curve) came closest to bounding the generation rates on the low side. Period 1 has virtually no off-gas generation, while Period 2 consisted primarily of $\mathrm{CO}_{2}$ from TIC destruction. Reactions on-going at the end of Period 3 continued into the early parts of Period 4 (dewatering). The location of the split between end of Period 3 and start of Period 4 was fixed in this series of tests but depends on the acid stoichiometry selected in general. 


\subsection{Period 4: Dewatering}

Following the conclusion of acid addition, the MWWT reflux line to the SRAT was closed, and collected condensate was removed as part of dewatering. Dewatering was initially driven by the high vapor pressure of water at $93^{\circ} \mathrm{C}$. The rate increased as heat was applied to raise the temperature to boiling and achieve the targeted boil-up rate corresponding to $5,000 \mathrm{lbs} / \mathrm{hr}$ in DWPF. The period at $93^{\circ} \mathrm{C}$ varied considerably in length in the eight pairs of 22-L bead-frit runs due to excessive hydrogen generation that began near the end of Period 3 with some feeds. Hydrogen generation gained in intensity in runs with Rh during the early part of Period 4, and went to levels well above the scaled DWPF limit of $0.65 \mathrm{lbs} / \mathrm{hr}$ during Period 4. Details on $\mathrm{H}_{2}$ can be found in the companion report. ${ }^{9}$

Significant nitrate, which had accumulated in the MWWT during Period 3 and not yet been refluxed to the SRAT, was purged to the equivalent of the Slurry Mix Evaporator Condensate Tank (SMECT) during Period 4. The nitrate ISE tracked nitrate concentration in the MWWT during eight of the sixteen runs. An example of ISE MWWT nitrate data is given in Figure 80. Additional data are given in Appendix A.

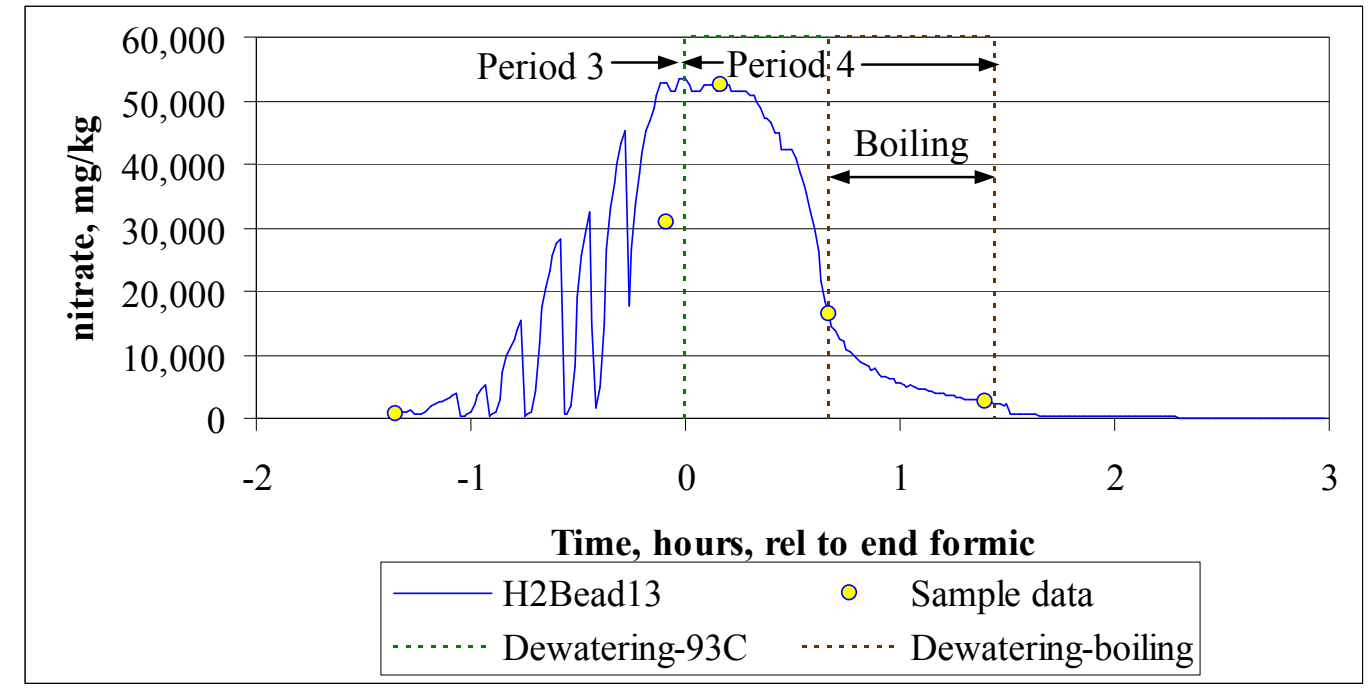

Figure 80. MWWT nitrate ion concentration by ISE

The MWWT nitrate concentration typically peaked near the end of Period 3 (because nitrite destruction was nearing completion, not because acid addition was nearing completion). The jagged structure of concentration versus time prior to the end of Period 3 at 0 hours was due to pulsed refluxing of the accumulating condensate in the MWWT. This pulsing was done in order to get limited short-term mixing around the tip of the nitrate ISE. Dewatering during the SRAT caused about seven volume turnovers of the MWWT. There was little nitrate $\left(\mathrm{HNO}_{3}\right.$ based on condensate $\left.\mathrm{pH}\right)$ left in the MWWT when reflux was initiated at the end of Period 4 (about +1.4 hours for H2Bead13).

The nitrate ISE data indicate that nitrate ion was refluxing into the SRAT from the MWWT during Period 3. This nitrate comes from the condensation-absorption of $\mathrm{NO}_{2}$ into condensing water vapor in the SRAT condenser during nitrite destruction. This process is the external reflux analog to the return of $\mathrm{HNO}_{2}$ and $\mathrm{HNO}_{3}$ into the SRAT slurry due to internal refluxing of condensate from the cooler regions of the SRAT vessel walls. Conditions in the SRAT condenser and MWWT are apparently too harsh (low pH) most of the time for the nitrous acid to be stable, and it reverts to $\mathrm{HNO}_{3}$ and $2 \mathrm{NO}$ per reaction [A-2] in Appendix A. There is no flowmeter on the reflux line, but the frequency of pulsed drops of at least 20 grams of condensate from the MWWT at a time (probably often 40-60 grams) indicated that the condensate return 
flow exceeded 120 grams per hour during Period 3. An average concentration of $15,000 \mathrm{mg} / \mathrm{L}$ nitrate in this stream would return 1.8 grams of nitrate to the SRAT which is relatively small compared to the 250 grams in the starting sludge. However, the reflux flowrate assuming saturation of the air purge leaving the SRAT with water was $750 \mathrm{~g} /$ hour, which would have returned $11.2 \mathrm{~g}$ of nitrate to the SRAT during the final hour of Period 3. This upper bound return rate is equivalent to a $+3 \%$ delta in the calculated nitrite-to-nitrate conversion for the $\mathrm{ABC}$ simulant system, e.g. 15\% nitrite-to-nitrate conversion could have been as much as $20 \%(=3 \% / 15 \%)$ due to refluxing of nitrate from the MWWT. Typical nitrite-tonitrate conversions in runs with prototypical noble metal and mercury loadings are about $10-25 \%$, so the MWWT reflux prior to dewatering probably contributes less than a quarter of the observed nitrate formation.

Cations such as $\mathrm{Ni}, \mathrm{Cu}$, and $\mathrm{Zn}$ continued to slowly dissolve during Period 4 in the $\mathrm{Ag}, \mathrm{Pd}$, and no noble metal runs. These cations stopped dissolving in the $\mathrm{Rh}$ runs and may have already begun to reprecipitate during Period 4 (maximum extents of dissolution for these cations in the $\mathrm{Rh}$ runs were already low). Formate loss continued during Period 4 at varying rates dependent on the noble metals. The feeds with no noble metals and with $0.2 \mathrm{wt} \%$ silver essentially completed formate loss for the SRAT cycle during Period 4 at the same time that nitrite destruction was completed.

A correlation between formate loss and $\mathrm{CO}_{2}$ generation was developed for the two $0.2 \mathrm{wt} \% \mathrm{Ru}$ SRAT cycles. Much of this loss was spread over Period 4 and Period 5. The $\mathrm{CO}_{2}$ rates were converted into a running total $\mathrm{CO}_{2}$ mass. The $\mathrm{CO}_{2}$ from TIC destruction was subtracted from the total to get the $\mathrm{CO}_{2}$ derived from formate destruction by difference. Formate sample results from H2Frit2 and H2Bead13 were converted into formate moles using material balance slurry masses. These moles were subtracted from the moles of formic acid added to get the moles of formate lost as a function of time. The two sets of $\mathrm{CO}_{2}$ and two sets of formate loss are shown in Figure 81.

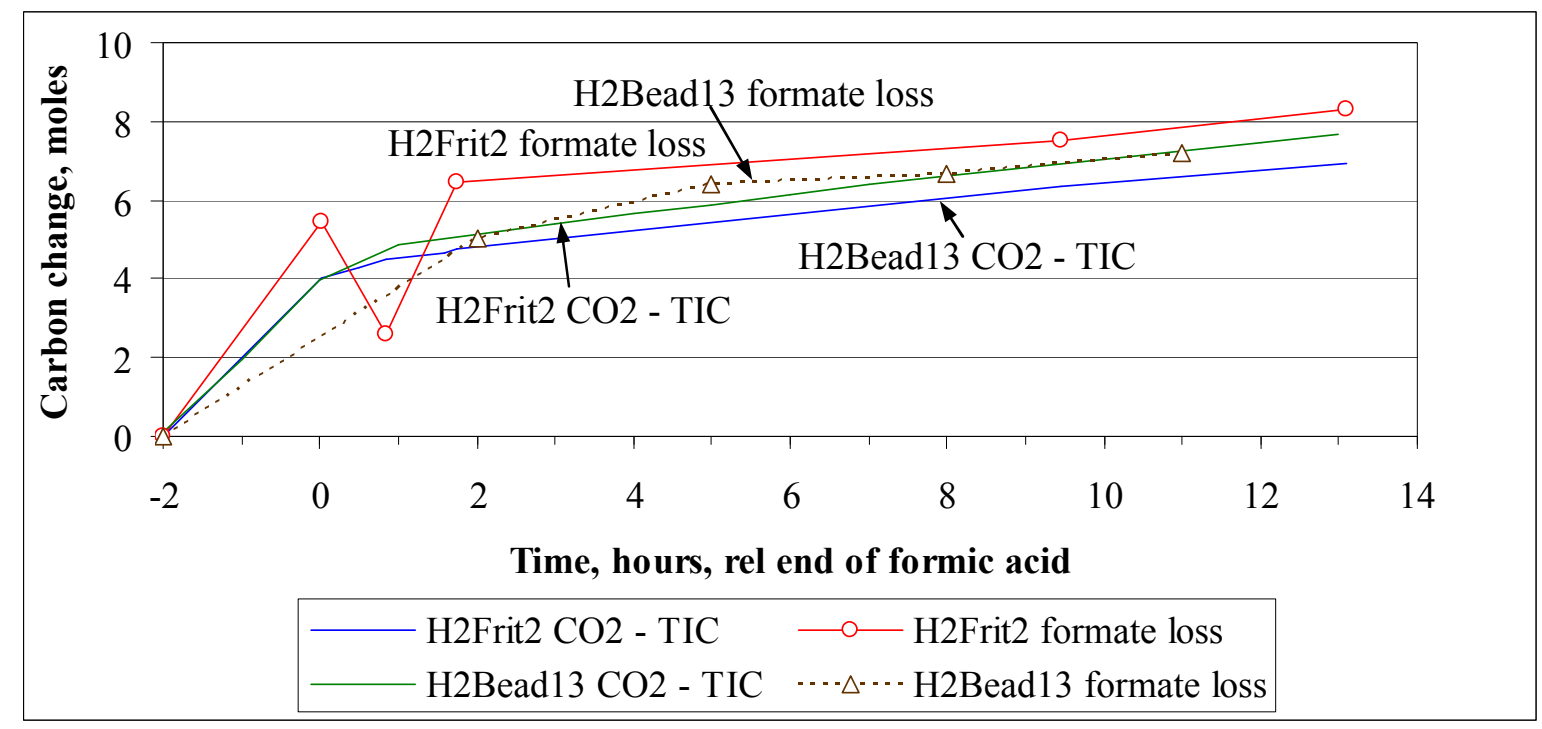

Figure 81. Net $\mathrm{CO}_{2}$ Production versus Formate Loss at $0.2 \% \mathrm{Ru}$

The IC samples from H2Bead13 were specifically intended to track anions and were caustic quenched. The samples from H2Frit2 were not originally intended solely for careful anion analysis. Consequently, these samples were not caustic quenched. The H2Frit2 formate loss ran higher than H2Bead13, perhaps because of subsequent formate losses in the unquenched samples during the month between sampling and analysis. The H2Bead13 IC based formate loss data fell along the two traces from the net $\mathrm{CO}_{2}$ produced after subtracting the TIC contribution as expected. The H2Frit2 SRAT product formate was a suspect 
result and is not shown (>14 moles loss). The formate loss from the H2Bead13 SRAT product was 6.2 moles, which was lower than the last three quenched sample results instead of higher. These formate variations appear to reflect shifts in the IC performance from day to day, since the SRAT product samples were analyzed on different days than the samples from the middle of the SRAT cycle. Only the sample from H2Frit2 at 0.83 hours was off the general trend for samples that were run together. The close agreement between formate loss and $\mathrm{CO}_{2}$ formation may also have been due to the fact that the amount of TIC absorption in this run was fairly small (formate lost to $\mathrm{CO}_{2}$ made it to the GC) and there was probably minimal ammonium ion formation which also consumes formate; see the discussion for Period 5 .

\subsection{Period 5: Reflux}

All sixteen 22-L runs were refluxed for twelve hours except H2Bead16. The mixer shaft became uncoupled from the motor late in the reflux period of H2Bead16. The SRAT heating mantle was turned off. The contents sat hot, but unmixed and not boiling. Mixing was ultimately restored after about two hours. The twelve hour nominal end of the boiling reflux period had passed. Consequently, it was assumed that the reactions that had been in progress had approximately reached the appropriate endpoint, and the run transitioned into the SME cycle.

The apparent driver for much of the chemistry seen in Period 5 was the $\mathrm{pH}$. Profiles for six of the frit runs are given in Figure 82 covering Periods 4 and 5 and the end of Period 3. Some of the $\mathrm{pH}$ readings could be off by over half a $\mathrm{pH}$ unit based on post-run checks.

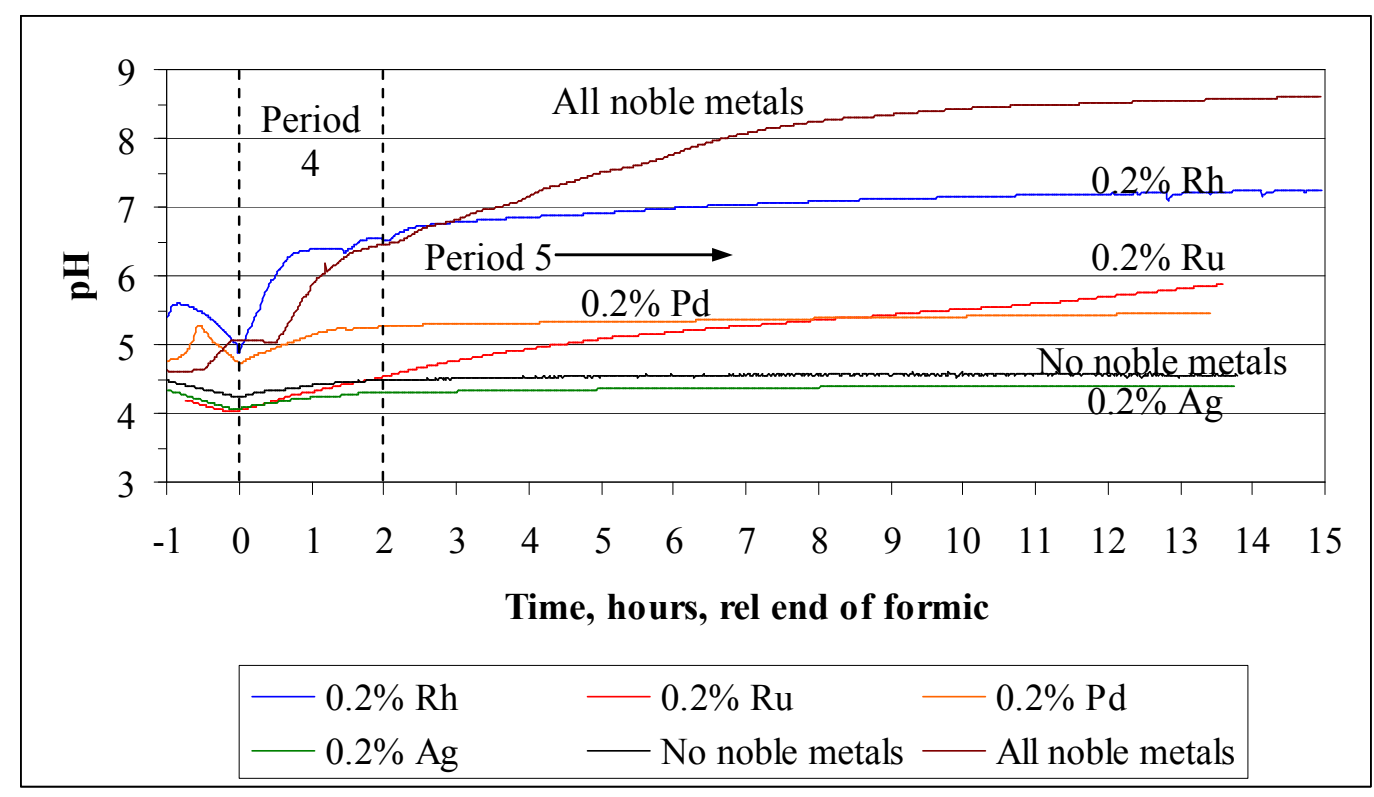

Figure 82. Composite pH profiles for frit runs

The $\mathrm{pH}$ behavior reflected the overall catalytic activity in the SRAT. The $0.2 \% \mathrm{Rh}$ case and the all noble metal case both had significant increases in the $\mathrm{pH}$ from the end of acid addition into Period 5. Conversely, the case with $0.2 \% \mathrm{Ag}$ and the case with no noble metals had a small $\mathrm{pH}$ rise immediately after acid addition (Period 4), while nitrite was still being destroyed, and then held an essentially constant low $\mathrm{pH}$ until the end of the SRAT cycle. The case with Ru behaved like the no noble metal run in terms of $\mathrm{pH}$ until about 1.0-1.5 hours after acid addition. This time corresponded with the onset of significant hydrogen generation and destruction of nitrite. The $0.2 \% \mathrm{Pd}$ case did not reach the low $\mathrm{pH}$ 's of the $\mathrm{Ag}$, 
$\mathrm{Ru}$ and no noble metal runs at the end of acid addition, but it did hold fairly constant $\mathrm{pH}$ during reflux. $\mathrm{Pd}$ appeared to be particularly active at promoting formic acid consuming reactions with nitrite ion, which may explain the higher minimum $\mathrm{pH}$. The $0.2 \% \mathrm{Pd}$ case $\mathrm{pH}$ came from $\mathrm{H} 2 \mathrm{Frit} 4$ and was about one unit greater than the $\mathrm{Ag}$ and no noble metal runs. Post-run calibration checks for the $\mathrm{pH}$ probe in H2Frit4 were very good (the corresponding bead run, H2Bead15, did not obtain $\mathrm{pH}$ data). There was a slight upward drift on $\mathrm{pH}$ in the $0.2 \% \mathrm{Pd}$ run that may indicate that the Pd still had some catalytic activity during this period. $\mathrm{Ru}$ and $\mathrm{Rh}$ were both obviously still catalytically active during Period 5 when considering the entire set of available data $\left(\mathrm{CO}_{2}, \mathrm{H}_{2}, \mathrm{pH}\right.$, formate, etc.).

Measured off-gas generation during Period 5 was primarily $\mathrm{CO}_{2}$ with small amounts of $\mathrm{H}_{2}$. The sums of these two gas generation rates combined with any $\mathrm{NO}, \mathrm{NO}_{2}$, and $\mathrm{N}_{2} \mathrm{O}$ are shown in Figure 83 .

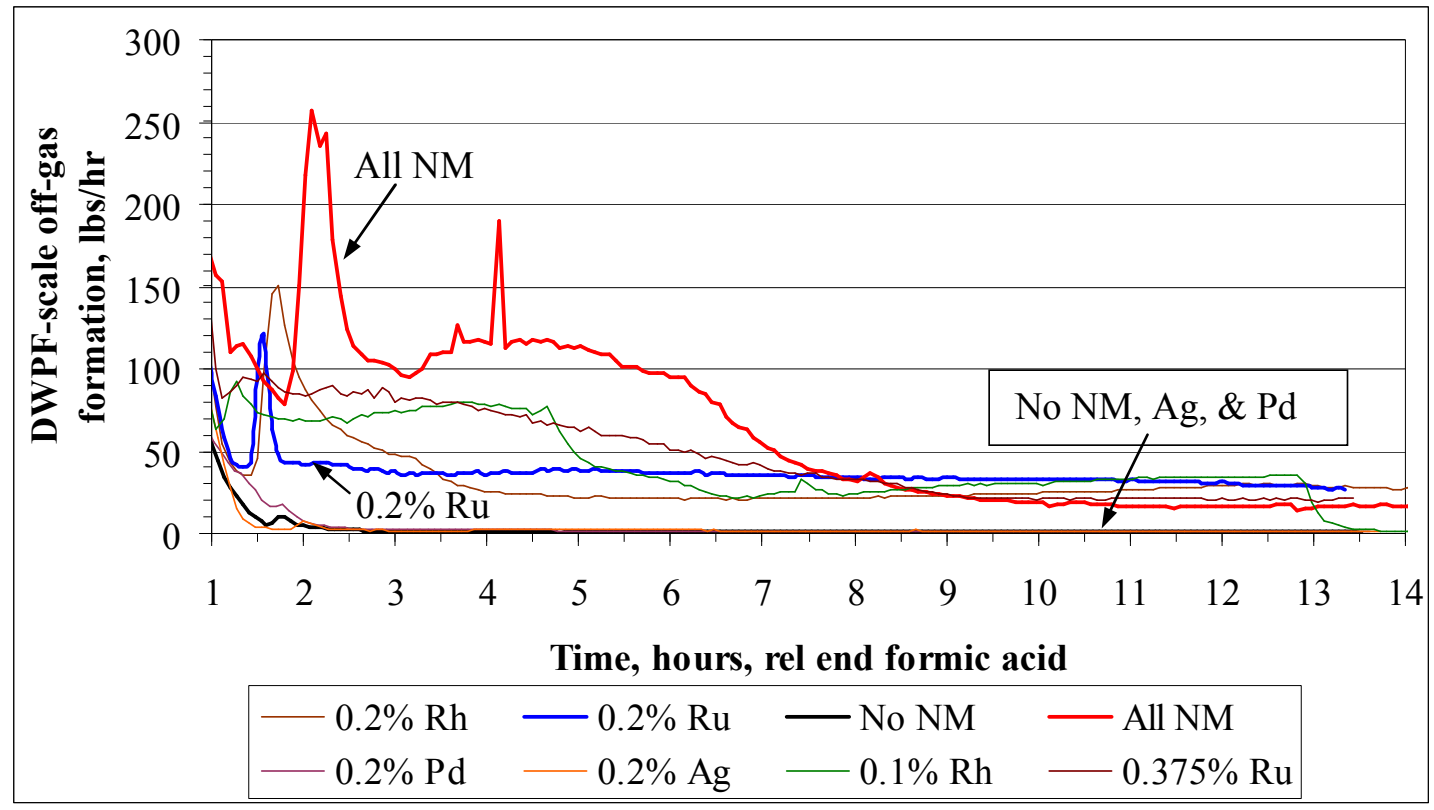

Figure 83. Total off-gas generation rate during Period 5

The no noble metal, Ag, and Pd runs essentially stopped producing off-gas about 2.5 hours after formic acid addition. This coincides closely with the ultimate destruction of nitrite ion in Figure 78. The 0.2 $\mathrm{wt} \% \mathrm{Ru}$ run was nearly in a steady-state gas generation mode at $0.2 \mathrm{lbs} / \mathrm{hr}$ for about the last twelve hours of the SRAT. The $0.2 \mathrm{wt} \% \mathrm{Rh}$ run transitioned to a near steady-state rate at about +4 hours, while the 0.1 $\mathrm{wt} \% \mathrm{Rh}$ run transitioned at about +6.5 hours. The $0.375 \mathrm{wt} \% \mathrm{Ru}$ run was more active than the $0.2 \mathrm{wt} \%$ $\mathrm{Ru}$ run early in Period 5, but shifted into a near steady-state mode at about +8 hours. The all noble metal run steadied out late in Period 5, but it was not possible to tell whether this was due to constant catalytic activity or to the nearly complete destruction of the formic acid and formate ion that occurred in this run. (The other seven cases all had considerably more formate at the end of the SRAT than the all noble metal run.)

The increasing $\mathrm{pH}$ in certain runs during Period 5 led to reactions that were not observed in other runs. When $\mathrm{pH}$ was low and constant, continued slow dissolution of some of the insoluble hydroxides and hydrous oxides was observed, such as $\mathrm{Ni}(\mathrm{OH})_{2}, \mathrm{CuO}$, and $\mathrm{ZnO}$ (the latter two metal oxide species are equivalent to $\mathrm{M}(\mathrm{OH})_{2}$ when they dissolve and the $\mathrm{O}^{2-}$ combines with a water molecule). The quantities of these species in the sludge were small, and the impact of some partial dissolution on the $\mathrm{pH}$ was minor. 
When $\mathrm{pH}$ was increasing, the dissolution of insoluble species such as $\mathrm{Ni}, \mathrm{Cu}$, and $\mathrm{Zn}$ appeared to stop. This behavior would seem to imply that these species were undergoing $\mathrm{pH}$ controlled equilibrium dissolution, and that dissolution was not hydrolysis rate limited. In the latter case, dissolution could have continued with rising $\mathrm{pH}$ as long as the $\mathrm{pH}$ was acidic enough to promote continued dissolution. The initial dissolution of some of these species when $\mathrm{pH}$ was falling also indicated increasing dissolution with decreasing $\mathrm{pH}$, but this did not necessarily imply equilibrium limited dissolution was favored over hydrolysis rate limited dissolution because of the various competing reactions for acid that were occurring at the end of Period 3 and start of Period 4.

Some of the $\mathrm{CO}_{2}$ generated by formate destruction began to be reabsorbed in runs with increasing $\mathrm{pH}$ during Period 5, presumably by the following reaction sequence.

$$
\mathrm{CO}_{2}+\mathrm{H}_{2} \mathrm{O} \rightarrow \mathrm{H}_{2} \mathrm{CO}_{3} \leftrightarrow \mathrm{HCO}_{3}^{-}+\mathrm{H}^{+} \leftrightarrow \mathrm{CO}_{3}^{2-}+2 \mathrm{H}^{+}
$$

Mn and Mg were observed to largely precipitate out of the supernate, potentially as the insoluble carbonate species (insoluble bicarbonate salts were another possibility). The ORP data suggest that the SRAT may have reverted to an oxidizing state in catalytically active runs with increasing $\mathrm{pH}$, so $\mathrm{Mn}^{2+}$ may have converted back to $\mathrm{Mn}^{4+}$ as insoluble $\mathrm{MnO}_{2}$. An alternative design for the ORP probe could permit oxidation-reduction potential readings to be taken during boiling. Lesser amounts of Ca were also precipitated. Samples of five SRAT products from the bead runs confirmed the presence of inorganic carbon, Table 23.

Table 23. SRAT Product TIC Content

\begin{tabular}{|l|c|c|c|}
\hline Trim species & TIC, $\mathrm{mg} / \mathrm{kg}$ & Std. Deviation & Formate Loss \\
\hline $0.1 \% \mathrm{Rh}$ & 3140 & 1230 & $48 \%$ \\
\hline $0.2 \% \mathrm{Rh}$ & 4110 & n.a. & $60 \%$ \\
\hline All noble metals & 5470 & n.a. & $82 \%$ \\
\hline $0.375 \% \mathrm{Ru}$ & 2030 & 880 & $30 \%$ \\
\hline $0.2 \% \mathrm{Ru}$ & 980 & 880 & $27 \%$ \\
\hline
\end{tabular}

n.a. $=$ single analysis, so no statistics available

The concentration of SRAT product TIC seemed correlated with the extent of formate loss in these five cases. It is perhaps most significant to general DWPF simulations that the two runs with Ru, which held $\mathrm{pH}$ below 6 during reflux, were able to incorporate TIC into the SRAT product. Sludge Batch 4 data had indicated that the SRAT product $\mathrm{pH}$ needed to reach the 7-7.5 range for significant TIC accumulation in the SRAT slurry. It may be that the excellent initial dissolution of $\mathrm{Mn}, \mathrm{Mg}$, and $\mathrm{Ca}$ facilitated the absorption and retention of carbonate and/or bicarbonate by rapidly converting newly absorbed TIC into insoluble precipitates.

Limited data were obtained on the rate of TIC absorption. Sample analyses were restricted to the all noble metal run case. This case was the closest to a prototypically trimmed sludge batch since it had all four noble metals, although the trimmed noble metal concentrations could be referred to as bounding. The TIC data from H2Bead14 are shown in Figure 84. 


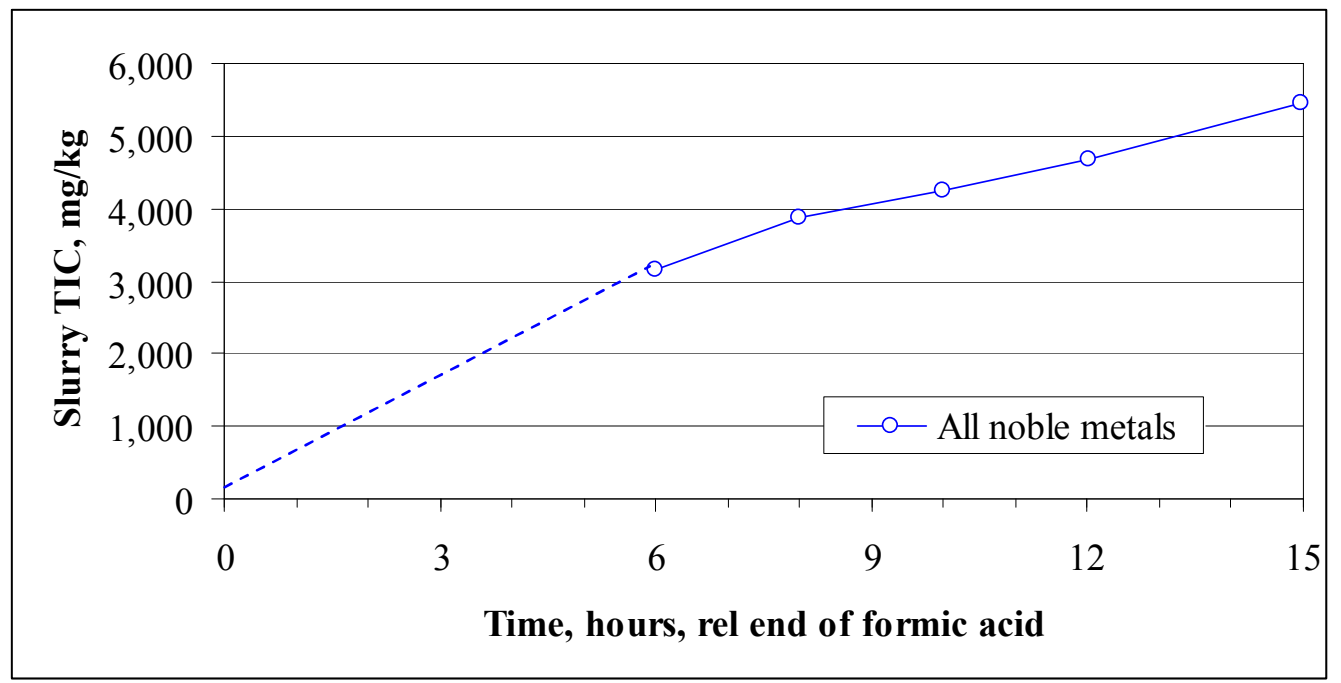

Figure 84. TIC absorption during reflux

Several additional samples were archived from the 0-6 hour period after the end of formic acid, however issues with the existing TIC analytical instruments did not warrant attempting to expand the range of the data set at this time. The dashed line in Figure 84 indicates that some absorption occurred between total TIC destruction during acid addition (Period 2) to the first data point with over $3,100 \mathrm{mg} / \mathrm{kg}$ TIC. The data do not pinpoint when absorption was actually initiated, but absorption clearly occurred over more than the nine hour period covered by the sample data.

Ammonium ion formation also occurred in some of the runs during Period 5. Ammonium was most easily detected in the FAVC condensate sample from the end of the SRAT cycle. A detection limit of about $10,000 \mathrm{mg} / \mathrm{kg}$ existed for the SRAT product without special techniques due to interferences with sodium. Results are summarized in Table 24, along with the calculated nitrite-to-nitrate conversion for the overall SRAT cycle.

Table 24. SRAT $\mathrm{NH}_{4}{ }^{+}$Content

\begin{tabular}{|c|c|c|c|}
\hline Trim species & $\mathrm{FAVC} \mathrm{NH}_{4}^{+}, \mathrm{mg} / \mathrm{kg}$ & $\begin{array}{c}\text { SRAT Product } \mathrm{NH}_{4}^{+}, \\
\mathrm{mg} / \mathrm{kg}\end{array}$ & $\begin{array}{l}\text { Nitrite-to-nitrate } \\
\text { Conversion }\end{array}$ \\
\hline $0.1 \mathrm{wt} \% \mathrm{Rh}$ & 50,000 & 59 & $-5 \%$ \\
\hline $0.2 \mathrm{wt} \% \mathrm{Rh}$ & 4,800 & 84 & $-5 \%$ \\
\hline All noble metals & 47,600 & 1,440 and 165 & $-30 \%$ \\
\hline $0.2 \mathrm{wt} \% \mathrm{Ru}$ & n.a. & 22 & $6 \%$ \\
\hline $0.375 \mathrm{wt}^{0} \% \mathrm{Ru}$ & 1,660 & $<21$ & $0 \%$ \\
\hline
\end{tabular}

n.a. - not analyzed

The two results for the all noble metals case come from the frit run product and the bead run product respectively. Different methods were used to deal with the sodium interference, which may have impacted reproducibility, or the two matching runs may have been as different as indicated. The FAVC value for the $0.1 \mathrm{wt} \% \mathrm{Rh}$ run might appear to be difficult to reconcile with the other three values. The 0.1 $\mathrm{wt} \% \mathrm{Rh}$ runs were more catalytically active, however, during reflux than the $0.2 \mathrm{wt} \% \mathrm{Rh}$ runs based on the $\mathrm{H}_{2}$ and $\mathrm{CO}_{2}$ data. Generally, low to negative nitrite-to-nitrate conversions correlated with ammonium formation. That correlation was expected from nitrogen balance considerations, i.e. the nitrogen had to 
go somewhere. IC data for nitrate presented in Section 3.0 support the traditional chemistry that nitrite converted to nitrate in most runs during the end of acid addition and start of dewatering. Subsequently, a fraction of the nitrate was lost that depended on the noble metal trimmed in that case and its sustained activity during Period 5. The calculated nitrate loss tended to offset the gain from nitrite conversion. In three of the above cases the reaction(s) appeared to destroy all nitrate formed during nitrite destruction plus some of the nitrate from the starting sludge and nitric acid addition. Nitrate loss was presumably the only source of the ammonium ion in these tests by process of elimination. ${ }^{17}, 18$ In the original coupled DWPF process, there was ammonium nitrate in the Precipitate Hydrolysis Aqueous (PHA) feed stream, and that was considered the primary source of ammonium. The consensus of the early researchers was that the SRAT ammonium formation reaction was a noble metal catalyzed reaction between formic acid and nitrate ion:

$$
4 \mathrm{HCO}_{2} \mathrm{H}+\mathrm{NO}_{3}^{-} \rightarrow \mathrm{NH}_{3}+3 \mathrm{CO}_{2}+\mathrm{HCO}_{3}^{-}+2 \mathrm{H}_{2} \mathrm{O}
$$

This reaction also produces a bicarbonate ion which could promote the observed $\mathrm{Mg}$ and $\mathrm{Mn}$ precipitation. King et al. ${ }^{19}$ gave the following reaction, formic acid reduction of nitrate, also known as denitration, as another possible ammonium formation reaction:

$$
5 \mathrm{HCO}_{2} \mathrm{H}+\mathrm{NO}_{3}^{-} \rightarrow \mathrm{NH}_{3}+\mathrm{HCO}_{2}^{-}+4 \mathrm{CO}_{2}+3 \mathrm{H}_{2} \mathrm{O}
$$

This reaction is generally associated with high nitric acid concentrations (low $\mathrm{pHs}$ ), but the presence of sufficient catalyst might off-set this limitation. Consequently, ammonium ions could be present in the SRAT and CPC off-gas system from several reactions even when not using the coupled process flowsheet. The bead-frit systems with detected ammonium ion all had excess $\mathrm{CO}_{2}$ formation following nitrite destruction and $\mathrm{Mn}$ reduction, i.e. the period of nitrate loss, and the molar $\mathrm{CO}_{2}$ formation rate was greater than that of $\mathrm{H}_{2}$. These observations are consistent with either of the reactions [26-27].

Historical data (Figure 1, ref. 18) showed ammonium formation starting about two hours after acid addition following the initial sharp hydrogen peak attributed to $\mathrm{Rh}$. The concentration grew steadily in the SRAT product slurry until the end of the SRAT cycle. An occasional simulant run has produced a product with an ammoniac odor, particularly in runs where mixing may have been an issue (mixing was not an issue in the bead-frit SRAT cycles). Significant ammonium ion formation, however, was not postulated for recent DWPF sludge batches or generally prototypical noble metal and mercury concentrations with conservative acid addition strategies. Consequently, the study of ammonium ion formation was not emphasized in the planning for the bead-frit work. Sampling for ammonium ion was primarily limited to bead systems with high catalytic activity and potential issues in closing the nitrogen species material balance that might be alleviated by including ammonium ion in the exiting streams

A catalytic reaction scheme has been proposed for reduction of nitrate in the presence of hydrogen. ${ }^{20}$ The authors used palladium catalyst; separate papers cited ferrous ion, metallic iron, and copper as catalysts; research emphasized promoting nitrogen formation over ammonium ion formation since the end use was drinking water. Significant catalytic activity was present at room temperature with Pd. The best catalysts seem to combine a noble metal $(\mathrm{Pd}, \mathrm{Rh}, \mathrm{Ru})$ with a transition metal $(\mathrm{Cu}, \mathrm{Ni}, \mathrm{Fe}, \mathrm{Sn}$, and $\mathrm{In})$, most of which can be found in sludge. ${ }^{21}$ 
WSRC-STI-2008-00131

Revision 0

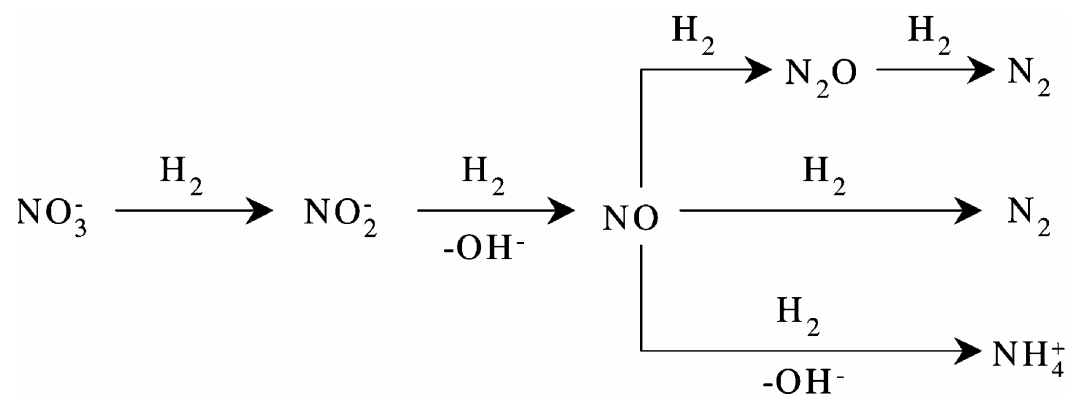

A noteworthy feature of this scheme was that it consumed a lot of hydrogen molecules (3-4 per nitrate). Note that the path from nitrite ion to $\mathrm{N}_{2} \mathrm{O}$ is consistent with the observed SRAT catalysis of nitrite destruction by Pd to produce $\mathrm{N}_{2} \mathrm{O}$ discussed earlier in this report. The NO is presumably held on the catalyst awaiting one of the three follow-up reactions. This overall reaction sequence is inhibited by nitrite ion, so it would be consistent with nitrate loss reactions that are delayed until sometime during reflux. It also implies that nitrate destruction doesn't commence until after nitrite destruction. SRAT IC data during nitrite destruction show the nitrate concentration increasing due to nitrite-to-nitrate conversion, making evaluation of a simultaneous nitrate loss reaction virtually impossible.

Production of small quantities of $\mathrm{N}_{2} \mathrm{O}$ has been observed during reflux in some SRAT cycles including $\mathrm{H} 2 \mathrm{Bead} 12 \& 13$ (the two $\mathrm{Ru}$ only runs; close to detection limits). Partial consumption of hydrogen, formed from catalytic conversion of formic acid to $\mathrm{H}_{2}+\mathrm{CO}_{2}$, is consistent with the ratio of $\mathrm{H}_{2} / \mathrm{CO}_{2}$ being less than one in essentially every SRAT run. Finally, these reactions produce base, which is consistent with loss of acidity and rising $\mathrm{pH}$ seen during reflux most SRAT cycles. Therefore, the typical SRAT behavior does not preclude the above reaction sequence from occurring in the SRAT cycle. Detection of the formation of small quantities of nitrogen gas over and above the nitrogen in the air purge is unlikely with the current analytical equipment during the normal SRAT experiments. Specially designed SRAT experiments, however, could be performed to monitor nitrogen formation by using an argon-oxygen purge instead of an air purge, in order to positively identify that reactions of the above type occur. Alternatively, labeled isotopic nitrogen could be added as nitrate or nitrite and the cycloidal mass spectrometer could provide direct evidence for nitrogen formation in the off-gas as well as identifying the source term.

Off-gas data for Period 5 primarily show a mixture of air-He from the inlet purge combined with relatively small quantities of $\mathrm{CO}_{2}$ and $\mathrm{H}_{2}$. Oxides of nitrogen were only infrequently observed, and only at very small concentrations when not zero. The $\mathrm{CO}_{2}$ was much lower than seen during Periods 2 and 3 (TIC destruction and formate reduction reactions with the vol $\% \mathrm{CO}_{2}$ frequently $>10 \%$ ). The quantities of both $\mathrm{CO}_{2}$ and $\mathrm{H}_{2}$ varied considerably in the eight systems studied. A table was prepared taking the production rate of $260 \mathrm{~g}$ of $\mathrm{CO}_{2}$ as approximately the minimum that could be made completing the nitrite and $\mathrm{Mn}$ reduction reactions plus TIC destruction without catalytic assistance, and then calculating how much additional $\mathrm{CO}_{2}$ was made, listed as excess $\mathrm{CO}_{2}$ in Table 25. Hydrogen generation and SRAT overall formate loss were added to the table for subsequent discussion. 
Table 25. SRAT excess $\mathrm{CO}_{2}, \mathrm{H}_{2}$ and formate loss

\begin{tabular}{|l|c|c|c|c|}
\hline Trim species & Excess $\mathrm{CO}_{2}, \mathrm{~g}$ & $\mathrm{H}_{2}, \mathrm{~g}$ & Moles $\mathrm{CO}_{2} / \mathrm{H}_{2}$ & Formate Loss \\
\hline $0.1 \% \mathrm{Rh}$ & 265 & 2.85 & 4.26 & $48 \%$ \\
\hline $0.2 \% \mathrm{Rh}$ & 280 & 0.59 & 21.7 & $60 \%$ \\
\hline $0.2 \% \mathrm{Ru}$ & 145 & 1.6 & 4.15 & $27 \%$ \\
\hline $0.375 \% \mathrm{Ru}$ & 215 & 2.3 & 4.28 & $30 \%$ \\
\hline All noble metals & 380 & 1.3 & 13.4 & $82 \%$ \\
\hline $0.2 \% \mathrm{Pd}$ & 110 & 0.05 & - & $22 \%$ \\
\hline $0.2 \% \mathrm{Ag}$ & 0 & 0.03 & - & $11 \%$ \\
\hline No noble metals & 0 & 0 & - & $9 \%$ \\
\hline
\end{tabular}

The results in Table 25 show only a weak correlation statistically between excess $\mathrm{CO}_{2}$ production and $\mathrm{H}_{2}$ generation. They do show that the quantity of excess $\mathrm{CO}_{2}$ consistently exceeded the quantity of $\mathrm{H}_{2}$ by a considerable amount in the first five systems where both values were out of the numerical noise. The excess $\mathrm{CO}_{2} / \mathrm{H}_{2}$ ratio was typically greater than four implying that hydrogen generation was neither the primary nor the sole cause of subsequent formate losses following the initial losses during nitrite destruction and $\mathrm{Mn}$ reduction. Note that $\mathrm{CO}_{2}$ formed and absorbed by the slurry as TIC represents additional formate converted to $\mathrm{CO}_{2}$ but not seen by the $\mathrm{GC}$ and incorporated into the molar ratio of $\mathrm{CO}_{2} / \mathrm{H}_{2}$. Consequently, the true ratios of excess $\mathrm{CO}_{2}$ generated to $\mathrm{H}_{2}$ generated would be expected to be higher than those in Table 25. The preliminary conclusion is that catalytic hydrogen generation appears to account for less than a quarter of the formate loss following the nitrite destruction and $\mathrm{Mn}$ reduction losses for this sludge system.

Excess $\mathrm{CO}_{2}$ production did correlate with formate loss as seen in Figure 85.

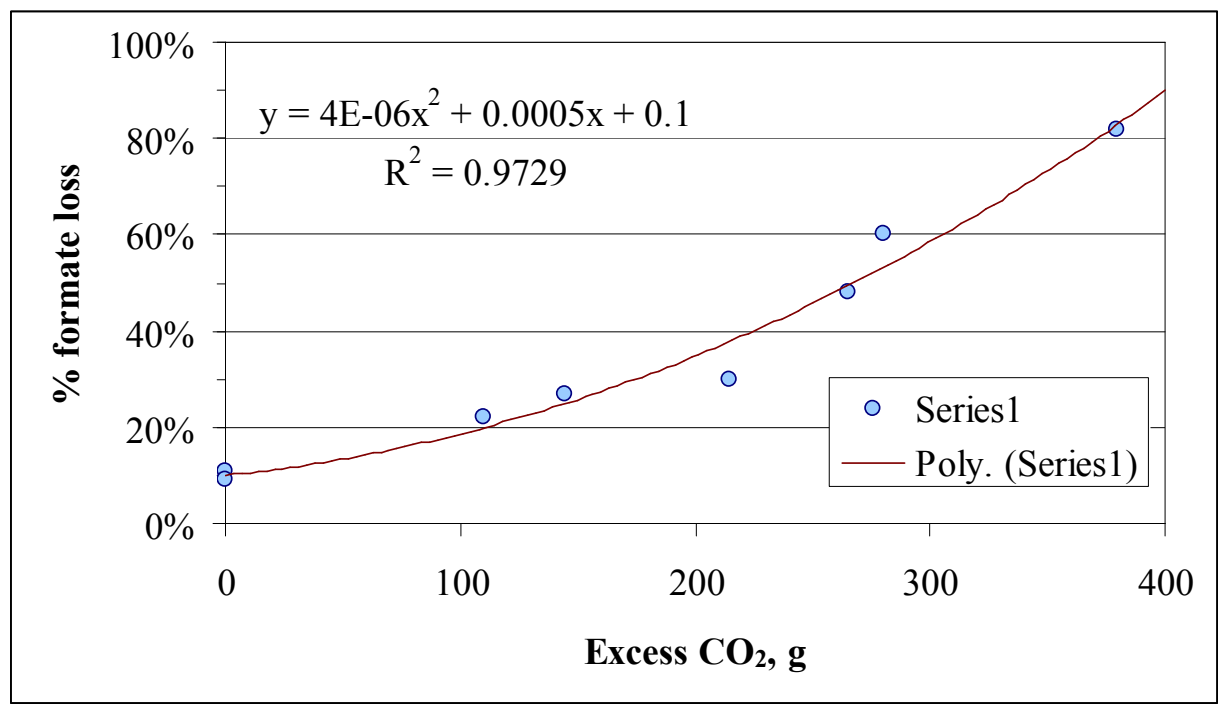

Figure 85. Formate loss correlation with $\mathrm{CO}_{2}$

Initially, a linear regression was forced through $10 \%$ loss at no excess $\mathrm{CO}_{2}$ (for first principles reasons), so only the slope of the line was adjustable during regression. While the resulting $\mathrm{R}^{2}$ of 0.90 was a fairly strong indication of correlation, the raw data suggested significant curvature and that a higher order polynomial would provide a significantly better fit. The curvature of the quadratic fit with $\mathrm{R}^{2}$ of 0.97 , and still with a forced intercept of $10 \%$, indicates that formate loss was growing faster than detected $\mathrm{CO}_{2}$ 
generation (the model had two adjustable parameters, not three). This modeled trend is qualitatively consistent with the observed increasing absorption of $\mathrm{CO}_{2}$ as TIC with the rising $\mathrm{pH}$ 's associated with large extents of formate loss (acid loss). The correlation could be used to estimate the carbonate absorption from the difference between formate loss and $\mathrm{CO}_{2}$ released assuming no other carbon-based byproducts of formate loss. Propagation of error could be expected to be fairly significant, however, for the final results.

The desire for a complete description of reactions destroying formate after nitrite destruction remains a future goal. Catalytic hydrogen generation and catalytic ammonium ion generation represent two processes producing $\mathrm{CO}_{2}$ from the formate that survived nitrite destruction and $\mathrm{Mn}$ reduction. Formic acid denitration represents a third reaction. Catalytic wet air oxidation (CWAO) has also been proposed to account for some of the excess $\mathrm{CO}_{2}$ formed above a one-to-one molar ratio with hydrogen. Evidence for CWAO was found in some of the high oxalate testing for SB3, where oxalate to formate conversion was observed. Additional evidence was found in the form of mercury impact on hydrogen study, ${ }^{22}$ where a run with an inert purge produced lower $\mathrm{CO}_{2}$ quantities during reflux than a matching run with an air purge ( $\mathrm{CWAO}$ requires oxygen, so removing oxygen should inhibit $\mathrm{CWAO}$ production of $\mathrm{CO}_{2}$ ). $\mathrm{CWAO}$ proceeds as:

$$
\mathrm{HCOOH}+1 / 2 \mathrm{O}_{2} \rightarrow \mathrm{CO}_{2}+\mathrm{H}_{2} \mathrm{O}
$$

The CWAO reactions are catalyzed by similar noble metals to hydrogen generation at boiling temperatures. CWAO reactions are not limited to formate ion. Oxalate ions and other organic molecules can be decomposed by CWAO including portions of the antifoam molecules and salt processing solvents.

Several other possibilities exist for formate destruction. First, there may be another process destroying formate to $\mathrm{CO}_{2}$ that has not yet been identified. Second, the production of hydrogen in the SRAT slurry may be larger than detected at the $\mathrm{GC}$ for the same reason that the production rate of $\mathrm{CO}_{2}$ may be larger than detected at the GC; there may be one or more reactions occurring within the SRAT slurry that consume some fraction of the hydrogen atoms or molecules as they are being formed at the active catalytic sites.

A plot was prepared to show the total, or cumulative, mass of off-gas produced as a function of processing time for the eight different cases. The total off-gas represents the combined cumulative production of $\mathrm{H}_{2}, \mathrm{CO}_{2}, \mathrm{NO}, \mathrm{NO}_{2}$, and $\mathrm{N}_{2} \mathrm{O}$ at DWPF-scale from the beginning of the SRAT cycle through the time indicated. The graph is given in Figure 86. Data were taken from the eight bead runs, although a similar plot was obtained for seven frit runs (the no noble metal frit run was missing too much off-gas data). The variable transition time between Period 4 and Period 5 for the eight bead runs is indicated by the hashed rectangular box at about +2 hours after formic acid addition. The graph is different than Figure 83, which showed the rate of gas formation as a function of time, since this graph shows the total gas produced as a function of time. A steady (horizontal) production rate in Figure 83 corresponds to a positive linear slope in Figure 86. 
WSRC-STI-2008-00131

Revision 0

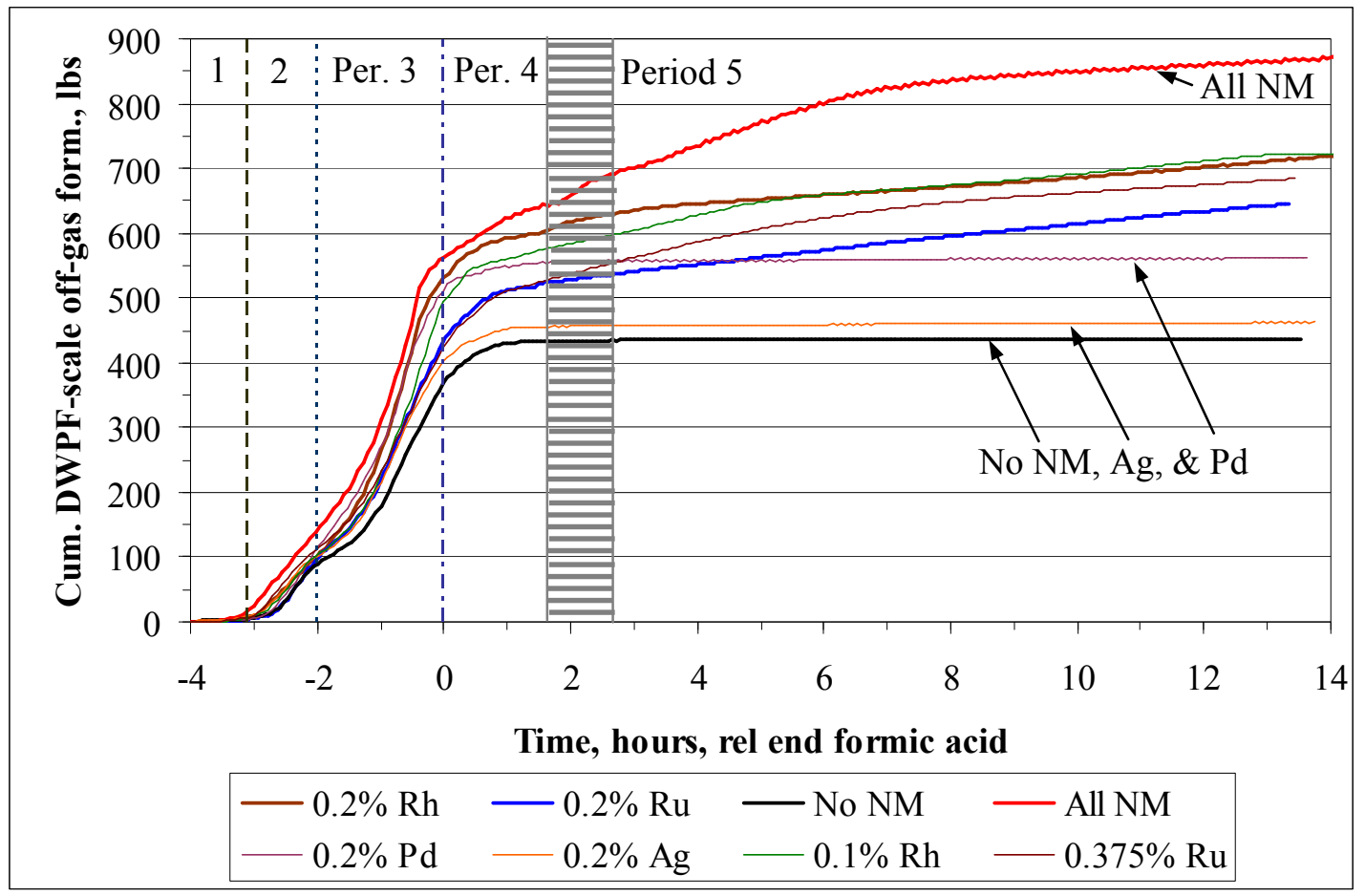

Figure 86. Cumulative off-gas formation for frit runs

The cumulative off-gas production formation totals were bounded by the all noble metal run (upper bound) and the no noble metal run (lower bound). The total off-gas for the no noble metal, silver, and palladium runs were nearly flat through Period 5 indicating negligible off-gas formation during reflux. The greater catalytic significance of Pd relative to Ag primarily occurred prior to reflux and is shown by the $22 \%$ higher off-gas production total. The one noteworthy difference in the frit run data was the placement of the $0.2 \mathrm{wt} \% \mathrm{Rh}$ curve which got ahead of the other runs early in Period 2 and stayed ahead of the all noble metal run until about a third of the way through reflux. It is believed that this was due to GC issues early in that run. The cumulative off-gas plots do not include any ammonia gas that may have evolved, though this seems the likeliest source of ammonium ion in the FAVC.

Runs with $\mathrm{Rh}$ and $\mathrm{Ru}$ continued to produce significant quantities of off-gas during Period 5 as shown by the positive slopes of the totals during Period 5. There was not a large difference between the $0.2 \mathrm{wt} \% \mathrm{Rh}$ and $0.2 \mathrm{wt} \% \mathrm{Ru}$ results (bold brown and bold blue) during Period 5. The Ru run started and ended Period 5 about the same amount less than the $\mathrm{Rh}$ run. Conversely, the $0.375 \mathrm{wt} \% \mathrm{Ru}$ run was equivalent to the $0.2 \mathrm{wt} \% \mathrm{Ru}$ run at the beginning of Period 5, but produced enough additional off-gas that it was closer to the $0.2 \mathrm{wt} \% \mathrm{Rh}$ run by the end of Period 5. This greater slope implies that the $0.375 \mathrm{wt} \% \mathrm{Ru}$ run had more catalytic activity than either the $0.2 \mathrm{wt} \% \mathrm{Ru}$ or $0.2 \mathrm{wt} \% \mathrm{Rh}$ run during Period 5 . For the two $\mathrm{Ru}$ concentrations, the implication is either that all of the $\mathrm{Ru}$ is active, and the run with more $\mathrm{Ru}$ has more activity because it has more $\mathrm{Ru}$, or that the fraction of active $\mathrm{Ru}$ is relatively independent of the total quantity. In the latter case, for example, $10 \%$ of $0.375 \mathrm{wt} \% \mathrm{Ru}$ remaining active is more than $10 \%$ of 0.2 $\mathrm{wt} \% \mathrm{Ru}$ remaining active. While the $0.375 \mathrm{wt} \% \mathrm{Ru}$ slope was greater than $0.2 \mathrm{wt} \% \mathrm{Rh}$, it wasn't necessarily greater than the slope for the $0.1 \mathrm{wt} \% \mathrm{Rh}$ case, so the conclusion that $\mathrm{Ru}$ was overall more catalytically active than Rh during Period 5 could not be made.

University of Georgia researchers examined formic acid reaction chemistry as part of the program to elucidate noble metal/formic acid chemistry during DWPF feed preparation in 1991-1992. Their first 
technical report discussed means of isolating and analyzing various reactions affecting formic acid. ${ }^{23} \mathrm{~A}$ sum of oxygen and carbon dioxide molar flowrates can be formed that removes the effect of formic acid oxidation from the resulting quantity, Appendix B. Formic acid oxidation was a significant source of formate loss in their simple system tests.

$\mathrm{CO}_{2}$ produced from TIC destruction or along with significant hydrogen generation are readily visible graphically, see figures in Appendix B. Reviewing data from the eight different starting compositions has indicated the presence of additional $\mathrm{CO}_{2}$ production not related to TIC destruction and above that associated with hydrogen generation or oxidation. This additional $\mathrm{CO}_{2}$ production, however, was only obvious in the three trim cases containing $\mathrm{Rh}$, including the run with all noble metals. $\mathrm{CO}_{2}$ was produced during the period from near the start of dewatering into the first 3-5 hours of Period 5 in all three cases. This reaction period followed the primary, Rh-driven hydrogen generation period. More additional $\mathrm{CO}_{2}$ was produced in the run with $0.2 \mathrm{wt} \% \mathrm{Rh}$ than in the run with $0.1 \mathrm{wt} \% \mathrm{Rh}$. This observation gave a second potential tie between the $\mathrm{CO}_{2}$ and $\mathrm{Rh}$. (An order of magnitude drop in $\mathrm{Rh}$ concentration, however, might make this reaction difficult to detect.) One possible explanation for the extra $\mathrm{CO}_{2}$ production in these three cases is the reduction of Rh by formic acid. XAS data on the oxidation state of Rh during the SRAT have not yet been obtained that might confirm this hypothesis.

One aspect of SRAT chemistry relevant to Period 5 was not examined due to the nature of the testing. The acid stoichiometry broadly controls the timing of nitrite destruction relative to the end of acid addition. All tests in the bead-frit set had equivalent acid additions and fairly similar times for the completion of nitrite destruction. In tests with a series of different acid additions, it has been noted that different effects occur with respect to hydrogen and oxides of nitrogen at the onset of reflux. It is believed that some of the effects are due to varying amounts of nitrite ion in the MWWT reflux to the SRAT. The later that nitrite is destroyed, i.e. the lower the acid addition, the more likely that significant nitrite will be condensing in the MWWT near the end of dewatering. The onset of reflux has apparently caused both increases and decreases in the hydrogen generation rate depending on whether an increase in nitrite ion concentration in the SRAT slurry would promote or inhibit the current noble metal catalytic activity. Small quantities of $\mathrm{N}_{2} \mathrm{O}$ are observed shortly after the start of reflux, indicating renewed nitrite destruction. The quantities seem to vary with the stoichiometry and amount dewatered.

\subsection{Recommendations for Stoichiometric Acid Calculations}

Acid calculations for DWPF have three parts. The first part is a calculation of the total moles of acid required for processing, the second part is the estimation of the effect of processing on species that impact melter redox such as nitrate and formate ions, and the third part is a calculation of the predicted melter redox from the projected composition of the SME product. This study focused on CPC chemistry rather than melter chemistry and was primarily concerned with the first two parts of the DWPF acid requirement calculations.

\subsubsection{Calculation of the Stoichiometric Acid Requirement}

The analysis in Section 5.3.2 and subsequent sections leads to some observations concerning the calculation of the acid requirement for the SRAT. Observations specific to particular acid consumption terms were discussed earlier. Based on the existence of competing chemical reactions for the available acid, it might be reasonable to propose one stoichiometric acid equation that would approximately give the minimum acid required to achieve nitrite destruction while taking into account that Mn reduction was occurring at the same time. This equation could tend to underestimate the actual minimum acid required to accomplish nitrite destruction depending on the actual extent of Mn reduction when all other sources of acid consumption were properly counted. Therefore, a factor would be needed to increase the acid calculated to that needed to actually accomplish both goals. Presumably, the factor would be closer to $100 \%$, however, than the current DWPF acid stoichiometry equation. 
An alternative approach could be taken to calculating the SRAT acid requirement. Instead of attempting to calculate the minimum acid requirement, an equation could be devised that attempts to calculate a nominal acid addition that would potentially reduce all $\mathrm{Mn}$ and destroy all nitrite simultaneously, but that would arguably not put significant excess acid into the system that would be available for hydrogen generation.

The current stoichiometric acid equation implemented at DWPF is an attempt at a first principles calculation of the minimum requirement, and it stands as follows:

$$
\frac{\text { moles acid }}{\text { L slurry }}=\text { base equivalents }+2 * \text { total TIC }+0.75 * \text { nitrite }+1.2 * \mathrm{Mn}+\mathrm{Hg}
$$

All of the individual terms are in moles per L of slurry. Base equivalents is measured by a slurry titration to $\mathrm{pH}$ 7. The other four terms are also measured on the slurry, not on the supernate. The coefficients for nitrite and $\mathrm{Mn}$ were empirically selected. The 0.75 for nitrite is greater than the 0.667 needed for reaction [5] in Section 2.4.4 but less than that for the two reactions where formate is converted to $\mathrm{CO}_{2}$. The 1.2 for $\mathrm{Mn}$ is sufficient for $40 \%$ reduction $(40 \%$ of $3=1.2)$. These two coefficient recommendations were made by C. W. Hsu in 1992. ${ }^{24}$ The implementation equations used in the DWPF stoichiometric acid calculation Excel workbook were developed by Marek and Eibling based on Hsu's recommendations. ${ }^{25}$ The coefficient of 2 on slurry TIC does not take into account the partial titration of soluble carbonate in the measurement of the base equivalents at $\mathrm{pH} 7$.

A revised calculation for the minimum acid requirement based on the reaction analyses in this report leads conservatively to an equation of the following form for this simulant system:

$$
\frac{\text { moles acid }}{L \text { slurry }}=\text { base equivalents }+H g+\text { soluble } T I C+1.5 *(C a+M g)+1.0 * \text { nitrite }+1.5 * M n
$$

The equation gives the acid required to complete the necessary reactions and lists the acid consumers in the approximate order that they appear to occur during acid addition with $\mathrm{ABC}$ simulant:

- Readily titratable base uses the initial acid added to the SRAT.

- $\mathrm{HgO}$ and $\mathrm{Mg}(\mathrm{OH})_{2}$ both react out of the insoluble solids as $\mathrm{pH}$ drops below seven.

- $\mathrm{CaCO}_{3}$ dissolution and TIC destruction follow immediately afterwards, but little nitrite destruction or Mn reduction has occurred by that point.

- Nitrite destruction and $\mathrm{Mn}$ reduction compete for the final acid in the minimum case.

Adequate nitrite destruction does not have to coincide with $50 \% \mathrm{Mn}$ reduction, so this is one area where the equation is still approximate. Anywhere from $0-100 \%$ of the Mn could be reduced when nitrite destruction is complete. The $50 \% \mathrm{Mn}$ reduction assumption minimizes the uncertainty that Mn could bring to the calculated acid requirement for an unstudied system. The 50\% Mn reduction, however, also reflects the fact that in most of the systems studied in detail there is significant partial Mn reduction at the time that adequate nitrite destruction occurs.

More data on $\mathrm{Hg}$, and the timing of its reduction reaction, are presented in a memo using data drawn from the $\mathrm{Rh}-\mathrm{Ru}-\mathrm{Hg}$ matrix study. ${ }^{26,12}$ Insoluble carbonate seemed to be adequately accounted for in the $\mathrm{Ca}$ and $\mathrm{Mg}$ terms. $\mathrm{Ca}(\mathrm{OH})_{2}$ is sufficiently soluble that it should convert to $\mathrm{CaCO}_{3}$ over time in the presence of the dissolved carbonate in waste supernate. Real waste presumably also contains some $\mathrm{MgCO}_{3}$, which 
has a similar solubility to $\mathrm{Mg}(\mathrm{OH})_{2}$. The fairly clean separation in dissolution timing that put $\mathrm{Mg}$ ahead of $\mathrm{Ca}$ with the $\mathrm{ABC}$ simulant may become less distinct with real waste containing some $\mathrm{MgCO}_{3}$. This, however, would not impact the proposed acid requirement equation.

Insoluble TIC and readily neutralized hydroxide associated with the slurry $\mathrm{Ca}$ and $\mathrm{Mg}$ have been combined into a new term with a coefficient of $75 \%$ of the theoretical acid required if $\mathrm{Ca}$ and $\mathrm{Mg}$ are $100 \%$ speciated with basic anions. That is, the coefficient conservatively assumes that $25 \%$ of the $\mathrm{Ca}$ and $\mathrm{Mg}$ may be present as sulfates, oxalates, phosphates, etc. which do not require acid to dissolve. The 1.5 coefficient on $\mathrm{Mn}$ is appropriate for a $50 \%$ reduction target. A coefficient of one on soluble TIC recognizes that the base equivalents titration picks up roughly half of the acid required to convert soluble TIC into $\mathrm{CO}_{2}$, and therefore the proposed coefficient eliminates potential double counting of acid demand. The coefficient of one on mercury appears to be correct and unambiguous. This term has been a relatively minor contributor to the total from the calculation, but there is no reason to exclude it. Only limited data from the test with $\mathrm{Ru}$ and $\mathrm{Hg}$ might contradict the conservative nature of this equation due to the reduced solubilities of $\mathrm{Ca}, \mathrm{Mg}$, and $\mathrm{Mn}$ seen in that test. Those results were not consistent with other SRAT run data using other simulants.

The coefficient of one on nitrite is toward the low end of the calculated coefficients seen in this testing and with typical SB3 and SB4 levels of noble metals, as well as with no noble metals. $\mathrm{N}_{2} \mathrm{O}$ production, with its associated cost of two moles acid per mole nitrite destroyed, is sufficiently large in most runs to raise the average coefficient from the theoretical minimum value of 0.667 to something near unity. The $\mathrm{ABC}$ simulant scoping tests consumed about one mole acid per mole nitrite destroyed with typical noble metal and mercury loadings. Mercury seemed to suppress $\mathrm{N}_{2} \mathrm{O}$ formation and promote $\mathrm{NO}$ formation. The first significant exception noted to date was in the bead-frit matching test with $0.2 \mathrm{wt} \% \mathrm{Ru}$ and 1.5 $\mathrm{wt} \% \mathrm{Hg}$, where $\mathrm{N}_{2} \mathrm{O}$ production dropped significantly, but it appears that this was due to catalyzed formic acid reduction of nitrite to NO with a cost of 1.5 moles acid per mole nitrite so the overall effect on the nitrite coefficient was probably not to cause it to fall below one. $\mathrm{Rh}-\mathrm{Ru}-\mathrm{Hg}$ tests also showed a reduction in $\mathrm{N}_{2} \mathrm{O}$ production as the initial mercury concentration increased. In spite of the shift in nitrite destruction byproduct distribution, the quantity of acid required for nitrite destruction appeared to stay fairly close to one mole acid per mole nitrite.

The proposed minimum acid requirement equation should predict acid demand fairly similarly to the equation shown in Figure 75 since it is a very similar equation in concept. Most of the simulant systems in Figure 75 were based on $\mathrm{Mg}(\mathrm{OH})_{2}$ and $\mathrm{CaCO}_{3}$. The 1.4 *slurry TIC term is approximately accomplishing the same thing as the $\mathrm{Ca}$ term in the new proposed equation combined with the soluble TIC term. The JMP statistical database used to prepare Figure 75 does not yet include Ca or soluble TIC data, so some work remains to be done to test the new minimum acid requirement equation against actual SRAT experimental data.

A similar equation format with a few small changes gives a potential nominal stoichiometric acid equation:

$$
\frac{\text { moles acid }}{L \text { slurry }}=\text { base equivalents }+H g+\text { soluble } T I C+1.8 *(C a+M g)+1.1 * \text { nitrite }+3 * M n
$$

This nominal acid equation is guaranteed to give a larger result than the proposed minimum acid requirement equation [30], since no coefficients were made smaller and no terms were dropped. This equation is nearly a theoretical equation for the acid requirement in origin. It is a more correct "first principles" equation than the current DWPF stoichiometric acid equation because it is more complete and apparently has more accurate coefficients. This "first principles" nominal acid equation, however, has 
been developed in concert with analytical data on the reactions occurring during acid addition plus a database of reactions that successfully destroyed nitrite to less than $1,000 \mathrm{mg} / \mathrm{kg}$ in the SRAT product. This quantity of acid requirement data on a variety of sludge systems was not available when the original DWPF stoichiometric acid requirement algorithm was developed.

The nitrite coefficient was increased $10 \%$ relative to the proposed minimum acid equation. Nevertheless, as discussed earlier, there can be no single correct constant coefficient for the nitrite term, since the coefficient properly has noble metal and $\mathrm{Hg}$ composition dependence. Manganese is assumed to be fully reduced by the available acid in this equation. This extent of reduction has been seen frequently in runs with adequate acid. Samples taken shortly after the end of acid addition indicate total dissolution of the Mn into the supernate as the 2+ ion, though Mn may not remain in the supernate through the end of the SRAT cycle. (The 4-L run H2Sim 1 with $80 \%$ as much acid as the bead-frit runs only achieved about $65 \% \mathrm{Mn}$ dissolution along with complete nitrite destruction. As acid addition levels were increased, more and more $\mathrm{Mn}$ went into solution before hydrogen generation became an issue. ${ }^{7}$ ) A larger fraction, 90\%, of the $\mathrm{Ca}$ and $\mathrm{Mg}$ are assumed to be acid consuming than in the minimum acid version, and if this is not the case, then some of the additional acid would presumably go toward $\mathrm{Cu}, \mathrm{Ni}$, and $\mathrm{Zn}$ neutralization and dissolution, i.e. extra acid would not immediately and necessarily go into hydrogen generation.

The suggested nominal acid equation needs to be tested against a larger database to see what frequency, if any, of times this equation would have predicted an acid addition that was actually more acid than required to produce excessive hydrogen. The soluble TIC term will be a short-term impediment to the equation validation testing, since many of the systems studied in the past do not have a measured value for the soluble TIC of the starting feed.

Estimation of a successful acid addition strategy for a new sludge composition is a recurring challenge as is estimating the impact of a composition shift in one of the equation inputs on the range of successful stoichiometric factors. An equation that estimates the acid requirement at a modest level above the minimum requirement, and yet is not excessive, has the potential to provide an acid addition target that will work successfully the first time, i.e. be somewhere in between too little acid and too much acid.

One thing that this proposed nominal acid equation has not been developed to handle is high oxalate waste. High oxalate waste (oxalate $>\sim 10,000 \mathrm{mg} / \mathrm{kg}$ ) was shown to impact the base equivalents titration, and to somehow tie up or consume acid in addition to the terms that had been previously identified and used in the DWPF acid equation. The acid consumed may simply be protonating the oxalate ion as $\mathrm{pH}$ falls, similar to what occurs with carbonate and nitrite. Oxalate is more stable than the other two anions during the SRAT, and it may simply hold the acid protons. Presumably, a linear correction term (coefficient times oxalate concentration) would be needed before high oxalate wastes could be handled by this approach. Some species dissolved and reprecipitated in the presence of oxalate that stayed in solution in the bead-frit runs.

Both the proposed minimum and nominal acid equations offer one advantage to SRNL over the current DWPF minimum acid equation. That is the elimination of the slurry TIC measurement. This measurement has been a source of considerable uncertainty within SRNL. It may also have had a larger than expected impact on the experimentally determined range of suitable stoichiometric factors.

The proposed minimum and nominal acid equations were applied to the slurry used in the bead-frit and hydrogen program runs. The individual terms needed for the equations at $22-\mathrm{L}$ scale are given in moles in Table 26. 
Table 26. Stoichiometric Acid Equation Inputs

\begin{tabular}{|l|r|r|c|}
\hline Consumer & Moles & Consumer & Moles \\
\hline Base Equivalents & 4.508 & $\mathrm{NO}_{2}^{-}$ & 6.590 \\
\hline Nominal TIC $(849 \mathrm{mg} / \mathrm{kg})$ & 1.194 & $\mathrm{Mg}$ & 1.698 \\
\hline Basis TIC $(1350 \mathrm{mg} / \mathrm{kg})$ & 1.900 & $\mathrm{Ca}$ & 1.697 \\
\hline Soluble TIC & 0.773 & $\mathrm{Mn}$ & 1.990 \\
\hline $\mathrm{Hg}$ & 0.000 & & \\
\hline
\end{tabular}

Values correspond to $14.4 \mathrm{~L}$ of untrimmed A-B-C blended sludge simulant, the nominal charge in the sixteen bead-frit runs. The actual 22-L bead-frit runs were performed at about 28.2 moles of acid each. Using the basis TIC value, the current DWPF equation and the two proposed equations calculate the following total acid requirements, Table 27.

Table 27. Comparison of Three Acid Equations

\begin{tabular}{|l|c|c|c|}
\hline Input Term & $\begin{array}{c}\text { Current equation } \\
\text { Moles acid }\end{array}$ & $\begin{array}{c}\text { Proposed minimum } \\
\text { acid eqn., moles acid }\end{array}$ & $\begin{array}{c}\text { Proposed nominal } \\
\text { acid eqn., moles acid }\end{array}$ \\
\hline Base Equivalents & 4.508 & 4.508 & 4.508 \\
\hline TIC $(1350 \mathrm{mg} / \mathrm{kg})$ & 3.800 & 0.0 & 0.0 \\
\hline Soluble TIC & 0.0 & 0.773 & 0.773 \\
\hline $\mathrm{NO}_{2}^{-}$ & 4.943 & 6.590 & 7.249 \\
\hline $\mathrm{Mg}$ & 0.0 & 2.547 & 3.056 \\
\hline $\mathrm{Ca}$ & 0.0 & 2.546 & 3.055 \\
\hline $\mathrm{Mn}$ & 2.388 & 2.985 & 5.970 \\
\hline Total Acid & 15.64 & 19.95 & 24.61 \\
\hline
\end{tabular}

The lowest acid window hydrogen simulant 4-L run (H2Sim1) was at 23.1 moles acid (on a 22-L basis; this run destroyed nitrite $(<100 \mathrm{mg} / \mathrm{kg})$, reduced $63 \%$ of the $\mathrm{Mn}$, and made no $\left.\mathrm{H}_{2}\right){ }^{7} \mathrm{H} 2 \mathrm{Sim} 1 \mathrm{was}$ at $116 \%$ of the proposed minimum acid equation result (23.1/19.9), and the data indicate that the run could have succeeded with somewhat less acid, though perhaps not with $16 \%$ less acid. By comparison, H2Sim1 was at $148 \%$ of the current DWPF stoichiometric acid equation. While the two proposed equations sum to larger acid requirements due in part to increased coefficients on nitrite and $\mathrm{Mn}$, it should be noted that the sum of the soluble $\mathrm{TIC}, \mathrm{Ca}$, and $\mathrm{Mg}$ terms in the new equations also exceeds the insoluble TIC term in the current DWPF equation.

The new nominal acid equation result exceeded the acid quantity used in $\mathrm{H} 2 \mathrm{Sim} 1$ by $6 \%$. It actually gave a close match to the acid added in $\mathrm{H} 2 \mathrm{Sim} 2$, which at 22-L scale was equivalent to 24.9 moles, or $101.2 \%$ of the nominal result. $\mathrm{H} 2 \mathrm{Sim} 2 \mathrm{had} \geq 81 \% \mathrm{Mn}$ reduction and 0.013 DWPF-scale $1 \mathrm{bs} \mathrm{H}_{2} / \mathrm{hr}$ in the SRAT, i.e. it would be considered a very successful run during qualification or flowsheet work. A broader range of comparison tests, however, is needed to validate either of the new equations. The two new equation results are closer to the actual acid quantities for the simulant used in these tests than the current DWPF stoichiometric acid algorithm, but that is to be expected since much of the data that were used to revise the stoichiometric acid equation came from testing with this simulant.

\subsubsection{Estimation of Anion Changes During Processing}

In addition to calculating the total moles of acid to add to a given volume of slurry, it is also necessary to provide estimates for nitrite-to-nitrate conversion and formate loss before using the current redox algorithm in order to divide the total acid into a formic acid fraction and nitric acid fraction. The 
conversion of about $25 \%$ of the nitrite into $\mathrm{N}_{2} \mathrm{O}$ (in the no noble metal and $0.2 \mathrm{wt} \% \mathrm{Ag}$ runs) and reduction of $100 \%$ of the $\mathrm{Mn}$ gives some bounding guidance on what assumptions could be made. Only nitrite not converted into $\mathrm{N}_{2} \mathrm{O}$ could be converted into nitrate, so roughly $75 \%$ of the nitrite could convert to nitrate. A maximum of one third of the nitrite moles participating in conversion could become nitrate in a well insulated system per the stoichiometric coefficients, or an overall nitrite-to-nitrate conversion of 25 mole \%. Noble metals and mercury appear to be influencing the nitrite-to-nitrate conversion. As various catalysts accelerate the formic acid reduction of nitrite, the amount of nitrite ion converted to nitrate should decrease. Considerable experimental data for nitrite-to-nitrate conversion have fallen around $20 \pm 10 \%$ since the practice of insulating the SRAT during acid addition was initiated 4-5 years ago (prior to that, the conversion percentage had been significantly higher). As discussed earlier in this report, measurements of both nitrite-to-nitrate conversion and formate loss can be expected to be roughly $\pm 10 \%$ due to error accumulation in the calculations, i.e. $20 \pm 10 \%$ or $30 \pm 10 \%$.

It is also necessary to estimate the formate loss. Each mole of nitrite converted into $\mathrm{N}_{2} \mathrm{O}$ produces one mole of $\mathrm{CO}_{2}$, each mole of $\mathrm{Hg}$ reduced produces one mole of $\mathrm{CO}_{2}$, and each mole of $\mathrm{Mn}$ reduced produces one mole of $\mathrm{CO}_{2}$. Each mole of $\mathrm{CO}_{2}$ represents a matching mole of destroyed formate ion. Therefore, a minimum formate loss could be calculated for a given feed from the following equation with $25 \%$ nitrite to $\mathrm{N}_{2} \mathrm{O}$ conversion:

$$
\text { minimum moles formate lost }=0.25 * \text { moles nitrite }+ \text { moles } \mathrm{Mn}+\text { moles } \mathrm{Hg}
$$

This equation might be particularly useful for simulant SRAT runs without noble metals or mercury, such as melter feed preparation runs. Actual formate losses would be expected to increase above the value of this calculation as the catalytic activity in the SRAT increases, i.e. this equation is approximately a lower bound equation on the likely formate loss. One issue is that $\mathrm{Hg}$ appears to promote $\mathrm{NO}$ formation at the expense of $\mathrm{N}_{2} \mathrm{O}$ formation, at least in the system with $\mathrm{Ru}$ and $\mathrm{Hg}$, but both forms of catalytic nitrite destruction cause formate loss and $\mathrm{CO}_{2}$ formation. The $\mathrm{NO}$ reaction consumes half as much formate, but if significantly more nitrite is converted by accelerating reaction [8] than was formerly converted by reaction [9], then the estimated formate loss should still be reasonable. The percent formate loss would be expected to fall as the formic acid addition increased in the absence of noble metals. Oxalate ion can partially convert to formate ion as well, but there was only a small concentration of oxalate in the starting A-B-C sludge simulant so this was not a significant factor in the process simulations. There may be some additional insights in future tests on the formate loss estimation equation depending on what interactions are seen between $\mathrm{Hg}$ and $\mathrm{Rh}$ and/or $\mathrm{Hg}$ and all noble metals.

\subsection{Closing Thoughts on Chemistry and Acid Consumption}

The main chemical reactions occurring during and shortly after acid addition appear to have been well characterized and put into sequence. These are the reactions that occur before significant catalytic hydrogen generation. An improved understanding of them was essential if better control of total acid is the best strategy for mitigating the risk of exceeding the DWPF design basis hydrogen generation rates. The expanded characterization of SRAT chemistry was also a natural step in making a critical examination of the current DWPF stoichiometric acid requirement equation. The obvious benefit of an improved stoichiometric acid equation is the reduced chance of putting excessive acid into the SRAT and triggering an overly large maximum hydrogen generation rate. Investigations into both areas had been planned by SRNL and were supported by the catalytic hydrogen review panel members.

The applicability of the proposed acid requirement equations should be enhanced by the fact that $\mathrm{Ag}, \mathrm{Pd}$, and $\mathrm{Rh}$ concentrations are typically $<0.02 \mathrm{wt} \%$ in the dried solids, while this study went to $0.2 \mathrm{wt} \%$. Similarly, $\mathrm{Ru}$ concentrations are typically $<0.08 \mathrm{wt} \%$, while this study pushed the range to $0.375 \mathrm{wt} \%$. 
Presumably, the calculated variability in the moles of acid required to destroy a mole of nitrite (1.0-1.6) would fall into a smaller range if the noble metals were confined to lower maximum concentrations.

The $\mathrm{Rh}, \mathrm{Ru}$, and all noble metal cases in the bead-frit program exhibited some chemical reactions during boiling that are still poorly characterized as to their identity, their sequence, and their relative significance. These reactions occur in parallel with hydrogen generation, so they may be impacting the maximum hydrogen generation rate. Competing formate consuming reactions certainly seem like they should have some impact on hydrogen generation. These uncharacterized competing reactions currently make practical prediction of hydrogen generation using models extremely difficult.

Formate loss during boiling was tracked in selected runs, but the data were not specific as to what reaction(s) were consuming it. A small quantity of TIC absorption rate data were obtained, but this does not help to identify the source of formate conversion to $\mathrm{CO}_{2}$ and then to TIC. The significance of catalytic wet air oxidation is also difficult to quantify, since the byproducts of CWAO on formic acid are only $\mathrm{CO}_{2}$ and water, neither of which is uniquely present in the off-gas or SRAT slurry due to CWAO. Consumption of relatively small amounts of oxygen is difficult to separate from the normal fluctuations in the GC oxygen data from injection to injection. In fact it is even difficult to identify small oxygen losses by averaging over several scans after the GC has been online for 7-10 hours and its calibration has started to drift. Ammonium ion concentration as a function of time was not envisioned as a significant study issue at the beginning of the test program, and no rate data were obtained; some archived samples could be analyzed if the interference issue with $\mathrm{Na}^{+}$can be resolved. If a study into ammonium ion formation is ultimately needed, it should probably be moved into SRAT tests with more ordinary noble metal and mercury loadings.

Finally, the data in this report were developed from tests with non-radioactive simulants of real waste. Certain simulants were already available in drum quantities that permitted rapid preparation of 110 gallons of relatively generic waste simulant in a short time. This met the needs of the hydrogen generation program and the melter feed rheology program. The existing simulants were all prepared by the traditional method that predates DWPF start-up. A newer coprecipitation method produces simulants with somewhat different speciation and physical properties. The generality of the conclusions made on the generic blend simulant system used here need to be tested against data from coprecipitated simulant tests and against real waste results (past, present, and/or future).

The noble metals used in this study were all added as simple trim chemicals to the completed simulant sludge waste prior to processing. The earlier form of noble metal hydrogen program testing indicated that coprecipitating the noble metals along with the bulk insoluble cations delayed their activation, i.e. had an effect on the reaction timeline during boiling as well. The bead-frit test sequence was not the appropriate place to address such issues. The hydrogen generation program scope still includes tests to compare coprecipitated noble metal simulant to actual waste tested in the Shielded Cells, and also to interact with the sludge simulant matrix study which is based on the newer coprecipitated simulants, so opportunities to address some of these issues will become available in the next year or so. 


\subsection{CONCLUSIONS}

Sixteen melter feeds were successfully prepared to support the melter feed rheology modifier program effort to evaluate spherical beads as a replacement for glass frit. This task provided an excellent opportunity to perform investigations into noble metal driven chemistry, and to produce high noble metal concentration samples needed for X-ray absorption spectroscopy (XAS) at off-site labs. These simulations were also the first detailed investigation into the behavior of single noble metal DWPF feeds in fifteen years. Details of the noble metal-hydrogen generation interactions and of the XAS work are covered in separate reports. In addition, the panel of catalyst experts who evaluated the SRNL understanding of CPC chemistry supported SRNL plans to obtain additional data needed to create a SRAT reaction timeline and to improve the DWPF stoichiometric acid calculation in order to improve control of excess acid that leads to hydrogen generation.

The SRAT and SME chemistry results covered in this report include many new findings. Not every result that was observed at high noble metal concentrations can be assumed to translate to more typical concentrations. $\mathrm{Ag}, \mathrm{Pd}, \mathrm{Rh}$, and $\mathrm{Ru}$ were tested singly, in combination, and without any. Mercury was not a component of the melter feed preparation program, so only limited data on the impact of mercury was integrated into the reported findings. Significant chemistry findings included:

- Ag showed negligible catalytic activity on its own. The other three noble metals were all catalytically active in multiple ways.

- The rate of nitrite destruction can be accelerated by the noble metal catalysts present in site waste.

- Homogeneous nitrite conversion to nitrate and NO occurred in every case.

- Nitrite conversion to $\mathrm{N}_{2} \mathrm{O}$ by formic acid can be catalyzed, but it occurs to a significant extent in the absence of catalysts. Pd was the most active catalyst for promoting $\mathrm{N}_{2} \mathrm{O}$ formation, with 0.2 $\mathrm{wt} \% \mathrm{Pd}$ doubling the mass of $\mathrm{N}_{2} \mathrm{O}$ produced relative to the noble metal free system.

- Nitrite conversion to $\mathrm{N}_{2} \mathrm{O}$ by formic acid was catalyzed by $\mathrm{Rh}$ almost as effectively as by Pd.

- Nitrite reduction by formic acid generating $\mathrm{NO}$ and $\mathrm{CO}_{2}$ does not occur noticeably in the absence of a catalyst. $\mathrm{Ru}$ was the most effective catalyst for increasing $\mathrm{NO}-\mathrm{NO}_{2}-\mathrm{N}_{2} \mathrm{O}_{4}$ formation. $\mathrm{Ru}$ plus $\mathrm{Hg}$ was even more effective at producing these gases and minimizing $\mathrm{N}_{2} \mathrm{O}$ formation.

- Accelerating nitrite destruction came at the expense of decelerating Mn reduction.

- The distribution of oxides of nitrogen in the off-gas was a strong function of the noble metal type and concentration and presence or absence of $\mathrm{Hg}$.

- The stoichiometric acid required to destroy a mole of nitrite ion was a function of composition, particularly of the noble metal and $\mathrm{Hg}$ composition, and it is not a true constant as assumed in the current DWPF acid addition equation.

- The contribution of refluxed nitrate ion from the MWWT to the SRAT accounted for a relatively small fraction of the nitrite-to-nitrate conversion total.

- Carbonate conversion to $\mathrm{CO}_{2}$ occurred primarily before significant destruction of formate ion to $\mathrm{CO}_{2}$ except in the test with $\mathrm{Hg}$. Complete carbonate destruction occurred before much $\mathrm{Mn}$ reduction or nitrite destruction.

- $\mathrm{CO}_{2}$ formed during nitrite destruction was partially absorbed in the SRAT condenser condensate stream. What were apparently bubbles of $\mathrm{CO}_{2}$ were seen disengaging from the condensate in the MWWT, and TIC was detected in a simultaneous sample of the MWWT condensate.

- Destruction of formate and formic acid by Rh and Ru catalysts caused the SRAT pH to rise to the point that some of the $\mathrm{CO}_{2}$ being evolved was absorbed by the system as carbonate and/or bicarbonate (both are TIC). As TIC began increasing in the slurry, cations such as $\mathrm{Mg}, \mathrm{Mn}$, and to some extent $\mathrm{Ca}$ began to reprecipitate out of the SRAT supernate. 
- The concentration of formate ion increased linearly during formic acid addition at a rate equal to the formic acid addition rate for nearly $75-80 \%$ of the addition period. It was only after the $\mathrm{pH}$ was nearing 5 that formate began disappearing significantly due to Mn reduction and nitrite reduction.

- Insoluble cations were dissolved during acid addition. The first major cation to dissolve was $\mathrm{Mg}$, followed by $\mathrm{Ca}$, and then $\mathrm{Mn}$. The soluble species of these three cations were essentially entirely dissolved (certain insoluble species such as $\mathrm{CaC}_{2} \mathrm{O}_{4}$ apparently were not dissolved).

- When catalytic activity was low, and when $\mathrm{pH}$ was also low, other cations began to dissolve at a slow rate. These included $\mathrm{Ni}, \mathrm{Cu}$, and $\mathrm{Zn}$. None of these species achieved $100 \%$ dissolution by the end of the SRAT in any of the runs.

- Ammonium ion formation occurred to a significant extent in some of the particularly active systems. Ammonium ion was detected in SRAT FAVC condensate samples, as well as in several SRAT product slurry samples.

Reactions consuming acid were monitored with SRAT slurry and supernate samples up until significant catalytic destruction of formic acid began to occur. Interpretation of some of the sample data became more difficult once catalytic formate destruction became significant, e.g. as $\mathrm{pH}$ reversed and began to rise toward seven.

One SRAT processing goal is to destroy nitrite to less than $1000 \mathrm{mg} / \mathrm{kg}$ in the SRAT product to draw hydrogen generation into the SRAT instead of the SME. Mn reduction consumes acid in parallel with nitrite destruction according to the available data. The precise extent of $\mathrm{Mn}$ reduction at $1000 \mathrm{mg} / \mathrm{kg}$ nitrite varies. (Assuming 50\% Mn reduction limits the error in the acid consumed by Mn reduction to $50 \%$ of the maximum amount for full $\mathrm{Mn}$ reduction, i.e. a coefficient of $1.5 \mathrm{moles}$ acid $/ \mathrm{mole}$ Mn instead of 3.0 moles/mole for full reduction.) A potential new minimum acid requirement equation is given by the following (with all terms in moles per liter slurry).

$$
\frac{\text { moles acid }}{L \text { slurry }}=\text { base equivalents }+H g+\text { soluble } T I C+1.5 *(C a+M g)+1.0 * \text { nitrite }+1.5 * M n
$$

The reactions were observed to occur approximately in the order from left to right. Only the nitrite that needs to be destroyed to meet the SRAT product target needs to be used as the input, not the entire feed quantity of nitrite. $\mathrm{Ca}$ and $\mathrm{Mg}$ are assumed to be present as $75 \%$ soluble basic salts and $25 \%$ non-basic salts, although most cation dissolution data shows that this is a conservative estimate. These species seem to have tied up a significant fraction of insoluble TIC that can be destroyed, which is why a soluble TIC term appears in the equation instead of a total TIC term.

Mn reduction could proceed further than the 50\% target in some systems leaving nitrite destruction insufficiently complete at $100 \%$ of the above calculated acid requirement. Both mercury and noble metal concentrations were observed to impact the nitrite destruction kinetics. The equation is too simple to capture the inherent complexity of some of the parallel catalytic reactions occurring during acid addition. $\mathrm{Ca}$ and $\mathrm{Mg}$ could also be present as more than $75 \%$ soluble basic salts. Consequently, this acid equation would probably require a small stoichiometric correction factor greater than $100 \%$ to ensure nitrite destruction.

An alternative approach to the computation of the acid requirement is proposed. In this approach, an equation was written that attempts to calculate a nominal acid addition instead of a minimum acid addition. 
WSRC-STI-2008-00131

Revision 0

$$
\frac{\text { moles acid }}{L \text { slurry }}=\text { base equivalents }+H g+\text { soluble TIC }+1.8 *(C a+M g)+1.1 * \text { nitrite }+3 * M n
$$

This equation recognizes that post-acid addition sampling frequently shows that $90-100 \%$ of the Mn has been reduced and dissolved, and that nitrite has also been virtually destroyed, yet there is insufficient excess acid remaining to produce hydrogen above the DWPF SRAT or SME limits. The actual amount of acid to add could be adjusted slightly up or down from the value that this equation yields depending on circumstances, but presumably the first choice would be a $100 \%$ factor. $\mathrm{Ca}$ and $\mathrm{Mg}$ are assumed to reach $90 \%$ dissolution starting as some sort of acid consuming form (equivalent to $100 \%$ dissolution with $10 \%$ not consuming acid).

These two proposed acid equations need further evaluation. DWPF should continue to use the current stoichiometric acid equation until the proposed minimum acid equation has been given further scrutiny. One reason this has not already been done is a general lack of soluble TIC data for much of the historical process simulation feed composition data. Another is that complete data for $\mathrm{Ca}$ and $\mathrm{Mg}$ have not been incorporated into some of the smaller databases. There are certainly some simulants for which the necessary data are available. The SB2 qualification sample was also analyzed for soluble TIC. These data need to be reviewed, and supporting analyses need to be made on new simulants as they become available in order to help to validate or revise these two new equations. 
WSRC-STI-2008-00131

Revision 0

This page left blank. 


\subsection{RECOMMENDATIONS}

Some historical data were reviewed related to $\mathrm{Ca}$ and $\mathrm{Mg}$ dissolution before proposing the two alternative acid equations, but a more thorough review of historical data is warranted. Current data should also be reviewed in the context of the new equations as it becomes available. It was noted that radioactive test data and coprecipitated simulant data generally agreed with the traditional recipe simulant data with respect to obtaining high extents of dissolution of these two cations during the SRAT. No attempt has been made to date to gather data on the systems with measured soluble TIC and to apply these acid equations to those runs to see what outcome is obtained with respect to nitrite destruction and hydrogen generation. This evaluation needs to be done.

The testing described here and/or performed in parallel with these tests does not as yet include much data concerning the impact of mercury on the results. Several matching tests to the bead-frit runs were planned that would include mercury and would produce samples for XAS characterization. One run with $\mathrm{Ru}$ and $\mathrm{Hg}$ has been performed. A run with $\mathrm{Rh}$ and $\mathrm{Hg}$ and a run with all noble metals and $\mathrm{Hg}$ should still be performed to provide comparison samples and data.

The dissolution reaction chemistry timeline was obtained on an A-B-C blend simulant system based on a traditional simulant preparation recipe that pre-dates DWPF start-up. These simulants have fairly well defined speciation, but do not have the prototypical coprecipitation of the insoluble hydroxides found in real wastes. Currently, SRNL does the majority of its process development and flowsheet work with newer coprecipitated simulants. A series of samples should be obtained during one or more runs with a coprecipitated simulant to track $\mathrm{Mg}, \mathrm{Ca}$, and $\mathrm{Mn}$ dissolution, and TIC and nitrite destruction, to see if there are any major differences compared to the results in this report which come from a single simulant feed. Such sampling during acid addition can be disruptive to control of the acid stoichiometry (potentially too much mass is removed as samples relative to the mass in the vessel at 4L scale, causing an artificial increase in the stoichiometry from nominal acid added to reduced sludge slurry mass). It might be best to sample in a $22-\mathrm{L}$ run or else in a 4-L run where control of stoichiometry is not critical.

Some of the carbon balance work in this report could be revisited if a new analytical instrument becomes available that can provide more accurate analyses of the TIC in the starting sludge and SRAT slurry samples. The uncertainty of the TIC value potentially compromises some of the conclusions concerning the relative significance of other reactions producing $\mathrm{CO}_{2}$. The distribution of soluble and insoluble carbonate in the SRAT product was not pursued, although it was hypothesized that most of the SRAT product TIC was present in precipitated $\mathrm{Ca}, \mathrm{Mg}$, and $\mathrm{Mn}$ species.

Speciation of uranium could be a potential issue, particularly if there is a significant carbonate form in the insoluble solids. A uranium carbonate species could consume acid that is not accounted for by the new equations without the slurry TIC input. Also, dissolution of an oxide or hydroxide form of uranium at pH's below seven could have an identical effect. Shielded Cells data needs to be reexamined to determine if $U$ is actively dissolving. Mn has been a problematic species; it often dissolves and reprecipitates before the end of the SRAT leaving no strong marker that it has consumed acid in the SRAT product analyses. Similar behavior by U could mask its potential to consume acid during processing.

The oxidation-reduction probe seemed to indicate a reversal from a reducing to an oxidizing state after formic acid addition in a run that produced a lot of hydrogen near the end of acid addition. Boiling was delayed for about an hour, allowing ORP data to be obtained further into the SRAT cycle than in other

runs. A solid-state ORP junction should be fabricated that can withstand the boiling conditions of the 
SRAT, so that additional data on the redox potential can be obtained that will permit a better characterization of the supernate potential during hydrogen generation throughout the SRAT cycle.

The nitrate ion-selective electrode gave a crude characterization of nitrate concentration in the MWWT during the SRAT cycle. The data quality were impacted by the selected acid stoichiometry which had the majority of nitrite destruction occur prior to boiling, when condensate flow induced mixing of the MWWT contents is poor. A lower acid stoichiometry run prior to the bead-frit block produced superior data (the integrated area derived average nitrate concentration during dewatering was in agreement with the composite dewatering sample nitrate ion concentration). The bulk of the ISE data indicate that nitrate refluxing from the MWWT was not the major factor in determining the percent nitrite-to-nitrate conversion at the bead-frit stoichiometry. It could be inferred, however, that if significant nitrite destruction continued beyond dewatering, then more nitrate could be returned to the SRAT in reflux than was seen in this study. Before studying this issue further, it would be advisable to equip a 22L-scale MWWT with a small mixer. Since most 22L scale SRAT simulations do not have Hg, the MWWT does not need to serve as a water-Hg phase separator, and mixing would create a uniform nitrate concentration around the probe. 


\subsection{REFERENCES}

${ }^{1}$ Plodinec, M. J., Report of the Hydrogen Generation Review Panel - Review of Hydrogen Generation in the DWPF. March 15, 2007.

${ }^{2}$ Davis, B. A., Catalytic Hydrogen Generation Program, HLW-DWPF-TTR-2007-0016, March 8, 2007.

3 Koopman, D. C., Task Technical and Quality Assurance Plan - Catalytic Hydrogen Generation Program. WSRC-RP-2007-00338, April 9, 2007, SRNL, Aiken, SC 29808.

${ }^{4}$ Koopman, D. C., Analytical Study Plan for Catalytic Hydrogen Generation Program. SRNL-PSE2007-00154, August 9, 2007.

${ }^{5}$ Davis, B. A., Improvement of SRAT Acid Equation. HLW-DWPF-TTR-2007-0015, March 8, 2007.

${ }^{6}$ Pickenheim, B. R., Improvement of SRAT Acid Equation. WSRC-RP-2007-00348, June7, 2007, SRNL, Aiken, SC 29808.

${ }^{7}$ Koopman, D. C., Preparation, Characterization, and Preliminary SRAT/SME Testing of a Simulant for the Hydrogen and Rheology Modifiers Program. SRNL-PSE-2007-00191, September 11, 2007.

${ }^{8}$ Pickenheim, B. R., Task Technical and Quality Assurance Plan - Use of Beads to Replace Frit in DWPF. WSRC-RP-2007-00199, March 29, 2007, SRNL, Aiken, SC 29808.

${ }^{9}$ Koopman, D. C., Noble Metal Chemistry and Hydrogen Generation During Simulated DWPF Melter Feed Preparation. WSRC-STI-2008-00002, May 2008, SRNL, Aiken, 29808.

${ }^{10}$ Fox, E. B. and B. R. Pickenheim, Speciation of Ru and Hg During Simulated Nuclear Waste Processing. SRNL-MST-2008-00151, SRNL, Aiken, SC, 29808 (July 30, 2008).

${ }^{11}$ Haber, F. and A. B. Lamb, Thermodynamics of Technical Gas Reactions. Longmans, Green, and Co., London, UK, 1908.

${ }^{12}$ Koopman, D. C. and T. B. Edwards, Catalytic Interactions of Rh, Ru, and Hg During Simulated DWPF Processing with Hydrogen Generation. WSRC-STI-2008-00235. July 2008, SRNL, Aiken, SC, 29808.

${ }^{13}$ Lecloux, A. J., Chemical, biological, and physical constraints in catalytic reduction processes for drinking water. Catalysis Today 53, 23-34 (1999).

${ }^{14}$ Höller, V., K. Rådevik, I. Yuranov, L. Kiwi-Minsker, and A. Renken, Reduction of nitrite-ions in water over Pd-supported on structured fibrous materials. Applied Catalysis B: Environmental 32, 143-150 (2001).

${ }^{15}$ Pintar, A., J. Batista, J. Levec, and T. Kajiuchi, Kinetics of the catalytic liquid-phase hydrogenation of aqueous nitrate solutions. Applied Catalysis B: Environmental 11, 81-98 (1996). 
${ }^{16}$ Koopman, D. C., C. M. Jantzen, and T. B. Edwards, Acid Addition Stoichiometry for Sludge Batch 3 Processing in the Defense Waste Processing Facility. WSRC-TR-2003-00118, Feb. 2003, SRNL, Aiken, SC, 29808.

${ }^{17}$ Carter, J. T., Nitric Acid Flowsheet Ammonium Nitrate Accumulation in the DWPF CPC Vessel Vent System. SRTC-LSE-92-0042, October 23, 1992, WSRC-SRTC, Aiken, SC, 29808.

${ }^{18}$ Hsu, C. W., Ammonium Generation During SRAT Cycle (U). WSRC-RP-92-1212, October 13, 2992, WSRC-SRTC, Aiken, SC, 29808.

${ }^{19}$ King, R. B., and N. K. Bhattacharyya, H. D. Smith, and K. D. Wiemers, Noble Metal-Catalyzed Ammonia Generation by Formic Acid Reduction of Nitrate in Simulated Nuclear Waste Media. Environmental Science and Technology 31, 4, p. 984 (1997).

${ }^{20}$ Lemaignan, L., C. Tong, V. Begon, R. Burch, and D. Chadwick, Catalytic denitrification of water with palladium-based catalysts supported on activated carbons. Catalysis Today 75 (2002) 75-78.

${ }^{21}$ Barrabes, N., J. Just, A. Dafinov, F. Medina, J. L. G. Fiero, J. E. Suieras, P. Salagre, and Y. Cesteros, Catalytic reduction of nitrate on $\mathrm{Pt}-\mathrm{Cu}$ and $\mathrm{Pd}$-Cu on active carbon using continuous reactor - the effect of copper nanoparticles. Applied Catalysis B: Environmental, 62, 1-2, 77-85 (10 January 2006).

${ }^{22}$ Koopman, D. C. and M. A. Baich, Impact of Mercury-Noble Metal Interactions on SRAT Processing of SB3 Simulants. WSRC-TR-2004-00548, December 2004, SRNL, Aiken, SC, 29808.

${ }^{23}$ King, R. B., A. D. King, and N. K. Bhattacharyya, "Technical Report to the Westinghouse Savannah River Laboratory on Elucidation of Noble Metal/Formic Acid Chemistry During DWPF Feed Preparation, Report 1, March, 1991”. SRL-PTD-91-0063, June 24, 1991, WSRC, Aiken, SC, 29808.

${ }^{24}$ Hsu, C. W., Defense Waste Processing Facility Nitric Acid Requirement for Treating Sludge. WSRCRP-92-1056, WSRC-SRTC (September 1992).

${ }^{25}$ Marek, J. C. and R. E. Eibling, Draft Calculational Algorithms for Nitric Acid Flowsheet. SRTC-PTD92-0050, WSRC-SRTC (September 1992).

${ }^{26}$ Koopman, D. C., Timing of Mercury Reduction During SRAT Acid Addition. SRNL-PSE-2008-00169, SRNL, Aiken, SC, 29808 (August 2008). 


\subsection{ACKNOWLEDGEMENTS}

The author wishes to acknowledge the contributions of a number of people. One key element of this report was the sample data. Obtaining the samples during the process simulations added a considerable burden to the work load of the ACTL laboratory technicians. The efforts of J. W. DuVall, V. J. Williams, I. A. Reamer, R. J. Workman, T. O. Burckhalter, and D. M. Marsh are especially appreciated in this regard. Various researchers assisted the technicians with data logging during the busier periods. Consequently thanks are also due to M. E. Stone, E. B. Fox, and J. R. Abramczyk. Once the samples were pulled, they were sent to Analytical Development and to the Process Science Analytical Lab. The quality of the bulk of the ICP-AES and IC data from D. R. Best, P. T. Simmons, and W. A. Thomas was critical to developing some of the conclusions in this report, and their efforts were greatly appreciated. Finally, a report on SRAT chemistry requires gas composition data. Developing and validating the GC gas composition data was made more difficult by some anomalous behavior that developed in the instruments during processing. Thanks are due to J. M. Pareizs and M. F. Williams who maintained the GCs during the testing and reprocessed the GC data after the runs were over. 
WSRC-STI-2008-00131

Revision 0

This page intentionally left blank. 
WSRC-STI-2008-00131

Revision 0

\section{APPENDIX A. MWWT CHEMISTRY}


A program was initiated to study the chemistry in the MWWT during the sixteen bead-frit SRAT simulations. This program involved several parts, which included sampling of the MWWT content with immediate caustic quenching of the sample, as well as sampling the composite condensate from SRAT cycle dewatering for anions. In addition, a nitrate ion ISE was tested prior to the runs in a variety of solutions containing nitrate and formate ions of different concentrations. Vendor literature had already indicated a potential interference from nitrite ion. Testing indicated that the probe tended to drift slowly out of calibration. Vendor literature also indicated that there was a temperature dependence to the correlation between millivolts and concentration. These issues were evaluated, and it was determined that they did not necessarily represent insurmountable obstacles toward tracking the concentration of nitrate ion in the MWWT as a function of time.

There were several reasons for initiating such a study of MWWT chemistry. Two modes of MWWT operation during acid addition had been tried in the last five years. In one mode the MWWT was allowed to accumulate condensate during acid addition, and that condensate was removed and counted against the target for dewatering in the SRAT. In the other mode, the MWWT was set to reflux during acid addition and no condensate was withdrawn. The first mode gave an indication of the quantity of condensate that passed through the MWWT during acid addition, which, in the second mode would be returned to the SRAT as reflux. There was some curiosity regarding the composition of the refluxing stream during acid addition.

Another observation had been made during prior SRAT simulations, which involved the impact of the onset of reflux from the MWWT after dewatering on the hydrogen generation rate. The observed impact of reflux was to cause a decrease in the hydrogen generation rate. The decrease was sometimes more significant than others, but the only effect seen was a decrease, never an increase in the hydrogen generation rate, during the four to five GC readings following the onset of reflux. The impact of reflux in older data when the MWWT was relatively oversized compared to the SRAT in terms of relative volumes was even more pronounced. The oversized MWWT would typically get about three volume turnovers during dewatering prior to reflux, while the more prototypically sized MWWT would get about seven volume turnovers. The hypothesis was that the inhibiting species to hydrogen generation that had accumulated in the MWWT was more effectively removed from the smaller MWWT prior to reflux by the increased number of volume turnovers.

A third issue with the MWWT was the near total lack of observations of significant nitrite ion concentrations in samples of condensates in spite of large nitrate ion concentrations. The presumed chemistry for nitrate incorporation into the MWWT condensate was through absorption of $\mathrm{NO}_{2}$ gas into condensing water vapor in the SRAT condenser:

$$
2 \mathrm{NO}_{2}+\mathrm{H}_{2} \mathrm{O} \rightarrow \mathrm{HNO}_{2}+\mathrm{HNO}_{3}
$$

This reaction produces equimolar quantities of nitrite and nitrate ions, but sample results were inconsistent with this reaction. It was hypothesized that the low $\mathrm{pH}$ of the condensate might be destroying the nitrite ions in the condenser or MWWT through reaction:

$$
3 \mathrm{HNO}_{2} \rightarrow \mathrm{HNO}_{3}+\mathrm{H}_{2} \mathrm{O}+2 \mathrm{NO}
$$

Formic acid is also present in the SRAT condenser condensate and MWWT, so reactions between nitrite ion and formic acid could also have been occurring that were destroying the nitrite ion.

Complicating the analysis of the MWWT was the fact that this is not a mixed tank, either in DWPF or in the lab-scale equipment. Therefore, concentration gradients can be expected to form as a function of 
time. These could be especially significant prior to boiling, when the volume turnover rate of the MWWT contents is fairly slow. The increased feed rate of condensate to the MWWT at boiling versus during acid addition seems to accomplish considerably more localized mixing, and the ISE readings became much smoother functions of time after boiling commenced.

To convert the ISE millivolt reading into nitrate ion concentration, it was assumed that a relationship between nitrate ion concentration and millivolts would be fundamentally of the usual form (Nernst equation), but that corrections would need to be added for ion interferences, temperature drift, and calibration drift. A time-dependent nitrate concentration function of the following form was postulated.

$$
\log _{10} c(t)=a+b^{*} V(t)+f_{\mathrm{NO} 2_{-}}(t)+g_{\mathrm{HCO} 2-}(t)+h_{\text {Temperature }}(t)+j_{\text {Calibration }}(t)
$$

The two constants, $a$ and $b$, have theoretical values through the Nernst equation. The probe voltage, V, and the unknown functions of time describing the interferences from nitrite and formate ion concentrations, temperature, and calibration drift were expanded in truncated Taylor series with time as the variable, such that the voltage could be equated to time by a linear function, and the identified interferences could also be expanded in terms of voltage instead of in time. This approach would work best when the change in voltage as a function of time was linear, or, failing that was monotonically increasing or decreasing.

$$
\log _{10} c(t) \approx r(t)+s(t) * V(t)
$$

Sample pairs were used to approximate $r(t)$ and $s(t)$ as constants during the time between the two samples. The two constants were allowed to be different between different pairs of consecutive samples.

$$
\log _{10} c(t) \approx \bar{r}_{i j}+\bar{s}_{i j} * V(t)
$$

In this final form, the average $r$ and $s$ values ( $r_{i j}$ bar and $s_{i j}$ bar) are determined between sample $i$ and sample $\mathrm{j}$ using the measured nitrate ion concentrations of those two samples, and the result is then applied to the millivolt readings between $t_{i}$ and $t_{j}$, the times of sample $i$ and sample $j$. This linear interpolation approach allowed conversion of the recorded millivolt readings into nitrate ion concentrations. The calculated nitrate ion concentrations were always exactly correct when they coincided with a sample, i.e. they matched the concentrations measured by IC. Some amount of conversion error was present during the period in between samples, so samples were taken about every 30-45 minutes during the period of peak nitrate ion concentration. An attempt was also made to take a sample at the point of minimum voltage (maximum nitrate), since this coincided with the voltage no longer being a monotonic function of time.

The period of interest generally only last about four hours, so the supporting sample burden was not excessive. Typically, five samples were pulled to match concentration to millivolt reading. The first came after the ISE reading indicated significant nitrate ion had accumulated, a second was taken about 30-45 minutes later, a third was taken near the minimum ISE reading (maximum nitrate), a fourth was taken about 30-45 minutes after that, and the fifth sample floated around in case one of the others appeared to have been pulled early or late.

One example of the nitrate ISE results that were obtained during the bead-frit testing was given in Figure 80 for the $0.2 \mathrm{wt} \% \mathrm{Ru}$ case. Eight ISE data sets were obtained overall during the testing along with supporting condensate ion concentration data by IC. These data sets covered six of the eight noble metal 
trim cases: all four cases at $0.2 \mathrm{wt} \%$ noble metal, the all noble metal case, and the $0.375 \mathrm{wt} \% \mathrm{Ru}$ case. The $0.2 \mathrm{wt} \%$ Rh case and the $0.375 \mathrm{wt} \%$ Ru case were repeated to evaluate data reproducibility.

Distinct differences were seen between the six cases. The two sets of data at $0.2 \mathrm{wt} \% \mathrm{Rh}$ are given first in Figure 87.

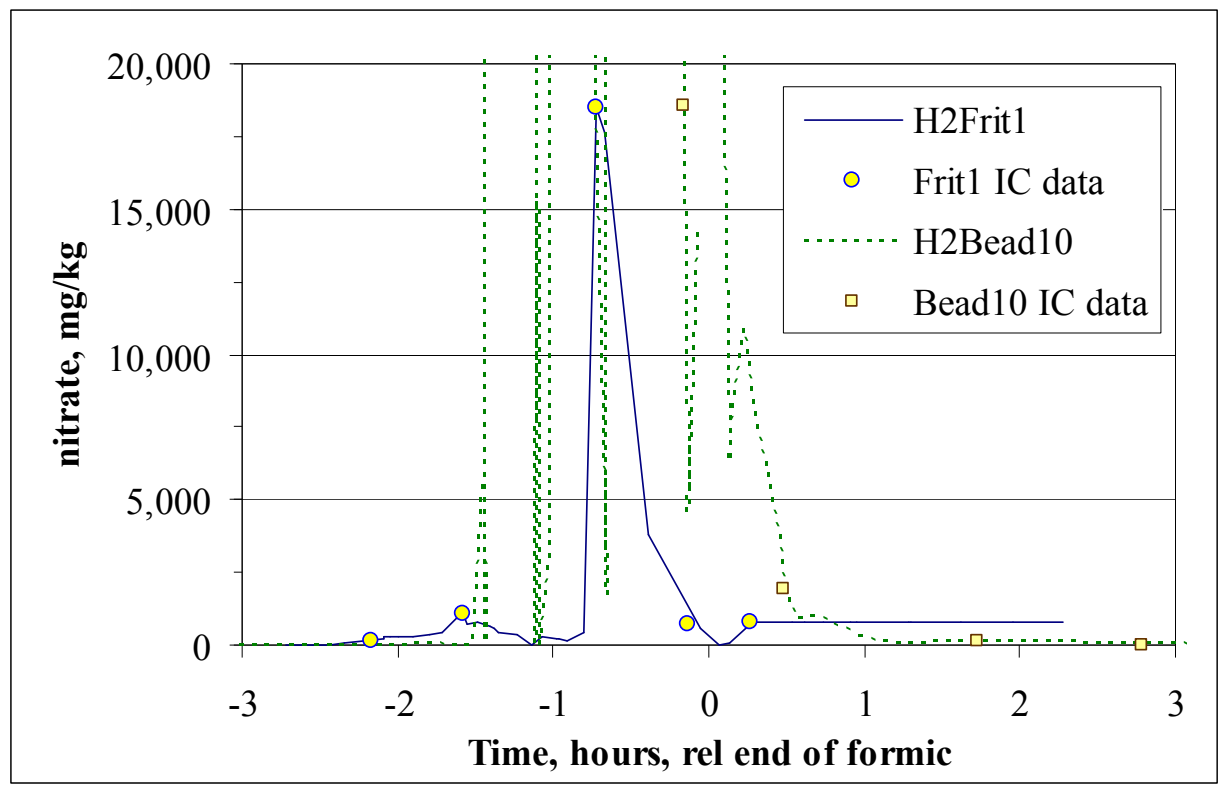

Figure 87. MWWT nitrate at $0.2 \mathrm{wt} \% \mathrm{Rh}$

The two sets of data are not particularly impressive. The ISE readings fluctuated considerably during the end of formic acid addition. Nitrite destruction was occurring rapidly in the SRAT during this time. Cycling the volume in the MWWT by stopping and starting the reflux flow during H2Bead10 in an attempt to obtain some mixing around the ISE probe tip seemed to scramble the data in this case, while in other instances this strategy seemed to help. Nevertheless, sample data indicate that the MWWT was over $17,500 \mathrm{mg} / \mathrm{kg}$ nitrate during the last half hour of acid addition.

Caustic quenched MWWT samples contained some residual nitrite ion. Small amounts of nitrite ion were detected in H2Frit1 at -2.2 to -1.5 hours $(280$ and $670 \mathrm{mg} / \mathrm{kg}$ ) and at -0.13 and +0.27 hours (480 and 100 $\mathrm{mg} / \mathrm{kg}$ ). Only the peak nitrate ion sample had no detectable nitrite. The other four samples were within a factor of three of having equimolar quantities of nitrite and nitrate. Small amounts of nitrite ion were detected in H2Bead10 at -0.17 and +0.48 hours $(410$ and $110 \mathrm{mg} / \mathrm{kg}$ ). These quantities were an order of magnitude less than the measured nitrate ion concentration. Samples from both runs did not exceed 1000 $\mathrm{mg} / \mathrm{kg}$ of formate during the sampling timeframe. There are many potential explanations for differences between $\mathrm{H} 2 \mathrm{Frit} 1$ and $\mathrm{H} 2 \mathrm{Bead} 10$, including the different air purge rates during the period from -0.5 hours to +1.5 hours, poor performance of the SRAT condenser water bath (difficulty holding $25^{\circ} \mathrm{C}$ ), and temperature of the SRAT heating mantle.

Data for the $0.2 \mathrm{wt} \% \mathrm{Ru}$ case is given in Figure 88. 
WSRC-STI-2008-00131

Revision 0

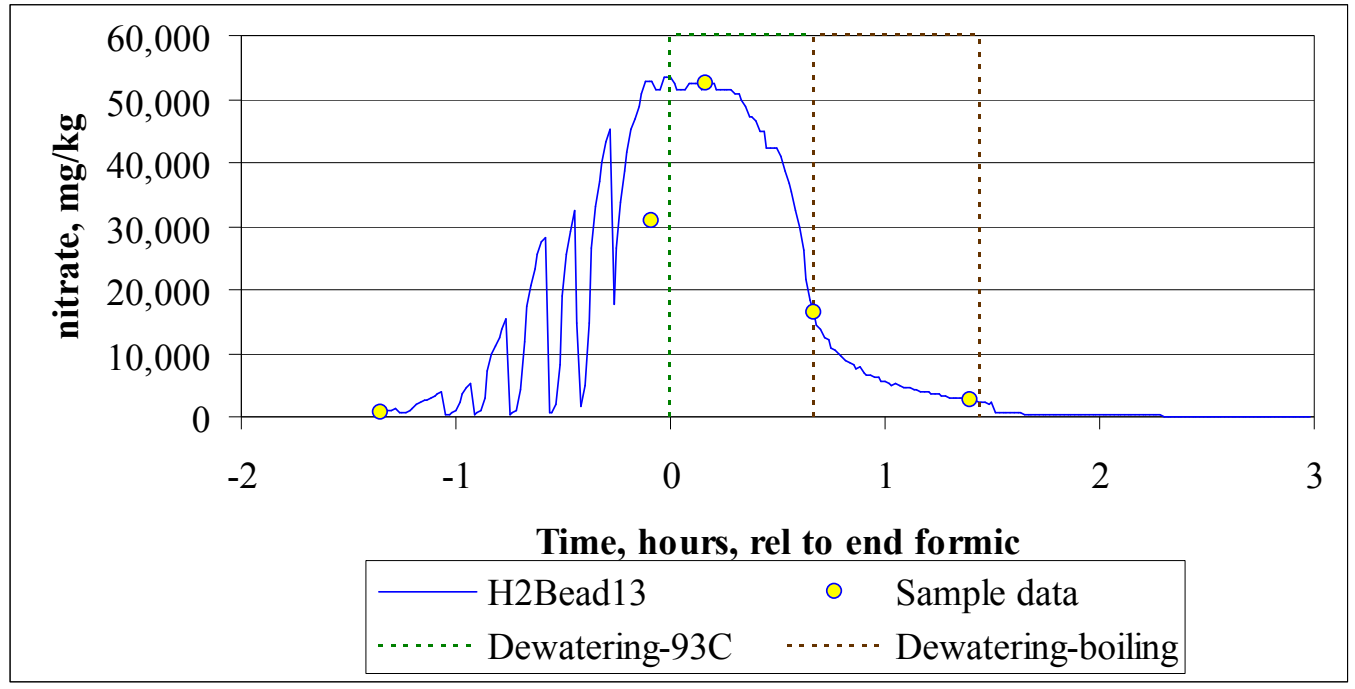

Figure 88. MWWT nitrate at $0.2 \mathrm{wt} \% \mathrm{Ru}$

These data were very similar to those at $0.375 \mathrm{wt} \% \mathrm{Ru}$ in form. The sawtooth pattern prior to the end of acid addition was driven by the pulsed refluxing which produced some mixing at the expense of a stable voltage. The maximum measured nitrate ion concentration was over $50,000 \mathrm{mg} / \mathrm{kg}$. None of the caustic quenched samples had detectable nitrite ion. Formate ion reached a maximum of $7,600 \mathrm{mg} / \mathrm{kg}$ at +0.67 hours in the samples. ISE data for $0.2 \mathrm{wt} \% \mathrm{Ag}$ are given in Figure 89.

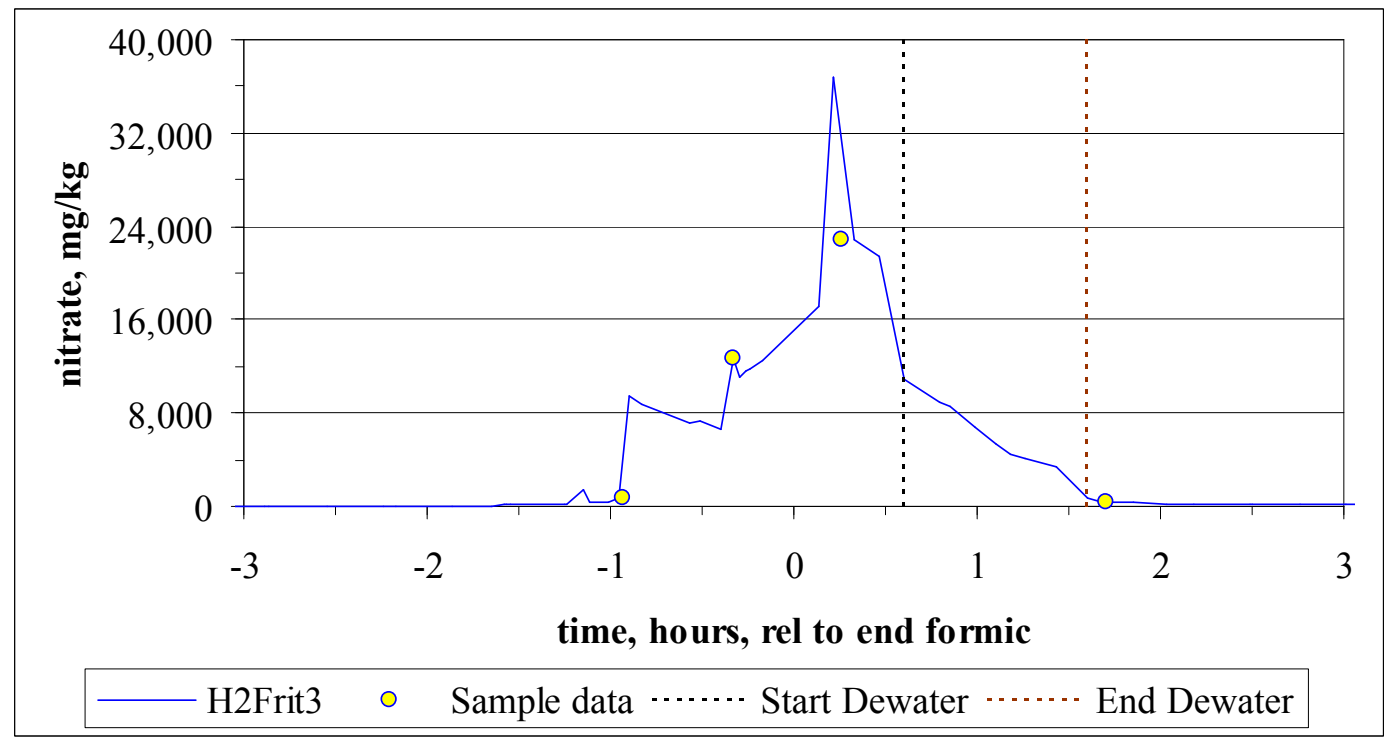

Figure 89. MWWT nitrate at $0.2 \mathrm{wt} \% \mathrm{Ag}$

The maximum measured nitrate by IC was just under $24,000 \mathrm{mg} / \mathrm{kg}$, but the ISE readings suggested a higher maximum. Formate rose to the $5000-6000 \mathrm{mg} / \mathrm{kg}$ range after acid addition. Small quantities of nitrite were detected prior to the end of acid addition, $120-400 \mathrm{mg} / \mathrm{kg}$. At -1 hour, the nitrite and nitrate were comparable, if small, quantities in the IC results. ISE results at $0.2 \mathrm{wt} \% \mathrm{Pd}$ are given in Figure 90. 
WSRC-STI-2008-00131

Revision 0

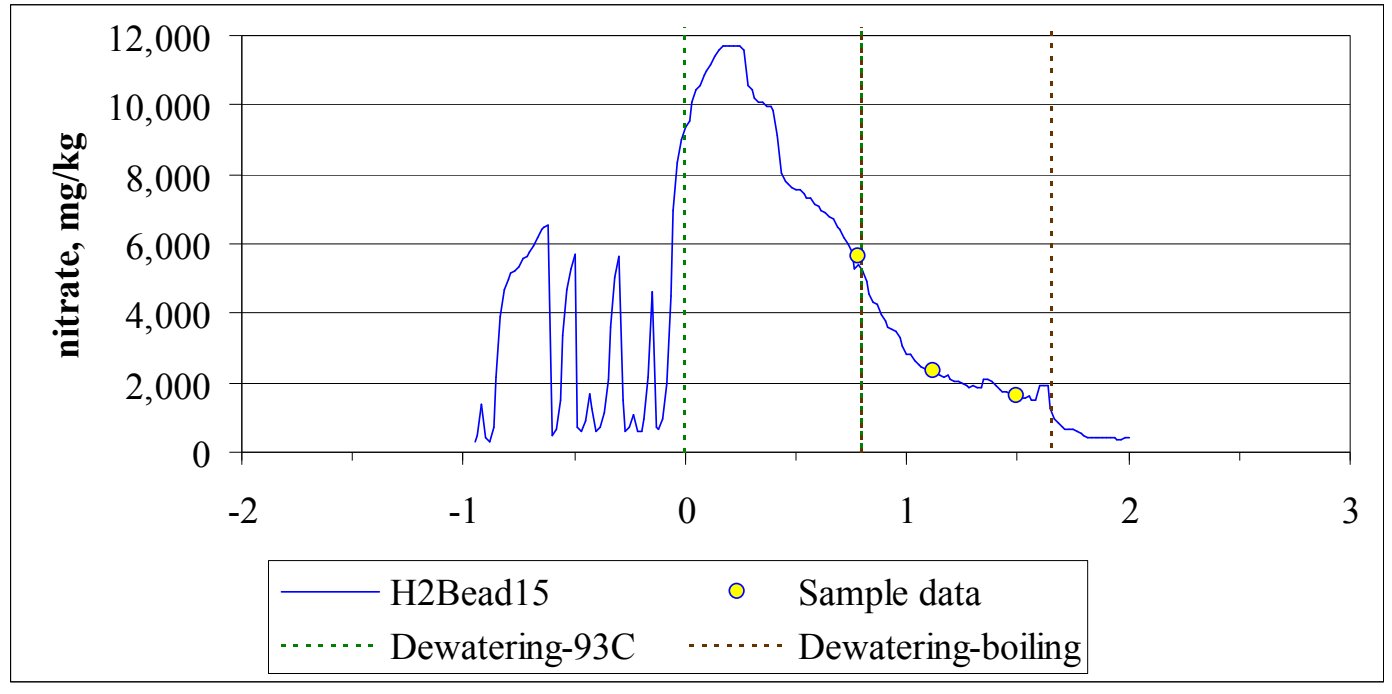

Figure 90. MWWT nitrate at $0.2 \mathrm{wt} \% \mathrm{Pd}$

The stop-start reflux technique was again used during acid addition in this run giving rise to the saw tooth pattern to the data prior to the end of acid addition. The maximum sample nitrate was $6000 \mathrm{mg} / \mathrm{kg}$, but the ISE indicated potentially a maximum of nearly $12,000 \mathrm{mg} / \mathrm{kg}$ was reached shortly after acid addition. The maximum formate observed was $1430 \mathrm{mg} / \mathrm{kg}$ at +0.7 hours. Nitrite was only observed once, at 150 $\mathrm{mg} / \mathrm{kg}$ at +1.5 hours. The ISE data with all noble metals present are given in Figure 91 .

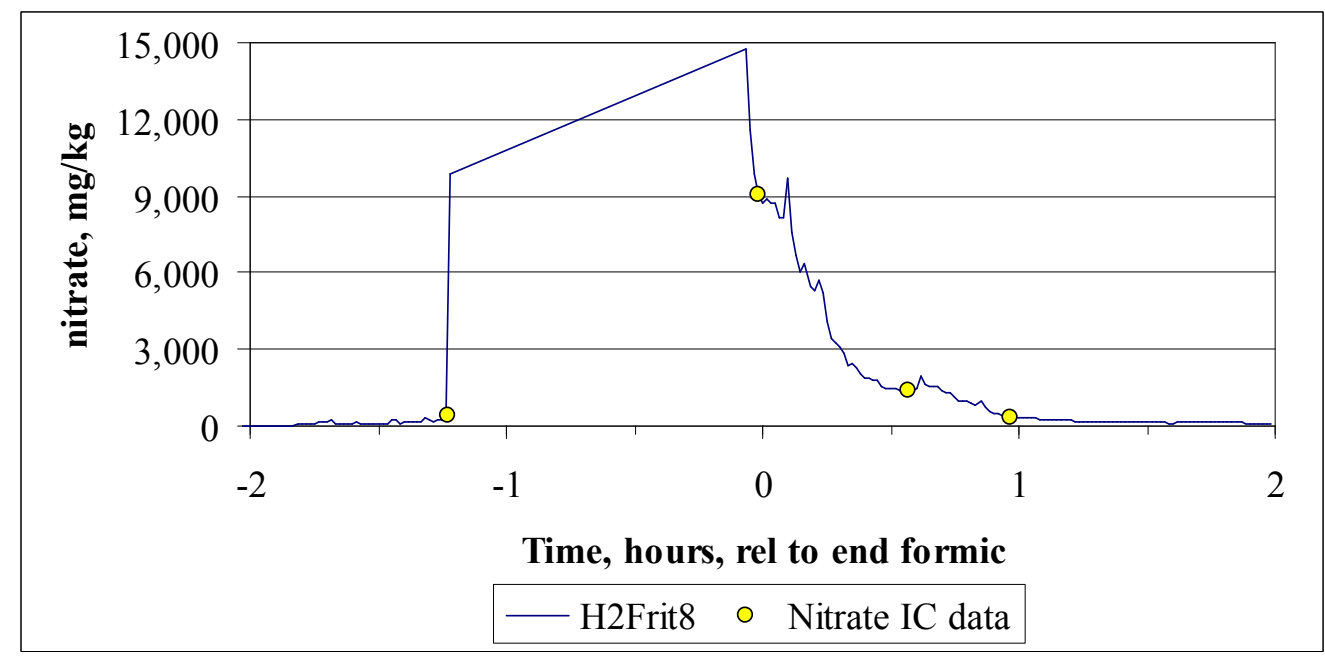

Figure 91. MWWT nitrate with all noble metals

There are no supporting sample data from -1.2 hours to 0 hours that were reliable. The sampling did not permit calibration of the data in that range, although the ISE voltages were less than those for the 0 hour sample with 9,000 $\mathrm{mg} / \mathrm{kg}$ nitrate suggesting more nitrate was present. Without a better bounding sample, however, the conversion from millivolts to concentration was problematic, and all concentrations above $9,000 \mathrm{mg} / \mathrm{kg}$ are extrapolations of the data. The maximum formate seen was $1020 \mathrm{mg} / \mathrm{kg}$ at +0.57 hours. Only one sample had detectable nitrite, $120 \mathrm{mg} / \mathrm{kg}$ at -1.23 hours. This was roughly half the corresponding molar nitrate ion concentration. Two data sets were obtained for $0.375 \mathrm{wt} \% \mathrm{Ru}$, 


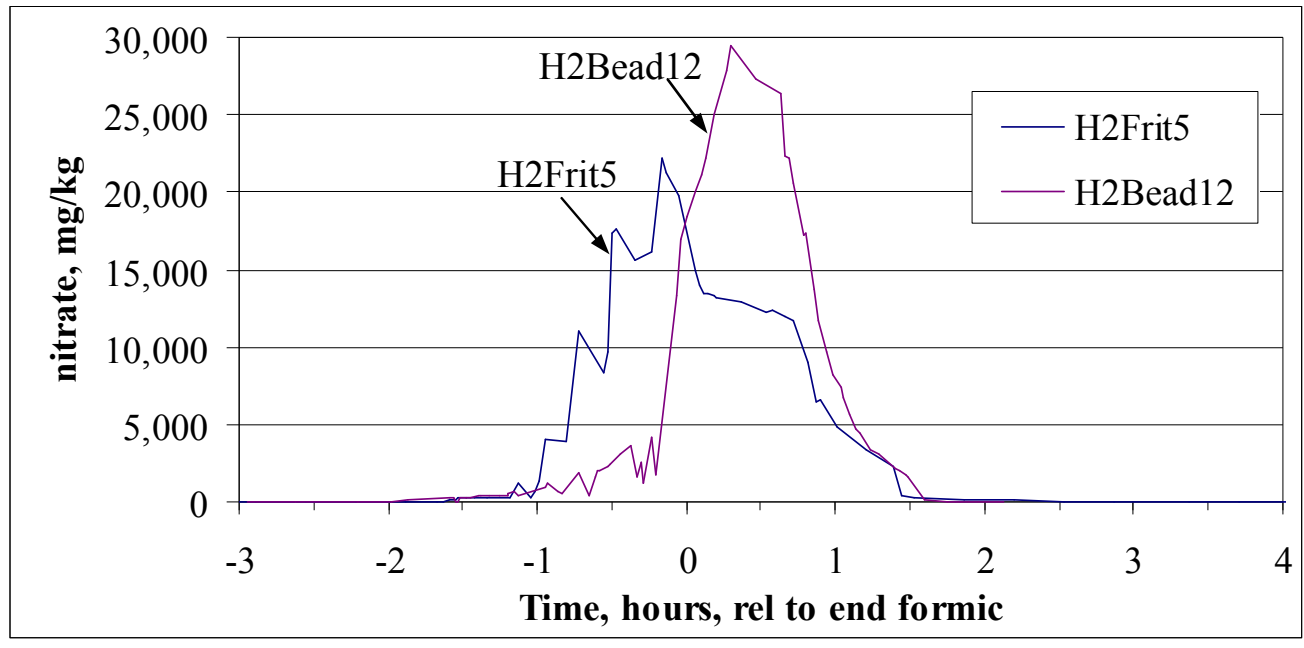

Figure 92. MWWT nitrate at $0.375 \mathrm{wt} \% \mathrm{Ru}$

The nitrate ISE data were only mildly reproducible prior to boiling, but were not greatly dissimilar. Nitrite was detected in four H2Frit5 quenched samples at concentrations from 130-610 mg/kg. The first and last of these were at concentrations similar to nitrate ion, while the other two were lower. Nitrite was detected in two H2Bead12 samples prior to the nitrate maximum at nitrite concentrations from 230-830 $\mathrm{mg} / \mathrm{kg}$ that were about half the molar concentration of nitrate. Both runs had maximum sample formate concentrations in the $3500-4000 \mathrm{mg} / \mathrm{kg}$ range after acid addition.

MWWT nitrate ion results from the bead-frit testing were not outstanding. There could be significant offsets between the converted millivolt readings and the actual concentrations. Initial testing of the nitrate ISE prior to the bead-frit group was done at a lower acid stoichiometry. This delayed nitrite destruction further into the boiling period when mixing in the MWWT was enhanced and the ISE readings were more stable. Superior quality data were obtained under those conditions compared to the bead-frit tests. Unfortunately, a lot of nitrite destruction occurred in the bead-frit tests during the latter stages of formic acid addition, and hydrogen generation in several cases further delayed the start of boiling to the detriment of the quality of the ISE data. It is recommended that future use of the ISE be in runs with lower acid stoichiometry or in runs without $\mathrm{Hg}$, where a small mixer could be mounted in the MWWT to make the collected condensate homogeneous.

Nevertheless, some results were obtained about the nature of the chemistry in the MWWT. Most of the observations of nitrite ion came while nitrate was just starting to accumulate in the MWWT, i.e. the nitrate concentration was small, the nitrite concentration was small, and the formate concentration was negligible. Presumably, the condensate was only mildly acidic at this time. It appears that such conditions are needed for nitrite ion to survive long enough to be sampled from the MWWT. When significant acidity and/or formate concentration were present, nitrite was generally not found in the samples.

The general shape of the MWWT nitrate ion concentration versus time data was generally similar from case to case. Nitrate increased above a few hundred $\mathrm{mg} / \mathrm{kg}$ by about -1 hour relative to the end of acid addition, grew to a maximum, and then fell after acid addition was over such that by about 1.5 hours after acid addition, it was back to a fairly small value. The period of interesting MWWT nitrate concentrations overlapped Period 3 and Period 4 as described in Sections 5.3 and 5.4. The "peak" in the MWWT nitrate 
was later than the peaks in the off-gas species, which is not unexpected since the concentration took some time to build up in the accumulated volume of condensate held in the MWWT. The liquid residence time of the MWWT is not precisely known during acid addition, but it is much longer than the gas residence time of the SRAT head space which is about four minutes. Consequently off-gas composition changes are detected faster than MWWT condensate composition changes, and a time delay in the maximum nitrate concentration is appropriate for the MWWT relative to the off-gas.

The ISE readings were found to fluctuate considerably when the MWWT contents were fairly stagnant, i.e. during acid addition. This indicates that the liquid in the MWWT was stratified in horizontal layers of differing nitrate ion concentration (fresh condensate came in near the top of the liquid in the MWWT and was refluxed back to the SRAT from a point near the bottom of the MWWT). In spite of the small volume of the MWWT and the high mobility of the $\mathrm{H}^{+}$ion in aqueous solution, the nitrate ion was unable to diffuse rapidly enough to eliminate the concentration gradients. This is the likely scenario for the DWPF MWWT as well, since it is larger, but has the same relative volume to the SRAT as the lab-scale equipment. The ability of diffusion to eliminate gradients in the DWPF MWWT is less than that in the lab-scale MWWT because of the longer length scale in DWPF. (Conversely, a poorly mixing MWWT is ideal for gravity separating small mercury droplets from the condensate.)

It is difficult to attribute the inhibition of hydrogen generation at the onset of reflux to nitrite ion. While the detection limit of the IC was $100 \mathrm{mg} / \mathrm{kg}$, the general trend of the data was that nitrite ion was near or below the detection limit by the time reflux started (presumably the caustic quenched samples bound the nitrite ion content of the reflux). In spite of the lack of detectable nitrite, many of the GC data sets had a small burst of $\mathrm{NO}, \mathrm{NO}_{2}$, and/or $\mathrm{N}_{2} \mathrm{O}$ at the onset of reflux. Detectable, if small, quantities of these gases lasted for just two to three scans of the GC and then were gone.

Tests with $\mathrm{Ru}$ only were effective at producing more $\mathrm{NO}, \mathrm{NO}_{2}$, and $\mathrm{N}_{2} \mathrm{O}_{4}$ than the other tests, and the nitrate ISE data for the two $\mathrm{Ru}$ cases reached maximum nitrate concentrations of $25,000-50,000 \mathrm{mg} / \mathrm{kg}$. These were the highest nitrate concentrations seen in the MWWT data. It is reasonable to assume that the two results are related. Conversely, the $0.2 \mathrm{wt} \% \mathrm{Pd}$ case, which made the most $\mathrm{N}_{2} \mathrm{O}$ and had low nitriteto-nitrate conversion, only reached a maximum of about $11,000 \mathrm{mg} / \mathrm{kg}$ nitrate in the MWWT.

Because of the processing sequence at the acid stoichiometry of the bead-frit runs, the quantity of nitrate returned to the SRAT through the reflux line prior to boiling does not appear to have been a large fraction of the nitrate formed during processing. Most of the nitrate brought into the SRAT was removed in the SRAT dewatering step, and there was very little nitrate left in the MWWT at the start of reflux. If, however, the acid stoichiometry had been lower, and the time for nitrite destruction had been shifted into dewatering instead of during the end of acid addition, then nitrate could still have been building up in the MWWT at the end of dewatering, instead of declining, and the situation at the onset of reflux could be significantly different with respect to the nitrate concentration in the condensate. 
WSRC-STI-2008-00131

Revision 0

\section{APPENDIX B. FORMIC ACID DESTRUCTION}


University of Georgia researchers considered four classes of reactions for the destruction of formic acid during processing in the presence of noble metals. ${ }^{1}$ These were:

Oxidation: $2 \mathrm{HCO}_{2} \mathrm{H}+\mathrm{O}_{2} \rightarrow 2 \mathrm{H}_{2} \mathrm{O}+2 \mathrm{CO}_{2}$

Decomposition: $\mathrm{HCO}_{2} \mathrm{H} \rightarrow \mathrm{H}_{2}+\mathrm{CO}_{2}$

Dehydration: $\mathrm{HCO}_{2} \mathrm{H} \rightarrow \mathrm{H}_{2} \mathrm{O}+\mathrm{CO}$

And metal reduction: $\mathrm{HCO}_{2} \mathrm{H}+\mathrm{M}^{n+} \rightarrow \mathrm{M}^{(n-2)+}+2 \mathrm{H}^{+}+\mathrm{CO}_{2}$

One of their observations was that the extent of reactions other than oxidation of formic acid could be discerned by graphing twice the $\mathrm{O}_{2}$ content plus the $\mathrm{CO}_{2}$ content of the off-gas and comparing it to a straight line. $\mathrm{CO}_{2}$ associated with decomposition or metal reduction would show up as an increase in this sum relative to the nominal baseline. Oxidation was identified as a significant reaction in simple systems.

The same analysis can be applied to the molar flowrate sum composed of twice the molar $\mathrm{O}_{2}$ flowrate plus the molar $\mathrm{CO}_{2}$ flowrate. Deviations in such graphs versus a horizontal line were developed for the bead run data. Some deviations were caused by the adjustments to the air purge flowrate, and these deviations do not speak to the process chemistry. The simplest graphs were for the no noble metal case and the $0.2 \mathrm{wt} \% \mathrm{Ag}$ case, Figure B1.

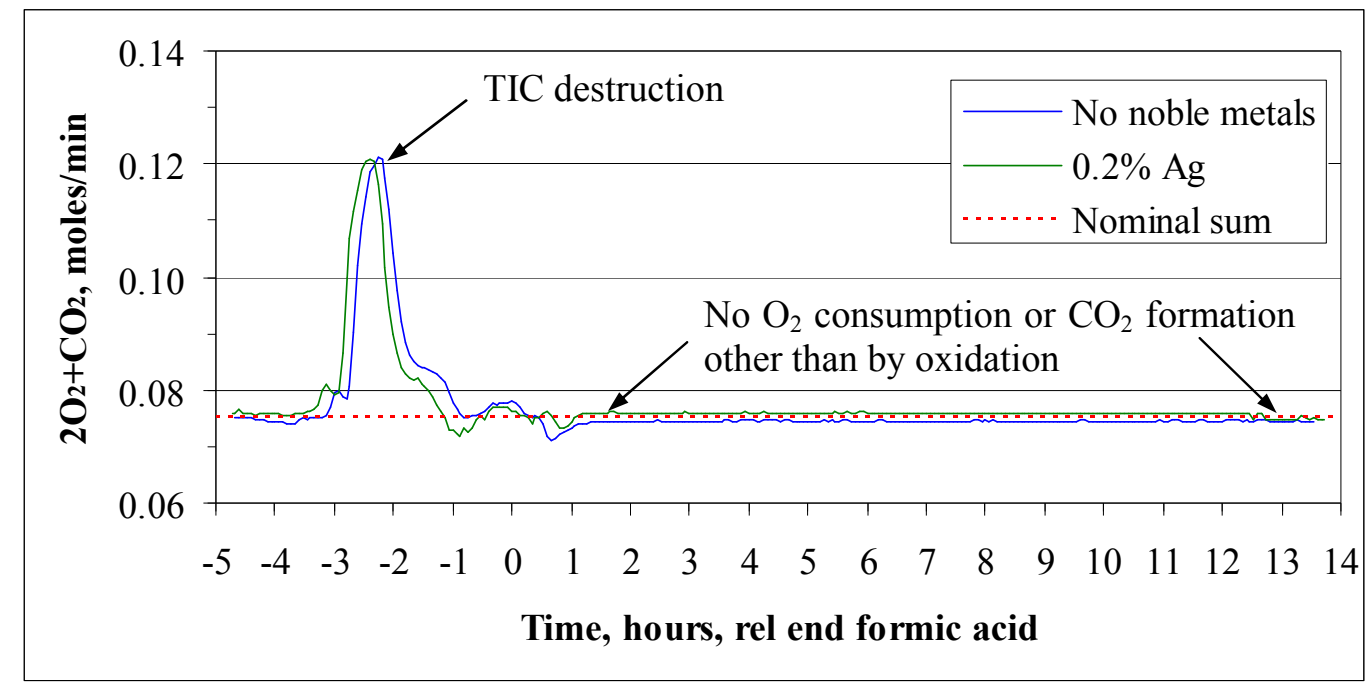

Figure B1. $2 \mathrm{O}_{2}+\mathrm{CO}_{2}$ baseline behavior

TIC destruction $\mathrm{CO}_{2}$ is obvious as a positive deviation in the sum from the nominal value. This feature was apparent on all the plots of this type. The fluctuations from -2 hours to +1 hours are associated with nitrite destruction. Nitrite destruction to $\mathrm{NO}$ is consuming some of the $\mathrm{O}_{2}$ to form $\mathrm{NO}_{2}$, while nitrite destruction to $\mathrm{N}_{2} \mathrm{O}$ is forming some $\mathrm{CO}_{2}$. The two effects are approximately off-setting. Once nitrite destruction is complete, the sum is nearly constant as expected.

${ }^{1}$ Landon, L. F., University of Georgia Technical Reports (Elucidation of Noble Metal/Formic Acid Chemistry During DWPF Feed Preparation, Report 1), SRL-PTD-91-0063, WSRC-SRL, June 1991. 
The behavior of the $0.2 \mathrm{wt} \% \mathrm{Pd}$ system, Figure B2, was only slightly more complicated than that for the two relatively inactive systems in Figure B1.

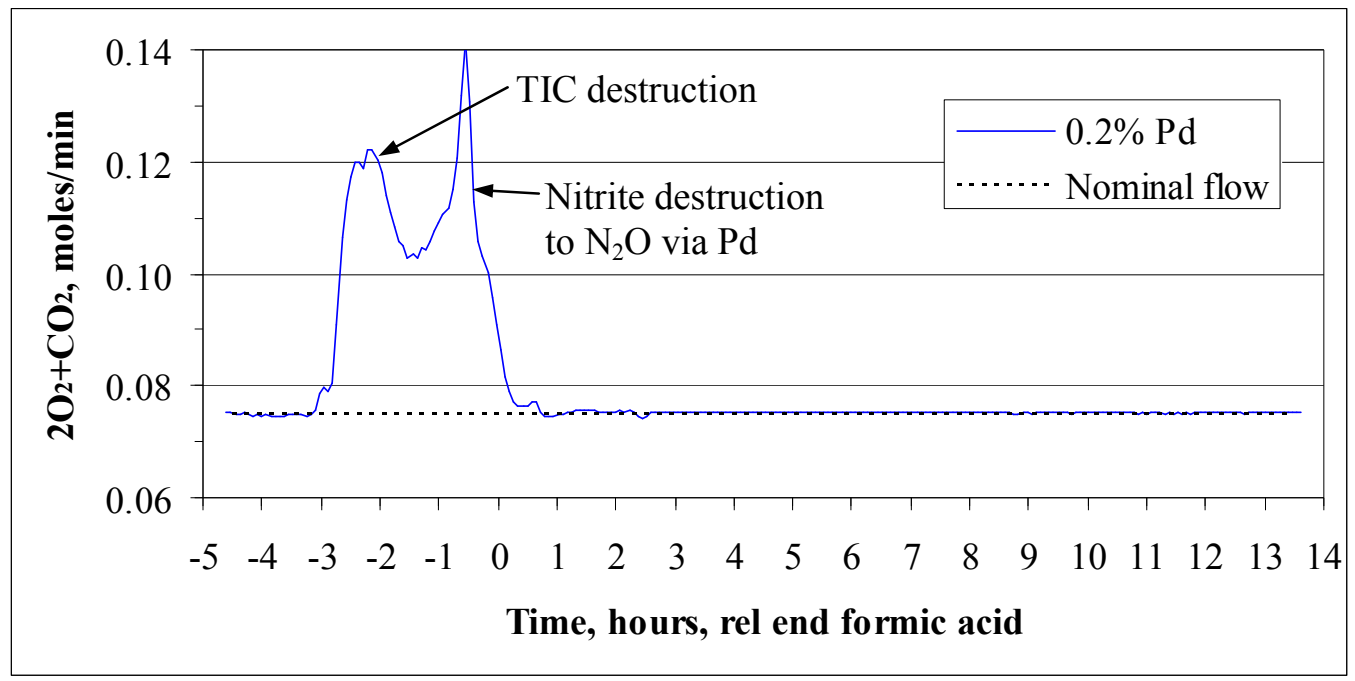

Figure B2. $2 \mathrm{O}_{2}+\mathrm{CO}_{2}$ behavior at $0.2 \mathrm{wt} \% \mathrm{Pd}$

The graph has only a single significant difference from the baseline behavior with no noble metals, which is due to the spike in $\mathrm{CO}_{2}$ generation associated with enhanced $\mathrm{N}_{2} \mathrm{O}$ production in the presence of $\mathrm{Pd}$ catalyst with no associated $\mathrm{O}_{2}$ destruction to offset it. Note how the graphs are nearly perfectly horizontal from +2 hours to +13 hours in both Figures B1 and B2.

The graph for $0.1 \mathrm{wt} \% \mathrm{Rh}$ is more complicated, Figure B3. One reason is that the air purge was increased to dilute the peak in the hydrogen generation rate at about +0.5 hours, which also increased the molar flowrate of oxygen. Hydrogen generation (aka "decomposition") rate is shown also.

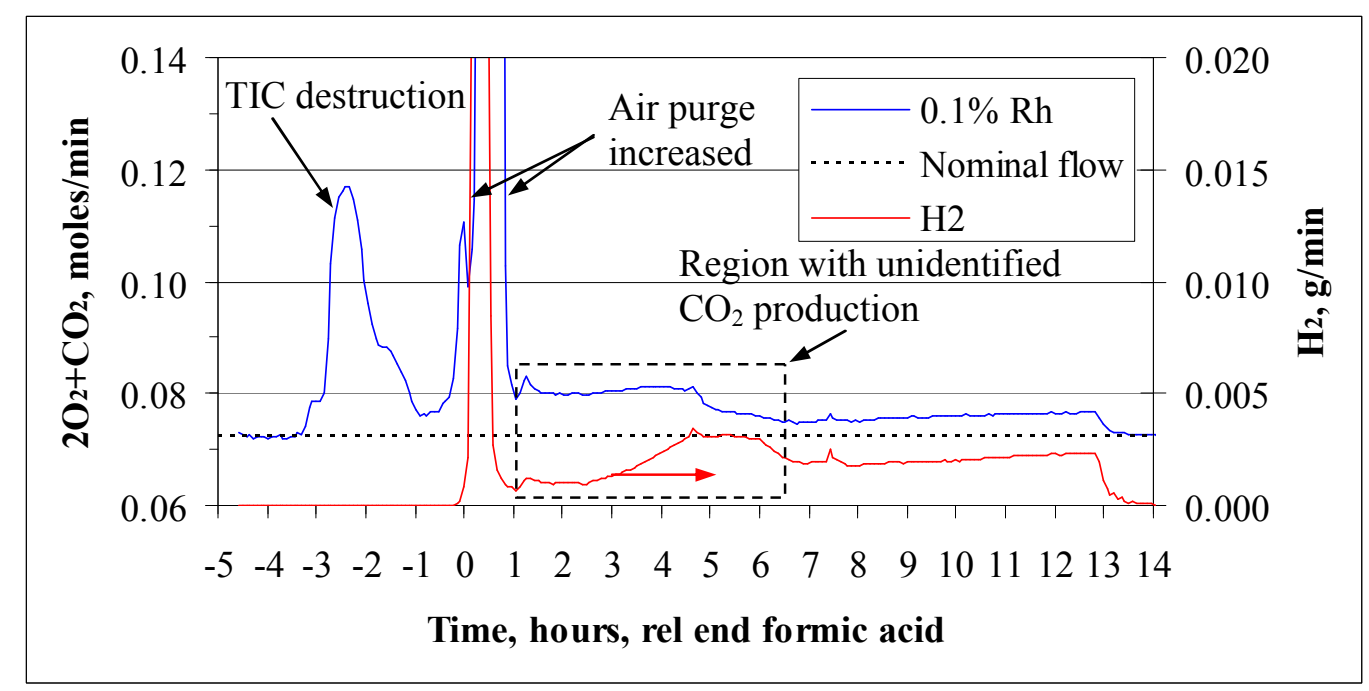

Figure B3. $2 \mathrm{O}_{2}+\mathrm{CO}_{2}$ behavior at $0.1 \mathrm{wt} \% \mathrm{Rh}$

There is a positive deviation in the sum of $2 \mathrm{O}_{2}+\mathrm{CO}_{2}$ from the time that the air purge was returned to nominal after the hydrogen peak until +13 hours when mixing was lost and the SRAT temperature began 
to fall slowly. The deviation from +6.5 hours to +13 hours seems to follow the shape of the hydrogen generation rate data fairly well. For several hours prior to +6.5 hours, however, it appears that there is another reaction making significant $\mathrm{CO}_{2}$ but not hydrogen occurring in addition to any oxidation. One possibility is reduction of the oxidation state of rhodium. The data for $0.2 \mathrm{wt} \% \mathrm{Rh}$ look somewhat different, Figure B4, both these also have an increase in $\mathrm{CO}_{2}$ not due to hydrogen generation or oxidation.

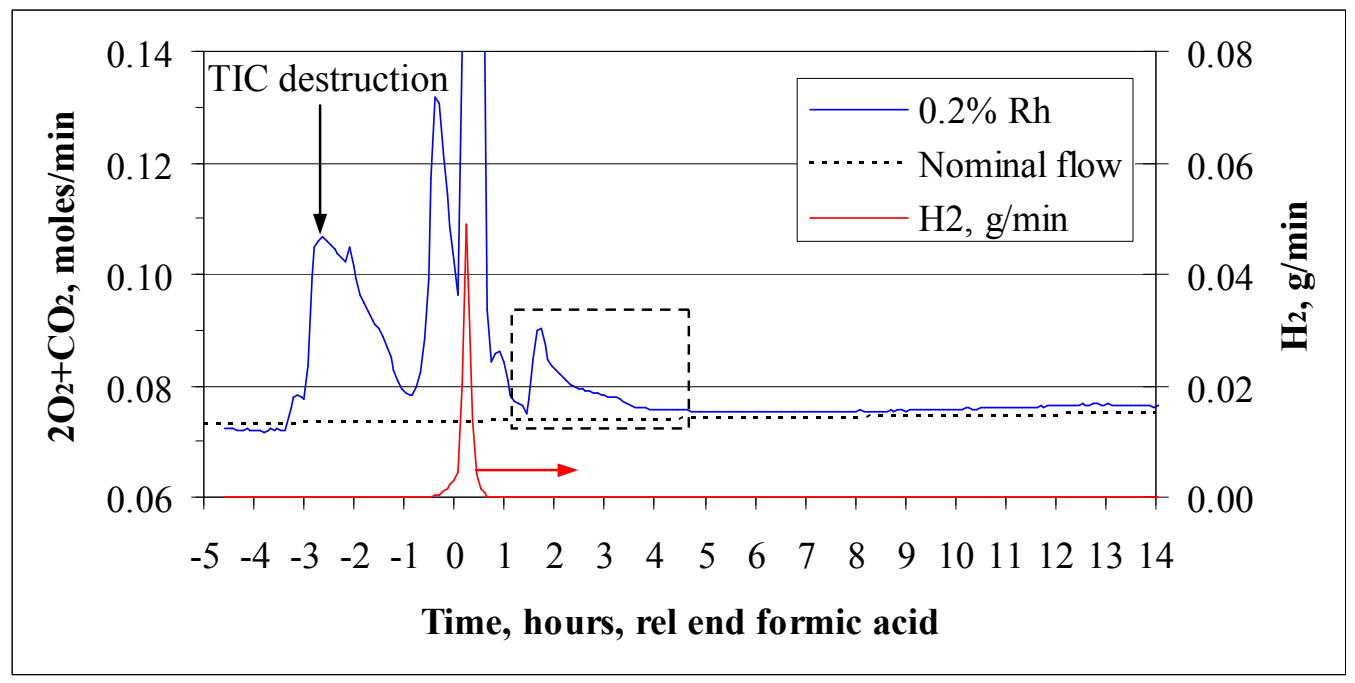

Figure B4. $2 \mathrm{O}_{2}+\mathrm{CO}_{2}$ behavior at $0.2 \mathrm{wt} \% \mathrm{Rh}$

The timing of the increased $\mathrm{CO}_{2}$ production (dashed box) is similar to that in Figure $\mathrm{B} 3$, which may indicate that it is the same reaction in both systems. The magnitude of the increase is larger in Figure B4 than in B3, which would be qualitatively consistent with Rh reduction in a system with twice as much Rh. The nominal flow line is slightly sloped due to small drift in some of the GC calibrations during this SRAT cycle. XANES or other oxidation state data have not been obtained for Rh. Such data could confirm whether or not this reaction is potentially due to $\mathrm{Rh}$ reduction.

The systems with Ru were also examined. Figure B5 has the data for the $0.2 \mathrm{wt} \% \mathrm{Ru}$ SRAT.

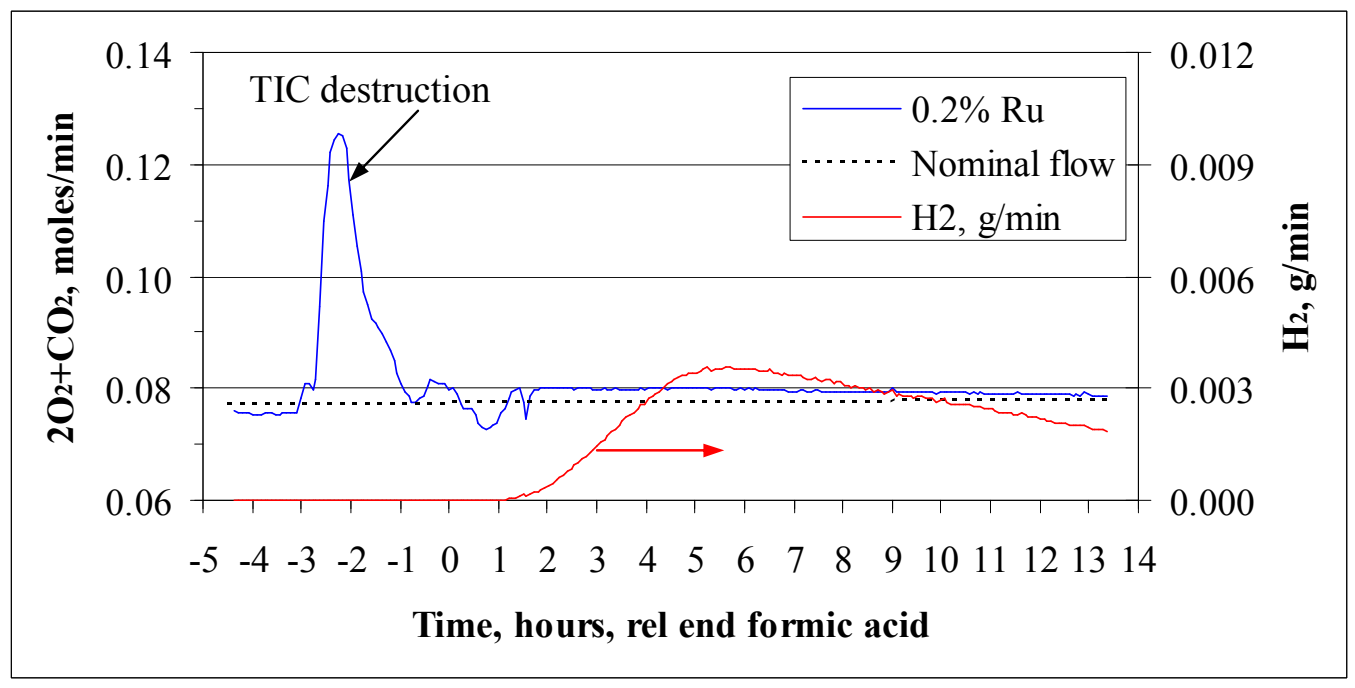

Figure B5. $2 \mathrm{O}_{2}+\mathrm{CO}_{2}$ behavior at $0.2 \mathrm{wt} \% \mathrm{Ru}$ 
There is far less activity on this graph than on the $\mathrm{Rh}$ graphs during reflux. Some additional $\mathrm{CO}_{2}$ production is indicated, but there is formic acid decomposition and hydrogen generation going on during most of the reflux period that could account for most of the increase. If Ru reduction is occurring, it would appear to be a slow process spread over a long time since there is no narrow window of significantly heightened $\mathrm{CO}_{2}$ generation like there was on the $\mathrm{Rh}$ graphs that would be associated with it. This appears to be consistent with the XANES data for Ru samples which showed very little change in the oxidation state of $\mathrm{Ru}$ from the end of acid addition to the end of the SRAT cycle. Figure B6 shows the behavior at $0.375 \mathrm{wt} \% \mathrm{Ru}$.

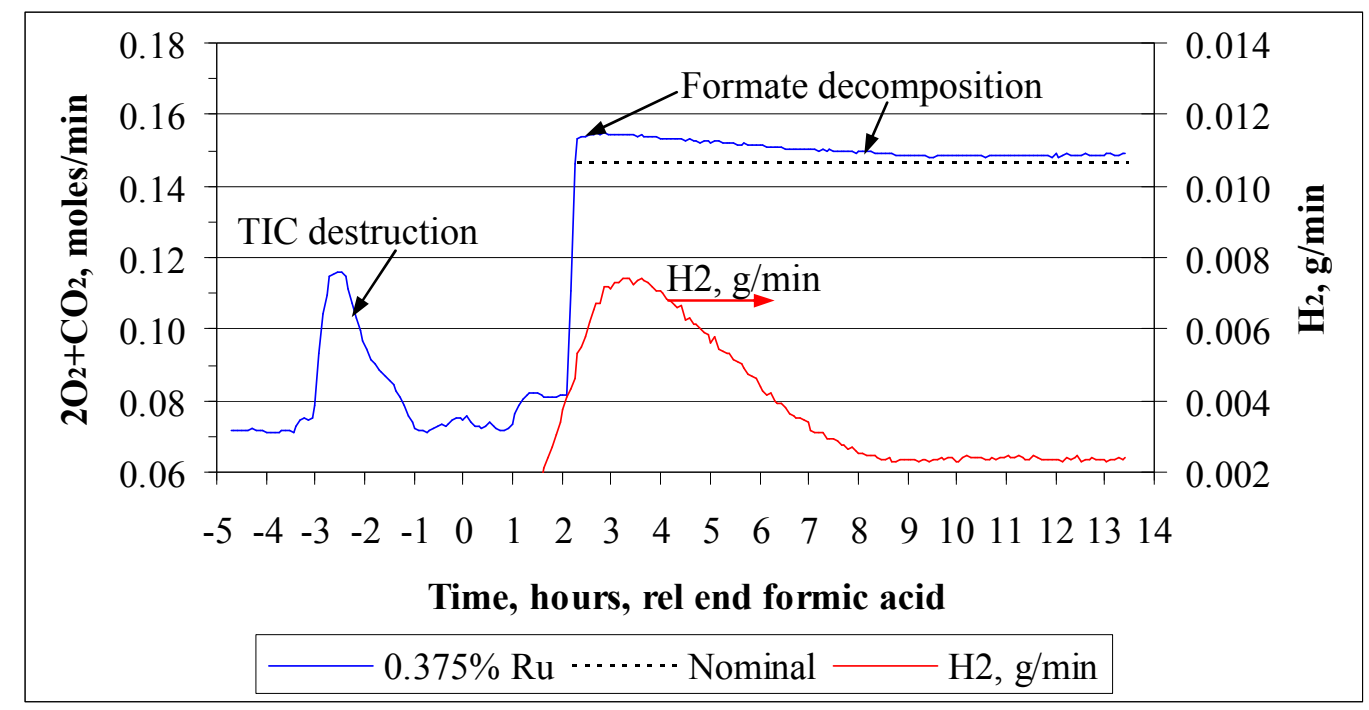

Figure B6. $2 \mathrm{O}_{2}+\mathrm{CO}_{2}$ behavior at $0.375 \mathrm{wt} \% \mathrm{Ru}$

This graph is somewhat different in appearance because the hydrogen generation rate reached a point where it was necessary to double the air purge (at about +2.2 hours) and at the same time doubled the oxygen molar feed rate. This run produced about twice as much hydrogen as the $0.2 \mathrm{wt} \% \mathrm{Ru}$ run. The associated larger increase in $\mathrm{CO}_{2}$ from decomposition of formic acid was clearly visible from +2 to +8 hours in the $2 \mathrm{O}_{2}+\mathrm{CO}_{2}$ flow. There was no evidence for a discrete period of Ru reduction in these data either.

Based on the graphs above, an interpretation can be attempted for the equivalent graph for the run with all noble metals, Figure B7. 
WSRC-STI-2008-00131

Revision 0

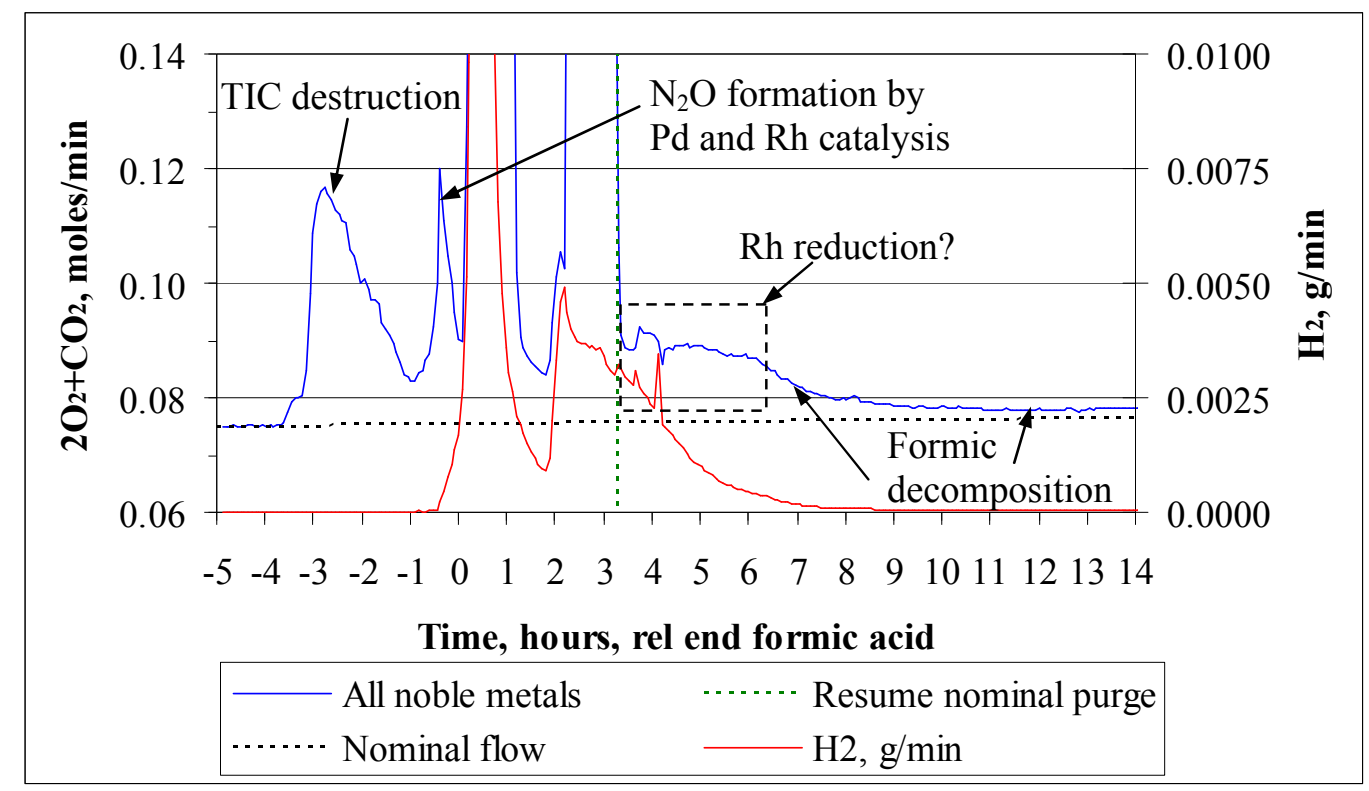

Figure $\mathrm{B}$ 7. $2 \mathrm{O}_{2}+\mathrm{CO}_{2}$ behavior with all noble metals

The period from near the end of formic acid addition to +3.3 hours had increased air purges and increased oxygen molar flowrates. Once the nominal air purge was resumed, however, there was some additional $\mathrm{CO}_{2}$ formation above that expected from formic acid decomposition to hydrogen that was perhaps due to $\mathrm{Rh}$ reduction as on the two graphs for the Rh-only systems $\left(2 \mathrm{O}_{2}+\mathrm{CO}_{2}\right.$ flow fairly steady while $\mathrm{H}_{2}$ was clearly falling). There was another clearly identified peak at about -0.5 hours associated with the joint $\mathrm{Rh}-\mathrm{Pd}$ catalysis of $\mathrm{N}_{2} \mathrm{O}$ formation. There was a small amount of excess $\mathrm{CO}_{2}$ until the end of reflux due to continued catalytic hydrogen formation.

The analysis shows many of the reactions already discussed in the main body of the report from a slightly different perspective. In addition, there is the possibility that a $\mathrm{Rh}$ reduction reaction was identified following the peaks in hydrogen generation in the runs with $\mathrm{Rh}$. The analysis of Figure $\mathrm{B} 7$ would have been nearly impossible without the data from the other six figures from the single noble metal systems. This point emphasizes the need to occasionally study model systems in order to have bench marks for evaluating data from SRAT runs with the full range of chemistry. 
Distribution:

J. C. Griffin, 773-A

D. A. Crowley, 999-W

C. C. Herman, 999-W

A. B. Barnes, 999-W

D. J. McCabe, 773-42A

B. J. Giddings, 786-5A

S. D. Fink, 773-A

C. W. Gardner, 773-A

N. E. Bibler, 773-A

C.M. Jantzen, 773-A

J. R. Harbour, 773-42A

D. K. Peeler, 999-W

J. E. Occhipinti, 704-S

D. C. Sherburne, 704-S

R. T. McNew, 704-27S

J. F. Iaukea, 704-30S

J. W. Ray, 704-S

J. L. Dunning, 766-H

H. B. Shah, 766-H

J. M. Gillam, 766-H

B. A. Hamm, 766-H

B. A. Davis, $704-27 \mathrm{~S}$

D. D. Larsen, 766-H

E. W. Holtzscheiter, 704-15S

T. L. Fellinger, 704-26S

J. M. Bricker, 704-27S

E. B. Fox, 999-2W

B. R. Pickenheim, 999-W

M. E. Stone, 999-W

R. E. Eibling, 999-W

D. P. Lambert, 999-W

J. M. Pareizs, 773-A

S. H. Reboul, 773-42A

C. J. Bannochie, 773-42A

J. D. Newell, 999-W 